\title{
Auswirkungen von Trockenheit und Entlaubung auf den Wasserhaushalt von Stiel- und Traubeneiche
}

\author{
Dissertation \\ zur Erlangung des Doktorgrades \\ der Mathematisch-Naturwissenschaftlichen Fakultäten \\ der Georg-August-Universität zu Göttingen
}

\author{
vorgelegt von \\ Thomas Gieger \\ aus \\ Uelzen
}

Göttingen 2002 
D7

Referent: Prof. Dr. Chr. Leuschner

Korreferent: Prof. Dr. M. Runge

Tag der mündlichen Prüfung: 17.06.2002 


\section{Inhaltsverzeichnis}

Abbildungsverzeichnis III

Tabellenverzeichnis V V

1 Einleitung 1

2 Material und Methoden $\quad \mathbf{5}$

2.1 Versuchsaufbau .................... 5

2.1.1 Versuche mit jungen Eichen 1999 und 2000 . . . . . . . . . 5

2.1.2 Freilanduntersuchungen $2001 \ldots \ldots \ldots$

2.2 Wasserhaushalt . . . . . . . . . . . . . . . . 10

2.2.1 Blatt-Wasserpotential . . . . . . . . . . . . . 10

2.2 .2 Druck-Volumen-Kurve . . . . . . . . . . . . . . . . 11

2.2.3 Stomatäre Leitfähigkeit, berechnete hydraulische Leitfähigkeit der Pflanze und Transpiration . . . . . . . . . . . . . . 14

2.2.4 Hydraulische Leitfähigkeit von Zweigen . . . . . . . . . . . . 18

2.2.5 Blattwassergehalt . . . . . . . . . . . . . . . 18

2.3 Ober- und unterirdische Biomasse . . . . . . . . . . . . . . . 19

2.3.1 Blattfläche und -biomasse . . . . . . . . . . . . . . 19

2.3.2 Wurzelbiomasse . . . . . . . . . . . . . . . . 19

2.3.3 Höhen- und Stammbasiszuwachs _. . . . . . . . . . . 20

2.4 Holzanatomie . . . . . . . . . . . . . . . . . . . . . 20

2.4.1 Jahrringanalyse an Zweigquerschnitten . . . . . . . . . . . 20

2.4.2 Jahrringanalyse $2001 \ldots \ldots$. . . . . . . . . . . . . 21

2.5 Chemische Blattanalysen . . . . . . . . . . . . . . . 21

2.5.1 Kohlenstoff-Isotopen-Verhältnis . . . . . . . . . . . . . 21

2.5.2 Stickstoffgehalt und $\mathrm{C} / \mathrm{N}$-Verhältnis . . . . . . . . . . . 22

2.5 .3 Chlorophyllgehalt . . . . . . . . . . . . 23

2.5 .4 Stärkegehalt....................... 24 
2.6 Photosynthese $2000 \ldots \ldots \ldots$. . . . . . . . . . . . . . . 24

2.7 Statistische Methoden . . . . . . . . . . . . . . . . 25

3 Ergebnisse $\quad 27$

3.1 Zeitgleiche Kombination von Entlaubung und Trockenheit 1999 . . . . 27

3.1.1 Wasserhaushaltsparameter 1999 . . . . . . . . . . 27

3.1.2 Ober- und unterirdische Biomasse $1999 \ldots \ldots$. . . . . . . 37

3.1.3 Blatt- und Stamminhaltsstoffe 1999 . . . . . . . . . . . . . 40

3.1.4 Früh- und Spätholzbreiten der Zweige 1999 . . . . . . . . . . . 43

3.2 Zeitversetzte Kombination von Entlaubung und Trockenheit 2000 . . . 46

3.2.1 Wasserhaushaltsparameter $2000 \ldots . . \ldots 46$

3.2.2 Ober- und unterirdische Biomasse 2000 . . . . . . . . . . . 54

3.2.3 Blatt- und Stamminhaltsstoffe 2000 . . . . . . . . . . . 57

3.2.4 Photosynthese $2000 \ldots \ldots$. . . . . . . . . . . 61

3.3 Freilanduntersuchungen $2001 \ldots \ldots \ldots$. . . . . . . . . . 63

3.3.1 Wasserpotential und stomatäre Leitfähigkeit 2001 . . . . . . . . 63

3.3.2 Jahrringanalyse bei 20-jährigen Stieleichen 2001 . . . . . . . . 64

3.3.3 Spezifische Blattfläche und Blattinhaltsstoffe 2001 . . . . . . . 64

3.3.4 Feinwurzelbiomasse $2001 \ldots \ldots$. . . . . . . . . 66

3.3.5 Stärkegehalt in Stammproben 2001 . . . . . . . . . . . . 67

4 Diskussion

4.1 Auswirkungen von Trockenheit und Entlaubung bei jungen Eichen in Abhängigkeit ihres zeitlichen Auftretens . . . . . . . . . . . . . . . 68

4.1.1 Reaktion auf Trockenheit . . . . . . . . . . . . 68

4.1.2 Reaktion auf Entlaubung . . . . . . . . . . . . . . . 79

4.1.3 Kombination von Entlaubung und Trockenheit . . . . . . . . . 84

4.2 Artunterschiede in der Reaktion auf Trockenstress und Entlaubung . . . 86

4.3 Vergleich der Ergebnisse von jungen mit 20-jährigen Stieleichen . . . . 88

4.3.1 Unterschiede zwischen jungen und 20-jährigen Bäumen im Jahr nach letztmaliger Entlaubung . . . . . . . . . . . . 88

4.3.2 Ursache-Wirkung-Schema bei jungen und älteren Eichen . . . . 90

5 Zusammenfassung $\quad 92$

$\begin{array}{lr}\text { Literaturverzeichnis } & 94\end{array}$ 


\section{Abbildungsverzeichnis}

2.1 Klimadaten der Station Göttingen 1999 und 2000 . . . . . . . . . . . 8

2.2 Klimadiagramm der Station Celle-Wietzenbruch . . . . . . . . . . . 9

2.3 Chlorophyll-Eichkurve ................... 23

3.1 Wasserpotentiale $1999 \ldots \ldots \ldots$. . . . . . . . . . 27

3.2 Blattwassergehalt $1999 \ldots \ldots \ldots \ldots$

3.3 Maximale stomatäre Leitfähigkeit 1999 . . . . . . . . . . . . . . . . . 29

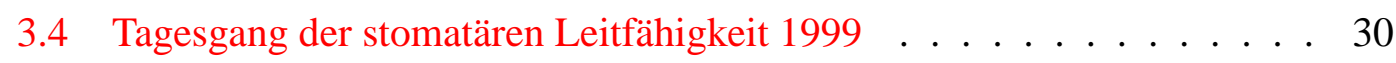

3.5 Tagestranspirationssumme $1999 \ldots \ldots$. . . . . . . . . . 32

3.6 Hydraulische Leitfähigkeit Boden-Blatt 1999 . . . . . . . . . . . . . 33

3.7 Osmotische Potentiale, $\mathrm{RWC}_{\mathrm{sp}}$ und Elastizitätsmodul . . . . . . . . . . 34

3.8 Blattfläche und spezifische Blattfläche 1999 . . . . . . . . . . . . . 37

3.9 Blatt- und Feinwurzelbiomasse sowie das Blatt/Feinwurzelverhältnis

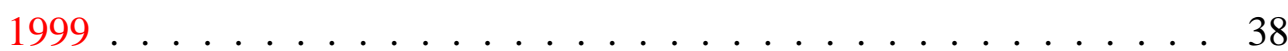

3.10 Höhen- und Stammzuwachs 1999 . . . . . . . . . . . . . . . . 39

3.11 Kohlenstoff-Isotopenverhältnis $1999 \ldots$. . . . . . . . . . . . . . 40

$3.12 \mathrm{~N}-$ Gehalt und $\mathrm{C} / \mathrm{N}-$ Verhältnis $1999 \ldots \ldots$. . . . . . . . . . . . . 41

3.13 Blatt-Chlorophyllgehalt $1999 \ldots \ldots \ldots$. . . . . . . . . . . 42

3.14 Stärkegehalt $1999 \ldots \ldots$. . . . . . . . . . . . . . . 43

3.15 Wasserpotentiale $2000 \ldots \ldots$. . . . . . . . . . 46

3.16 Blattwassergehalt $2000 \ldots \ldots$. . . . . . . . . . . . . 47

3.17 Maximale stomatäre Leitfähigkeit 2000 . . . . . . . . . . . . . . 48

3.18 Tagesgang der stomatären Leitfähigkeit 2000 . . . . . . . . . . . . . . 49

3.19 Tagestranspirationssumme $2000 \ldots \ldots$. . . . . . . . . . 50

3.20 Hydraulische Leitfähigkeit Boden-Blatt 2000 . . . . . . . . . . . . . 52

3.21 Osmotische Potentiale, $\mathrm{RWC}_{\mathrm{sp}}$ und Elastizitätsmodul . . . . . . . . . . 53

3.22 Blattfläche und spezifische Blattfläche 2000 . . . . . . . . . . . 55 
3.23 Blatt- und Feinwurzelbiomasse sowie das Blatt/Feinwurzelverhältnis $2000 \ldots \ldots \ldots \ldots \ldots \ldots \ldots$

3.24 Höhen- und Stammzuwachs 2000 . . . . . . . . . . . . . . . 57

3.25 Kohlenstoff-Isotopenverhältnis $2000 \ldots \ldots$. . . . . . . . . 58

3.26 N-Gehalt und C/N-Verhältnis 2000 . . . . . . . . . . . . . . 59

3.27 Blatt-Chlorophyllgehalt $2000 \ldots \ldots$. . . . . . . . . . . 60

3.28 Stärkegehalt $2000 \ldots \ldots$. . . . . . . . . . . . . . 61

3.29 Photosyntheseparameter 2000 . . . . . . . . . . . . . 62

3.30 Netto-Photosynthesevermögen 2000 . . . . . . . . . . . . . . . . 62

3.31 Wasserpotentiale und maximale stomatäre Leitfähigkeit 2001 . . . . . 63

3.32 Spezifische Blattfläche und Blattinhaltstoffe 2001 . . . . . . . . . . . 66

3.33 Feinwurzelbiomasse $2001 \ldots \ldots$. . . . . . . . . . . 67

3.34 Stärkegehalt $2001 \ldots \ldots$. . . . . . . . . . . . . 67

4.1 Vergleich verschiedener Wasserzustandsparameter bei direkter Messung am Blatt und der aus der P/V-Kurve abgeleiteten Werte . . . . . 75 


\section{Tabellenverzeichnis}

2.1 Übersicht über die Behandlungsvarianten . . . . . . . . . . . . . . . 6

3.1 Osmotikaberechnung $1999 \ldots \ldots \ldots \ldots$

3.2 Hydraulische Leitfähigkeit 1999 . . . . . . . . . . . . . . . . 36

3.3 Holzanatomie $1999 \ldots \ldots$. . . . . . . . . . . . . . 44

3.4 Osmotikaberechnung $2000 \ldots \ldots$. . . . . . . . . . . . . 54

3.5 Multiple Regressionsanalyse $2000 \ldots \ldots$. . . . . . . . . . . 58

3.6 Holzanatomie $2001 \ldots \ldots$. . . . . . . . . . . . . . . . 65

4.1 Hydraulische Leitfähigkeit 2000 . . . . . . . . . . . . . . . . 70

4.2 Blattflächen- und pflanzenbezogene Tagestranspirationsumme 1999 . . 81 


\section{Abkürzungsverzeichnis}

$\mathbf{A}_{\max }$ Netto-Photosyntheserate bei Lichtsättigung $\left[\mu \mathrm{mol} \mathrm{m} \mathrm{m}^{-2} \mathrm{~s}^{-1}\right]$

$\delta^{\mathbf{1 3}} \mathbf{C}$ Kohlenstoff-Isotopenverhältnis [\%o]

$\Delta \mathbf{w}$ Wassersättigungsdefizit zwischen Blatt und Umgebungsluft $\left[\mathrm{Pa} \mathrm{kPa}^{-1}\right]$

$\varepsilon$ Maximaler Elastizitätsmodul [MPa]

$\Psi_{\text {pd }}$ Predawn-Wasserpotential [MPa]

$\Psi_{\text {awp }}$ Nachmittägliches Wasserpotential [MPa]

$\mathbf{g}_{\mathbf{s}}$ Stomatäre Blattleitfähigkeit für Wasserdampf $\left[\mathrm{mmol} \mathrm{m}^{-2} \mathrm{~s}^{-1}\right]$

$\mathbf{g}_{\mathbf{s l}}$ Hydraulische Leitfähigkeit auf der Fließstrecke Boden-Blatt [mmol m $\mathrm{m}^{-2} \mathrm{~s}^{-1} \mathrm{MPa}^{-1}$ ]

$\mathbf{g}_{\mathbf{s m}}$ Maximale stomatäre Leitfähigkeit für Wasserdampf $\left[\mathrm{mmol} \mathrm{m} \mathrm{s}^{-1}\right]$

$\mathbf{E}_{\mathbf{d}}$ Tagestranspirationssumme $\left[\mathrm{mmol} \mathrm{m} \mathrm{d}^{-2}\right]$

RWC Relativer Blattwassergehalt [\%]

$\mathbf{R W C}_{\mathrm{p}}$ Relativer Wassergehalt am Turgornullpunkt [\%]

$\mathbf{R W C}_{\mathbf{s p}}$ Relativer symplastischer Wassergehalt am Turgornullpunkt [\%]

SLA Spezifische Blattfläche $\left[\mathrm{cm}^{2} \mathrm{~g}^{-1}\right]$

SWC Volumetrischer Bodenwassergehalt [\%]

$\Pi_{\mathbf{P}}$ Osmotisches Potential am Turgornullpunkt [MPa]

$\Pi_{0}$ Osmotisches Potential bei Wassersättigung [MPa]

VPD Wassersättigungsdefizit der Luft [kPa]

WUE $_{\mathbf{a}}$ Wassernutzungseffizienz $\left[\mu \mathrm{mol} \mathrm{CO} \mathrm{mmol}^{-1} \mathrm{H}_{2} \mathrm{O}\right]$ 


\section{Einleitung}

Eine durch Insektenfraß verursachte mehrjährige starke Entlaubung ist im Leben der Eichen ein häufiges und oft überregional synchrones Schadereignis. Danach tritt im Allgemeinen eine vollständige Erholung der geschädigten Bäume ein. Die Wahrscheinlichkeit von Eichenschäden kann jedoch stark ansteigen, wenn mehrjähriger starker Fraß zufällig mit einer weiteren Belastung, z.B. in Form von Witterungsextremen wie langanhaltender sommerlicher Trockenheit, zusammenfällt (DREYER 1994; THOMAS \& BLANK 1996). Eine Kombination aus mindestens zweimaliger Entlaubung in aufeinanderfolgenden Jahren und Witterungsextremen kann als wichtigster und häufigster auslösender Faktorenkomplex für Eichenschäden in Mitteleuropa angenommen werden (Hartmann 1996; Thomas et al. 2002). Als wesentliche Symptome werden vor allem das Zurücksterben der Krone vom Wipfel aus und ein rasches Absterben von Einzelbäumen wie auch kleinerer Baumgruppen meist innerhalb geschlossener Waldbestände genannt. Die Absterberate beträgt dabei zwischen zwei und fünf Bäumen pro Hektar und Jahr (HARTMAnN et al. 1989; HARTMAnN \& BlAnK 1992, 1998). Die Eiche ist mit einem Anteil von ca. 8\% an der Gesamtwaldfläche der Bundesrepublik Deutschland nach der Buche die zweitwichtigste einheimische Laubbaumart (BMELF 1994). Das Eichensterben ist damit auch aus forstwirtschaftlichen Gesichtspunkten von großer Bedeutung.

Erste Berichte über Eichensterben in Norddeutschland sind aus den Jahren 1740 1755, im vorigen Jahrhundert besonders aus den Jahren 1911-1935 sowie nach 1987 und 1997 bekannt (HARTMAnN et al. 1989; BLAnK 1997; HARTMANN \& BLAnK 1998; WACHTER 1999, 2001). Die Ergebnisse symptomanalytischer und dendrochronologischer Untersuchungen weisen auf einen sowohl räumlichen als auch zeitlichen Zusammenhang des Auftretens von Kahlfraß und Witterungsextremen mit dem Ausbruch von Schadereignissen in Norddeutschland hin (HARTMANN \& BLANK 1992; BLANK 1997; BLANK \& Riemer 1999). Dabei kommt vor allem dem Faktor "wiederholter Blattfraß in aufeinanderfolgenden Jahren", verursacht durch die EichenwicklerSchadgesellschaft (vor allem durch Raupen von Tortrix viridana L. und Operophthera brumata L.), eine besondere Bedeutung als Ursache der Schäden zu (HARTMANN 1996). 
Durch eine starke Entlaubung nach Insektenfraß wird die zum Aufbau von Leitgewebe zur Verfügung stehende Assimilatmenge reduziert. Dies führt nach RuBTSOV (1996) vor allem zu einer Reduzierung des Zuwachses der Bäume. Dieser verringerte Zuwachs ist in erster Linie auf eine Reduktion der Spätholzbildung zurückzuführen (BLANK 1997). Eine derart reduzierte Spätholzbildung kann sich direkt auf die Wasserversorgung des Sprosses auswirken. Eichen als Ringporer weisen eine deutliche Differenzierung des Holzes in das im Frühjahr gebildete, weitlumige Frühholz und das im Sommer angelegte, englumige Spätholz auf. Dabei wird den weitlumigen Gefäßen des Frühholzes eine wesentlich größere Bedeutung für den Wassertransport beigemessen als dem Spätholz (Zimmermann \& BROWN 1971). Vor allem das im laufenden Jahr gebildete Frühholz besitzt nach ELLMORE \& EWERS (1986) eine hohe Transportkapazität. Mindestens $70 \%$ des im Spross translozierten Wassers werden im äußersten Jahrring transportiert (LONGMAN \& COUTTS 1974; GRANIER et al. 1994), wobei der größte Teil des Wassers im Frühholz verlagert wird. Blattfraß führt jedoch im Folgejahr zu einer Verringerung der Gefäßoberfläche im Frühholz und damit zu einer verringerten Transportkapazität (HUBER 1993).

Demgegenüber stehen die Befunde von FLEISCHER (1989) und GRANIER et al. (1994), nach dem eine Wasserleitung über den gesamten äußeren Splintteil stattfindet. Die älteren Jahrringe können somit eine wichtige Transportreserve darstellen. Untersuchungen von GRANIER et al. (1994) belegen, dass nach einer künstlichen Embolisierung der äußersten Frühholzgefäße nur eine geringe Reduktion des gesamten Saftflusses durch den Stamm stattfindet, da in diesem Falle älteres Xylem reaktiviert wurde. Auch unter natürlichen Bedingungen kommt als Transportreserve vor allem das Spätholz in Frage, da bei Eichen der nördlichen gemäßigten Zonen die Frühholzgefäße so weitlumig sind, dass spätestens zum Ende des Winters eine vollständige Blockierung durch Embolien erfolgt ist (ZIMmermann 1983). Dies entspricht auch den Befunden von TYREE \& COCHARD (1996), welche auf eine erhöhte Embolisierungsgefahr mit steigender Gefäßgröße bei den von ihnen untersuchten Eichen hinweisen. Ist jedoch der Spätholzanteil infolge von Entlaubung aufgrund einer verringerten, für den Aufbau von Leitelementen zur Verfügung stehenden Assimilatmenge stark reduziert, so ist eine Einschränkung der Wasserversorgung des Sprosses wesentlich eher und in stärkerem Ausmaß zu erwarten als bei nicht fraßgeschädigten Bäumen. Ein derartiger Zusammenhang ist bislang noch nicht untersucht worden.

Starke Trockenheit kann im Extremfall zu Cavitation, d.h. zu einem Abreißen der von der Wurzel bis ins Blatt führenden Wassersäule führen. Dabei können sich nach- 
folgend Embolien entwickeln, die das betroffene Leitelement für die Wasserleitung unbrauchbar machen. Da im Gegensatz zu Zerstreutporern Cavitation bei Eichen bereits bei vergleichsweise wenig negativen Wasserpotentialen auftritt, und Eichen nahe an der Grenze zur Cavitation agieren, ist eine effektive stomatäre Regulation des Wasserverbrauchs nötig um eine Embolisierung des Leitgewebes zu vermeiden (VIVIN et al. 1993; Cochard et al. 1996). Cochard et al. (1996) und TYREE \& COCHARD (1996) weisen bei der Traubeneiche auf eine effektive stomatäre Kontrolle des Wasserhaushalts hin, die eine Absenkung des Wasserpotentials auf stark negative Werte verhindert. Experimente von PICON et al. (1996) und PICON et al. (1997) mit einjährigen Eichenkeimlingen (Quercus robur L. und Q. petraea [Matt.] Liebl.) ergaben bei beiden Arten Hinweise auf eine effektive stomatäre Kontrolle des Blattwasserstatus unter simuliertem Trockenstress. Bei Zunahme der Belastung durch Trockenstress reagieren sie mit einer Reduktion der Blattleitfähigkeit und einem Absenken der Blattwasserpotentiale (PICON et al. 1996, 1997). Unter normalen sommerlichen Bedingungen ist somit eine geringe Embolisierungsgefahr anzunehmen, welche jedoch unter extremeren Bedingungen (langanhaltende und auch im Folgejahr auftretende sommerliche Trockenheit) ansteigen kann. Versuche mit dreijährigen $Q$. robur in Frankreich (SIMONIN et al. 1994) unter simuliertem langanhaltenden Trockenstress bestätigen diese Annahme.

Ein entlaubungsbedingt verringerter Assimilatspeicher kann sich auch unterirdisch in einer verringerten Feinwurzelbildung äußern. So finden z.B. BLOCK et al. (1995) eine nach starker Entlaubung reduzierte Feinwurzelbiomasse bei $Q$. robur. Als Reaktion auf Trockenheit werden vermehrt Feinwurzeln gebildet, um die Wasserversorgung des Sprosses zu sichern (VAN HeEs 1997; ThOMAS 2000). Steht nach Entlaubung nur noch eine verringerte Menge an Assimilaten für die Bildung von Feinwurzeln zur Verfügung, so kann dies über eine verringerte Wasseraufnahmekapazität stressverschärfend sein. Eine geringere Feinwurzelbiomasse bedeutet eine schlechtere Wasserversorgung des Sprosses sowie ein früheres Auftreten von Trockenstress im Sommer (HARTMAnN 1996).

\section{Zielsetzung}

Untersuchungen zur Wirkung von Entlaubung und Trockenstress in Kombination miteinander sind bei Bäumen bislang nur vereinzelt durchgeführt worden (vgl. z.B. PARKer \& PATton 1975; Wright et al. 1989; Kolb et al. 1999). Vor dem Hintergrund des Eichensterbens in Mitteleuropa fehlen Arbeiten zu einem mechanistischen Zusammenhang zwischen mehrmaliger Entlaubung und sommerlicher Trockenheit vollstän- 
dig. Ziel der Arbeit ist es daher, über eine Aufklärung der Wechselbeziehungen zwischen Entlaubung und Trockenstress als primäre Schadfaktoren einen Teilbeitrag zu den Ursache-Wirkung-Beziehungen des Eichensterbens zu leisten.

\section{Hypothese}

Entlaubung führt über einen verringerten Assimilatspeicher zu einer Reduktion des Spätholzes. Durch Reduktion des Spätholzes kommt es bei entlaubten Bäumen bei schlechter Wasserversorgung zu Trockenstress und schließlich zu Trocknisschäden.

\section{Alternativhypothese}

Entlaubung führt über eine Reduzierung der Assimilatmenge - neben einer verringerten Spätholzbildung - zu einer Verringerung der Feinwurzelbiomasse, welches bei Wassermangel zu einer Beeinträchtigung des Wasserhaushalts führt.

Die Kombination der Faktoren "zweimalige Entlaubung in aufeinanderfolgenden Jahren" und "Trockenstress" soll dabei in zwei verschiedenen Jahren mit zu Versuchsbeginn dreijährigen $Q$. robur und $Q$. petraea unter kontrollierten Bedingungen getestet werden. Untersuchungen zur zeitgleichen Kombination beider Faktoren (Trockenheit im Jahr der zweiten Entlaubung) werden im ersten Jahr getestet. Im zweiten Jahr wird dann der Effekt der zeitversetzten Kombination (Trockenheit ein Jahr nach Ende der letztmaligen Entlaubung) untersucht.

Zudem sollen die an jungen Eichen gewonnenen Ergebnisse mit Untersuchungen an 20-jährigen Stieleichen im Freiland verglichen werden. Dabei wird davon ausgegangen, dass der Wirkungspfad über einen entlaubungsbedingt verringerten Assimilatspeicher bei jungen und älteren Bäumen gleich ist. Eine Reduktion des Spätholzes kann daher bei jungen wie älteren Bäumen zu einer verringerten Wasserleitungskapazität unter Trockenstressbedingungen führen. Gleichzeitig kann eine Verringerung der Feinwurzeln nach Entlaubung zu einer eingeschränkten Wasseraufnahme führen, die bei Trockenstress - unabhängig vom Baumalter - stressverschärfend wirkt. 


\section{Material und Methoden}

\subsection{Versuchsaufbau}

\subsubsection{Versuche mit jungen Eichen 1999 und 2000}

\section{Pflanzenmaterial und Kultivierungsbedingungen}

Anfang April 1998 wurden dreijährige Stiel- und Traubeneichen von der Baumschule Rahte (Wietze, Niedersachsen) bezogen. Dabei wurde auf einen möglichst gleichförmigen Habitus (v.a. Höhe, Stammdurchmesser und Kronenausbildung) der Bäume geachtet. Die Kultivierung im Botanischen Garten der Universität Göttingen erfolgte in 90-Liter Plastikgefäßen mit einem Durchmesser von $80 \mathrm{~cm}$ und einer Höhe von $50 \mathrm{~cm}$. Als Substrat wurde kalkhaltiger Sand (84,2\% Sand; 15,3\% Schluff; 0,5\% Ton) mit einem $\mathrm{pH}_{\left(\mathrm{H}_{2} \mathrm{O}\right)}$-Wert von etwa 7 verwendet. Die Düngung mit je $1000 \mathrm{ml}$ Nährlösung (mM: N 1,5; K 6,9; Mg 2,1; Ca 0,9; P 0,5; S 7,3; $\mu$ M: Fe 135; B 13,5; Mn 7,5; Zn 6,9; Mo 3,6; pH 4,8) wurde in den Jahren 1998 bis 2000 einmal monatlich von Mai bis September durchgeführt. Die Überwinterung erfolgte von Anfang November bis Ende März der jeweiligen Jahre unter einem Rolldach. Dort wurden die Pflanzcontainer zusammengestellt und mit einer ca. $50 \mathrm{~cm}$ dicken Laubstreu bedeckt.

\section{Entlaubung}

In den Jahren 1998 und 1999 wurde die Simulation der Entlaubung kurz nach dem Blattaustrieb Anfang Mai manuell durchgeführt. Dabei wurde die Blattspreite entfernt, so dass nur die Mittelrippe stehen blieb. Dadurch wurde eine Reduktion der Blattfläche bei allen entlaubten Bäumen von mindestens $85 \%$ des ersten Blattaustriebes erreicht. Die Wiederbelaubung war in beiden Jahren Mitte Juni abgeschlossen, so dass auch die entlaubten Bäume eine geschlossene Krone aufwiesen. Die Bestimmungen der Wasserpotentiale wie auch die Porometrie erfolgten somit an vollständig entwickelten und intakten Blättern. 
Tab. 2.1: Übersicht über die unterschiedlichen Behandlungsvarianten in den Untersuchungsjahren 1999 und 2000 einschließlich der Vorbehandlungen 1998. C, Kontrolle; De, Entlaubung; Dr, Trockenstress; DeDr, Kombination von Trockenstress und Entlaubung

\begin{tabular}{|c|c|c|c|c|}
\hline \multicolumn{5}{|c|}{ Varianten 1999} \\
\hline Jahr & $\mathrm{C}$ & $\mathrm{De}$ & Dr & DeDr \\
\hline 1998 & Kontrolle & Entlaubung & - & Entlaubung \\
\hline 1999 & Kontrolle & Entlaubung & Trockenstress & Entlaubung \& Trockenstress \\
\hline \multicolumn{5}{|c|}{ Varianten 2000} \\
\hline Jahr & $\mathrm{C}$ & De & Dr & DeDr \\
\hline 1998 & Kontrolle & Entlaubung & - & Entlaubung \\
\hline 1999 & Kontrolle & Entlaubung & - & Entlaubung \\
\hline 2000 & Kontrolle & - & Trockenstress & Trockenstress \\
\hline
\end{tabular}

\section{Trockenheit}

Im Anzuchtjahr 1998 wurden alle Bäume ausreichend bewässert. Trockenstress wurde in den Jahren 1999 und 2000 für etwa acht Wochen von Anfang Juli bis Ende August appliziert. Zur Vermeidung einer unkontrollierten Bewässerung durch Niederschläge erfolgte die Aufstellung der Töpfe nach dem Anzuchtjahr unter einem automatischen Rolldach, welches die Bäume nur bei Regen überdeckte. Während der Trockenperiode wurde der volumetrische Bodenwassergehalt (SWC) der obersten $15 \mathrm{~cm}$ der sandgefüllten Pflanzgefäße jeden zweiten Tag mit einer transportablen TDR-Sonde mit dem 6051X1 Trase System (Soil Moisture Equipment Co., Santa Barbara, CA, USA) überprüft und die Mittelwerte aus drei Messungen pro Tag gebildet. Der SWC der trockengestressten Bäume in beiden Untersuchungsperioden verringerte sich von $10 \%$ auf ca. 0,5-2,5\% und verblieb für die folgenden 55 Tage (1999) bzw. 60 Tage (2000) auf diesem niedrigen Niveau. Der SWC der ausreichend bewässerten Varianten wurde innerhalb beider Untersuchungsperioden deutlich über $8 \%$ gehalten. Die Behandlungsvarianten 1999 sollten den Effekt gleichzeitiger Wirkung der Stressoren "zweifache Ent- 
laubung" und "sommerliche Trockenheit" simulieren. Aufgrund der Ende 1999 gewonnenen Ergebnisse wurde dann für 2000 die Kombination einer zeitversetzten Wirkung der Stressoren überprüft. Eine Übersicht über die verschiedenen Behandlungsvarianten bei $Q$. robur und $Q$. petraea in den einzelnen Untersuchungsjahren gibt Tabelle 2.1. Pro Variante konnten bei beiden Arten 1999 fünf Bäume, 2000 aufgrund vorhandener Ersatzbäume sechs Bäume pro Variante einbezogen werden.

\section{Wachstum und Schadsymptomatik}

Mit Ausnahme des Anzuchtjahres 1998, in dem insgesamt vier Bäume bis Ende April nachgepflanzt wurden, kam es nur im Jahr 1999 bei der DeDr-Variante bei $Q$. robur am Anfang der Trockenperiode und im Jahr 2000 bei der Dr-Variante bei $Q$. petraea gegen Ende der Trockenphase zu einem Absterben je eines Einzelbaumes. Von diesen beiden Bäumen konnte die im Jahr 1999 abgestorbene Stieleiche durch einen Ersatzbaum mit gleicher Vorbehandlung ersetzt werden. Vor allem in den Jahren 1998 und 1999 kam es trotz prophylaktischer Spritzung mit 0,1\%-iger Saprol-Lösung zu einem starken Mehltaubefall (Microsphaera alphitoides) des zweiten Blattaustriebes der Entlaubungsvarianten beider Arten. Um eine weitere Beeinträchtigung der Pflanzen zu vermeiden, wurden alle Bäume mehrmals ab Mitte Mai bis in den August hinein behandelt. Im Jahre 2000 wurde Anfang Mai und Anfang Juni erfolgreich gegen Mehltau gespritzt. Im Jahr 1999 kam es ab Ende August bei allen entlaubten Varianten zu einer deutlich früheren Vergilbung einzelner Blätter als bei den nicht entlaubten Bäumen. Dies wird vor allem auf den deutlichen Mehltaubefall während der Vegetationsperiode zurückgeführt. Ende August 2000 kam es bei den trockengestressten Bäumen (Dr- und DeDrVariante), vor allem bei Q. petraea, zu starken Vergilbungen an einzelnen Blättern. In allen drei Jahren von 1998 bis 2000 wiesen die Blätter aller Bäume blattoberseits einen braunschwarzen, abwischbaren Belag aus Pilzmyzel epiphytischer Schwärzepilze (sog. Rußtau) auf. Dieser Belag wurde durch wiederholtes Abwischen der befallenen Blätter während der Vegetationsperiode erfolgreich entfernt.

\section{Witterungsbedingungen 1999-2000}

Für die Jahre 1999 und 2000 wurden die meteorologischen Daten der Klimastation Göttingen vom Deutschen Wetterdienst herangezogen (Abb. 2.1). Die Vegetationsperiode 1999 war im Vergleich zum vieljährigen Mittel (1961-1990) um $1^{\circ} \mathrm{C}$ wärmer und wies eine deutlich höhere Sonnenscheindauer (117\%) auf. Die Zahl der Sommertage mit ei- 
nem Temperaturmaximum über $25^{\circ} \mathrm{C}$ wurde mit 42 angegeben. Im Jahr 2000 zeigte sich eine ausgeprägte Schlechtwetterperiode von Ende Juni bis Anfang August. Sonnenscheindauer und Lufttemperatur entsprachen dem vieljährigen Mittel. Allerdings wurden nur 27 Sommertage erreicht, da der Juli in dieser Hinsicht komplett ausfiel. Im Vergleich zum Vorjahr war diese Vegetationsperiode daher als deutlich kühler und sonnenärmer zu charakterisieren.

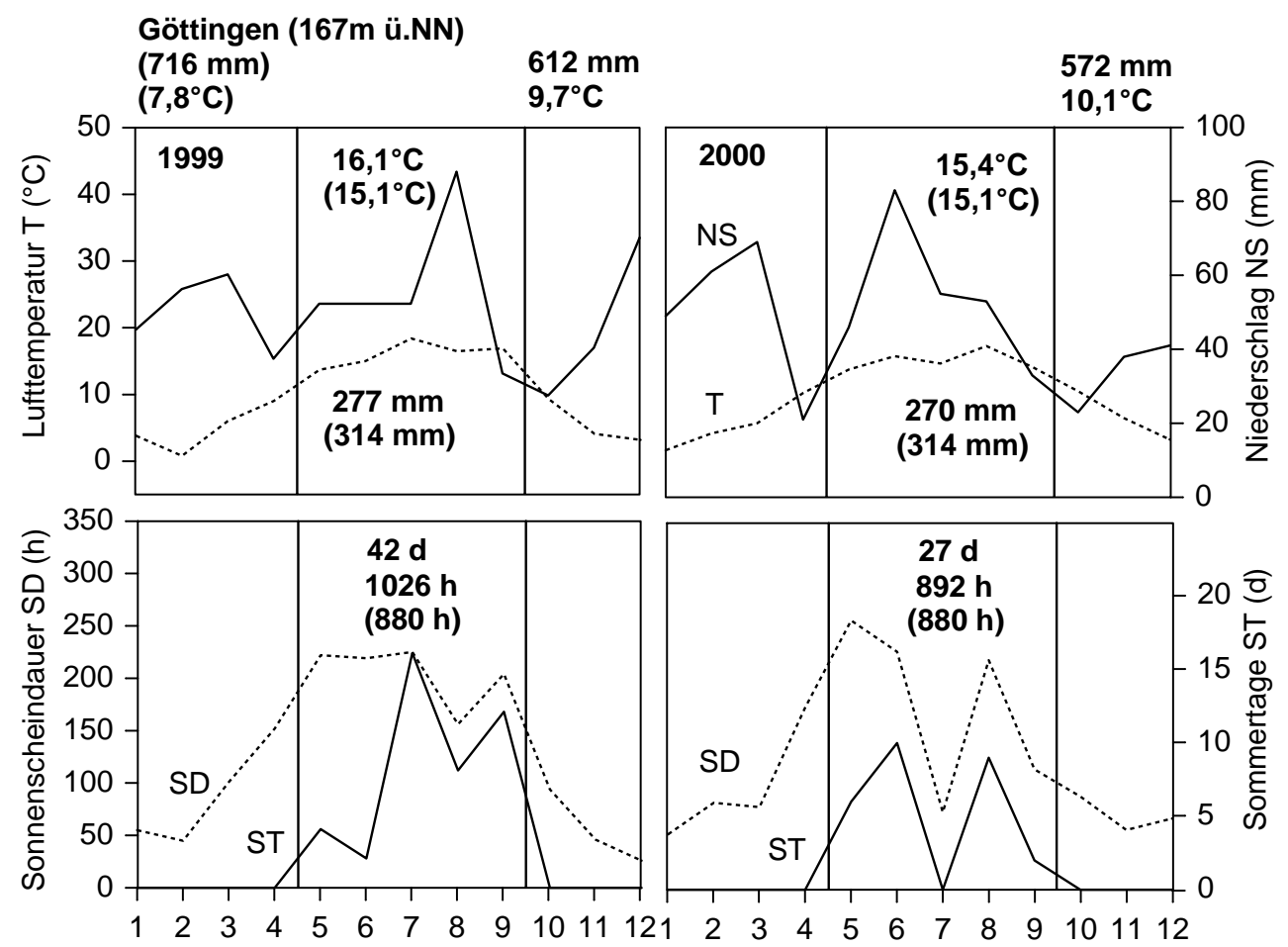

Abb. 2.1: Klimadaten der Untersuchungsjahre 1999 und 2000 für die Station Göttingen. Dargestellt sind die Monatswerte der jeweiligen Jahre sowie die vieljährigen Mittel (1961-1990, in Klammern). Die Dauer der Vegetationsperiode ist durch vertikale Linien gekennzeichnet. Werte innerhalb der Linien stellen die berechneten Temperaturmittelwerte sowie die Summen der Niederschläge, Sonnenscheindauer und Anzahl der Sommertage mit $\mathrm{T}_{\max }>25^{\circ} \mathrm{C}$ dar. Daten: Deutscher WetTERdienst.

\subsubsection{Freilanduntersuchungen 2001}

Um die an jungen Eichen gewonnenen Ergebnisse mit denen älterer Bäume zu vergleichen, wurden im Sommer 2001 Untersuchungen zum Wasserhaushalt und zur Holzanatomie an ca. 20-jährigen, etwa 5 m hohen Stieleichen auf dem Gelände der Baumschule Rahte (Wietze, Niedersachsen) durchgeführt. Die Varianten waren: C, Kontrol- 
le; De1, einmal entlaubt (Mai 2000); De2, zweimal entlaubt (Mai 1999 und 2000). Die Entlaubung erfolgte manuell an frisch ausgetriebenen jungen Blättern des ersten Blattaustriebes. Dabei ließ es sich z.T. nicht vermeiden, daß es zu Beschädigungen an Zweigen und Knospen kam. Der Entlaubungsgrad betrug 90 bis $97 \%$ der Blattfläche des Erstaustriebes. Zur Untersuchung wurden die NO-exponierten, äußeren Bäume einer drei- bis vierzähligen, in NW-SO-Richtung verlaufenden Reihe ausgewählt. Pro Variante standen sechs Bäume zur Verfügung. Allen Bäumen wurden im Winter 2000/2001 im Rahmen einer Untersuchung zur Frosthärte Bastproben mittels Korkbohrer entnommen (vgl. MEYER 2001). Bereits in der zweiten Messperiode Ende Juli 2001 wurde ein Kontrollbaum gegen einen vergleichbaren, benachbarten ersetzt, da er starke Beeinträchtigungen im Wasserhaushalt zeigte. Ein Grund hierfür kann in einer möglichen Ringelung durch die o.g. Korkbohrerproben liegen. Mehltaubefall trat nur unwesentlich an den jungen Blättern des zweiten Blattaustriebes auf. Die Messungen der Wasserpotentiale wie auch die Porometrie erfolgten an unbeschädigten, vitalen grünen Blättern.

\section{Witterungsbedingungen im Freiland}

Das Klimadiagramm der von den Freilandbäumen 2001 nur wenige Kilometer entfernten Klimastation Celle-Wietzenbruch (39m ü.NN) ist in Abb. 2.2 dargestellt.

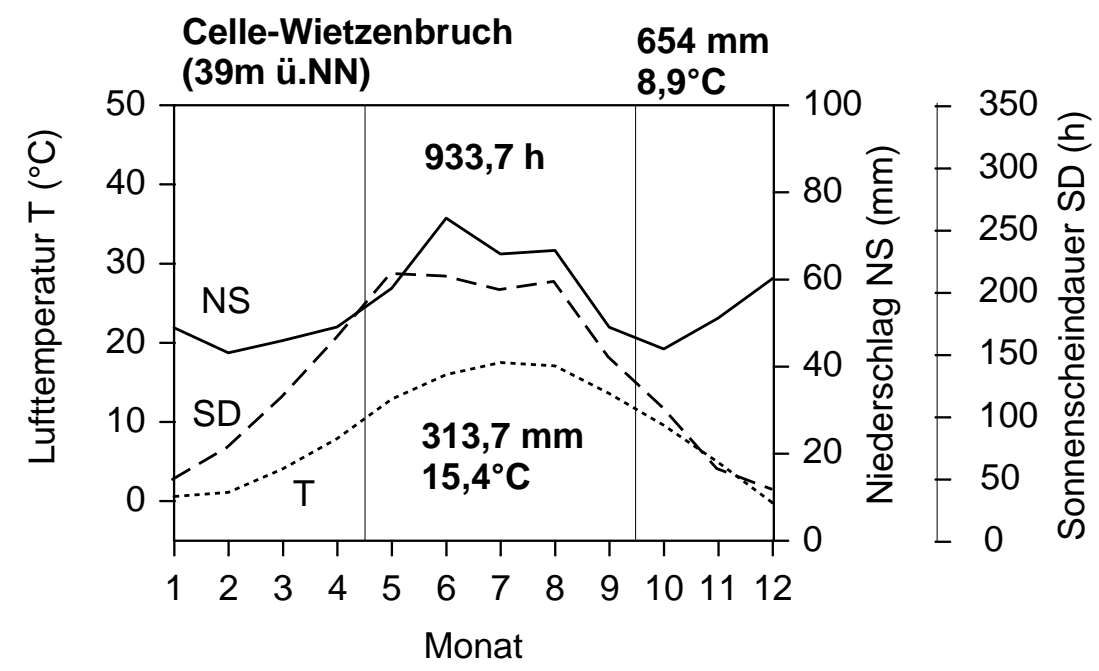

Abb. 2.2: Klimadiagramm der Station Celle-Wietzenbruch. Dargestellt sind die vieljährigen Mittel (1961-1990) der mittleren monatlichen Lufttemperatur, des Niederschlages und der Sonnenscheindauer. Die Dauer der Vegetationsperiode ist durch vertikale Linien gekennzeichnet. Werte innerhalb der Linien stellen den berechneten vieljährigen Temperaturmittelwert, die Summe der Niederschläge und der Sonnenscheindauer dar. Daten: Deutscher Wetterdienst. 
Datengrundlage sind die vieljährigen Mittel der Jahre 1961-1990. Im Vergleich mit der Station Göttingen (167m ü.NN) sind die klimatischen Bedingungen hier durch eine leichte Erhöhung der mittleren Jahrestemperatur und der Niederschlagssumme gekennzeichnet. Dies trifft auch für die Werte innerhalb der Vegetationsperiode zu, wobei zusätzlich die Sonnenscheindauer gegenüber der Station Göttingen leicht erhöht ist. Generell sind beide Stationen gut miteinander vergleichbar.

\subsection{Wasserhaushalt}

\subsubsection{Blatt-Wasserpotential}

Die Bestimmung des Blatt-Wasserpotentials $\Psi$ erfolgte mit der Druckkammermethode nach SCHOLANDER et al. (1965). In einem transpirierenden Blatt sind aufgrund des herrschenden Widerstandes bei Wassereinstrom durch das Plasmalemma das symplastische Wasserpotential $\Psi_{\text {sym }}$ und das apoplastische Wasserpotential $\Psi_{\text {apo }}$ verschieden. Beim Abschneiden des Blattes reißt der Wasserfaden im Xylem. Sym- und apoplastische Wasserpotentiale nähern sich bei dem nun fehlenden Transpirationssog einem Gleichgewichtspotential sehr schnell an. Bei herrschendem Gleichgewicht entsprechen sich $\Psi_{\text {sym }}$ und $\Psi_{\text {apo }}$.

Durch langsames Erhöhen des Druckes in der Messkammer wird der infolge des Abschneidens in die Leitbündel zurückgezogene Wasserfaden des Xylemsaftes wieder an die Schnittfläche gepresst. Da der Wassergehalt im Blatt während der Messung konstant bleibt und das matrikale wie auch das osmotische Potential im Xylemsaft vernachlässigbar gering sind (TYREE \& JARVIS 1982), entspricht der Kammerdruck bei Austritt des Xylemsaftes dem Druckwert des Blatt-Wasserpotentials, jedoch mit umgekehrtem Vorzeichen. Aufgrund des limitierten Blattmaterials der jungen Bäume konnten Tagesgänge des Wasserpotentials nicht erstellt werden. Daher wurden an sonnigen, wolkenfreien Tagen die frühmorgendlichen Maximal- $\left(\Psi_{\mathrm{pd}}\right.$, gemessen vor Sonnenaufgang) und die nachmittäglichen Minimalwerte ( $\Psi_{\text {awp }}$, gemessen zwischen 13:00 und 14:00 Uhr Ortszeit) bestimmt. Dieses wurde auch im Freiland 2001 beibehalten. Pro Variante standen 1999 fünf, 2000 und 2001 sechs Bäume zur Verfügung. Die Messungen wurden pro Baum an zwei (2001: vier) besonnten, aus der oberen Krone stammenden Blättern des zweiten Blattaustriebes durchgeführt. Alle Proben wurden mit einem Skalpell abgetrennt und sofort in die Scholander-Apparatur (PMS 1000, PMS Instruments, Corvallis, OR, USA) eingesetzt. Mit Hilfe einer Lupe wurde unter langsa- 
mer Druckerhöhung der Zeitpunkt des Feuchtwerdens der Schnittfläche ermittelt. Die Druckerhöhung lag bei maximal 0,03 MPa pro Sekunde. Zwischen dem Abtrennen der Probe und dem Anfang der Messung verstrich ca. eine Minute. Die Gesamtdauer aller Messungen betrug etwa eine Stunde, so dass eine gute Vergleichbarkeit der Varianten durch die zeitnahe Bestimmung des Wasserpotentials gegeben ist.

\subsubsection{Druck-Volumen-Kurve}

Die Druck-Volumen-Kurve (auch: P/V-Kurve) nach TYREE \& JARVIS (1982) dient der Bestimmung verschiedener Wasserzustandsgrößen von Pflanzenorganen und gibt die Veränderung des Wasserpotentials in Abhängigkeit vom Wasserzustand des Symplasten an. Bei der hier verwendeten Methode wurde der Wassergehalt des Gewebes vom Zustand der Aufsättigung bis zu niedrigen Wassergehalten durch schrittweises Auspressen der Probe in der Scholander-Druckkammer reduziert.

Druck-Volumen-Kurven wurden in den Jahren 1999 und 2000 jeweils vor und nach Trockenstress (d.h. Mitte bis Ende Juni und Ende August bis Anfang September) von je einem Zweig der oberen Baumkrone pro Baum mit vier Bäumen pro Variante erstellt. Der Zweig wurde mit einem Skalpell abgetrennt und sofort in ein wassergefülltes Gefäß überführt. Nach zehn Stunden Aufsättigung im Kühlschrank bei $7^{\circ} \mathrm{C}$ wurde dieser nochmals unter Wasser gekürzt und das Sättigungsgewicht $\left(\mathrm{FG}_{\mathrm{sat}}\right)$ bestimmt. Zur Vermeidung von Transpirationsverlusten wurde der Zweig während der Messung mit Cellophan-Folie umhüllt. Vor Messbeginn wurde der Sättigungs-Gleichgewichtsdruck bestimmt und danach die Probe jeweils 10 Minuten einem Anfangsdruck von 0,3 MPa ausgesetzt. Die ausgepresste Menge an Flüssigkeit wurde bei jeder Druckstufe mit zellstoffgefüllten EPPENDORF-Cups direkt an der Schnittfläche aufgefangen und gewogen. Anschließend wurde der Druck gesenkt (meist um 0,15 bis 0,35 MPa), bis keine Flüssigkeit mehr austrat. Ein neues Gleichgewicht zwischen Apo- und Symplast konnte sich jetzt zehn Minuten lang einstellen. Dann wurde das herrschende Wasserpotential als Gleichgewichtsdruck für diese Druckstufe bestimmt und nun die nächsthöhere Druckstufe für zehn Minuten eingestellt. Die Druckstufenintervalle betrugen im Bereich von 0 bis 2,7 $\mathrm{MPa}$ jeweils 0,3 $\mathrm{MPa}$ und wurden danach von 2,7 bis 3,7 $\mathrm{MPa}$ auf jeweils 0,2 MPa verringert. Nach Beendigung der Messung wurde erneut das Gewicht der Probe bestimmt, um den Gewichtsverlust während der Messung zu bestimmen. Das Trockengewicht (TG) wurde nach 48 Stunden Trocknung bei $105^{\circ} \mathrm{C}$ ermittelt und der Gesamtwassergehalt $\left(\mathrm{V}_{\mathrm{t}}\right)$ aus dem Trockengewicht und dem Sättigungsgewicht 
bestimmt. Der Transpirationsverlust während der Messung wurde über die Differenz zwischen dem Wasserverlust der Probe während der Messung und der Summe des ausgepressten Wassers errechnet und anteilig den Druckstufen zugerechnet. Trägt man den Kehrwert des Wasserpotentials $(-\Psi)$ gegen den kumulativen Wasserverlust $\left(\mathrm{V}_{\mathrm{e}}\right)$ auf, so erhält man die klassische Darstellung der P/V-Kurve mit einem nichtlinearen Abschnitt, der abhängig ist vom Turgor (P) und dem osmotischen Wert (П), und einem linearen Abschnitt, der bei einsetzender Grenzplasmolyse $(\mathrm{P}=0)$ beginnt und nur von $\Pi$ bestimmt wird (KOIDE et al. 1989). Am Turgornullpunkt entspricht das Wasserpotential $\Psi$ dem osmotischen Wert П. Für den linearen Abschnitt der P/V-Kurve gilt:

$$
\frac{-1}{\Psi}=\frac{1}{\Pi}
$$

П Osmotischer Wert

Folgende Zustandsgrößen der Probe lassen sich aus der P/V-Kurve ableiten: Den osmotischen Wert bei Wassersättigung $\left(\Pi_{0}\right)$ findet man durch Extrapolation des linearen Astes bis zum Schnittpunkt des Astes mit der Ordinate. Die Geradengleichung des linearen Astes wurde mit Hilfe linearer Regressionen der letzten Punkte des Graphen erstellt. Der osmotische Wert bei Grenzplasmolyse $\left(\Pi_{P}\right)$ wurde rechnerisch mit Hilfe linearer Regressionen für die letzten Punkte des linearen Astes unter schrittweiser Erhöhung der Anzahl der berücksichtigten Punkte ermittelt und graphisch überprüft, um so die größtmögliche Genauigkeit zu erreichen. Der Turgor (P) errechnet sich im nicht linearen Abschnitt aus gegebenem Wasserpotential und dem osmotischen Wert nach der Wasserpotentialgleichung. Den Wassergehalt des Symplasten bei Sättigung $\left(\mathrm{V}_{0}\right)$ bekommt man aus dem Schnittpunkt der extrapolierten Geraden mit der Abzisse. Der relative Wassergehalt des Symplasten $\left(\mathrm{RWC}_{\mathrm{s}}\right)$ ergibt sich aus Gleichung 2.2.

$$
R W C_{s}=V_{0} / V_{t}
$$

mit

$$
V_{t}=F G_{S a t}-T G
$$

$\mathrm{FG}_{\text {Sat }}$ Sättigungsgewicht [g]

TG Trockengewicht [g]

$\mathrm{V}_{0}$ Wassergehalt des Symplasten [g]

$\mathrm{V}_{\mathrm{t}}$ Gesamtwassergehalt der Probe $[\mathrm{g}]$ 
Der Wassergehalt des Apoplasten $\left(\mathrm{V}_{\mathrm{a}}\right)$ wird aus Gleichung 2.4 berechnet:

$$
V_{a}=V_{t}-V_{0}
$$

$\mathrm{V}_{\mathrm{t}}$ Gesamtwassergehalt der Probe $[\mathrm{g}]$

$\mathrm{V}_{0}$ Wassergehalt des Symplasten [g]

Der relative Wassergehalt des Apoplasten $\left(\mathrm{RWC}_{\mathrm{a}}\right)$ wird mit Gleichung (2.5) errechnet.

$$
R W C_{a}=1-\frac{V_{0}}{V_{t}}
$$

Der Wassergehalt am Turgor-Nullpunkt $\left(\mathrm{V}_{\mathrm{p}}\right)$ wird bei $\Pi_{\mathrm{p}}$ abgelesen. Der relative Wassergehalt am Turgornullpunkt $\left(\mathrm{RWC}_{\mathrm{p}}\right.$, in \%) wird nach Gleichung 2.6 bestimmt.

$$
R W C_{p}=1-\frac{V_{P}}{V_{t}}
$$

$\mathrm{V}_{\mathrm{p}}$ Wassergehalt des Symplasten bei Grenzplasmolyse [g]

Der relative symplastische Wassergehalt am Turgornullpunkt $\left(\mathrm{RWC}_{\mathrm{sp}}\right.$, in \%) errechnet sich dann aus $\mathrm{RWC}_{\mathrm{p}}$ und dem gegebenen $\mathrm{RWC}_{\mathrm{a}}$ am Turgornullpunkt. Der Elastizitätsmodul $\varepsilon$ beschreibt die Turgoränderung bei einer gegebenen Änderung der Menge des symplastischen Wassers (TYREE \& JARVIS, 1982). Wenn dabei die Menge des apoplastischen Wassers konstant bleibt, folgt nach KOIDE et al. (1989) Gleichung 2.7:

$$
\varepsilon=\frac{d P}{d R W C} \cdot\left(R W C_{\text {mean }}-R W C_{a}\right)
$$

$\mathrm{P}$ Turgor $[\mathrm{MPa}]$

RWC Relativer Wassergehalt

$\mathrm{RWC}_{\mathrm{a}}$ Relativer Wassergehalt des Apoplasten

$\mathrm{RWC}_{\text {mean }}$ Mittelwert des relativen Wassergehaltes

Zur Bestimmung von $\varepsilon$ nach KoIDE et al. (1989) wurde die Steigung dP/dRWC aus den ersten vier Werten des linearen Astes der Auftragung von P gegen RWC berechnet. Als RWC-Wert diente der Mittelwert aus den RWC-Werten dieser vier Punkte; $\mathrm{RWC}_{\mathrm{a}}$ wurde aus der Auftragung $-\frac{1}{\pi} / \mathrm{V}$ berechnet. Da das Ende des nicht linearen Astes der Druck-Volumen-Kurve meist nach nur fünf Messwerten erreicht wurde, konnte nur der Elastizitätsmodul für den Bereich bei Sättigung, d.h. der maximale Elastizitätsmodul, 
berechnet werden. Durch Auftragung des Wasserpotentials gegen den Turgor (- $\Psi / \mathrm{P}-$ Diagramm) lassen sich durch $\varepsilon$ bedingte Unterschiede der Pflanzen in der Fähigkeit zur Aufrechterhaltung eines hohen Turgors bei Abnahme der Wassergehalte bzw. sinkenden Wasserpotentialen darstellen.

Eine Veränderung der osmotischen Potentiale $\left(\Pi_{0}\right.$ und $\left.\Pi_{\mathrm{P}}\right)$ kann durch Osmoregulation verursacht werden. Nach NoITS AKIS \& TsiouvARAS (1990) kann eine Nettoänderung der Osmotika aus Zeitverläufen der osmotischen Potentiale und der symplastischen Wassergehalte vor und nach einem bestimmten Zeitpunkt abgeleitet werden (Gleichung 2.8).

$$
\frac{n_{1}}{n_{2}}=\frac{\Pi_{1}}{\Pi_{2}} \cdot \frac{V_{1}}{V_{2}}
$$

n Osmotikagehalt

Bei einem Quotienten von < 1 deutet dies auf eine Nettoanreicherung zwischen beiden Terminen hin, bei einem Quotienten von 1 oder $>1$ liegt keine Veränderung bzw. eine Abnahme der Osmotika vor (LINNENBRINK et al., 1992).

\subsubsection{Stomatäre Leitfähigkeit, berechnete hydraulische Leitfähigkeit der Pflanze und Transpiration}

\section{Messung der stomatären Leitfähigkeit}

Die Bestimmung der stomatären Leitfähigkeit von Wasserdampf $\left(\mathrm{g}_{\mathrm{s}}\right)$ und der Transpiration (E) erfolgte mit einem LI-1600 steady-state-Porometer (LI-COR Inc., Lincoln, NE, USA) an den Blättern des zweiten Blattaustriebes, um eine Vergleichbarkeit zwischen entlaubten und nicht entlaubten Varianten zu gewährleisten. Vor Beginn der Messung wird die relative Luftfeuchte der Umgebungsluft bestimmt. Wird danach ein Blatt in die Messkammer eingespannt, so erhöht sich in dieser die relative Luftfeuchte durch die Transpiration des Blattes. Für die Messkammer werden nun 100\% Wassersättigung angenommen. Durch ein Einströmen von trockener Luft (mit 2\% relativer Feuchte) in die Messkammer wird der vom Blatt verursachte Anstieg der Luftfeuchte bis zu dem Punkt ausgeglichen, an dem die relative Luftfeuchte wieder den Ausgangswert der Umgebungsluft erreicht hat. Nun sind steady-state-Bedingungen bezüglich der Luftfeuchte in der Messkammer gegeben und die jetzt ermittelte Einstromrate der trockenen Luft dient als Berechnungsgrundlage für die Transpirationsrate. Die Leitfähigkeit berechnet sich nach Gleichung 2.9 aus Transpiration, Wasserdampfdruckdifferenz zwischen Blatt und Messkammer sowie dem aktuellen Luftdruck. 


$$
E=\frac{g_{s} \cdot\left(e_{l}-e_{c}\right)}{P}
$$

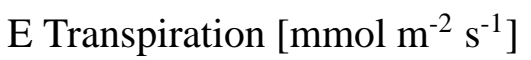

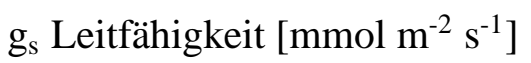

$\mathrm{e}_{1}$ Wasserdampfdruck im Blatt $[\mathrm{kPa}]$

$\mathrm{e}_{\mathrm{c}}$ Wasserdampfdruck in der Messkammer [kPa]

P Luftdruck [kPa]

Die stomatäre Leitfähgkeit $\left(\mathrm{g}_{\mathrm{s}}\right)$ wurde an Strahlungstagen der Jahre 1999 und 2000 an besonnten Blättern der oberen Krone in 1,5-h-Intervallen von 7:00 bis 17:30 Uhr gemessen. Dabei kamen jeweils fünf Blätter pro Pflanze und fünf (1999) resp. sechs (2000) Pflanzen pro Variante zum Einsatz. Die Dauer der Einzelmessung betrug $30 \mathrm{~s}$, um Änderungen der relativen Feuchte in der Messküvette zu minimieren. Die maximale stomatäre Leitfähigkeit $\left(\mathrm{g}_{\mathrm{sm}}\right)$ wurde aus diesen Tagesgängen ermittelt.

In der Freilandsaison 2001 wurde die $\mathrm{g}_{\mathrm{s}}$ an Strahlungstagen an besonnten Blättern des mittleren Kronenbereichs in etwa 3 bis 3,5 m Höhe in 1,5-h-Intervallen von 7:00 bis 17:30 Uhr gemessen. Dies geschah an jeweils fünf Blättern pro Baum und sechs Bäumen pro Variante. Die Dauer der Einzelmessungen, die Bestimmung von $\mathrm{g}_{\mathrm{sm}}$ wie auch die Messungen der relativen Feuchte der Umgebungsluft und der Umgebungstemperatur entsprachen den vorhergehenden Untersuchungsjahren 1999 und 2000.

\section{Wassersättigungsdefizit der Luft (VPD) und $\Delta$ w}

Die Berechnung des Wassersättigungsdefizits der Luft (VPD) und der Differenz der Wasserdampfmolenbrüche vom Blatt und der Umgebungsluft $(\Delta w)$ erfolgte auf Basis der mit dem Porometer in Kronenhöhe gemessenen Lufttemperatur und -feuchte. Das VPD stellt die Differenz aus dem Sättigungsdampfdruck $\left(\mathrm{e}^{0}\right)$ und dem Wasserdampfdruck der Umgebungsluft (e) dar (Gleichung 2.12). Der Sättigungsdampfdruck lässt sich mit Hilfe der MAGNUS-Formel (Gleichung 2.10) beschreiben:

$$
e^{0}=6,1078 \cdot e^{\left(\left(17,08085 \cdot T_{U}\right) /\left(234,175+T_{U}\right)\right)}
$$

$\mathrm{T}_{\mathrm{U}}$ Umgebungstemperatur $\left[{ }^{\circ} \mathrm{C}\right]$

$\mathrm{e}^{0}$ Sättigungsdampfdruck $[\mathrm{kPa}]$

e Wasserdampfdruck der Umgebungsluft [kPa] 
Über die relative Luftfeuchte (RF) kann aus Gleichung 2.11 der Wasserdampfdruck der Umgebungsluft (e) errechnet werden:

$$
e=\frac{R F \cdot e^{0}}{100}
$$

Das Sättigungsdefizit der Luft (VPD) ist dann:

$$
V P D=e^{0}-e
$$

VPD Sättigungsdefizit der Luft [kPa]

Bei jeder Blatttemperatur $\mathrm{T}_{1}$ kann Wasserdampfsättigung in den Blattinterzellularen angenommen werden (VON WiLlerT et al., 1995). Analog zur Berechung des Sättigungsdefizites der Luft kann somit auch die Wasserdampfdruckdifferenz $\left(\mathrm{VPD}_{1}\right)$ zwischen Blatt $\left(e_{1}\right)$ und Umgebungsluft (e) beschrieben werden als:

$$
V P D_{l}=e_{l}-e
$$

Das Sättigungsdefizit der Luft kann außer durch das VPD auch durch die Differenz der Wasserdampfmolenbrüche ( $\Delta \mathrm{w})$ ausgedrückt werden (VON WILLERT et al., 1995):

$$
\Delta w=\frac{e_{l}-e}{P}
$$

P Luftdruck [kPa]

Das Wassersättigungsdefizit (VPD) der Luft zur Zeit von $\mathrm{g}_{\mathrm{sm}}$ variierte im Untersuchungsjahr 1999 zwischen 1,5 und 3,0 kPa mit Ausnahme von Tag 183 (02.07.1999) mit 3,5 bis 4,9 kPa. Das VPD zum Zeitpunkt der Messung von $\mathrm{g}_{\mathrm{sm}}$ im Jahr 2000 lag zwischen 1,7 und 3,5 kPa. Nur am 20.06.2000 (Tag 171) wurde bei den Varianten C, De und DeDr von $Q$. robur ein VPD zwischen 4 und $5 \mathrm{kPa}$ gemessen. Zum Zeitpunkt der Messung der $\mathrm{g}_{\text {sm }}$ im Jahr 2001 lag das VPD zwischen 1,8 und 2,9 $\mathrm{kPa}$, nur am letzten Termin bei $1,4 \mathrm{kPa}$. Der Einfluss des VPD auf die gemessenen $\mathrm{g}_{\mathrm{sm}}$ wurde in allen drei Untersuchungsjahren überprüft. Eine Auftragung der $g_{\text {sm }}$ gegen das VPD zeigte keinen signifikanten Einfluss des VPD auf die $\mathrm{g}_{\mathrm{sm}}$. 


\section{Berechnung der Tagestranspirationssumme $E_{d}$}

Die Transpiration des Blattes wird vom LI-1600 auf Basis der ermittelten $\mathrm{g}_{\mathrm{s}}$-Werte ausgegeben. Die Berechung der Tagestranspirationssumme basiert auf der Integration von acht Zeitintervallen, die den Zeitraum von 45 Minuten vor und nach jedem Messzeitpunkt der $g_{s}$ umfassen. Die Summe aller Transpirationswerte ergibt die Gesamttranspiration pro Tag und Baum $\left(E_{d}\right)$. Aufgrund der stark unterschiedlichen Blattflächen zwischen entlaubten und nicht entlaubten Bäumen 1999 wurde nur die flächenbezogene Transpirationssumme aus Gründen der besseren Vergleichbarkeit zwischen den Jahren 1999 und 2000 dargestellt. Für den 12.07.1999 (Tag 193, Q. robur) konnte keine Berechnung durchgeführt werden, da aufgrund von Gewitter die Messung um 15:00 Uhr abgebrochen wurde.

\section{Spezifische hydraulische Leitfähigkeit Boden-Blatt}

Die spezifische hydraulische Leitfähigkeit auf der Fließstrecke Boden-Blatt $\left(\mathrm{g}_{\mathrm{sl}}\right)$ kann mit Hilfe der Bodenmatrixpotentiale und der $\Psi_{\text {awp }}$-Werte nach SALIEndRA et al. (1995) berechnet werden:

$$
g_{s l}=\frac{d F}{\Psi_{\text {Boden }}-\Psi_{\text {Blatt }}}
$$

Als Flussrate dF kann die Transpirationrate pro Baum dienen. In erster Näherung kann bei den gemessenen stark negativen Wasserpotentialen das Bodenmatrixpotential vernachlässigt werden. Die Berechnung erfolgte mit den gemessenen $\Psi_{\text {awp }}$-Werten und den ermittelten Transpirationswerten zum Zeitpunkt von $\Psi_{\text {awp }}$. Die Mittelwerte jeder Variante wurden aus fünf (1999) resp. sechs (2000) Einzelwerten gebildet. Ein Problem bei dieser Form der Berechnung stellten die um 13-14:00 Uhr gemessenen $\Psi_{\text {awp }}$-Werte dar. Aufgrund der z.T. am Vormittag gemessenen $\mathrm{g}_{\mathrm{sm}}$ müssen die zeitversetzt gemessenen nachmittäglichen Wasserpotentiale nicht unbedingt die stärkste Belastung des Wasserhaushaltes im Tagesgang widerspiegeln. Resultierend aus der geringeren Blattzahl pro Baum konnten jedoch keine Tagesgänge des Wasserpotentials bestimmt werden. Trotz dieser Einschränkung kann die berechnete $\mathrm{g}_{\mathrm{sl}}$ als ein Maß zur Abschätzung dienen. Da zur Berechnung der $\mathrm{g}_{\mathrm{sl}}$ auch eine möglichst zeitnahe Messung der Wasserpotentiale und der Transpiration erfolgen musste, konnte dieses für 1999 nur an zwei Terminen geschehen. 


\subsubsection{Hydraulische Leitfähigkeit von Zweigen}

Messungen der hydraulischen Leitfähigkeit wurden am Ende der Trockenperiode 1999 an diesjährigen (im Jahr 1999 gebildeten) und vorjährigen (im Jahr 1998 gebildeten) Zweigabschnitten von drei peripheren Zweigen pro Baum und fünf Bäumen pro Variante durchgeführt. Zu den Ergebnissen der hydraulischen Leitfähigkeit 2000 siehe BARTELS (2001). Die Messungen erfolgten mit der Druckmethode nach SPERRY et al. (1988) und SPERry \& SAliendra (1994). Hierbei wurden die Zweige zur Vermeidung zusätzlicher erntebedingter Embolien unter Wasser abgeschnitten. Danach wurden diese Zweigabschnitte im Labor in dies- und vorjährige Bereiche unterteilt und diese unter Wasser auf eine einheitliche Länge von $4 \mathrm{~cm}$ zugeschnitten. Die Durchmesser der einzelnen Proben lagen zwischen 4 und $6 \mathrm{~mm}$. Die Zweigsegmente wurden dann mittels Schlauch in natürlicher Fließrichtung an das Vorratsgefäß angeschlossen. Als Flüssigkeit wurde eine gefilterte $(0,2 \mu \mathrm{m})$ Lösung aus $\mathrm{HCl}$ und demineralisiertem, entgastem Wasser $(\mathrm{pH}=2)$ mit einem Druck von $6 \mathrm{kPa}$ verwendet. Die hydraulische Leitfähigkeit wird als Massenflussrate durch das Zweigsegment pro angelegtem Druckgradient angesehen. Zur Bestimmung der Massenflussrate wurde die innerhalb von zehn Minuten am unteren Ende der eingespannten Segmente austretende Flüssigkeit in vorgewogenen Glasröhrchen aufgefangen. Die aktuelle hydraulische Leitfähigkeit wurde bei konstantem Massenfluss bestimmt. Zur Beseitigung möglicher Embolien wurden die Segmente in Anlehnung an BRÉDA et al. (1993) für 20 Minuten einem Druck von 0,15 MPa ausgesetzt. Anschließend wurde die maximale hydraulische Leitfähigkeit analog zur aktuellen Leitfähgkeit bei $6 \mathrm{kPa}$ gemessen. Als Verlust an Leitfähigkeit wurde das prozentuale Verhältnis von aktueller zu maximaler Leitfähigkeit pro Zweig ermittelt und die Differenz zu 100\% berechnet.

\subsubsection{Blattwassergehalt}

Die Bestimmung der Blattwassergehalte mit der Scheibenstanzmethode nach SLAVIK (1974) erfolgte in beiden Untersuchungsjahren (1999 und 2000) vor, während und nach der Trockenstressperiode an insgesamt vier Terminen. Je Variante wurden bei vier Blättern pro Baum je fünf Blattscheiben mittels Stechbohrer entnommen, deren Frischgewicht bestimmt und anschließend in eine Glasschale gebracht, in der sich ein wassergesättigtes, gelochtes Schaumstoffpolster befand. Die Aufsättigung erfolgte ausschließlich über den feuchten Schaumstoff an den Randbereichen der Blattscheiben, so dass eine Übersättigung durch direkten Wasserkontakt vermieden wurde. Nach Ablauf von 4 Stunden wurde das Sättigungsgewicht ermittelt. Nach Trocknung bei $105^{\circ} \mathrm{C}$ bis zur Gewichtskonstanz erfolgte die Bestimmung des Trockengewichtes. 


\subsection{Ober- und unterirdische Biomasse}

Jeweils gegen Ende der Vegetationsperiode wurden die ober- und unterirdischen Biomassen bestimmt. Um eine hinreichende Anzahl an Bäumen pro Variante auch im folgenden Jahr zu gewährleisten, wurden 1999 bei beiden Arten nur je drei Bäume der Cund De-Variante sowie jeweils fünf Bäume der Dr- und DeDr-Variante vollständig geerntet. Am Ende der Vegetationsperiode 2000 erfolgte die Ernte aller Bäume mit sechs Bäumen pro Variante. Im Freiland (2001) fanden nur Untersuchungen zum spezifischen Blattgewicht und dem Feinwurzelgehalt im Oberboden mit sechs Bäumen pro Variante statt.

\subsubsection{Blattfläche und -biomasse}

Zum Zeitpunkt der Ernte im September 1999 und 2000 wiesen die Bäume noch eine vitale und grüne Krone auf. Die Bestimmung der Gesamt-Blattfläche pro Baum wurde mit einem Delta-T Image Analysis-System (Delta-T Devices Ltd., Cambridge, UK) durchgeführt. Die Gesamt-Blattbiomasse wurde nach Trocknung des Blattmaterials bei $105^{\circ} \mathrm{C}$ bis zur Gewichtskonstanz ermittelt. Zur Berechnung der spezifischen Blattfläche des zweiten Blattaustriebes (SLA, d.h. die einseitige Blattfläche pro BlattTrockengewicht) wurden je zwanzig Blätter je Baum mit fünf (1999) bzw. sechs (2000 und 2001) Bäumen pro Variante verwendet.

\subsubsection{Wurzelbiomasse}

Zur Bestimmung der Wurzelbiomassen wurden die Wurzelballen mit dem Substrat aus den Töpfen genommen und der anhaftende Sand mit Wasser vorsichtig ausgespült, um Verluste vor allem der Feinwurzeln zu minimieren. Anschließend erfolgte die Zerlegung des Wurzelballens in Stark- (>10 mm Durchmesser), Grob- (5-10 mm), Schwach- $(2-5 \mathrm{~mm})$ und Feinwurzeln $(<2 \mathrm{~mm})$. Die Feinwurzeln wurden danach nochmals mit demineralisiertem Wasser ausgespült und so von noch anhängendem Substrat unter Verwendung eines Drahtsiebes (Maschenweite 0,25 mm) gereinigt. Zur Abschätzung der Nekromasse wurde ein repräsentativer, unzerteilter Wurzelstrang ausgewählt und der Anteil der toten Wurzeln pro Größenklasse unter dem Binokular bestimmt. Als Unterscheidungskriterium dienten Farbe, Wurzelelastizität und der Zusammenhalt von Rinde und Zentralzylinder. Als abgestorben wurden Wurzeln mit schwarzer Rinde und dunklen Leitungsbahnen bzw. weißer, aber nicht turgeszenter Rinde und weißen 
Leitungsbahnen oder Wurzeln ohne Rinde bzw. Leitungsbahnen angesehen (vgl. auch Leuschner et al. 2001). Nach Trocknung bei $105^{\circ} \mathrm{C}$ bis zur Gewichtskonstanz wurden die Wurzelmassen abzüglich des Anteils der Nekromasse für jede Größenklasse bestimmt und daraus zusammen mit den Blattbiomassen das Blatt/Feinwurzel-Verhältnis berechnet. Da während der Anzucht in der Baumschule eine Unterschneidung der Wurzelballen erfolgte, wurden für die Betrachtung der Effekte der Faktoren Entlaubung und Trockenheit nur die in den jeweiligen Jahren in den Töpfen gebildeten Feinwurzeln zu Grunde gelegt. Im Freiland wurde Anfang Oktober 2001 bei allen Bäumen statt der Gesamt-Wurzelmasse nur der Feinwurzelgehalt im Oberboden gemessen. Im Abstand von 50, 100 und $150 \mathrm{~cm}$ vom Stamm wurden jeweils sechs Stechbohrerproben vom Oberboden bis in $15 \mathrm{~cm}$ Tiefe genommen. Die Proben wurden sofort gekühlt und ins Labor gebracht. Die Bestimmung der Feinwurzelmasse erfolgte wie in den vorhergehenden Jahren. Aufgrund der nahe beieinanderstehenden Bäume wurde eine Beprobung nur entlang der freistehenden NO-Richtung vom Stamm durchgeführt, um eine sichere Zuordnung der Feinwurzeln zu gewährleisten.

\subsubsection{Höhen- und Stammbasiszuwachs}

Die Erfassung des jährlichen Höhen- und Stammbasis-Zuwachses geschah jeweils Anfang April und Anfang Oktober im Zeitraum 1998 bis 2000. Als Gesamthöhe der Bäume wurde der mit einem Zollstock gemessene Abstand von der Substratoberfläche bis zum höchsten noch vitalen Astende definiert. Zur Bestimmung des Stammbasisdurchmessers wurden je zwei um $90^{\circ}$ versetzte Messwerte an einer in etwa $10 \mathrm{~cm}$ Stammhöhe befindlichen, dauerhaft markierten Stelle mit einer Schieblehre gemessen und gemittelt. Die Berechnung der Zuwachsraten der Höhen resp. des Stammbasisdurchmessers erfolgte ausgehend vom Startwert zum Zeitpunkt des Anpflanzens der Bäume (April 1998) bis zum Ende des jeweiligen Untersuchungsjahres.

\subsection{Holzanatomie}

\subsubsection{Jahrringanalyse an Zweigquerschnitten}

Die Untersuchungen zur Holzanatomie wurden 1999 - getrennt nach dies- und letztjährigen Zweigen, an denen zuvor die hydraulische Leitfähigkeit bestimmt worden war an je drei Zweigsegmenten pro Baum mit fünf Bäumen pro Variante durchgeführt. Jeder Schnitt wurde unter dem Mikroskop (Photomikroskop III RS, Carl Zeiss, Oberko- 
chen/Württ., Deutschland) virtuell in vier Sektoren aufgeteilt. Innerhalb dieser Sektoren wurde an vier nach dem Zufallsprinzip ausgewählten Bereichen die Früh- und Spätholzbreite mit Hilfe eines Messokulars bestimmt. Die so gewonnenen Daten aller Bereiche und aller Sektoren wurden gemittelt und zur mittleren Früh- resp. Spätholzbreite pro Baum zusammengefasst. Zu den Ergebnissen der Untersuchungen der Zweige 2000 siehe BARTELS (2001).

\subsubsection{Jahrringanalyse 2001}

Im Jahr 2001 wurden den 18 Untersuchungsbäumen je eine Stammbohrprobe in etwa 1,5 m Höhe entnommen und mit einem computerunterstützten Messsystem in der Niedersächsischen Forstlichen Versuchsanstalt in Göttingen analysiert. Bei der Probenahme wurde darauf geachtet, möglichst genau entlang des Durchmessers zu bohren, damit stets zwei Radien pro Baum erfasst werden konnten. Die gemessenen Jahrringbreiten wurden danach in Früh- und Spätholzanteil unterteilt.

\subsection{Chemische Blattanalysen}

\subsubsection{Kohlenstoff-Isotopen-Verhältnis}

Bei der photosynthetischen $\mathrm{CO}_{2}$-Fixierung durch die Ribulose-BisphosphatCarboxylase/oxidase (RubisCo) diskriminiert diese stark gegen das natürlich in geringen Konzentrationen in der Luft vorhandene ${ }^{13} \mathrm{C}$-Isotop. Unter Trockenstressbedingungen sinkt der $\mathrm{CO}_{2}$-Gehalt im Blatt aufgrund der reduzierten Stomataöffnungsweite und die RubisCo diskriminiert weniger stark gegen ${ }^{13} \mathrm{C}$. Dadurch wird vermehrt ${ }^{13} \mathrm{C}$ eingebaut. Eine Änderung des ${ }^{13} \mathrm{C} /{ }^{12} \mathrm{C}$-Isotopenverhältnisses kann daher Aufschluss über die Langzeit-Wassernutzungseffizienz (long-term water-use efficiency) geben (FARQUHAR \& RICHARDS 1984; FARQUHAR et al. 1989) und ist somit ein Maß für das längerfristige Reaktionsverhalten der Pflanze auf Trockenstress (vgl. Ziegler 1995; PiCON et al. 1996, 1997). Das $\delta^{13}$ C-Verhältnis wird nach Gleichung 2.16 berechnet:

$$
\delta^{13} C[\% o]=\left(\frac{R_{s}}{R_{r}}-1\right) \cdot 1000
$$

$\mathrm{R}_{\mathrm{s}}$ Isotopen-Verhältnis der Probe

$\mathrm{R}_{\mathrm{r}}$ Isotopen-Verhältnis des Referenzstandards 
Die Bestimmung der $\delta^{13} \mathrm{C}$-Werte aus den Versuchen mit jungen Eichen erfolgte an Mischproben aus sechs Blättern pro Baum mit fünf (1999) resp. sechs (2000) Bäumen pro Variante. Die Proben wurden in beiden Jahren gegen Ende der Trockenperiode (Ende August) genommen. Im Freilandversuch 2001 wurden Mischproben aus sechs Blättern je Baum Mitte August geerntet und analysiert. In allen Fällen handelte es sich um sonnenexponierte Blätter aus dem oberen Kronenbereich. Das Pflanzenmaterial für die Bestimmung des Kohlenstoff-Isotopen-Verhältnisses $\left(\delta^{13} \mathrm{C}\right)$ wurde bei $70^{\circ} \mathrm{C}$ getrocknet und mit der Schwingmühle gemahlen. Danach wurden ca. 1,5 mg jeder Probe in Reinzinnkapseln eingewogen. Nach jeweils zehn Einwaagen wurden zwei Blindproben (Acetanilid) mitgemessen. Die Messungen erfolgten im Zentralen Isotopenlabor der Universität Göttingen mit einem On-Line-System, bestehend aus einem NA 1500 C/N Elementar Analyzer (Carlo Erba Strumentazione, Italien), einer Wasserfalle und einem nachgeschalteten Gas-Isotopen-Massenspektrometer (MAT 251, Finnigan, Bremen, Deutschland). Die Proben wurden im Elementar Analyzer verbrannt, gaschromatographisch aufgetrennt (vgl. Kapitel 2.5.2) und das restliche Wasser durch eine Wasserfalle entzogen. Ungefähr 1\% der jetzt gasförmigen Probe wird nun direkt in die Ionenquelle des Massenspektrometers geführt und dort gemessen. Die ermittelten Werte wurden nach der Messung mit Acetanilid als Sekundärstandard auf den international gültigen Primärstandard PDB (Peedee Belemnite; Calciumcarbonat) umgerechnet. Zur Kalibierung und Messtechnik vgl. REINEKING et al. (1993) und LANGEL et al. (1996).

\subsubsection{Stickstoffgehalt und C/N-Verhältnis}

Die Bestimmung der Stickstoffkonzentration im Blatt sowie die Berechnung der C/NVerhältnisse erfolgte in allen drei Jahren bei Blättern des zweiten Blattaustriebes, an denen parallel die $\delta^{13} \mathrm{C}$-Werte gemessen wurden. Hierzu wurde ein NA $1500 \mathrm{C} / \mathrm{N}$ Analyzers der Fa. Carlo Erba Strumentazione, Italien, verwendet. Für die Analyse wurden je ca. 2,5 mg Probe in Reinzinnkapseln eingewogen, bei $1020^{\circ} \mathrm{C}$ mit Sauerstoff verbrannt, danach Stickoxide bei $650^{\circ} \mathrm{C}$ zu Stickstoff reduziert und die $\mathrm{N}_{2}$ - und $\mathrm{CO}_{2}$ Peaks gaschromatographisch getrennt. Aus den so ermittelten Flächeneinheiten konnte über die Flächeneinheiten der Standards (Atropin als C- und N-Standard, $\mathrm{CaCO}_{3}$ als CStandard sowie pro Serie eine Leerkapsel als Blindwert) der Stickstoffgehalt errechnet werden. 


\subsubsection{Chlorophyllgehalt}

Die Bestimmung der Chlorophyllgehalte $\left(\mathrm{Chl}_{\mathrm{a}}\right.$ und $\left.\mathrm{Chl}_{\mathrm{b}}\right)$ erfolgte bei allen Bäumen 1999 von Juni bis August in ca. zweiwöchentlichem Abstand, 2000 je einmal monatlich von Juni bis September mittels zerstörungsfreier, kombinierter Rotlicht/IR-Messung mit einem SPAD-502 Chlorophyll Meter (Minolta Co. Ltd., Japan) an zehn Blättern pro Baum. Die Kalibrierung der so gewonnenen relativen Chlorophyllgehalte (dimensionslose. SPAD-Werte) wurden anhand einer Eichkurve mit 80 Einzelblättern beider Arten durchgeführt (Abb. 2.3). Dazu wurden bei beiden Arten Anfang August 1999 an je zehn Blättern pro Variante zuerst die relativen SPAD-Chlorophyllgehalte gemessen, diese geerntet und im Labor aus dem frischen Blattmaterial das Chlorophyll mittels N,N-Dimethylformamid (DMF) extrahiert. Dazu wurde pro Blatt eine Blattscheibe von $10 \mathrm{mg}$ Frischgewicht ausgestanzt, mit $2 \mathrm{ml}$ DMF versetzt und die Extinktion bei 647 $\mathrm{nm}$ und $664 \mathrm{~nm}$ am Durchfluss-Spektrometer (UV-120-002, Shimadzu, Japan) nacheinander gemessen. Der Gesamt-Chlorophyllgehalt wurde nach Gleichung 2.17 durch die Messung der Absorptionen nach MORAN (1982) bestimmt.

$$
C h l_{\text {total }}=C h l_{A_{664}}+C h l_{A_{647}}
$$

Aufgrund der geringen Blattanzahl der Bäume wurde auf eine destruktive Methode (z.B. DMF-Extraktion) zur Chlorophyllbestimmung verzichtet. Trotz einiger Einschränkungen bzgl. der Eichgeraden können die gemessenen SPAD-Werte dennoch als eine gute Grundlage für die Chlorophyllgehalte im Blatt dienen.

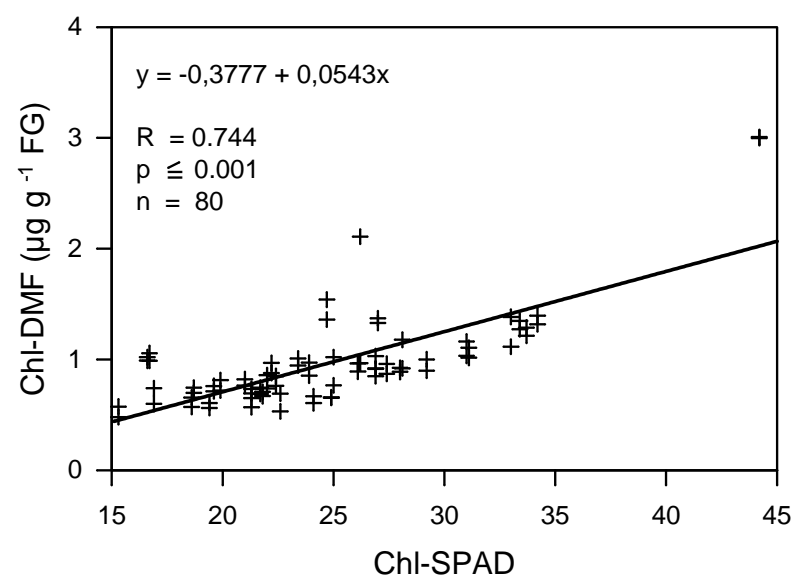

Abb. 2.3: Eichkurve zur Kalibrierung der an Blättern von $Q$. robur und $Q$. petraea gemessenen relativen SPAD-Chlorophyllgehalte mittels Chlorophyll-Extraktion mit DMF. 


\subsubsection{Stärkegehalt}

Die Bestimmung des Stärkegehaltes der Holzproben aus dem unteren Stammbereich der jungen Eichen bzw. der Stammbohrproben der Freilandbäume 2001 umfasste die jeweils letzten drei Jahrringe. Nach Zerkleinern und Einwiegen der Proben erfolgte der Aufschluß mit Dimethyl-Sulfoxid und 8-molarer $\mathrm{HCl}$ im Wasserbad bei $60^{\circ} \mathrm{C}$ für 30 Minuten. Danach wurde eine 8-molare $\mathrm{NaOH}$-Lösung zugegeben. Der pH der Probe wurde mittels Citratpuffer auf $\mathrm{pH}$ 4-5 eingestellt. Die Bestimmung der Stärkegehalte wurde enzymatisch mit dem UV-Test zur Bestimmung nativer Stärke (Boehringer, Mannheim, Deutschland) durchgeführt. Stärke wird duch Amyloglucosidase bei $\mathrm{pH}$ 4,6 zu D-Glucose gespalten. Diese wird mit Adenosin-Triphosphat unter Bildung von Adenosin-Diphosphat zu Glucose-6-Phosphat phosphoryliert (Messung der Extinktion 1). Durch Zugabe von Glucose-6-Phosphat-Dehydrogenase wir dieses oxidiert, wobei reduziertes NADPH entsteht (Messung der Extinktion 2). Diese Menge von NADPH ist proportional zu der bei der Stärke-Hydrolyse gebildeten Menge an D-Glucose. Die Extinktionen wurden bei $340 \mathrm{~nm}$ am Durchfluss-Spektrometer (UV-120-002, Shimadzu, Japan) bestimmt.

\subsection{Photosynthese 2000}

Messungen der Photosynthese erfolgten im Jahr 2000 mit einer LI-6400 Gaswechselanlage (LI-COR Inc., Lincoln, NE, USA) einmalig gegen Ende der Trockenperiode (21.08.2000) an allen Varianten beider Arten. In fünf Durchgängen wurde von 10:00 bis 17:00 Uhr jeweils ein Blatt pro Baum bei einer PAR von $1500 \mu \mathrm{E}$, einem $\mathrm{VPD}_{\text {leaf }}$ von 1 bis $1,5 \mathrm{kPa}$ und einer $\mathrm{CO}_{2}$-Konzentration der Umgebungsluft von 370 ppm gemessen. Die Dauer der Einzelmessung, d.h. bis zur Einstellung eines $\mathrm{CO}_{2}{ }^{-}$ Gleichgewichts in der Küvette, betrug ca. 10 Minuten. Aus den Messungen wurde das Netto-Photosynthesevermögen bei Lichtsättigung $A_{\max }$ sowie die aktuelle Wassernutzungseffizienz (WUE ${ }_{\mathrm{a}}$ ) bestimmt. Die WUE $\mathrm{a}$ ist der Quotient aus der $\mathrm{CO}_{2}$-Aufnahme und der $\mathrm{H}_{2} \mathrm{O}$-Abgabe (Gl. 2.18), also der gemessenen $\mathrm{A}_{\max }$ und der Transpiration. Im Gegensatz zum $\delta^{13} \mathrm{C}$-Wert ist die $\mathrm{WUE}_{\mathrm{a}}$ daher ein Maß für die kurzzeitige Reaktion der Pflanze unter Trockenstress (NoBeL, 1999). Da das $\Delta \mathrm{w}$ an allen Zeitpunkten der Messungen sehr ähnlich war, wurde der Mittelwert der $W_{U} E_{a}$ aus allen Messungen des Tages berechnet. 


$$
W U E=\frac{J_{\mathrm{CO}_{2}}}{J_{\mathrm{H}_{2} \mathrm{O}}}
$$

$\mathrm{J}_{\mathrm{CO}_{2}}$ Flussrate $\mathrm{CO}_{2}$

$\mathrm{J}_{\mathrm{H}_{2} \mathrm{O}}$ Flussrate $\mathrm{H}_{2} \mathrm{O}$

\subsection{Statistische Methoden}

Mittelwerte und Standardabweichungen sind in den Tabellen und Grafiken angegeben. Der Test auf Normalverteilung aller Datensätze wurde mit der UNIVARIATEProzedur (SAS 6.12, SAS Institute, Cary, NC, USA) und der Verteilung der W-Werte (Signifikanz-Niveau P < 0,1; SHAPIRO \& WILK 1965) durchgeführt. Zur Abschätzung eines möglichen Effekts von VPD auf die stomatäre Leitfähigkeit wurde in allen Jahren $\mathrm{g}_{\mathrm{sm}}$ gegen das VPD aufgetragen und die daraus resultierenden Korrelationskoeffizienten mittels $\chi^{2}$-Test $(P<0,05)$ auf Signifikanz getestet. Dabei wurde weder eine Korrelation zwischen VPD und $g_{s m}$ beim Betrachten sämtlicher Werte noch bei Auftragung pro Variante gefunden.

\section{Datensätze 1999 und 2000}

Im Jahr 1999 waren die Datensätze der Wasserpotentiale, der Blattfläche, der hydraulischen Leitfähigkeit und der Spätholzbreite sowie 2000 die Datensätze der Feinwurzelbiomasse, der Blatt/Feinwurzelverhältnisse und die $\mathrm{A}_{\max }$-Werte nicht normal verteilt. Dies gilt auch für die Stärkegehalte in den Jahren 1999 und 2000. Daher wurde bei diesen Datensätzen zur Bestimmung der Unterschiede zwischen den Varianten der nicht-parametrische H-Test nach Kruskall \& Wallis (cf. SACHS 1984) verwendet. Im Falle signifikanter H-Werte wurde dann ein paarweiser U-Test nach Wilcoxon, Mann und Whitney (cf. SACHS 1984) durchgeführt. In allen anderen Fällen waren die Daten normalverteilt und Signifikanzen wurden mit einer ANOVA separat für jeden Mess termin ermittelt. Eine Ausnahme bildeten die stomatären Leitfähigkeiten ( $g_{s m}$ und $g_{s}{ }^{-}$ Tagesgang), welche zusätzlich mit einer ANOVA mit Messwiederholung getestet wurden, um mögliche Einflüsse der beiden Faktoren innerhalb des Jahresverlaufs bzw. des Tagesgangs zu testen. Im Falle von signifikanten F-Werten wurden die Unterschiede der Mittelwerte zwischen den Varianten mit dem Tukey-Test auf Signifikanz überprüft. In diesen Tests (ANOVA, Tukey, H- und U-Test) betrug das Signifikanzniveau P < 0,05. Mögliche Zusammenhänge zwischen den Faktoren $\delta^{13} \mathrm{C}, \mathrm{g}_{\mathrm{sm}}$, Entlaubung, Trockenheit, 
$\mathrm{A}_{\max }$ und C/N im Jahr 2000 wurden mit einer multiplen Regression mit der RSQUAREProzedur (SAS, s.o.) untersucht, wobei $\mathrm{R}^{2}$ das Quadrat des multiplen Korrelationskoeffizienten zwischen 0 und 1 angibt.

\section{Datensätze 2001}

Alle Datensätze 2001, mit Ausnahme der Stärkegehalte, waren normalverteilt. Daher wurden die Signifikanzen mit einer ANOVA für jeden Meßtermin bestimmt. Nur bei der stomatären Leitfähigkeit wurde zusätzlich eine ANOVA mit Messwiederholung angewendet. Im Falle signifikanter F-Werte wurden auch hier die Unterschiede der Mittelwerte zwischen den Varianten mit dem Tukey-Test auf Signifikanz mit P $<0,05$ überprüft. Die Datensätze des Stärkegehaltes waren nicht normalverteilt. Analog zu den Daten der Jahre 1999 und 2000 wurde ein Unterschied zwischen den Varianten mittels $\mathrm{H}$-Test überprüft und im Falle signifikanter H-Werte anschließend ein paarweiser U-Test durchgeführt. 


\section{Ergebnisse}

\subsection{Zeitgleiche Kombination von Entlaubung und Trockenheit 1999}

\subsubsection{Wasserhaushaltsparameter 1999}

\section{Wasserpotentiale}

Als ein Maß für Trockenstress können die gemessenen Predawn- $\left(\Psi_{\mathrm{pd}}\right)$ und nachmittäglichen $\left(\Psi_{\text {awp }}\right)$ Wasserpotentiale angesehen werden (Abb. 3.1). Das Absinken von $\Psi_{\text {pd }}$ der trockengestressten Varianten Dr und DeDr bei beiden Arten von Juli bis Mitte August deutet auf eine Einschränkung der Wasserversorgung hin.

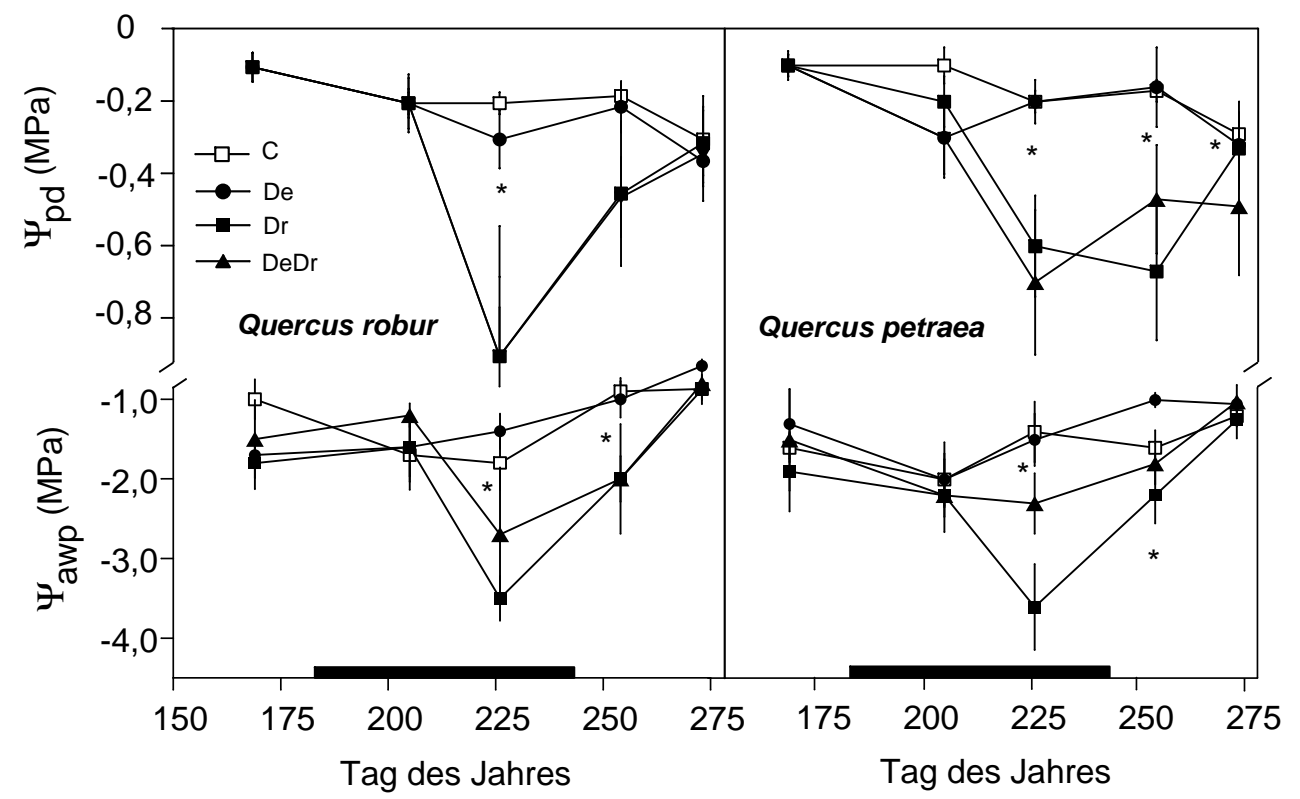

Abb. 3.1: Predawn- $\left(\Psi_{\mathrm{pd}}\right)$ und nachmittägliche ( $\left.\Psi_{\text {awp }}\right)$ Wasserpotentiale bei $Q$. robur und $Q$. petraea in der Untersuchungsperiode 1999. Der waagerechte Balken gibt die Dauer der Trockenperiode an. Signifikante Unterschiede aller trockengestressten gegenüber allen ausreichend bewässerten Varianten sind mit $\left(^{*}\right)$ gekennzeichnet. C, Kontrolle; De, Entlaubung 1998 und 1999; Dr, Trockenstress 1999; DeDr, Kombination aus Trockenstress und Entlaubung. 
$\mathrm{Zu}$ diesem Zeitpunkt werden bereits die am stärksten negativen Potentiale gemessen. Bei $Q$. robur wird ein etwas negativeres $\Psi_{\mathrm{pd}}$ als bei $Q$. petraea erreicht, jedoch bleibt das $\Psi_{\text {pd }}$ bei dieser Art länger auf einem niedrigen Niveau. Nach Ende der Trockenperiode kommt es zu einer Erholung der $\Psi_{\mathrm{pd}}$ bei den trockengestressten Varianten. Auch die nachmittäglichen Minima, die $\Psi_{\text {awp }}$-Werte, sinken bei den trockengestressten Bäumen mit zunehmender Trockenheit ab. Gegen Ende der Trockenperiode Mitte August werden die am stärksten negativen Potentiale gemessen.

\section{Blattwassergehalt}

Die Auftragung der Blattwassergehalte $\left(\mathrm{RWC}_{\text {leaf }}\right)$ gegen die zum gleichen Tageszeitpunkt gemessenen $\Psi_{\text {awp }}$-Werte ist in Abb. 3.2 dargestellt. Entlaubung hat nur bei $Q$. robur einen schwachen Effekt auf die Wassergehalte. Diese liegen etwas unter denen der Kontrollen. Bei Trockenstress kommt es zu einem Absenken der Wasserpotentiale, um die Wasserversorgung aufrecht zu erhalten. Ein Absenken von $\Psi_{\text {awp }}$ führt bei $Q$. robur zu keinen Änderungen der $\mathrm{RWC}_{\text {leaf }}$. Bei $Q$. petraea hingegen sinken die $\mathrm{RWC}_{\text {leaf }}$ gegen Ende der Trockenperiode ab, trotz einer Absenkung der $\Psi_{\text {awp }}$. Trockenheit in Kombination mit Entlaubung führt bei beiden Arten trotz eines Absenkens der $\Psi_{\text {awp }} \mathrm{zu}$ verringerten $\mathrm{RWC}_{\text {leaf }}$. Bei $Q$. petraea werden zudem die geringsten $\mathrm{RWC}_{\text {leaf }}$ im Vegleich mit $Q$. robur erreicht.

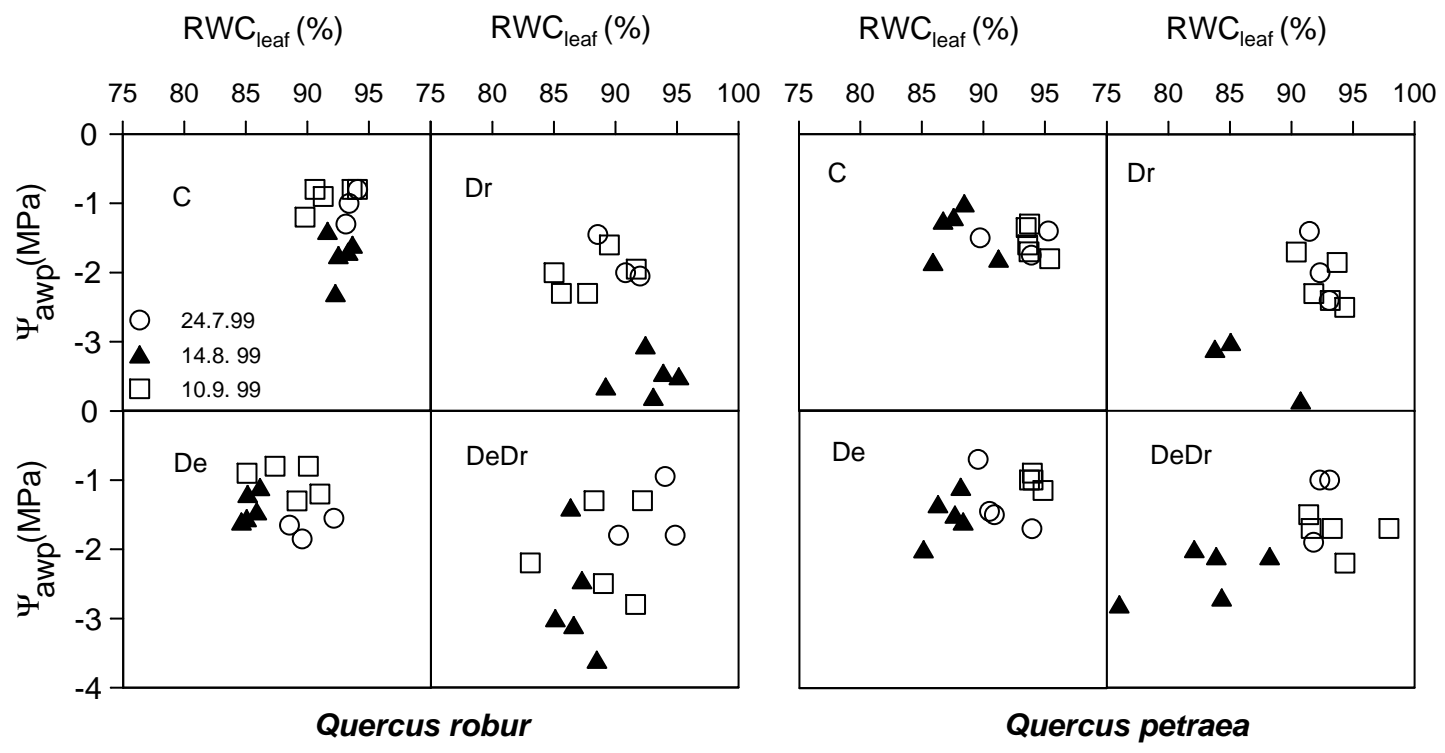

Abb. 3.2: Übersicht über die Änderung der Blattwassergehalte $\left(R \mathrm{RC}_{\text {leaf }}\right)$ und der nachmittäglichen Wasserpotentiale ( $\Psi_{\text {awp }}$ ) bei $Q$. robur und $Q$. petraea 1999. Gefüllte Symbole geben den Zeitpunkt der Trockenperiode, ungefülte Symbole die Zeitpunkte vor bzw. nach der Trockenperiode an. Varianten siehe Abb. 3.1. 


\section{Maximale stomatäre Leitfähigkeit}

Innerhalb der gesamten Untersuchungsperiode ist bei beiden Arten und zu jedem Messtermin die $\mathrm{g}_{\mathrm{sm}}$ der entlaubten Bäume im Vergleich zu den nicht entlaubten Bäumen signifikant erhöht (Abb. 3.3). Der Maximalwert wird am 16.08.1999 bei den entlaubten De-Bäumen bei $Q$. robur gemessen. Trockenheit führt bei den Dr- und DeDr-Bäumen beider Arten zu einer Abnahme der $\mathrm{g}_{\mathrm{sm}}$ im Vergleich mit den ausreichend bewässerten Bäumen ( $\mathrm{C}$ und De).

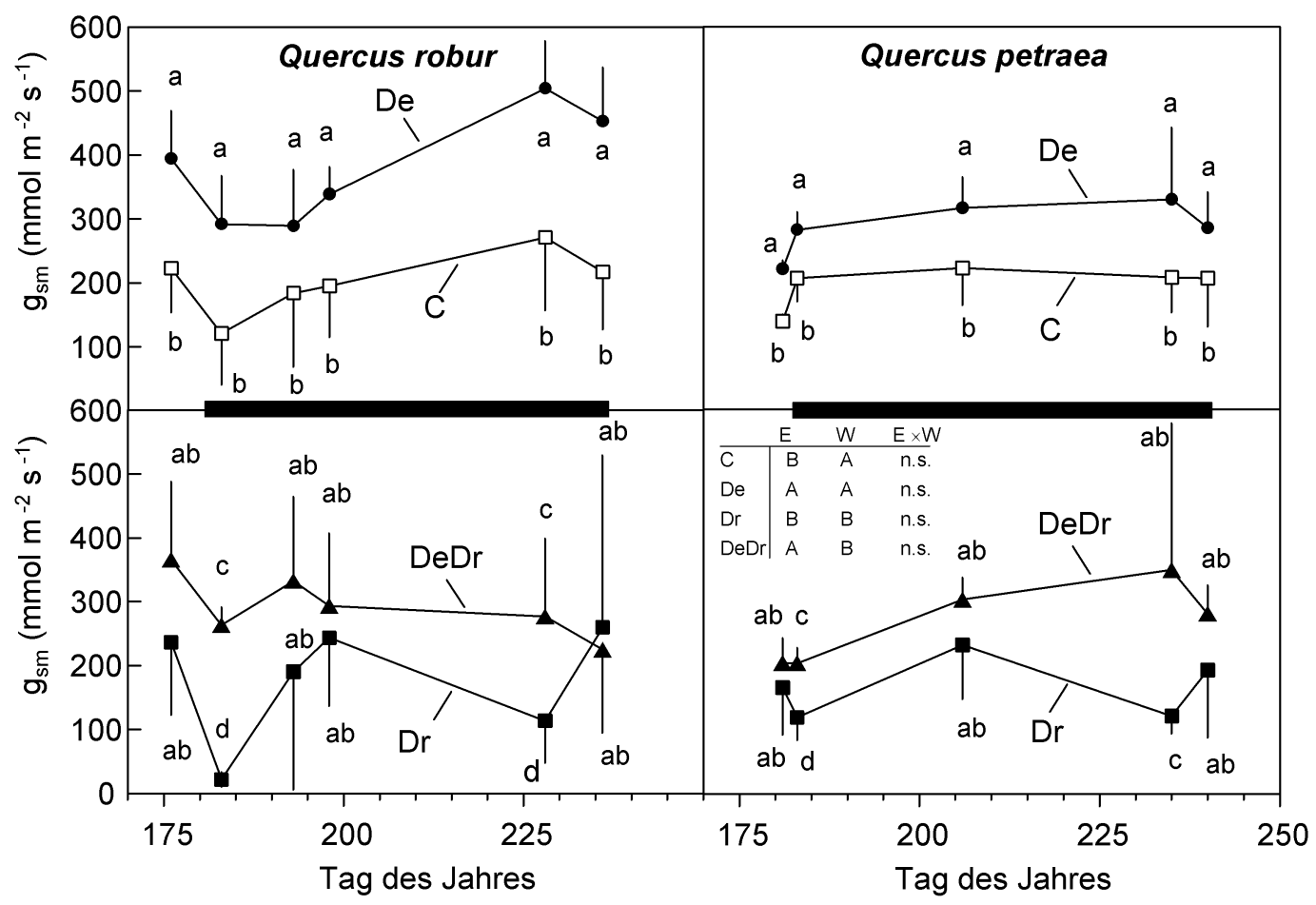

Abb. 3.3: Maximale stomatäre Leitfähigkeit bei unterschiedlichen Behandlungsvarianten bei $Q$. robur und $Q$. petraea 1999. Die Dauer der Trockenperiode ist durch einen schwarzen Balken markiert. Signifikante Unterschiede zwischen den Varianten sind mit Kleinbuchstaben gekennzeichnet (Kennzeichnungen gelten jeweils für beide Abbildungen einer Art). Die durch die Faktoren »Entlaubung «, »Trockenheit« und die Faktorenkombination »Entlaubung $\times$ Trockenheit« $(E, W, E \times W)$ bedingten signifikanten Unterschiede für die gesamte Untersuchungsperiode sind in Großbuchstaben in der separaten Legende, geltend für beide Arten, angegeben. n.s., nicht signifikant. Varianten s. Abb. 3.1. 
Eine Kombination aus Entlaubung und Trockenstress (DeDr) resultiert bei beiden Arten in einer deutlich höheren $\mathrm{g}_{\mathrm{sm}}$ am Anfang und am Ende der Trockenperiode als Trockenstress allein. Gleichzeitig erreichen oder überschreiten die $\mathrm{g}_{\mathrm{sm}}$ der DeDrVarianten jene der Kontrollbäume. Bei der Dr-Variante von $Q$. robur wird bereits Anfang Juli eine verringerte $\mathrm{g}_{\mathrm{sm}}$ gemessen, obwohl die wenige Tage zuvor gemessenen $\Psi_{\text {pd }}$ noch keine deutliche Absenkung zeigen. Allerdings wird an diesem Tag auch ein relativ geringer Bodenwassergehalt gemessen.

\section{Tagesgang der stomatären Leitfähigkeit}

Nicht nur in den erreichten maximalen $\mathrm{g}_{\mathrm{s}}$, sondern auch im Tagesverlauf der stomatären Leitfähigkeit unterscheiden sich die einzelnen Varianten voneinander. Die Tagesgänge der stomatären Leitfähigkeit $\mathrm{g}_{\mathrm{s}}$, das VPD sowie $\Delta \mathrm{w}$ zur Zeit der Messungen bei $Q$. robur und $Q$. petraea gegen Ende der Trockenperiode (16.08.1999 resp. 23.08.1999) sind in Abb. 3.4 dargestellt.

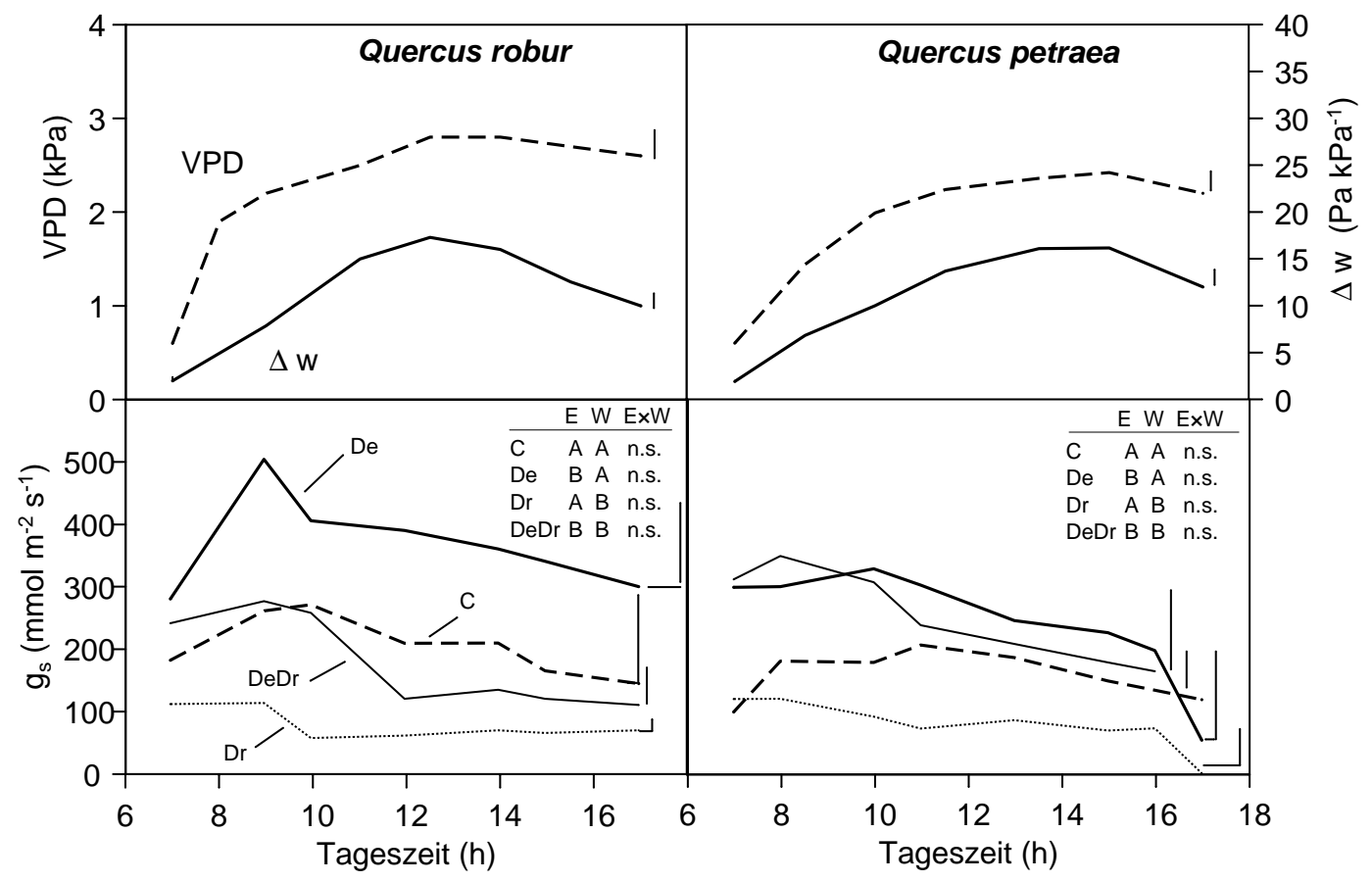

Abb. 3.4: Tagesgang der stomatären Leitfähigkeit $g_{s}$ bei $Q$. robur und $Q$. petraea sowie VPD und $\Delta \mathrm{w}$ gegen Ende der Trockenperiode im August 1999. Die maximalen Standardabweichungen sind durch vertikale Linien gekennzeichnet. Die Ergebnisse der Varianzanalyse sind in der separaten Legende angegeben (vgl. Abb. 3.3). Varianten siehe Abb. 3.1. 
Bei $Q$. robur erreichen alle Varianten den Maximalwert der $\mathrm{g}_{\mathrm{s}}$ in den frühen Vormittagsstunden, allerdings weisen nur die entlaubten Bäume eine hohe $\mathrm{g}_{\mathrm{s}}$ bis in die frühen Nachmittagsstunden, zum Zeitpunkt der Messung von $\Psi_{\text {awp }}$, auf. Bei $Q$. petraea wird die $\mathrm{g}_{\mathrm{sm}}$ bei De, Dr und DeDr-Bäumen am frühen Morgen bei relativ niedrigen VPD beobachtet, während die Kontrollbäume erst gegen Mittag bei höheren VPD ihre maximale $\mathrm{g}_{\mathrm{s}}$ erreichen. Trockenheit in Kombination mit Entlaubung führt zu einer höheren $\mathrm{g}_{\mathrm{s}}$ als der Faktor Trockenheit allein. Auch im Artvergleich ist ein Unterschied feststellbar. Unterscheiden sich die $\mathrm{g}_{\mathrm{s}}$ der DeDr- von den De-Bäumen bei $Q$. petraea nicht voneinander, so erreicht die DeDr-Variante bei $Q$. robur nur noch etwas mehr als die Hälfte der De-Variante.

\section{Tagestranspirationssumme $E_{d}$}

Die Tagestranspirationssumme (Abb. 3.5) ist nach Entlaubung bei beiden Arten erhöht. Zudem ist ein Artunterschied in der Stärke der Reaktion festzustellen. Bei $Q$. robur sind zumindest an zwei Terminen (im August) die $\mathrm{E}_{\mathrm{d}}$ signifikant erhöht, während bei $Q$. petraea an allen drei Terminen nur ein Trend zu leicht erhöhten $\mathrm{E}_{\mathrm{d}} \mathrm{zu}$ beobachten ist. Als Effekt der Trockenheit kommt es bei beiden Arten zu einer Reduktion der Transpiration bei den trockengestressten (Dr) Bäumen. Bei Q. robur am 16.08.1999 sowie bei $Q$. petraea am 23.08.1999 werden die geringsten $\mathrm{E}_{\mathrm{d}}$ erreicht. Zu diesem Zeitpunkt werden auch die am stärksten negativen $\Psi_{\text {pd }}$ gemessen, d.h. die Trockenheit erreicht an diesem Termin ihren Höhepunkt. Eine Kombination aus Entlaubung und Trockenstress resultiert bei beiden Arten in wesentlich höheren Transpirationssummen, vergleichbar mit denen der Kontrollbäume, als Trockenstress allein. Dabei werden z.T. ähnlich hohe $E_{d}$ wie bei den Kontrollen erreicht. 


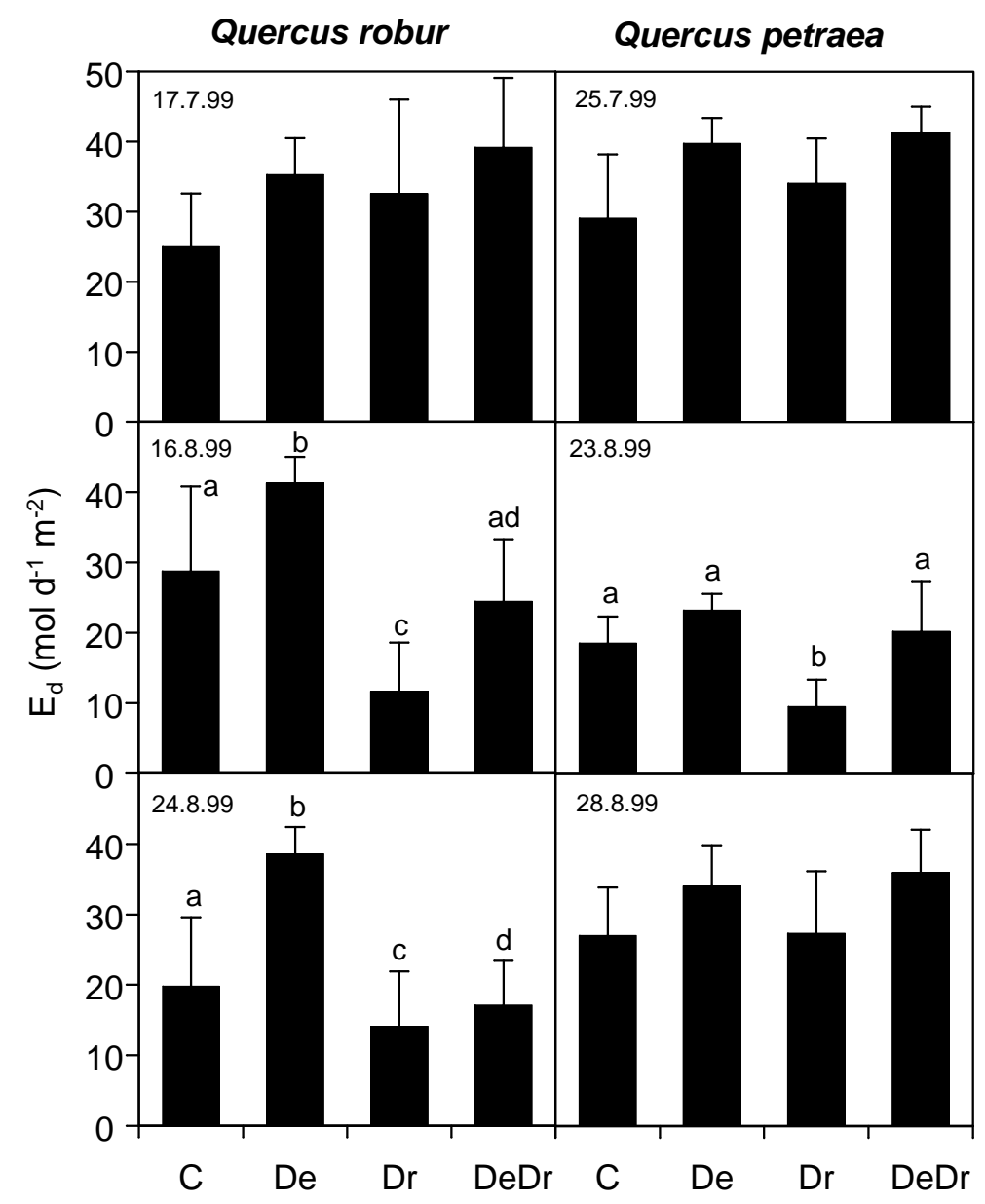

Abb. 3.5: Berechnete Tagestranspirationssumme bei $Q$. robur und $Q$. petraea in der Untersuchungsperiode 1999. Signifikante Unterschiede sind mit Kleinbuchstaben gekennzeichnet. Starker Trockenstress herrschte am 16.08.1999 (Q. robur) sowie am 23.08.1999 (Q. petraea). Varianten siehe Abb. 3.1.

\section{Hydraulische Leitfähigkeit Boden-Blatt}

Abbildung 3.6 zeigt die berechneten hydraulischen Leitfähigkeiten auf der Fließstrecke Boden-Blatt $\left(\mathrm{g}_{\mathrm{sl}}\right)$. Eine Einschränkung der Aussagekraft kann durch die verwendeten $\Psi_{\text {awp }}$-Werte gegeben sein, welche aufgrund der bei den trockengestressten Varianten früher aufgetretenen maximalen Leitfähigkeiten nicht unbedingt die maximal erreichten Potentiale darstellen. Trotz dieser Einschränkung werden deutliche Reaktionen beobachtet. Nach Entlaubung kommt es bei $Q$. robur allenfalls im Juli zu einer leicht verringerten $\mathrm{g}_{\mathrm{sl}}$ bei den entlaubten Bäumen, nicht aber im August. Im Gegensatz dazu 
ist die $\mathrm{g}_{\mathrm{sl}}$ bei $Q$. petraea im Juli wie auch im August stark reduziert. Am Ende der Trockenperiode im August sinken die $\mathrm{g}_{\mathrm{sl}}$ bei den trockengestressten Varianten (Dr und DeDr) bei beiden Arten ab. Bei $Q$. robur erreicht die $\mathrm{g}_{\mathrm{s} l}$ dieser Bäume nur noch rund ein Viertel der ausreichend bewässerten Varianten. Nur bei $Q$. petraea führt die Kombination von Entlaubung und Trockenheit zu einer noch stärkeren Reduktion der $\mathrm{g}_{\mathrm{sl}}$ als Trockenstress allein. Die $g_{s l}$ der DeDr-Bäume beträgt daher am 23.08.1999 nur noch ein Sechstel der Kontrolle.

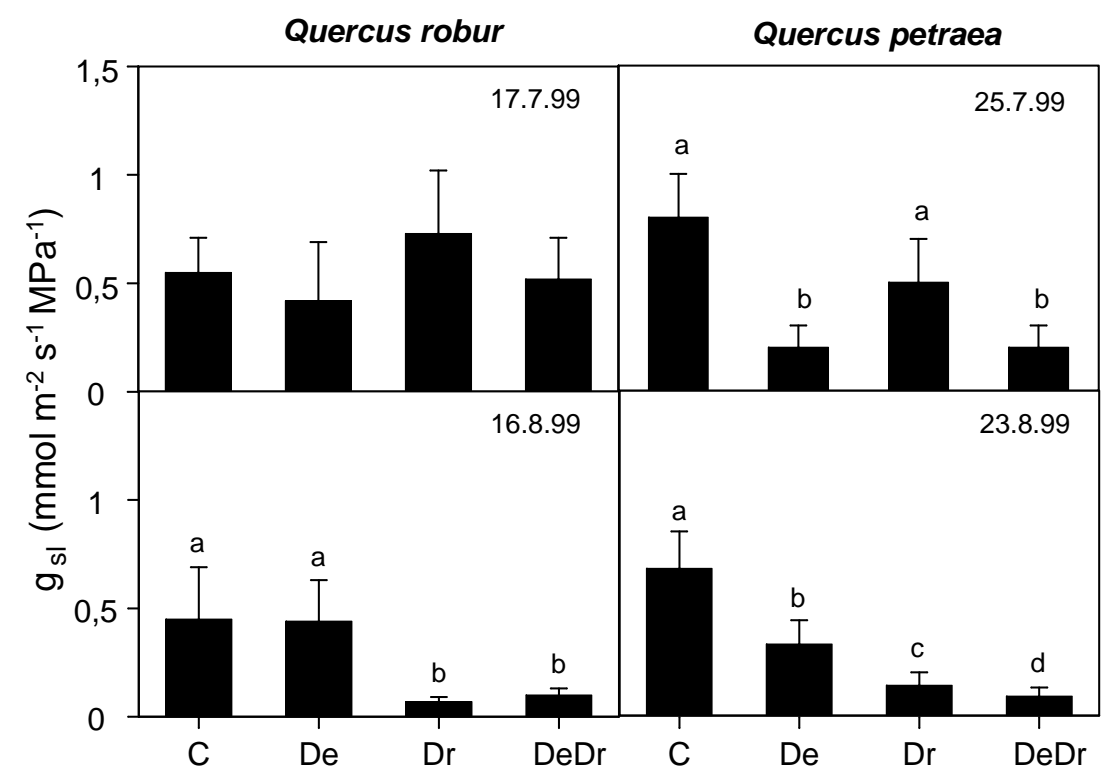

Abb. 3.6: Hydraulische Leitfähigkeit auf der Fließstrecke Boden-Blatt bei unterschiedlichen Behandlungsvarianten bei $Q$. robur und $Q$. petraea am Anfang und gegen Ende der Trockenperiode 1999. Signifikante Unterschiede zwischen den Varianten innerhalb eines Messtermines sind mit Kleinbuchstaben gekennzeichnet. Varianten siehe Abb. 3.1.

\section{Druck-Volumen-Kurve}

Die Ergebnisse der P/V-Kurven vor und nach Trockenstress (Juni resp. September) sind in Abb. 3.7 dargestellt. Der Elastizitätsmodul $\varepsilon$ ist bei beiden Arten zumindest im Trend bei den entlaubten Bäumen (De und DeDr) erhöht, d.h. die Zellwandelastizität ist nach Entlaubung verringert. Gleichzeitig weisen diese Varianten auch im Trend höhere $\mathrm{RWC}_{\mathrm{sp}}$-Werte auf. Bei den osmotischen Potentialen führt Entlaubung zumindest im Juni bei $\Pi_{0}$ zu signifikant positiveren Werten bei beiden Arten. 


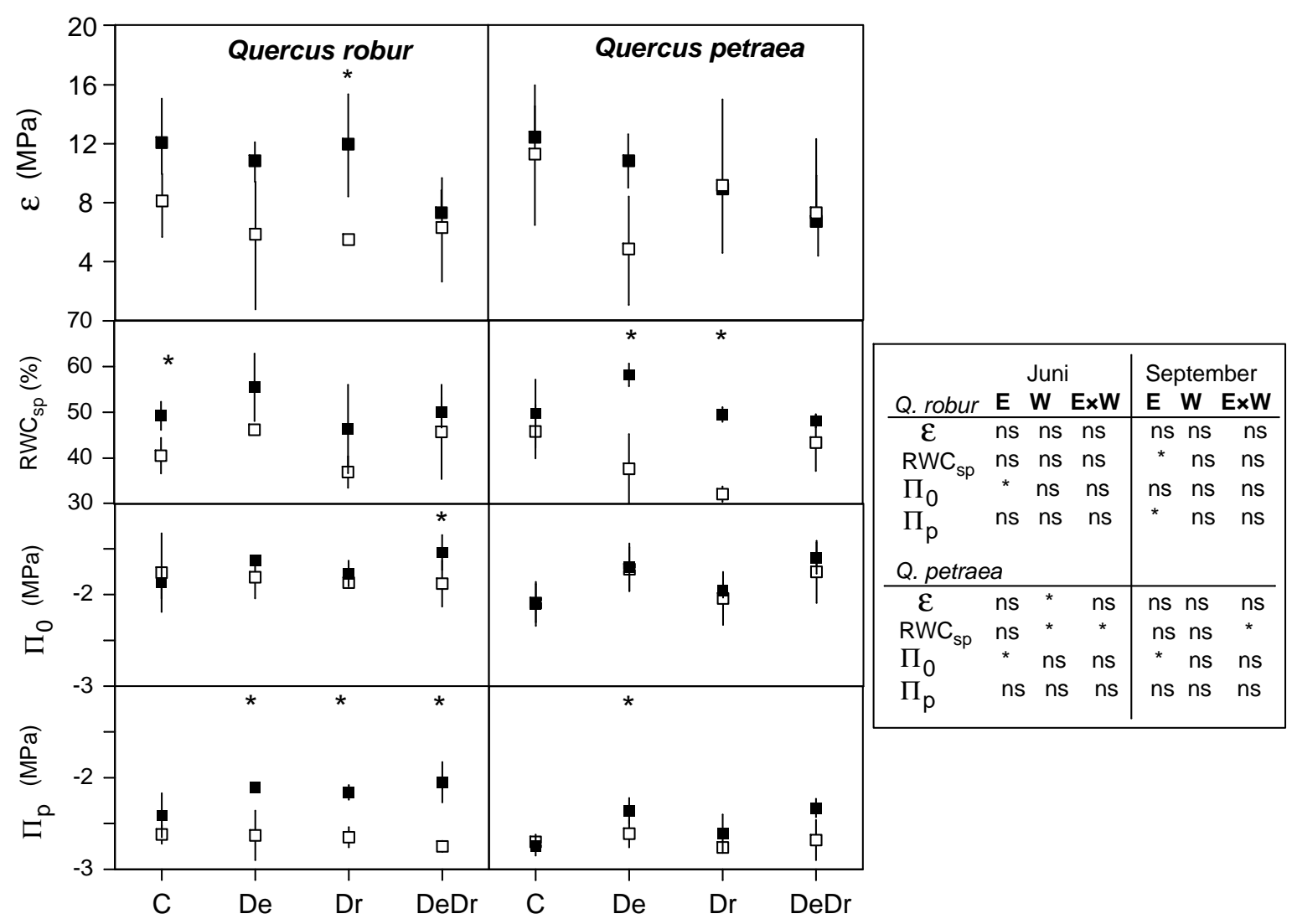

Abb. 3.7: Elastizitätsmodul $(\varepsilon)$, relativer symplastischer Wassergehalt am Turgornullpunkt $\left(\mathrm{RWC}_{\mathrm{sp}}\right)$ und die osmotischen Potentiale am Turgornullpunkt $\left(\Pi_{\mathrm{P}}\right)$ und bei Wassersättigung $\left(\Pi_{0}\right)$, gemessen bei unterschiedlichen Behandlungsvarianten bei $Q$. robur und $Q$. petraea vor (Juni, gefüllte Symbole) und nach (September, offene Symbole) der Trockenperiode 1999. Signifikante Unterschiede zwischen den Messterminen sind mit $\left(^{*}\right)$ gekennzeichnet. Die Ergebnisse der Varianzanalyse sind in der separaten Legende angegeben (vgl. Abb. 3.3). Varianten siehe Abb. 3.1.

Trockenheit hat im Gegensatz zum Faktor Entlaubung keinen Einfluss auf die gemessenen Parameter. Im Jahresverlauf kommt es bei $Q$. robur zu einer Abnahme des $\varepsilon$ bei den trockengestressten Bäumem sowie bei allen Varianten mit Ausnahme der Kontrolle zu einer Absenkung bei $\Pi_{\mathrm{p}}$. Bei $Q$. petraea sinken die $\mathrm{RWC}_{\mathrm{sp}}$ bei den De- und DrBäumen, während es nur bei den beiden entlaubten Varianten zu einer Abnahme der $\Pi_{p}$ kommt. Das Ergebnis der Änderung der Osmotikagehalte im Jahresverlauf zeigt Tab. 3.1. Bei beiden Arten kommt es, nur mit Ausnahme der De-Bäume, zu einer Zunahme an osmotisch wirksamen Substanzen, d.h. einem Quotienten kleiner Null. 
Tab. 3.1: Änderungen der Osmotikagehalte bei $Q$. robur und $Q$. petraea zwischen Juni (vor Trockenstress) und September (nach Trockenstress) 1999. Werte sind als Quotient der $\Pi_{0}{ }^{*} \mathrm{RWC}_{\mathrm{s}}$-Werte von Juni und September angegeben (Mittelwerte und Standardabweichungen). Varianten siehe Abb. 3.1.

\begin{tabular}{lllll}
\hline & C & De & Dr & DeDr \\
\hline$Q$. robur & $0,8 \pm 0,1$ & $0,9 \pm 0,3$ & $0,8 \pm 0,1$ & $0,7 \pm 0,1$ \\
$Q$. petraea & $0,8 \pm 0,1$ & $0,8 \pm 0,3$ & $0,4 \pm 0,4$ & $0,8 \pm 0,1$
\end{tabular}

\section{Hydraulische Leitfähigkeit}

\section{Hydraulische Leitfähigkeit vorjähriger Zweigabschnitte 1999}

Die hydraulischen Leitfähigkeiten der vorjährigen Zweigabschnitte von am Ende der Trockenperiode 1999 gemessenen Zweigen sind in Tab. 3.2 aufgeführt. Signifikante Unterschiede gibt es nur in den aktuellen Leitfähigkeiten bei $Q$. robur. Entlaubte Bäume (De) weisen eine fünffach höhere aktuelle Leitfähigkeit gegenüber der Kontrolle auf, aber auch bei den Dr- und den DeDr-Bäumen zeigt sich eine deutliche Erhöhung um das Doppelte bzw. Vierfache der Kontrolle. Damit erreichen auch die DeDr-Bäume ähnlich hohe Werte wie die nur entlaubten Bäume. Signifikante Unterschiede in dem berechneten Verlust an Leitfähigkeit zwischen den Varianten werden bei keiner Art festgestellt.

\section{Hydraulische Leitfähigkeit diesjähriger Zweigabschnitte 1999}

Die aktuelle hydraulische Leitfähigkeit (Tab. 3.2) der diesjährigen Zweigabschnitte bei entlaubten Bäumen bei $Q$. robur ist um das Zweifache gegenüber der Kontrolle erhöht. Bei $Q$. petraea hingegen sind die aktuellen Leitfähigkeiten der entlaubten, trockengestressten sowie der entlaubten und trockengestressten Bäume gegenüber der Kontrolle erniedrigt. Die maximale hydraulische Leitfähigkeit bei beiden Arten wird durch Entlaubung oder Trockenstress nicht beeinflußt. Dies gilt tendenziell auch für den berechneten Verlust an Leitfähigkeit. Wie bereits bei den vorjährigen Zweigen gezeigt, unterscheiden sich die Varianten nicht signifikant voneinander, jedoch überschreitet nur die DeDr-Variante bei $Q$. petraea mit im Mittel 64\% Verlust an Leitfähigkeit den kritischen Cavitationsschwellenwert von 50\% nach COCHARD et al. (1992). Im Vergleich 
Tab. 3.2: Aktuelle und maximale hydraulische Leitfähigkeit sowie der Verlust an Leitfähigkeit ( $\left(\mathrm{LF}_{\mathrm{akt}}, \mathrm{LF}_{\max }\right.$ und \% Verlust) diesjähriger und vorjähriger Zweigabschnitte bei $Q$. robur und $Q$. petraea, gemessen am Ende der Vegetationsperiode 1999. (Mittelwerte und Standardabweichungen. Angabe der Leitfähigkeiten in $\mathrm{g} \mathrm{H}_{2} \mathrm{O} \mathrm{h}^{-1}$ $\mathrm{kPa}^{-1}$ ). Signifikante Unterschiede zwischen den Varianten sind mit Kleinbuchstaben gekennzeichnet. Varianten siehe Abb. 3.1.

\begin{tabular}{llll}
\hline Variante & $\mathbf{L F}_{\text {akt }}$ & $\mathbf{L F}_{\mathbf{m a x}}$ & \% Verlust \\
\hline \multicolumn{4}{l}{$\begin{array}{l}\text { Diesjährige Zweigabschnitte } \\
\text { Q. robur } \\
\text { C }\end{array}$} \\
De & & \\
Dr & $0,03 \pm 0,02 \mathrm{a}$ & $0,10 \pm 0,08 \mathrm{a}$ & $45,9 \pm 27,7$ \\
DeDr & $0,06 \pm 0,04 \mathrm{~b}$ & $0,14 \pm 0,08 \mathrm{ab}$ & $49,3 \pm 31,9$ \\
$Q$. petraea & $0,03 \pm 0,01 \mathrm{a}$ & $0,05 \pm 0,01 \mathrm{ac}$ & $32,9 \pm 5,4$ \\
C & $0,05 \pm 0,06 \mathrm{a}$ & $0,07 \pm 0,08 \mathrm{ad}$ & $46,5 \pm 26,7$ \\
De & & & \\
Dr & $0,09 \pm 0,08 \mathrm{a}$ & $0,09 \pm 0,07$ & $28,5 \pm 22,4$ \\
DeDr & $0,03 \pm 0,02 \mathrm{~b}$ & $0,06 \pm 0,03$ & $44,9 \pm 20,0$ \\
& $0,03 \pm 0,01 \mathrm{~b}$ & $0,05 \pm 0,03$ & $46,3 \pm 24,8$ \\
& $0,03 \pm 0,02 \mathrm{~b}$ & $0,12 \pm 0,12$ & $64,2 \pm 27,3$
\end{tabular}

\section{Vorjährige Zweigabschnitte}

Q. robur

$\begin{array}{llll}\text { C } & 0,02 \pm 0,01 \mathrm{a} & 0,06 \pm 0,04 & 57,4 \pm 33,1 \\ \text { De } & 0,09 \pm 0,09 \mathrm{~b} & 0,15 \pm 0,11 & 39,8 \pm 21,8 \\ \text { Dr } & 0,05 \pm 0,06 \mathrm{c} & 0,14 \pm 0,11 & 64,1 \pm 29,5 \\ \text { DeDr } & 0,07 \pm 0,06 \mathrm{~d} & 0,13 \pm 0,08 & 44,9 \pm 22,3 \\ Q . \text { petraea } & & & \\ \text { C } & 0,11 \pm 0,17 & 0,25 \pm 0,22 & 66,4 \pm 29,0 \\ \text { De } & 0,04 \pm 0,03 & 0,17 \pm 0,09 & 70,1 \pm 18,6 \\ \text { Dr } & 0,10 \pm 0,19 & 0,24 \pm 0,25 & 67,4 \pm 30,5 \\ \text { DeDr } & 0,11 \pm 0,09 & 0,24 \pm 0,22 & 52,4 \pm 23,8\end{array}$


der hydraulischen Leitfähigkeiten zwischen dies- und vorjährigen Zweigen weisen die vorjährigen Zweigabschnitte trotz erhöhter maximaler Leitfähigkeiten (insbesondere bei $Q$. petraea) bei fast allen Varianten eine deutliche Erhöhung des Verlustes an Leitfähigkeit auf. Ältere Xylemgefäße sind demnach bereits nach einem Jahr wesentlich stärker embolisiert und stehen nur begrenzt als Reserve zu Verfügung.

\subsubsection{Ober- und unterirdische Biomasse 1999}

\section{Blattfläche und spezifische Blattfläche}

Die Gesamt-Blattflächen sowie die spezifische Blattfläche (SLA, berechnet aus dem Quotienten von Blattfläche zu Blattbiomasse) gegen Ende der Vegetationsperiode 1999 zeigt Abb. 3.8. Nach Entlaubung werden im zweiten Blattaustrieb bei beiden Arten wesentlich geringere Gesamt-Blattflächen (De und DeDr-Bäume) gebildet, obwohl die Krone vollständig wiederhergestellt ist. Gleichzeitig ist die SLA der entlaubten Varianten reduziert, d.h. bei gleicher Blattfläche werden im zweiten Blattaustrieb nach der Entlaubung schwerere Blätter gebildet.

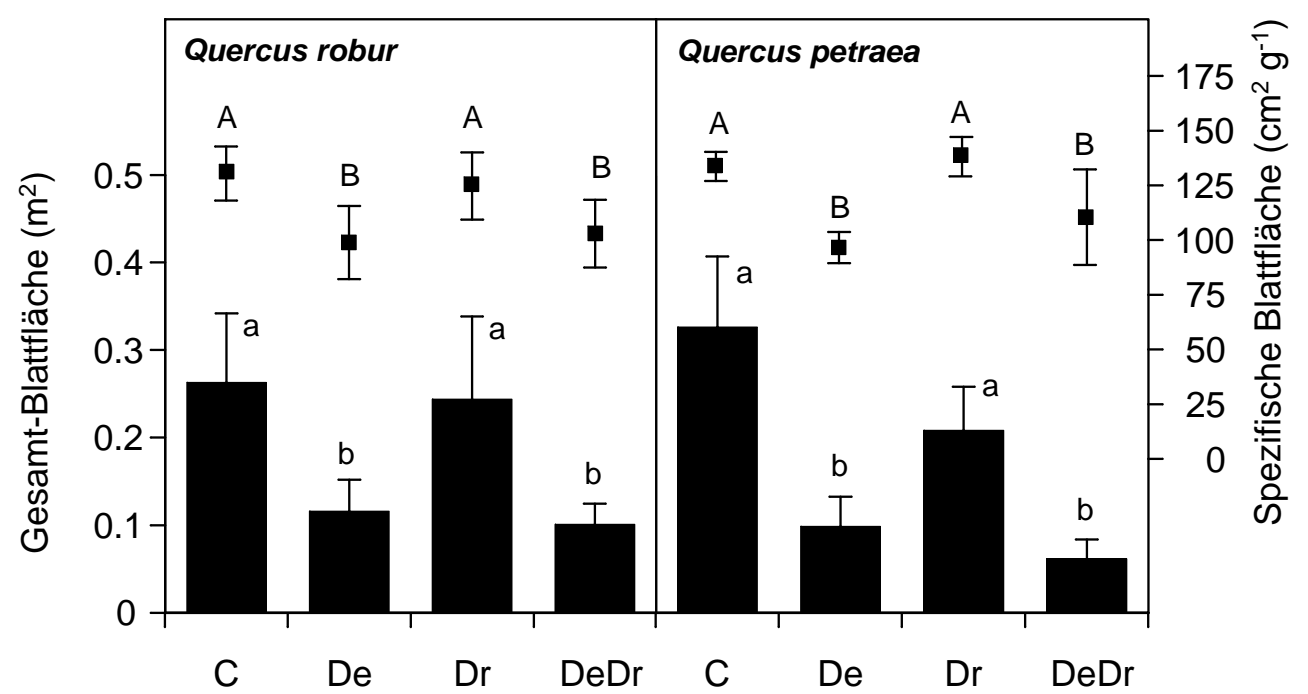

Abb. 3.8: Gesamt-Blattfläche (Säulen) und spezifische Blattfläche (SLA, gefüllte Quadrate) bei unterschiedlichen Behandlungsvarianten bei $Q$. robur und $Q$. petraea im Jahr 1999. Signifikante Unterschiede zwischen den Varianten sind mit Buchstaben gekennzeichnet. Varianten siehe Abb. 3.1. 
Dies ist vor allem bei der noch folgenden Betrachtung der C/N-Verhälnisse und Chlorophyllgehalte von Bedeutung. Nicht nur auf Baumniveau, sondern auch bei der Betrachtung der einzelnen Blätter werden entlaubungsbedingte Unterschiede in der Blattmorphologie deutlich. Bereits nach einmaliger Entlaubung im Sommer 1998 wie auch nach zweimaliger Entlaubung 1999 wurden festere und kleinere Blätter bei den entlaubten Bäumen beobachtet.

\section{Blatt- und Wurzelbiomasse und Blatt/Feinwurzelverhältnis}

Entlaubung führt bei den entlaubten Bäumen (De und DeDr) beider Arten nach Wiederbelaubung neben einer Reduktion der Gesamt-Blattfläche auch zu einer um mindestens 50\% verringerten Blattbiomasse am Ende der Vegetationsperiode (Abb. 3.9). Zusätzlich weisen auch die trockengestressten Dr-Bäume bei $Q$. petraea eine Reduktion ihrer Blattbiomasse am Ende der Vegetationsperiode auf. Eine Kombination aus Entlaubung und Trockenstress (DeDr) führt ausschließlich bei $Q$. petraea zur stärksten Reduktion der Blattbiomasse.
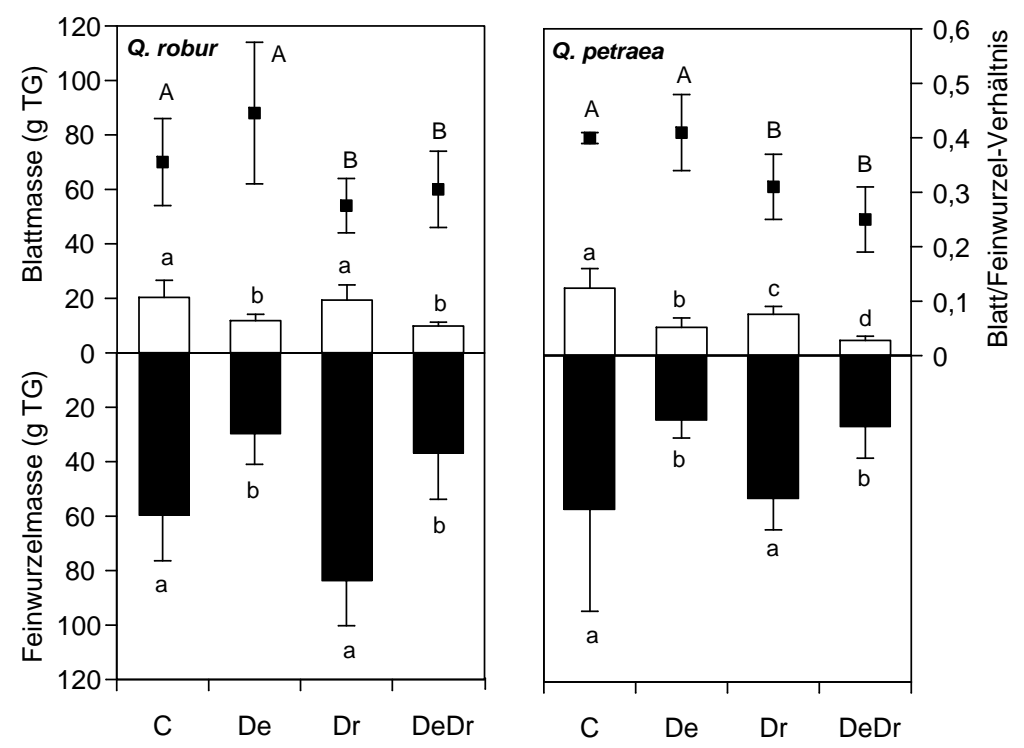

Abb. 3.9: Blatt- und Feinwurzelbiomasse (ungefüllte und gefüllte Säulen) sowie das trockengewichtsbezogene Blatt/Feinwurzelverhältnis (gefüllte Quadrate) bei unterschiedlichen Behandlungsvarianten bei $Q$. robur und Q. petraea im Jahr 1999. Signifikante Unterschiede zwischen den Varianten sind mit Buchstaben gekennzeichnet. Varianten siehe Abb. 3.1. 
Hierin zeigt sich ein deutlicher Artunterschied in der Reaktion auf die Trockenheit; $Q$. petraea reagiert wesentlich empfindlicher. Bei den Feinwurzelbiomassen zeigt sich bei beiden Arten nach Entlaubung eine deutliche Verringerung um mehr als 50\% gegenüber der Kontrolle. Im Gegensatz dazu hat Trockenheit keinen starken Einfluss auf die Feinwurzelmassen. Allerdings gibt es bei den trockengestressten Bäumen bei $Q$. robur eine Tendenz zu einer erhöhten Feinwurzelmasse verglichen mit den Kontrollbäumen. Eine Kombination beider Faktoren bewirkt keine Veränderung in den Feinwurzelbiomassen. Da bei beiden entlaubten Varianten (De und DeDr) sowohl eine oberals auch eine unterirdische Reduktion der Biomassen stattfindet, bleibt nach Entlaubung das Blatt/Feinwurzelverhältnis konstant. Im Gegensatz dazu verschiebt sich das Blatt/Feinwurzelverhältnis bei den trockengestressten (Dr und DeDr) Bäumen signifikant zu niedrigeren Werten im Vergleich zu den ausreichend bewässerten Bäumen, d.h. pro Einheit Blattbiomasse stehen mehr Feinwurzeln zu Verfügung.

\section{Höhen- und Stammbasis-Zuwachs}

Bei beiden Arten zeigt sich nach Entlaubung eine Reduktion in den Stammbasiszuwächsen (Abb. 3.10) bezüglich des Anfangswertes zu Versuchsbeginn im Frühjar 1998. Die Höhenzuwächse bei den entlaubten Varianten sind bei $Q$. robur signifikant verringert (Abb. 3.10), und auch bei $Q$. petraea liegen sie nur knapp über dem Signifikanzniveau. Bei beiden Arten hat weder Trockenstress allein noch in Kombination mit Entlaubung einen Einfluss auf den Stammbasis- oder Höhenzuwachs.

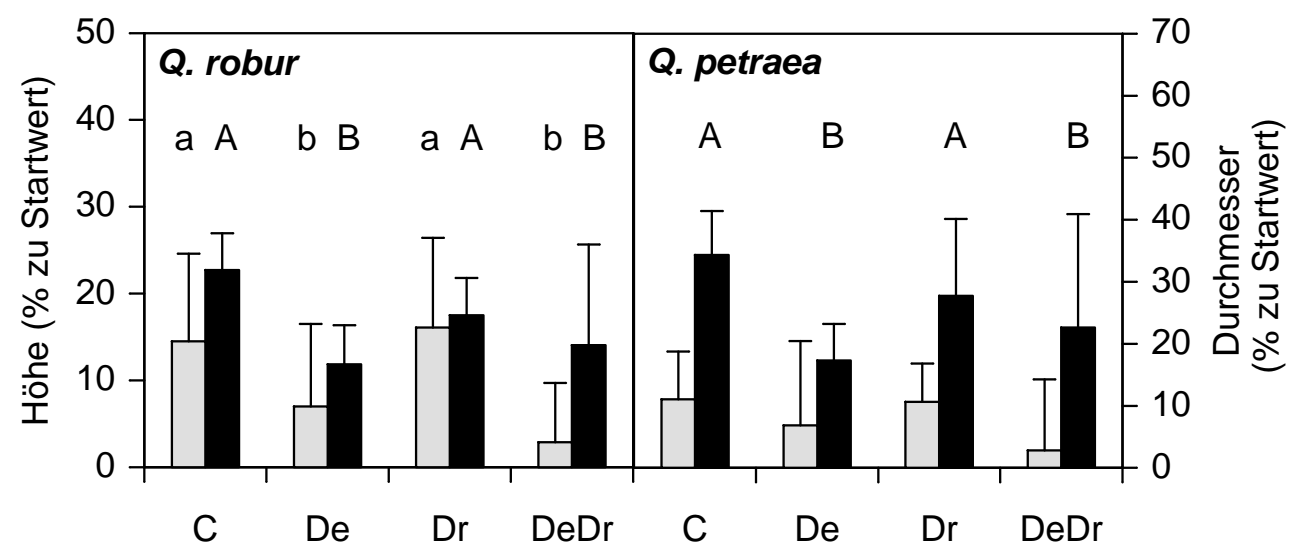

Abb. 3.10: Höhenzuwachs (graue Säulen) und Zunahme des Stammbasisdurchmessers (schwarze Säulen) bei unterschiedlichen Behandlungsvarianten bei $Q$. robur und $Q$. petraea im Jahr 1999. Signifikante Unterschiede zwischen den Varianten sind mit Klein- bzw. Großbuchstaben gekennzeichnet. Varianten siehe Abb. 3.1. 


\subsubsection{Blatt- und Stamminhaltsstoffe 1999}

\section{Kohlenstoff-Isotopenverhältnis}

Die Kohlenstoff-Isotopen-Verhältnisse in den Ende August geernteten Blättern $\left(\delta^{13} \mathrm{C}\right.$, Abb. 3.11) zeigen auch nach längerer Trockenperiode keine signifikanten Veränderungen zu positiveren Werten als ein Maß für eine höhere Wassernutzungseffizienz. Auffällig bleiben jedoch die leicht positiveren $\delta^{13} \mathrm{C}$-Werten bei den De-, Dr-, und vor allem den DeDr-Bäumen bei $Q$. robur. Bei dieser Art wurden Mitte August auch die am stärksten negativen Predawn-Wasserpotentiale sowie die höchsten TagesTranspirationssummen gemessen. Aufgrund der hohen Standardabweichung der Kontrollbäume lässt sich eine Einschränkung des Wasserhaushaltes, einhergehend mit vermehrter Fixierung von ${ }^{13} \mathrm{C}$, bei den übrigen Varianten nicht mit Sicherheit belegen.

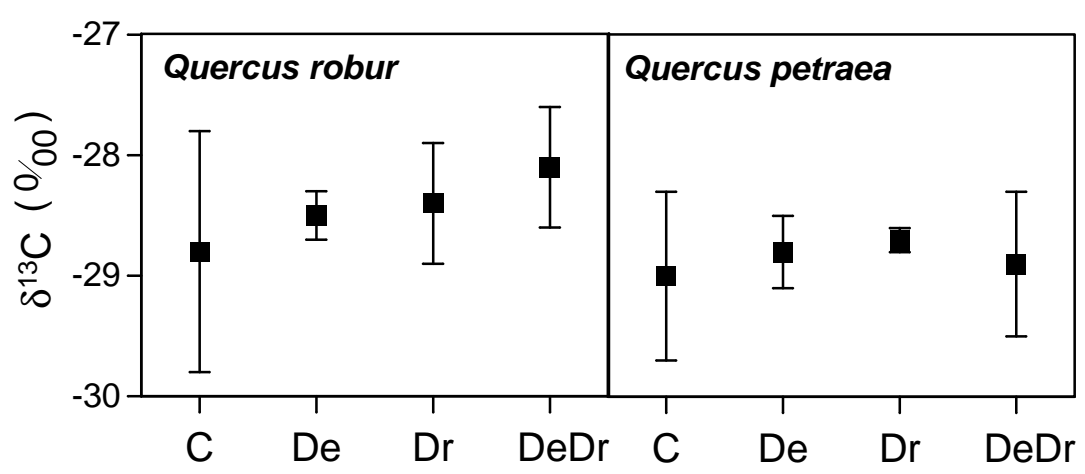

Abb. 3.11: Kohlenstoff-Isotopenverhältnis $\delta^{13} \mathrm{C}$ in Blättern des zweiten Blattaustriebes bei unterschiedlichen Behandlungsvarianten bei $Q$. robur und $Q$. petraea Ende August 1999. Signifikante Unterschiede zwischen den Varianten sind mit Kleinbuchstaben gekennzeichnet. Varianten siehe Abb. 3.1.

\section{$\mathrm{N}$-Gehalt und $\mathrm{C} / \mathrm{N}-$ Verhältnis}

Die N-Konzentration und das $\mathrm{C} / \mathrm{N}-$ Verhälnis in Blättern des zweiten Blattaustriebes (Abb.3.12) zeigen einen deutlichen Entlaubungseffekt bei den De- und DeDr-Bäumen. Beide entlaubten Varianten weisen doppelt so hohe N-Konzentrationen in den Blättern im Vergleich zu den nicht entlaubten Varianten auf. Dies führt zu einer Verringerung des $\mathrm{C} / \mathrm{N}$-Verhältnisses, d.h. bei gleicher Menge an Kohlenstoff im Blatt wird die Menge an Stickstoff in den Blättern des zweiten Blattaustriebes bei den entlaubten Bäumen erhöht. Trockenheit wirkt sich weder auf die N-Konzentration noch auf das $\mathrm{C} / \mathrm{N}-$ Verhältnis aus. 


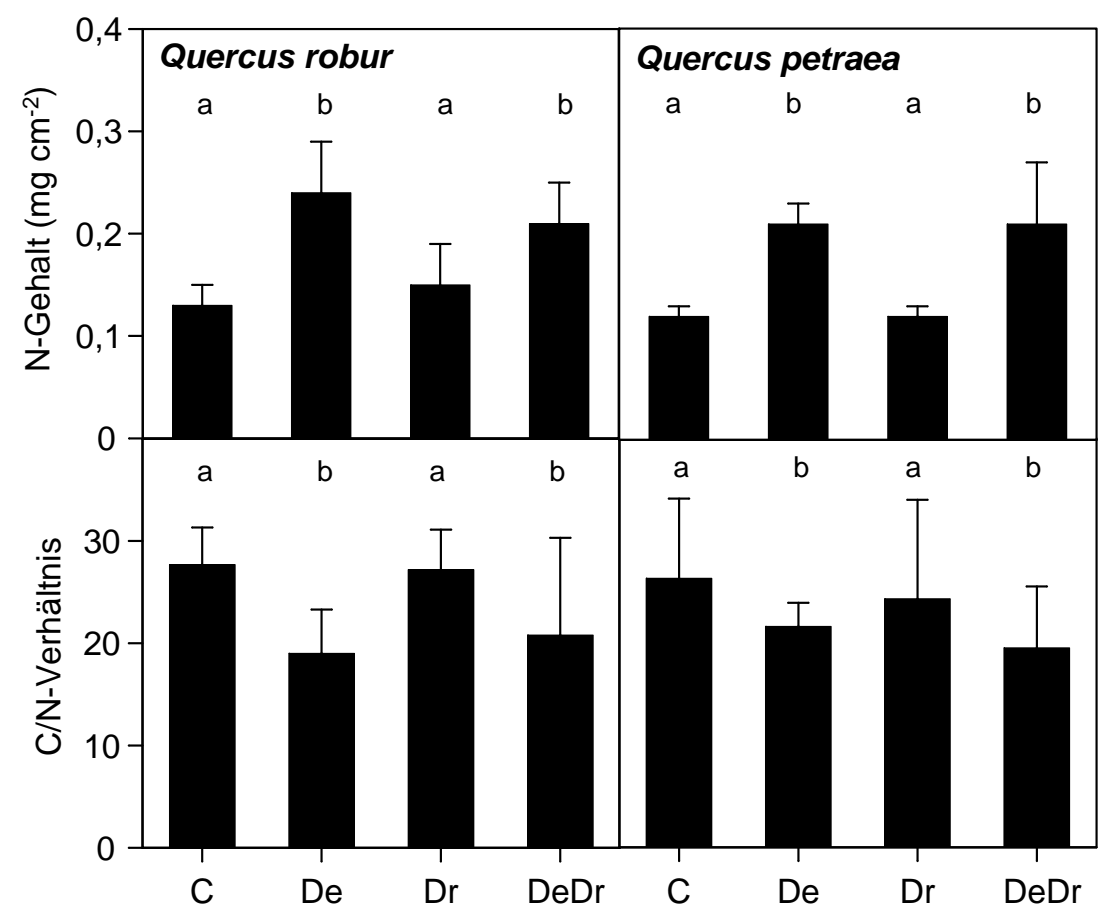

Abb. 3.12: $N-G e h a l t$ und $\mathrm{C} / \mathrm{N}-$-Verhältnis in Blättern des zweiten Blattaustriebes bei unterschiedlichen Behandlungsvarianten bei $Q$. robur und $Q$. petraea Ende August 1999. Signifikante Unterschiede zwischen den Varianten sind mit Kleinbuchstaben gekennzeichnet. Varianten siehe Abb. 3.1.

\section{Chlorophyllgehalt}

Die gemessenen Blatt-Chlorophyllgehalte (Abb. 3.13) weisen einen Effekt der Entlaubung auf. Bei $Q$. robur ist an allen fünf Messterminen der Chlorophyllgehalt bei beiden entlaubten Varianten (De und DeDr) erhöht. Bei Q. petraea wird diese Erhöhung bei den De- und DeDr-Bäumen erstmalig Ende Juli belegt. Danach verbleiben die Chlorophyllgehalte in den Blättern der entlaubten Bäume bis zum Ende der Vegetationsperiode auf dem erhöhten Niveau. Neben der Zunahme des Chlorophyllgehaltes bei den entlaubten Varianten wird gleichzeitig auch ein erhöhter Stickstoffgehalt im Blatt bei einer verringerten spezifischen Blattfläche beobachtet. 


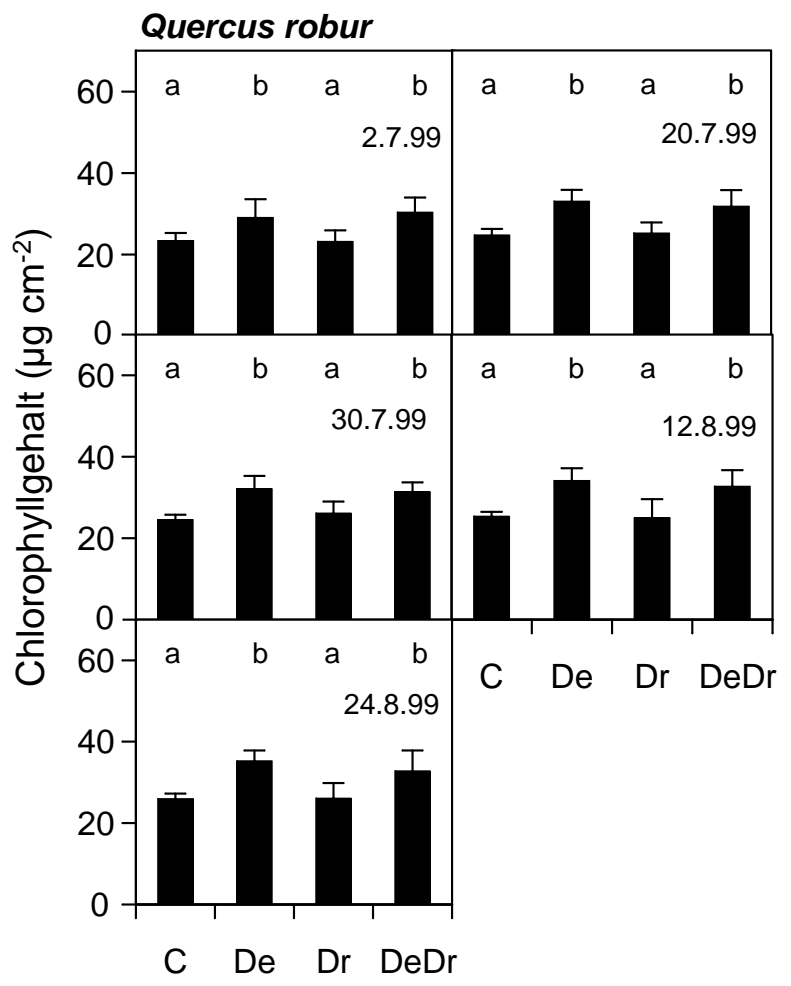

Quercus petraea

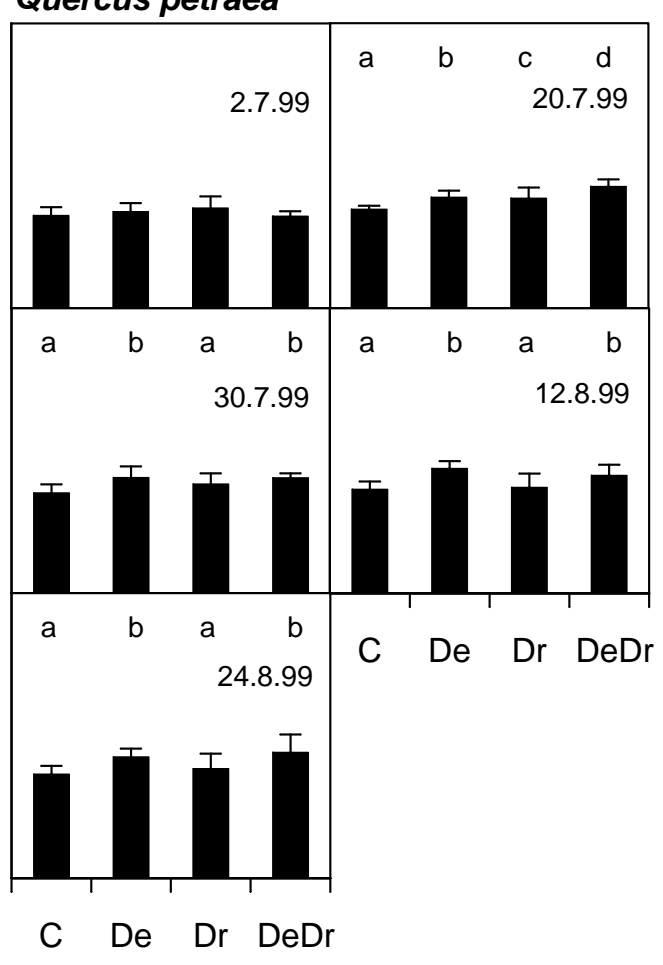

Abb. 3.13: Blatt-Chlorophyllgehalt bei unterschiedlichen Behandlungsvarianten bei $Q$. robur und $Q$. petraea in der Vegetationsperiode 1999. Signifikante Unterschiede zwischen den Varianten sind mit Kleinbuchstaben gekennzeichnet. Varianten siehe Abb. 3.1.

\section{Stärkegehalt im Spross}

Die am Ende der Vegetationsperiode 1999 bestimmten Stärkegehalte im Stamm zeigen eine uneinheitliche Reaktion auf den Faktor Entlaubung bei beiden Arten (Abb. 3.14). Während bei $Q$. robur die Entlaubung zu einer Zunahme des Stärkegehaltes der DeVariante gegenüber den beiden nicht entlaubten Varianten führt, weist bei $Q$. petraea nur die DeDr-Variante einen höheren Stärkegehalt gegenüber den nicht entlaubten Bäumen (C und De) auf. Zusammenfassend lässt sich feststellen, dass Entlaubung nicht zu einer Reduktion des Gesamtstärkegehaltes im Holz führt. Auch Trockenheit beeinflusst die Stärkegehalte nicht. 


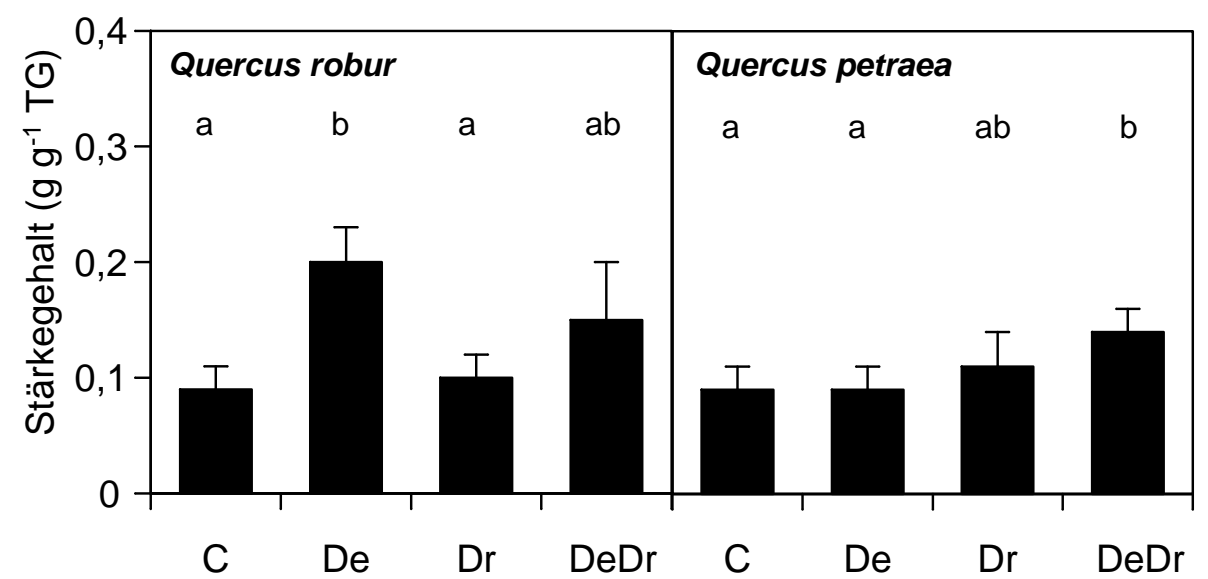

Abb. 3.14: Stärkegehalt von Stamm-Holzproben bei unterschiedlichen Behandlungsvarianten bei $Q$. robur und $Q$. petraea am Ende der Vegetationsperiode 1999. Die einzelnen Holzproben umfassen die letzten drei Jahrringe, d.h. die Jahre 1997 bis 1999. Signifikante Unterschiede zwischen den Varianten sind mit Kleinbuchstaben gekennzeichnet. Varianten siehe Abb. 3.1.

\subsubsection{Früh- und Spätholzbreiten der Zweige 1999}

Die Ergebnisse der Untersuchung der Jahrringbreiten von im September 1999 geernteten Zweigen, an denen zuvor die hydraulische Leitfähigkeit gemessen wurde, zeigt Tabelle 3.3. Die Proben umfassen jeweils die Jahrringe der letzten zwei Jahre, welche in Früh- und Spätholz unterschieden werden.

\section{Frühholzbreite}

Unterschiede zwischen den Varianten werden in den einzelnen Jahren bei keiner Art festgestellt. Auffallend ist jedoch, dass die DeDr-Bäume bei $Q$. robur etwas geringere Frühholzbreiten im Jahr 1999 im Vergleich zum Vorjahr (nur Entlaubung) aufweisen, obwohl zum Zeitpunkt der Frühholzbildung noch kein Trockenstress als zusätzlicher Faktor wirksam war. Im Vergleich der Frühholzbreiten 1998 und 1999 sind mit Ausnahme der DeDr-Variante bei $Q$. robur bei beiden Arten keine signifikanten Unterschiede festzustellen. 
Tab. 3.3: Früh- und Spätholzbreite $(\mathrm{mm})$ nach einmaliger (1998) und zweimaliger (1999) Entlaubung von Ende 1999 geernteten Zweigen bei Q. robur und Q. petraea. Trockenstress als Faktor wurde nur im Jahr 1999 appliziert. Mittelwerte und Standardabweichungen. Signifikante Unterschiede zwischen den Varianten sind mit Kleinbuchstaben, Unterschiede zwischen den beiden Jahren sind mit ${ }^{* * *}$ gekennzeichnet. FH, Frühholz; SH, Spätholz. Varianten siehe Abb. 3.1.

\begin{tabular}{|c|c|c|c|c|}
\hline Variante & FH 1998 & FH 1999 & & 1998/1999 \\
\hline \multicolumn{5}{|l|}{ Q. robur } \\
\hline $\mathrm{C}$ & $0,14 \pm 0,05$ & $0,10 \pm 0,03$ & & \\
\hline De & $0,13 \pm 0,03$ & $0,15 \pm 0,08$ & & \\
\hline Dr & $0,17 \pm 0,06$ & $0,14 \pm 0,06$ & & \\
\hline DeDr & $0,19 \pm 0,02$ & $0,14 \pm 0,02$ & & $* * *$ \\
\hline \multicolumn{5}{|c|}{ Q. petraea } \\
\hline $\mathrm{C}$ & $0,13 \pm 0,07$ & $0,10 \pm 0,02$ & & \\
\hline De & $0,17 \pm 0,05$ & $0,18 \pm 0,03$ & & \\
\hline $\mathrm{Dr}$ & $0,19 \pm 0,05$ & $0,17 \pm 0,03$ & & \\
\hline DeDr & $0,18 \pm 0,03$ & $0,18 \pm 0,03$ & & \\
\hline Variante & SH 1998 & SH 1999 & & 1998/1999 \\
\hline \multicolumn{5}{|l|}{ Q. robur } \\
\hline $\mathrm{C}$ & $0,18 \pm 0,03$ & $0,20 \pm 0,04$ & $\mathrm{a}$ & \\
\hline De & $0,16 \pm 0,07$ & $0,11 \pm 0,04$ & $a b$ & \\
\hline Dr & $0,18 \pm 0,05$ & $0,15 \pm 0,05$ & $a b$ & \\
\hline DeDr & $0,15 \pm 0,04$ & $0,08 \pm 0,01$ & $\mathrm{~b}$ & \\
\hline \multicolumn{5}{|c|}{ Q. petraea } \\
\hline $\mathrm{C}$ & $0,13 \pm 0,02$ & $0,10 \pm 0,02$ & & \\
\hline De & $0,20 \pm 0,05$ & $0,09 \pm 0,03$ & & $* * *$ \\
\hline $\mathrm{Dr}$ & $0,19 \pm 0,05$ & $0,14 \pm 0,07$ & & \\
\hline DeDr & $0,25 \pm 0,08$ & $0,11 \pm 0,02$ & & $* * *$ \\
\hline
\end{tabular}




\section{Spätholzbreite}

Nach zweimaliger Entlaubung (1999) sind bei Q. robur die Spätholzbreiten der DeDrBäume gegenüber den Kontrollbäumen verringert (Tabelle 3.3). Zudem zeigt sich auch bei den De-Bäumen ein Trend zur Reduktion gegenüber der Kontrolle. Beim Vergleich der Spätholzbreiten zwischen den Jahren 1998 und 1999 gibt es keinen signifikanten Unterschied. Allerdings ist bei beiden entlaubten Varianten eine leichte Abnahme der Spätholzbreiten 1999 gegenüber dem Vorjahr zu sehen. Bei Q. petraea ist weder 1998 noch 1999 ein Unterschied zwischen den Varianten zu beobachten (Tabelle 3.3). Auffällig ist bei dieser Art allerdings der Vergleich zwischen dies- und vorjährigen Spätholzbreiten. Nach zweimaliger Entlaubung sind die Spätholzbreiten bei den De- und DeDr-Bäumen gegenüber dem Vorjahr signifikant um fast die Hälfte reduziert. Im Artvergleich unterscheiden sich hier $Q$. robur und $Q$. petraea voneinander. Nur bei $Q$. petraea sind die Spätholzbreiten nach zweimaliger Entlaubung signifikant reduziert, während bei $Q$. robur nur ein leichter Rückgang festzustellen ist. Im Gegensatz zum Faktor Entlaubung hat Trockenheit allein keinen Einfluss auf die Bildung des Früh- oder Spätholzes. 


\subsection{Zeitversetzte Kombination von Entlaubung und Trockenheit 2000}

\subsubsection{Wasserhaushaltsparameter 2000}

\section{Wasserpotential}

Im Jahresverlauf 2000 zeigt sich bei beiden Arten ein Effekt der Trockenheit in zunehmend negativeren $\Psi_{\mathrm{pd}}$ (Abb. 3.15). Ab Ende Juni (29.06.2000, Tag 180) sind die $\Psi_{\mathrm{pd}}$ der trockengestressten Bäume bei beiden Arten (mit einer Ausnahme am 15.08.2000) signifikant gegenüber den ausreichend bewässerten Bäumen erniedrigt. Bereits Ende Juli (29.07.2000, Tag 210) werden bei den trockengestressten Varianten beider Arten die am stärksten negativen $\Psi_{\text {pd }}$ gemessen. Im Vergleich mit 1999 werden 2000 stärker negative $\Psi_{\text {pd }}$ gemessen, daher kann von einer stärkeren Beanspruchung des Wasserhaushalts ausgegangen werden.

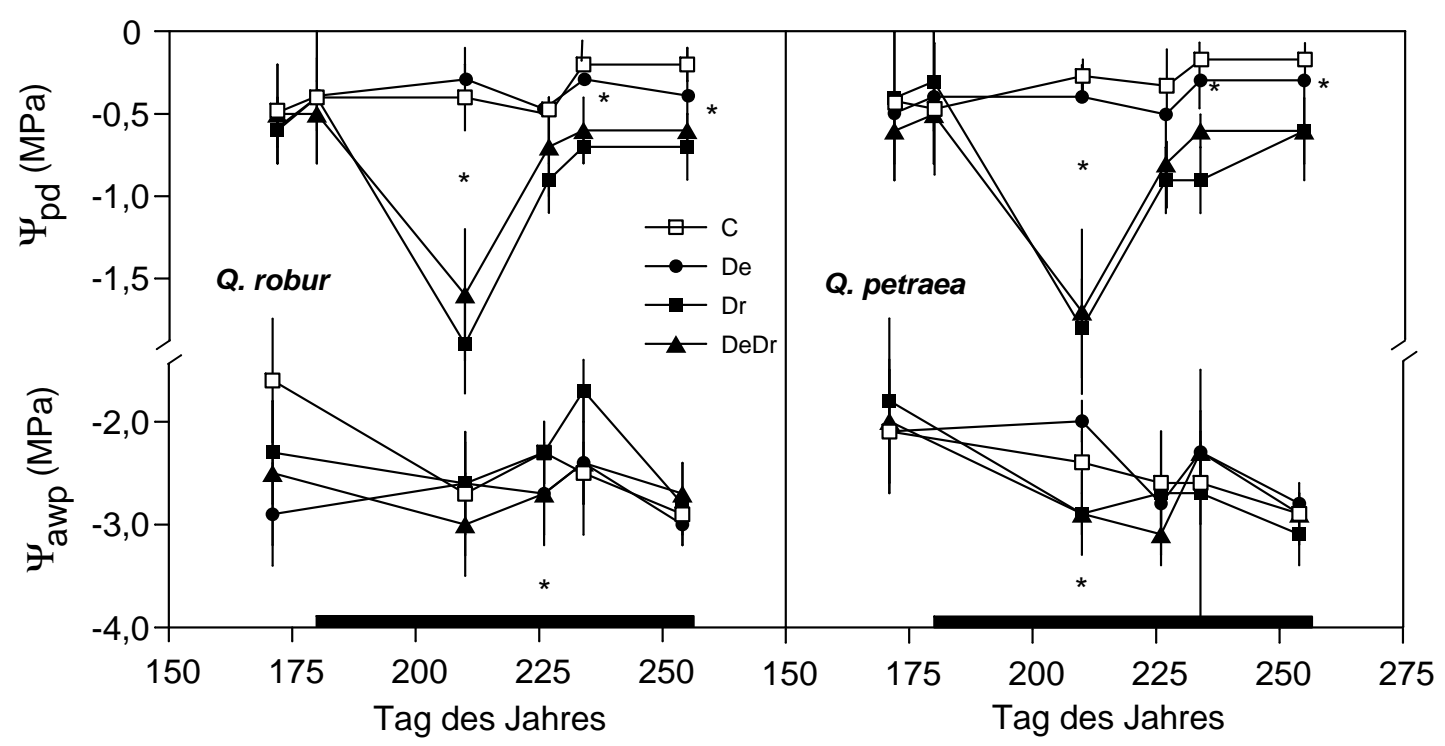

Abb. 3.15: Predawn- $\left(\Psi_{\mathrm{pd}}\right)$ und nachmittägliche ( $\left.\Psi_{\mathrm{awp}}\right)$ Wasserpotentiale bei $Q$. robur und $Q$. petraea in der Untersuchungsperiode 2000. Der waagerechte Balken gibt die Dauer der Trockenperiode an. Signifikante Unterschiede aller trockengestressten gegenüber allen ausreichend bewässerten Varianten sind mit $\left(^{*}\right)$ gekennzeichnet. C, Kontrolle; De, Entlaubung in den Jahren 1998 und 1999; Dr, Trockenstress 2000; DeDr, Kombination aus Trockenstress und Entlaubung. 
Trockenstress führt bei den $\Psi_{\text {awp }}$, anders als 1999, nur an je einem Termin pro Art zu einer signifikanten Abnahme. Dies ist am 15.08.2000 bei $Q$. robur und am 29.07.2000 bei $Q$. petraea der Fall. Entlaubung hatte während der gesamten Untersuchungsperiode 2000, wie bereits 1999, keinen signifikanten Einfluß auf die Wasserpotentiale.

\section{Blattwassergehalt}

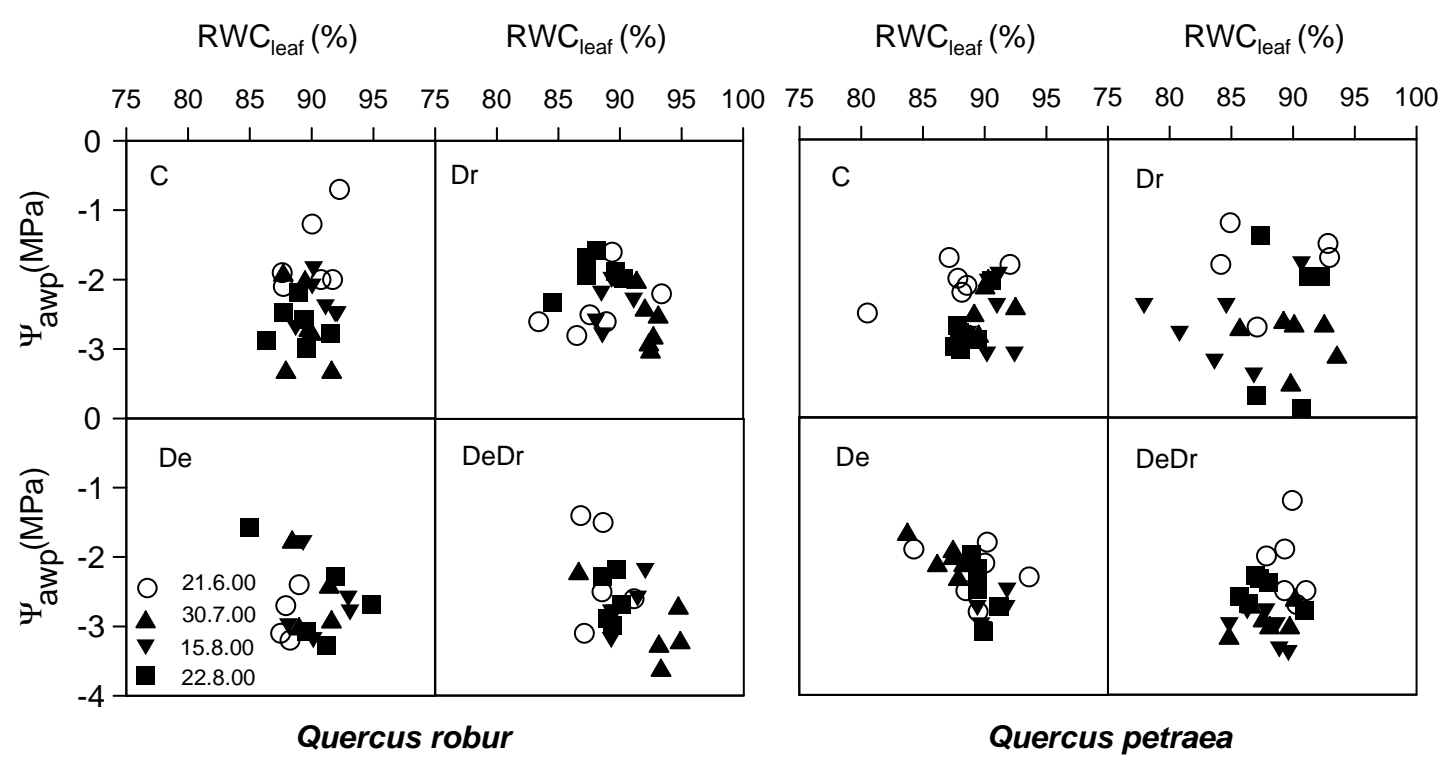

Abb. 3.16: Übersicht über die Änderung der Blattwassergehalte und der nachmittäglichen Wasserpotentiale ( $\Psi_{\text {awp }}$ ) bei $Q$. robur und $Q$. petraea in der Untersuchungsperiode 2000. Gefüllte Symbole geben den Zeitpunkt der Trockenperiode, ungefüllte Symbole die Zeitpunkte vor der Trockenperiode an. Varianten siehe Abb. 3.15.

Im Gegensatz zu 1999, als die De-Varianten einen bis um ca. 5\% verringerten relativen Blattwassergehalt $\left(\mathrm{RWC}_{\text {leaf }}\right)$ gegenüber der Kontrolle aufwiesen, unterscheiden sich die $\mathrm{RWC}_{\text {leaf }}$ der C- und De-Varianten bei $Q$. robur nicht mehr voneinander und liegen mit 85\% auf dem Niveau der entlaubten Bäume 1999 (Abb. 3.16). Gleichzeitig sind die $\Psi_{\text {awp }}$ gegenüber 1999 um das Zweifache verringert. Eine starke Absenkung von $\Psi_{\text {awp }}$ zur Aufrechterhaltung des $\mathrm{RWC}_{\text {leaf }}$ bei Trockenheit ist vor allem bei den DeDrBäumen festzustellen, während die Dr-Variante bei vergleichbaren RWC-Werten ein ähnliches $\Psi_{\text {awp }}$ wie die beiden ausreichend bewässerten Varianten (C und De) aufweist. Im Gegensatz zu 1999 findet nur bei DeDr eine Aufrechterhaltung des $\mathrm{RWC}_{\text {leaf }}$ unter Absenkung der $\Psi_{\text {awp }}$ statt. Bei den De- und C-Varianten beider Arten werden, bei ähnli- 
chen Blattwassergehalten wie 1999, im Jahr 2000 stärker negative $\Psi_{\text {awp }}$ gemessen. Bei $Q$. petraea findet nur bei den Dr-Bäumen eine Absenkung der $\Psi_{\text {awp }}$ als Reaktion auf Trockenstress statt, nicht aber bei den DeDr-Bäumen. Trotz der erfolgten Absenkung verringern sich die $\mathrm{RWC}_{\text {leaf }}$ jedoch noch bei den Dr-Bäumen. Hier werden sowohl die niedrigsten $\mathrm{RWC}_{\text {leaf }}$ als auch die am stärksten negativen $\Psi_{\text {awp }}$ gemessen.

\section{Maximale stomatäre Leitfähigkeit}

Die maximale stomatäre Leitfähigkeit $\left(\mathrm{g}_{\mathrm{sm}}\right)$ im Jahr 2000 ist in Abb. 3.17 dargestellt. Dabei zeigt sich, dass die $\mathrm{g}_{\mathrm{sm}}$ bei den entlaubten Bäumen beider Arten nicht mehr gegenüber der Kontrolle erhöht ist.



Abb. 3.17: Maximale stomatäre Leitfähigkeit bei $Q$. robur und $Q$. petraea bei unterschiedlichen Behandlungsvarianten 2000. Die Dauer der Trockenperiode ist durch einen schwarzen Balken markiert. Signifikante Unterschiede zwischen den Varianten sind mit Kleinbuchstaben gekennzeichnet (Kennzeichnung jeweils für beide $\mathrm{Ab}$ bildungen einer Art). Die durch die Faktoren »Entlaubung «, »Trockenheit « und die Faktorenkombination »Entlaubung $\times$ Trockenheit« $(E, W, E \times W)$ bedingten signifikanten Unterschiede für die gesamte Untersuchungsperiode sind in Großbuchstaben in der separaten Legende, geltend für beide Arten, angegeben. n.s., nicht signifikant. Varianten siehe Abb. 3.15. 
Eine Ausnahme bildet nur die De-Variante bei $Q$. petraea im Juni, bei der die $\mathrm{g}_{\mathrm{sm}}$ verglichen mit der Kontrolle noch um $15 \%$ erhöht ist. Die DeDr-Bäume von $Q$. petraea weisen nur im Juni eine verringere $\mathrm{g}_{\mathrm{sm}}$ auf, obwohl $\mathrm{zu}$ diesem Zeitpunkt noch kein Trockenstress appliziert wurde. Vergleicht man die gesamte Untersuchungsperiode 2000 mit den Ergebnissen von 1999, so kommt es bei den trockengestressten Varianten (Dr und DeDr) beider Arten 2000 zu einer starken Reduktion der $\mathrm{g}_{\mathrm{sm}}$ (Abb. 3.17). Entlaubungsbedingte Unterschiede zwischen diesen beiden Varianten zeigen sich im Gegensatz zu 1999 nicht mehr. Im Jahresverlauf hat nur der Faktor Trockenheit signifikante Auswirkungen auf die $\mathrm{g}_{\mathrm{sm}}$ bei beiden Arten.

\section{Tagesgang der stomatären Leitfähigkeit}

Im Gegensatz zu 1999 hat der Faktor Entlaubung keinen signifikanten Einfluss mehr auf die stomatäre Leitfähigkeit (Abb. 3.18). Leichte Unterschiede im Kurvenverlauf der $\mathrm{g}_{\mathrm{s}}$ sind jedoch noch ersichtlich. Bei $Q$. robur erreichen die De-Bäume erst gegen Mittag eine leicht höhere $\mathrm{g}_{\mathrm{s}}$ im Vergleich zur Kontrolle und bleiben auch im weiteren Tagesverlauf etwas weiter geöffnet.

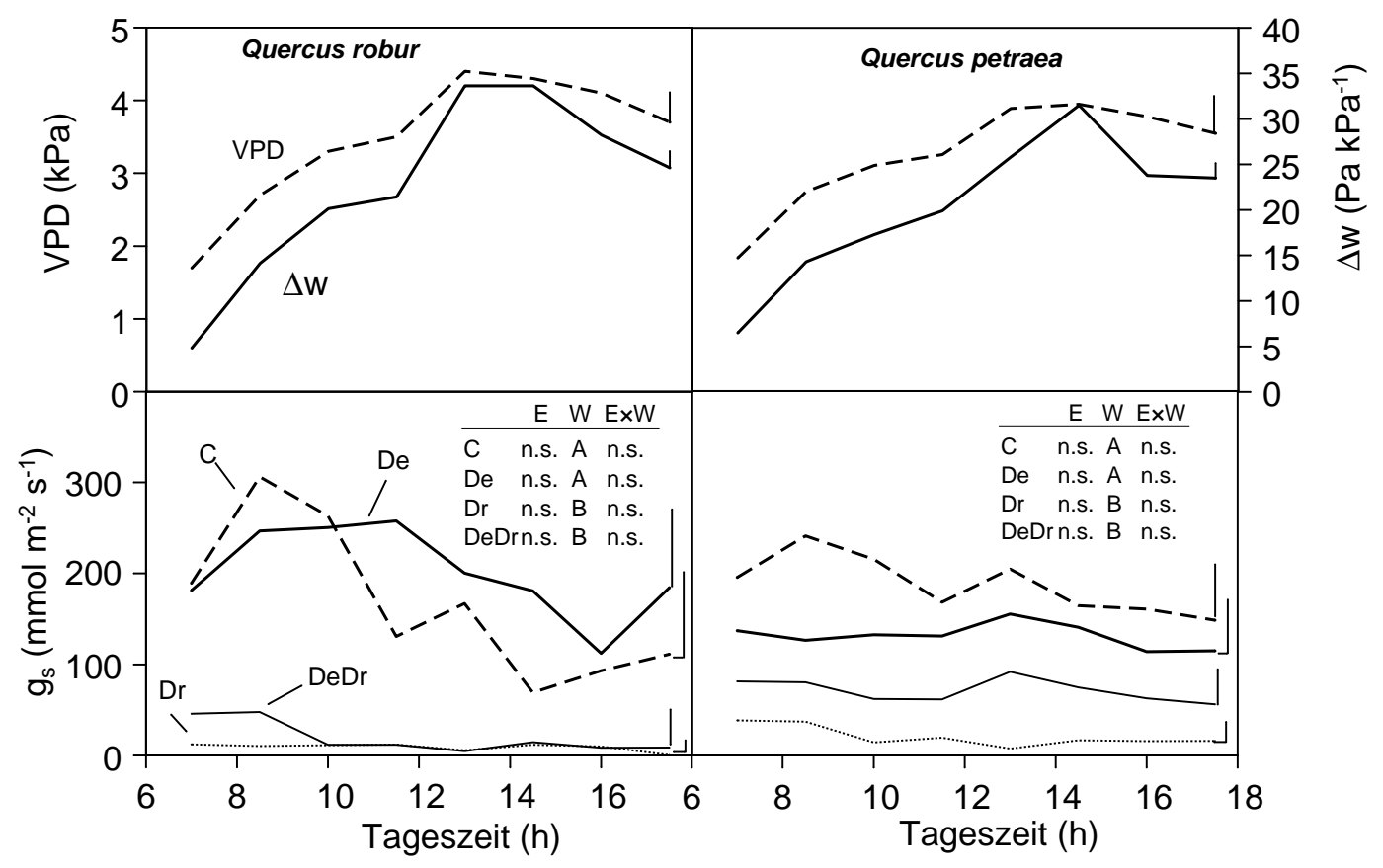

Abb. 3.18: Tagesgang der stomatären Leitfähigkeit $g_{s}$ bei $Q$. robur und $Q$. petraea sowie VPD und $\Delta \mathrm{w}$ während der Trockenperiode am 01.08.2000. Die maximalen Standardabweichungen sind durch vertikale Linien gekennzeichnet. Die Ergebnisse der Varianzanalyse sind in der separaten Legende angegeben (vgl. Abb. 3.17). Varianten siehe Abb. 3.15. 
Zwischen den trockengestressten Varianten Dr und DeDr zeigen sich hingegen keine Unterschiede. Bei $Q$. petraea ist die $\mathrm{g}_{\mathrm{s}}$ der entlaubten Bäume im Gegensatz zu Q. robur und den Befunden von 1999 deutlich verringert gegenüber der Kontrolle. Die DeDr-Bäume unterscheiden sich in ihren Leitfähigkeiten nur wenig von den nur trockengestressten (Dr) Bäumen. Hingegen führt Trockenheit als einziger signifikanter Faktor bei beiden Arten zu einer starken Reduktion der stomatären Leitfähigkeit der Dr- und DeDr-Bäume.

\section{Tagestranspirationssumme $E_{d}$}

Abbildung 3.19 zeigt die Tagestranspirationssummen im Untersuchungsjahr 2000.

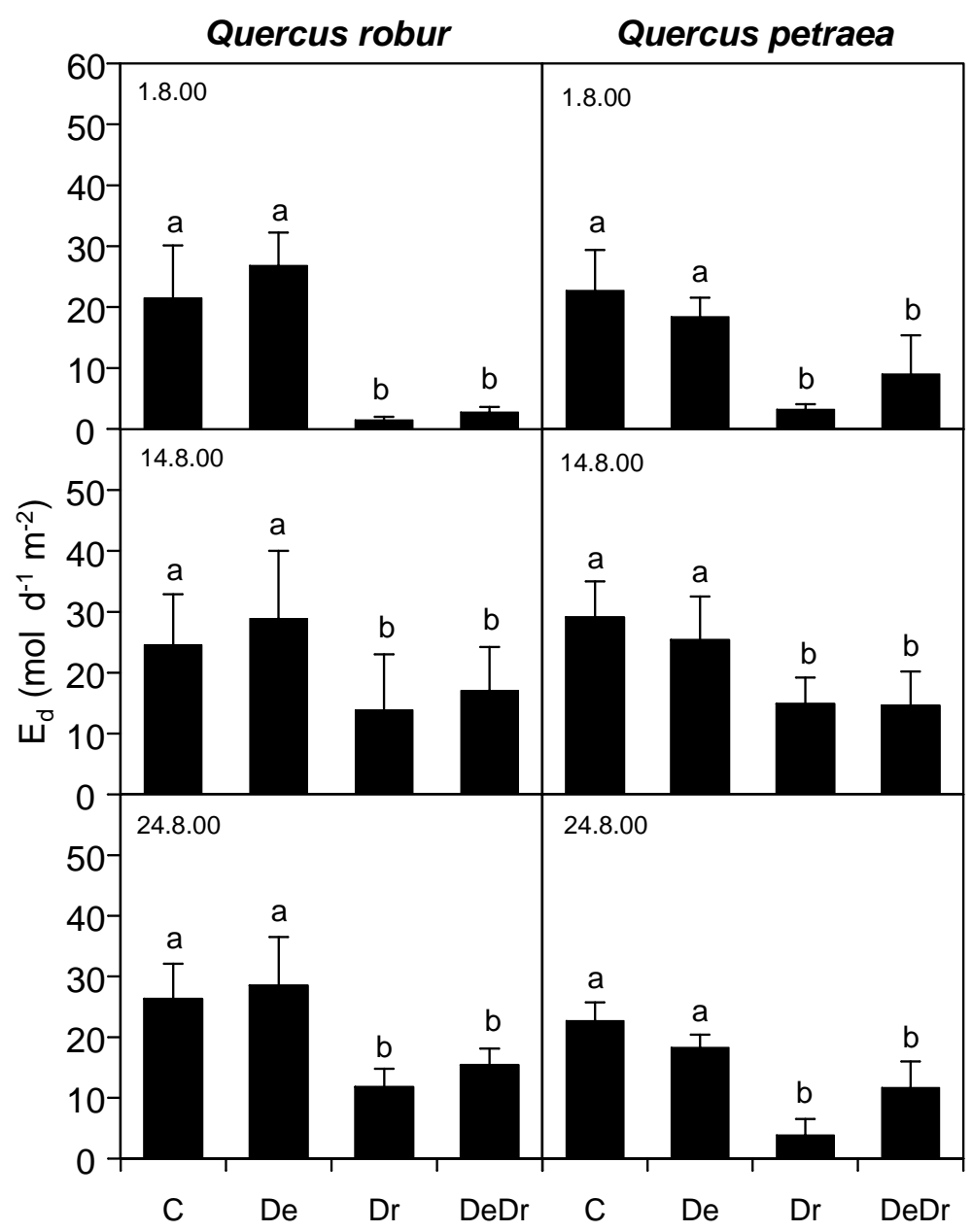

Abb. 3.19: Berechnete Tagestranspirationssumme bei $Q$. robur und $Q$. petraea in der Untersuchungsperiode 2000. Trockenstress herrschte an allen drei Terminen. Signifikante Unterschiede sind mit Kleinbuchstaben gekennzeichnet. Varianten siehe Abb. 3.15. 
Die Tagestranspirationssumme ist bei beiden Arten während der Trockenperiode 2000 an allen Terminen bei den Dr- und DeDr-Varianten stark reduziert. Dies liegt vor allem an den reduzierten $\mathrm{g}_{\mathrm{s}}$-Werten bis hin zu Stomataschluss Anfang August, dem Zeitpunkt der am stärksten negativen Predawn-Wasserpotentiale. Trockenstress führt also zu einer Einschränkung der Tagestranspirationssummen bei beiden Arten an allen drei Terminen. Auffällig blieb ein leichter (allerdings nicht signifikanter) Trend zu einer erhöhten $E_{d}$ bei den De- und DeDr-Bäumen im Vergleich zu den nicht entlaubten Varianten $C$ und Dr an allen drei Terminen bei Q.robur. Für $Q$. petraea trifft ein Trend zu höheren $\mathrm{E}_{\mathrm{d}}$-Werten bei DeDr gegenüber Dr an zwei Terminen (01.08.2000 und 24.08.2000) zu.

\section{Hydraulische Leitfähigkeit Boden-Blatt}

Abbildung 3.20 zeigt die berechnete hydraulische Leitfähigkeit auf der Fließstrecke Boden-Blatt $\left(\mathrm{g}_{\mathrm{sl}}\right)$ während der Vegetationsperiode 2000. Vor Beginn der Trockenperiode Ende Juni unterscheiden sich die Varianten bei $Q$. robur nicht voneinander. Im Gegensatz dazu ist bei $Q$. petraea zu diesem Zeitpunkt bei beiden entlaubten Varianten (De und DeDr) eine Reduktion der hydraulischen Leitfähigkeit zu beobachten, wie dies auch an den beiden Terminen innerhalb der Untersuchungsperiode 1999 der Fall war. Trockenstress führt bei beiden Arten zu einer Reduktion der $\mathrm{g}_{\mathrm{sl}}$ von bis zu $50 \%$ bei den Dr- und DeDr-Bäumen verglichen mit den ausreichend bewässerten Bäumen. Am 01.08.2000 ist die $\mathrm{g}_{\mathrm{sl}}$ bei den trockengestressten Varianten Dr und DeDr bei beiden Arten am stärksten reduziert. An diesem Termin erreichten auch die $\mathrm{E}_{\mathrm{d}}$ sowie die $\Psi_{\mathrm{pd}}$ der trockengestressten Bäume ihre Minimalwerte. Der Effekt der Entlaubung zeigt sich uneinheitlich. Bei $Q$. robur erreichen die De-Bäume zum Teil höhere, aber mindestens ähnlich hohe $\mathrm{g}_{\mathrm{sl}}$ wie die Kontrollen, während bei $Q$. petraea die $\mathrm{g}_{\mathrm{sl}}$ bei den De-Bäumen im Vergleich mit der Kontrolle sogar teilweise verringert ist. 


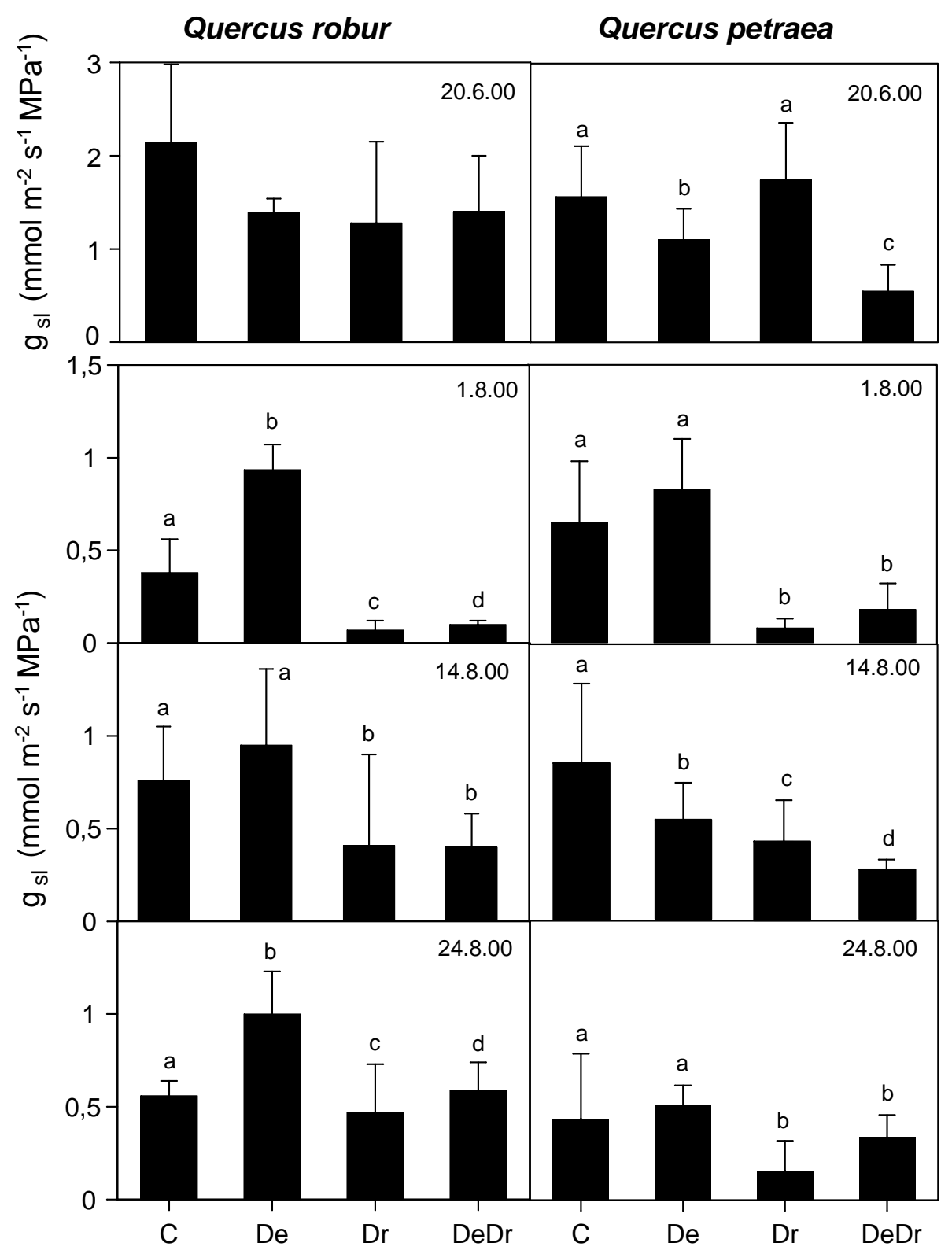

Abb. 3.20: Hydraulische Leitfähigkeit auf der Fließstrecke Boden-Blatt bei unterschiedlichen Behandlungsvarianten bei $Q$. robur und $Q$. petraea während der Untersuchungsperiode 2000. Zur Verbesserung der Übersichtlichkeit wechselt die Skalierung der Ordinate nach der ersten Messperiode im Juni (vor Beginn der Trockenperiode). Signifikante Unterschiede sind mit Kleinbuchstaben gekennzeichnet. Varianten siehe Abb. 3.15. 


\section{Druck-Volumen-Kurve}

Die Ergebnisse der P/V-Kurven vor und nach Trockenstress sind in Abb. 3.21 dargestellt. Ein Jahr nach letztmaliger Entlaubung treten keine entlaubungsbedingten Änderungen in den gemessenen Parametern der P/V-Kurve mehr auf. Der Faktor Trockenstress führt nur bei $Q$. petraea zu einer Abnahme der osmotischen Potentiale im September. Bei $Q$. robur sind die $\Pi_{\mathrm{p}}$ der trockengestressten Varianten bereits im Juni vergleichsweise niedrig, so dass Trockenheit zu keiner weiteren Absenkung führt.

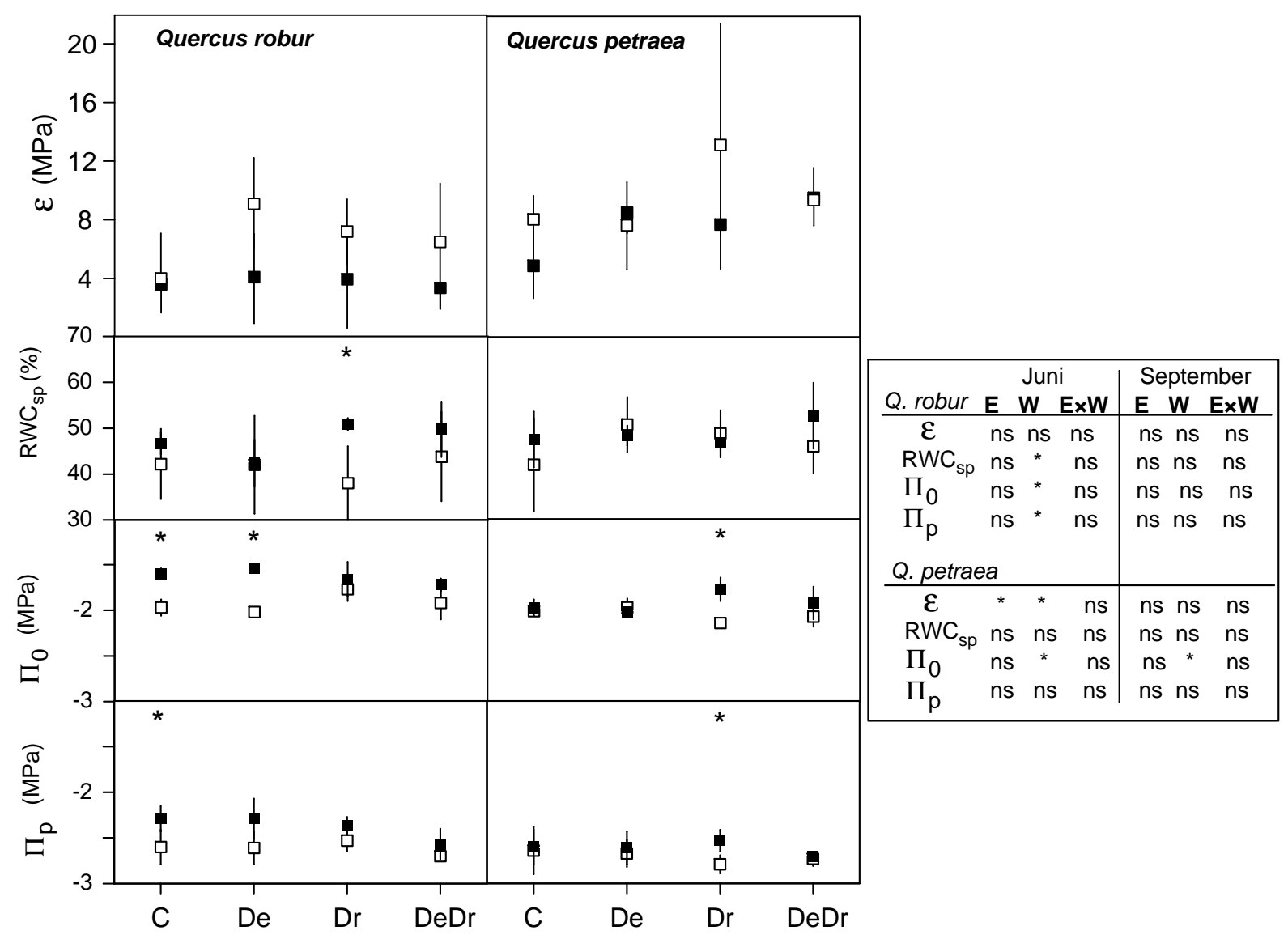

Abb. 3.21: Elastizitätsmodul $(\varepsilon)$, relativer symplastischer Wassergehalt am Turgornullpunkt $\left(\mathrm{RWC}_{\mathrm{sp}}\right)$ und die osmotischen Potentiale am Turgornullpunkt $\left(\Pi_{\mathrm{P}}\right)$ und bei Wassersättigung $\left(\Pi_{0}\right)$ gemessen bei unterschiedlichen Behandlungsvarianten bei $Q$. robur und $Q$. petraea vor (Juni, gefültte Symbole) und nach (September, offene Symbole) einer Trockenperiode 2000. Signifikante Unterschiede zwischen den Messterminen sind mit $\left(^{*}\right)$ gekennzeichnet. Die Ergebnisse der Varianzanalyse sind in der separaten Legende angegeben (vgl. Abb. 3.17). Varianten siehe Abb. 3.15. 
Tab. 3.4: Änderungen der Osmotikagehalte bei $Q$. robur und $Q$. petraea zwischen Juni (vor Trockenstress) und September (nach Trockenstress) 2000. Werte sind als Quotient der $\Pi_{0}{ }^{*} \mathrm{RWC}_{\mathrm{s}}$-Werte von Juni und September angegeben (Mittelwerte und Standardabweichungen). Varianten siehe Abb. 3.15.

\begin{tabular}{lllll}
\hline & C & De & Dr & DeDr \\
\hline$Q$. robur & $0,7 \pm 0,1$ & $0,7 \pm 0,3$ & $0,7 \pm 0,1$ & $0,7 \pm 0,1$ \\
$Q$. petraea & $0,8 \pm 0,2$ & $1,1 \pm 0,1$ & $0,8 \pm 0,1$ & $0,8 \pm 0,2$
\end{tabular}

Im Jahresverlauf sinken die osmotischen Potentiale bei den $\mathrm{C}$ und De Bäumen bei $Q$. robur, während bei $Q$. petraea dies nur bei den Dr-Bäumen erfolgt. Eine Abnahme der $\mathrm{RWC}_{\mathrm{sp}}$ wird nur bei der trockengestressten Variante bei $Q$. robur festgestellt, nicht aber bei $Q$. petraea. Betrachtet man die berechnete Netto-Osmotikaanreicherung (Tab. 3.4) von Juni bis September, so ist von einer Osmotikaanreicherung bei beiden Arten auszugehen. Eine Ausnahme bilden, hier wie bereits 1999, die entlaubten Bäume (De), bei denen kein Hinweis auf eine Osmotikaanreicherung gefunden wird.

\subsubsection{Ober- und unterirdische Biomasse 2000}

\section{Blattfläche und spezifische Blattfläche}

Die Gesamt-Blattflächen sowie die spezifische Blattfläche (SLA) gegen Ende der Vegetationsperiode zeigt Abb. 3.22. Im Gegensatz zum Vorjahr 1999 unterscheiden sich die Varianten bei beiden Arten nicht mehr in ihren Gesamt- und spezifischen Blattflächen. Effekte vorhergehender Entlaubung und Trockenheit sind im Kronenbereich nicht mehr feststellbar. Auch auf Blattbasis werden keine Veränderungen mehr beobachtet, d.h. äuBerlich unterscheiden sich die Blätter der einzelnen Varianten nicht mehr voneinander. 


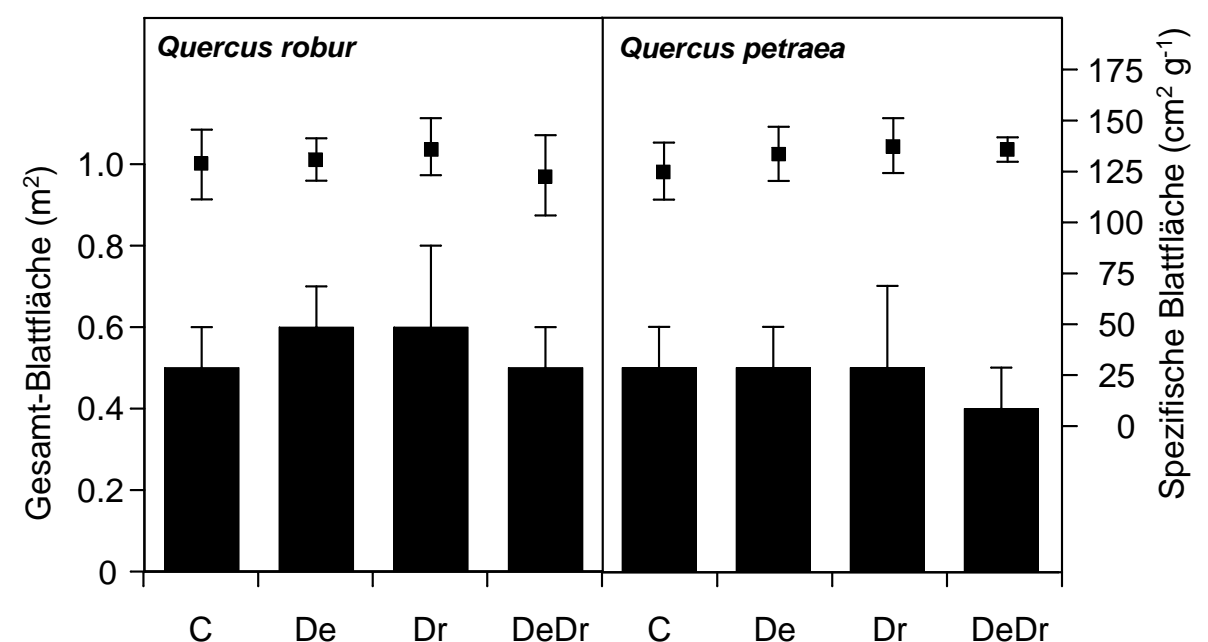

Abb. 3.22: Blattfläche und spezische Blattfläche (SLA, gefüllte Quadrate) bei unterschiedlichen Behandlungsvarianten bei $Q$. robur und $Q$. petraea in 2000. Signifikante Unterschiede sind mit Buchstaben gekennzeichnet. Varianten siehe Abb. 3.15.

\section{Blatt- und Wurzelbiomasse und Blatt/Feinwurzelverhältnis}

Ähnlich wie bei den Blattflächen ist auch bei den Blattbiomassen 2000 kein Unterschied mehr zwischen den Varianten bei beiden Arten feststellbar (Abb. 3.23). Bei den Feinwurzelbiomassen ist bei $Q$. robur allenfalls ein schwacher Trend zur Reduktion auch im Jahr nach letztmaliger Entlaubung zu beobachten. Bei $Q$. petraea ist dieser Trend stärker ausgeprägt, vor allem bei den DeDr-Bäumen kommt es zu einer signifikanten Abnahme der Feinwurzelbiomasse gegenüber der Kontrolle. Die noch immer verringerte Feinwurzelbiomasse bei den entlaubten Bäumen beider Arten resultiert in einem erhöhten Blatt/Feinwurzelverhältnis. Trockenheit führt bei beiden Arten zu einer im Trend leicht erhöhten Feinwurzelbiomasse, nicht aber zu Änderungen das Blatt/Feinwurzelverhältnisses wie im Jahr 1999. 

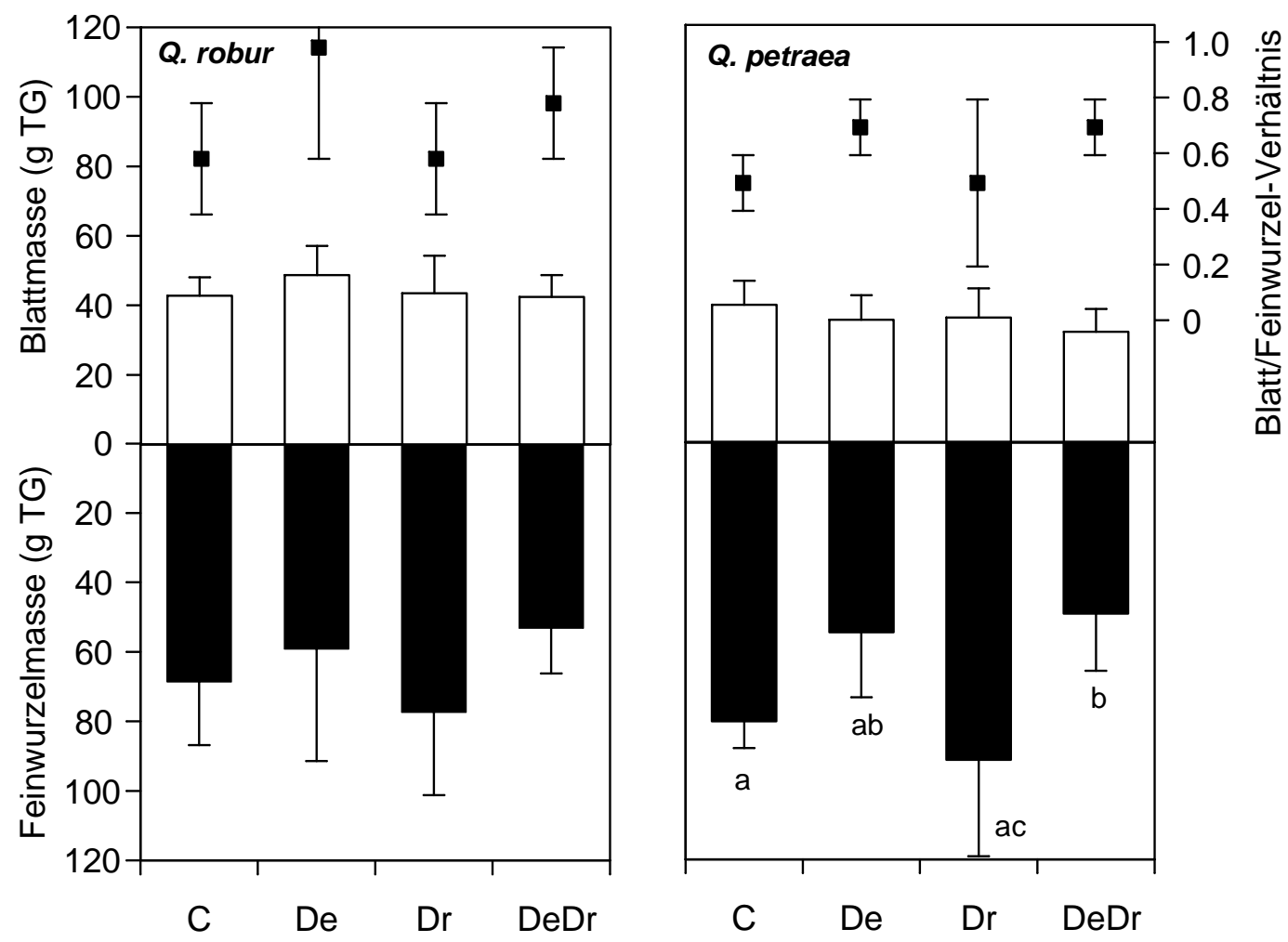

Abb. 3.23: Blatt- und Feinwurzelbiomasse (ungefüllte und gefüllte Säulen) sowie das trockengewichtsbezogene Blatt/Feinwurzelverhältnis (gefüllte Quadrate) bei unterschiedlichen Behandlungsvarianten bei $Q$. robur und Q. petraea im Jahr 2000. Signifikante Unterschiede zwischen den Varianten sind mit Buchstaben gekennzeichnet. Varianten siehe Abb. 3.15.

\section{Höhen- und Stammbasis-Zuwachs}

Im Folgejahr nach Ende der Entlaubung (2000) zeigt sich ein deutlicher Unterschied zwischen den Arten in ihren Zuwächsen an der Stammbasis (Abb. 3.24). Bezogen auf den Startwert von 1998 gibt es bei $Q$. robur keinen Unterschied im Stammbasiszuwachs zwischen den Varianten mehr. Hier findet daher bereits ein Jahr nach letztmaliger Entlaubung eine komplette Erholung des Zuwachses statt. Bei Q. petraea ist dieser, wie auch im Vorjahr, bei beiden entlaubten Varianten noch deutlich reduziert. Die Höhenzuwächse (Abb. 3.24) zwischen den Varianten hingegen unterscheiden sich 2000 bei beiden Arten nicht mehr voneinander. Trockenstress hat, wie auch im Vorjahr, keinen signifikanten Einfluss auf die Zuwächse. 


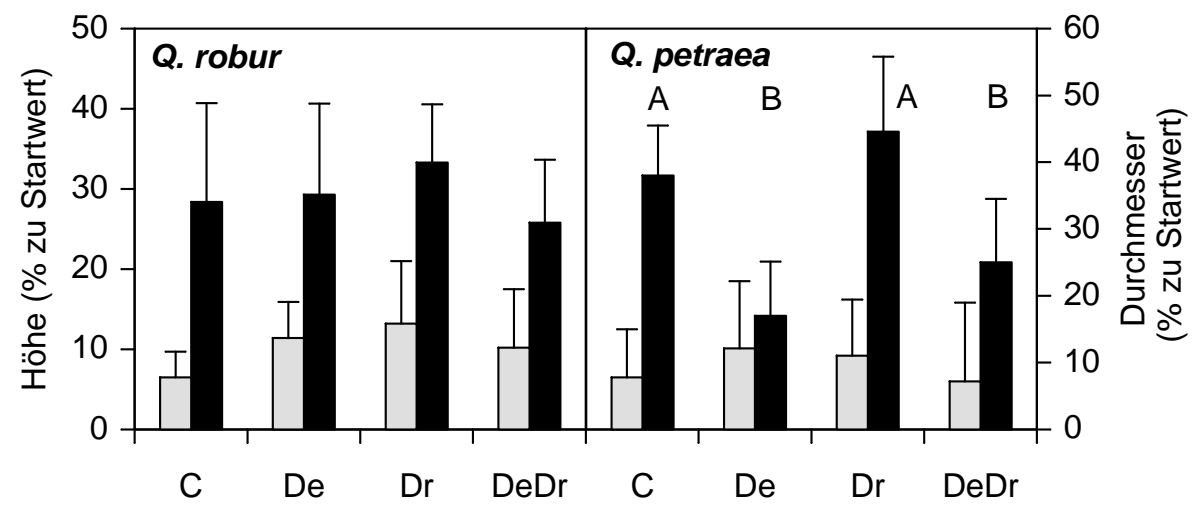

Abb. 3.24: Höhenzuwachs (graue Säulen) und Zunahme des Stammbasisdurchmessers (schwarze Säulen) bei unterschiedlichen Behandlungsvarianten von $Q$. robur und $Q$. petraea im Jahr 2000. Signifikante Unterschiede zwischen den Varianten im Durchmesser an der Stammbasis sind mit Großbuchstaben gekennzeichnet. Varianten siehe Abb. 3.15.

\subsubsection{Blatt- und Stamminhaltsstoffe 2000}

\section{Kohlenstoff-Isotopenverhältnis}

Abbildung 3.25 zeigt das Kohlenstoff-Isotopen-Verhältnis in den Blättern gegen Ende der Vegetationsperiode 2000 bei $Q$. robur und Q. petraea. In den Kohlenstoff-IsotopenVerhältnissen bei $Q$. robur (Abb. 3.25) zeigen sich wie im Vorjahr keine Unterschiede zwischen den Varianten. Hier lässt sich allenfalls ein Trend zu leicht positiveren ${ }^{13} \mathrm{C}$-Gehalten bei den trockengestressten Varianten Dr und DeDr feststellen. Anders reagieren die Dr- und DeDr-Varianten bei $Q$. petraea. Nach Trockenheit sind in diesem Sommer die $\delta^{13} \mathrm{C}$-Werte bei beiden trockengestressten Varianten erstmalig positiver, d.h. trockengestresste Bäume haben eine höhere Wassernutzungseffizienz. Tabelle 3.5 zeigt das Ergebnis der multiplen Regressionsanalyse bezüglich des KohlenstoffIsotopenverhältnisses. Bereits $66 \%$ der Variabilität von $\delta^{13} \mathrm{C}$ wird bei $Q$. petraea durch die Trockenheit und $\mathrm{A}_{\max }$ erklärt, während bei $Q$. robur nur $39 \%$ der Variabilität durch $\mathrm{A}_{\max }$ und $\mathrm{g}_{\mathrm{sm}}$ erklärt werden. 
Tab. 3.5: Ergebnisse der multiplen Regressionsanalyse der Faktoren Entlaubung (E), Trockenstreß $(W), g_{s m}, A_{\max }, C / N$ und der vorherzusagenden Variable KohlenstoffIsotopenverhältnis $\left(\delta^{13} \mathrm{C}\right)$ bei $Q$. robur und $Q$. petraea im Jahr 2000.

Q. robur Q. petraea

\begin{tabular}{llll}
$\mathrm{R}^{2}$ & Faktoren & $\mathrm{R}^{2}$ & Faktoren \\
\hline 0.47 & $\mathrm{~A}_{\max } \mathrm{g}_{\mathrm{sm}} \mathrm{E}$ & 0.72 & $\mathrm{~A}_{\max } \mathrm{g}_{\mathrm{sm}} \mathrm{W}$ \\
0.42 & $\mathrm{~A}_{\max } \mathrm{g}_{\mathrm{sm}} \mathrm{C} / \mathrm{N}$ & 0.67 & $\mathrm{~A}_{\max } \mathrm{W} \mathrm{C} / \mathrm{N}$ \\
0.39 & $\mathrm{~A}_{\max } \mathrm{g}_{\mathrm{sm}} \mathrm{W}$ & 0.66 & $\mathrm{~A}_{\max } \mathrm{E} \mathrm{W}$ \\
\hline 0.39 & $\mathrm{~A}_{\max } \mathrm{g}_{\mathrm{sm}}$ & 0.66 & $\mathrm{~A}_{\max } \mathrm{W}$ \\
0.32 & $\mathrm{~A}_{\max } \mathrm{W}$ & 0.64 & $\mathrm{~A}_{\max } \mathrm{C} / \mathrm{N}$ \\
0.21 & $\mathrm{~g}_{\mathrm{sm}} \mathrm{C} / \mathrm{N}$ & 0.62 & $\mathrm{~A}_{\max } \mathrm{g}_{\mathrm{sm}}$ \\
\hline 0.19 & $\mathrm{~g}_{\mathrm{sm}}$ & 0.61 & $\mathrm{~A}_{\max }$ \\
0.17 & $\mathrm{~W}$ & 0.40 & $\mathrm{~W}$ \\
& & 0.24 & $\mathrm{~g}_{\mathrm{sm}}$ \\
\hline
\end{tabular}

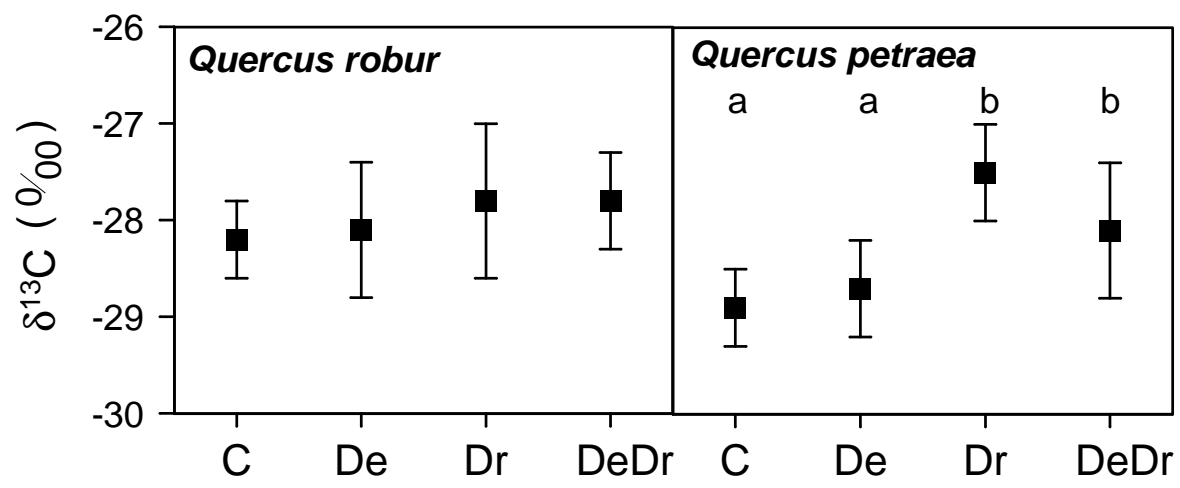

Abb. 3.25: Kohlenstoff-Isotopenverhältnis $\delta^{13} \mathrm{C}$ in Blättern des zweiten Blattaustriebes bei unterschiedlichen Behandlungsvarianten bei $Q$. robur und $Q$. petraea Ende August 2000. Signifikante Unterschiede zwischen den Varianten sind mit Kleinbuchstaben gekennzeichnet. Varianten siehe Abb. 3.15. 


\section{Stickstoffgehalt und $\mathrm{C} / \mathrm{N}$-Verhältnis}

Im Gegensatz zum Vorjahr 1999 lassen sich bei den N-Gehalten der Blätter keine Unterschiede zwischen den Varianten mehr feststellen (Abb. 3.26). Dies gilt auch für das C/N-Verhälnis (Abb. 3.26) bei $Q$. robur. Nur bei $Q$. petraea sind die $\mathrm{C} / \mathrm{N}-$ Verhältnisse der im Vorjahr letztmalig entlaubten Bäume (De und DeDr) noch leicht, aber signifikant, erniedrigt. Bei gleichen N-Konzentrationen ist der Kohlenstoffanteil im Blattmaterial auch ein Jahr nach letztmaliger Entlaubung noch reduziert. $Q$. petraea reagiert demnach wesentlich empfindlicher auf den Faktor Entlaubung. Trockenheit hat wie bereits 1999 bei beiden Arten keinen Einfluss auf die N-Konzentration und auf das C/N-Verhältnis.

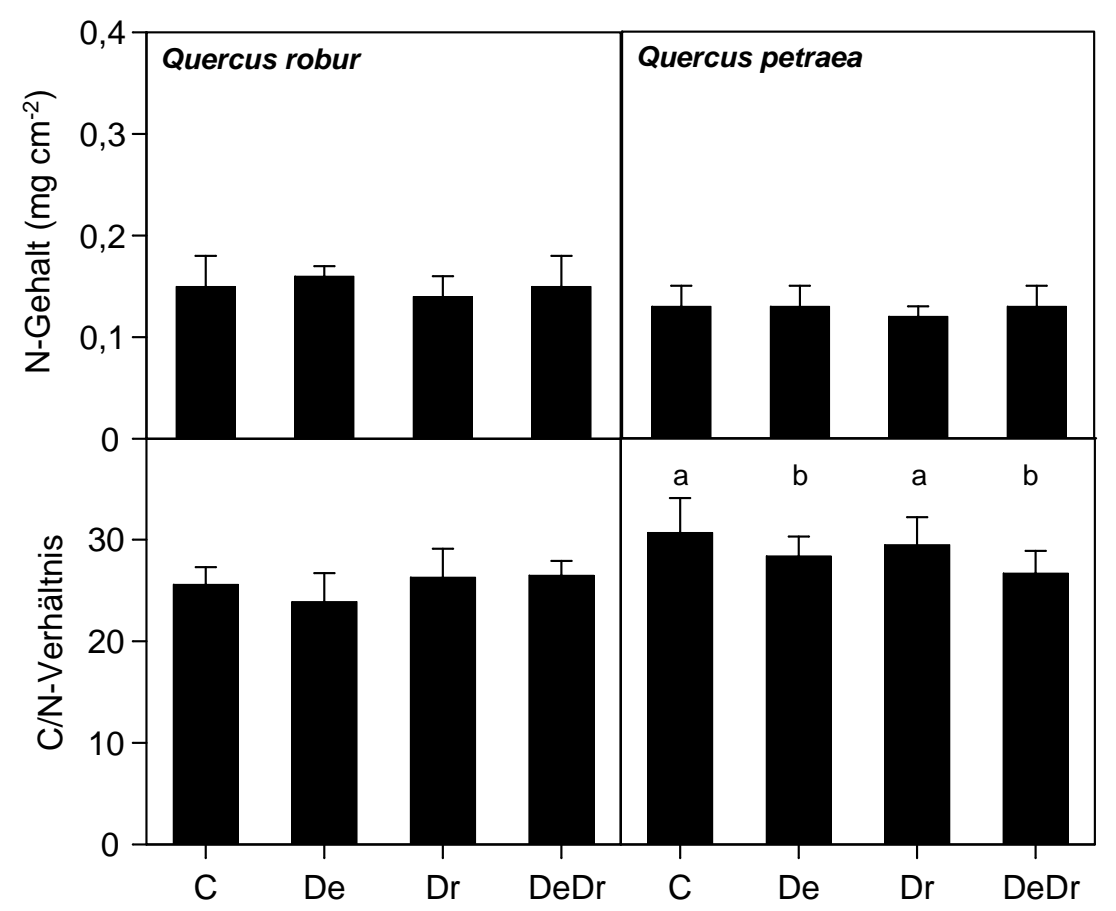

Abb. 3.26: $\mathrm{N}$-Gehalt und $\mathrm{C} / \mathrm{N}-$ Verhältnis in Blättern des zweiten Blattaustriebes bei unterschiedlichen Behandlungsvarianten bei $Q$. robur und $Q$. petraea Ende August 2000. Signifikante Unterschiede zwischen den Varianten sind mit Kleinbuchstaben gekennzeichnet. Varianten siehe Abb. 3.15. 


\section{Chlorophyllgehalt}

Bei den Blättern lassen sich im Jahr 2000 mit einer Ausnahme keine Unterschiede in den flächenbezogenen Chlorophyllgehalten zwischen den Varianten nachweisen (Abb. 3.27). Nur am 20.07.2000 sind die Chlorophyllgehalte bei den entlaubten Varianten von $Q$. petraea gegenüber den nicht entlaubten Varianten signifikant erniedrigt. Dies steht im Gegensatz zu 1999, als die Entlaubung zu einer starken Zunahme der Chlorophyllgehalte in den Blättern des zweiten Blattaustriebes führte.

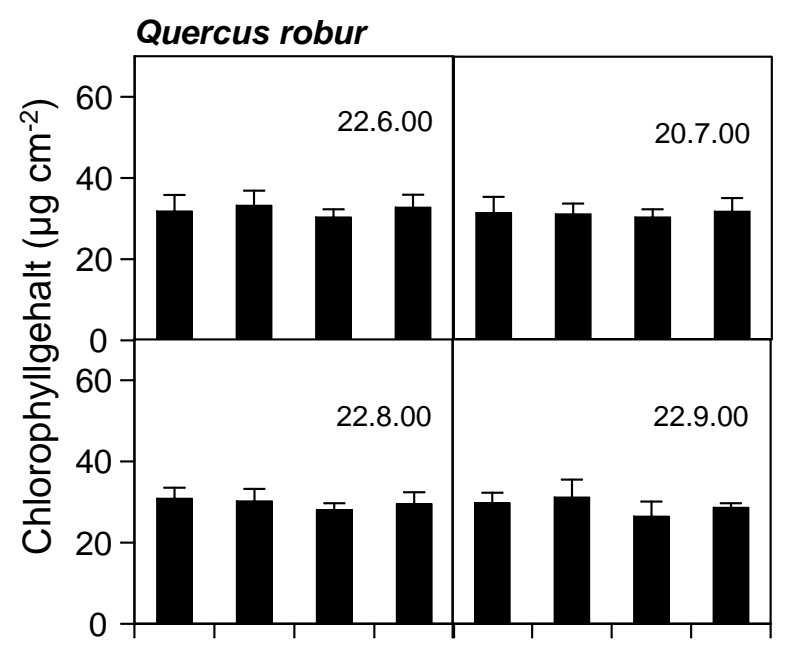

Quercus petraea

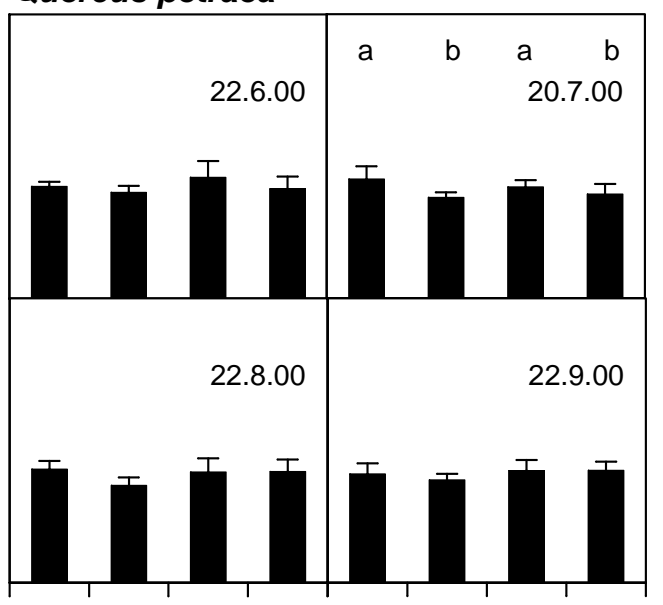

C De Dr DeDr C De Dr DeDr C De Dr DeDr C De $\operatorname{Dr}$ DeDr

Abb. 3.27: Blatt-Chlorophyllgehalt in der Vegetationsperiode 2000 bei unterschiedlichen Behandlungsvarianten bei $Q$. robur und $Q$. petraea. Signifikante Unterschiede zwischen den Varianten sind mit Kleinbuchstaben gekennzeichnet. Varianten siehe Abb. 3.15.

\section{Stärkegehalt im Spross}

Ähnlich wie im Jahr 1999 zeigt sich kein deutlicher Effekt der Stressoren Entlaubung und Trockenheit auf den Stärkegehalt im Stamm. Die Analyse umfasst in diesem Jahr den Zeitraum 1998 bis 2000, d.h. vom ersten Jahr der Entlaubung bis zum Folgejahr nach Entlaubung. (Abb. 3.28). Bei Q. robur weisen die DeDr-Bäume im Vergleich mit De und Dr leicht erhöhte Stärkegehalte im Holz auf, nicht jedoch im Vergleich mit den Kontrollen, wie dies 1999 der Fall war. Bei Q. petraea können im Gegensatz zu 1999 keine signifikanten Unterschiede zwischen den einzelnen Varianten nachgewiesen werden. 


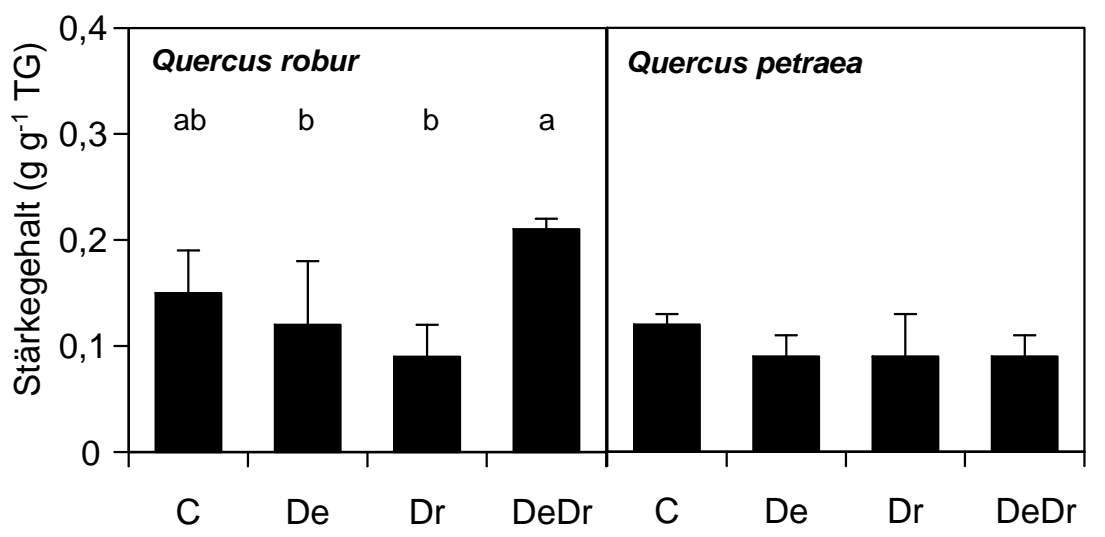

Abb. 3.28: Stärkegehalt von Stamm-Holzproben am Ende der Vegetationsperiode 2000 bei unterschiedlichen Behandlungsvarianten bei $Q$. robur und $Q$. petraea. Die Holzproben umfassen die letzten drei Jahrringe, d.h. die Jahre 1998 bis 2000. Signifikante Unterschiede zwischen den Varianten sind durch Kleinbuchstaben gekennzeichnet. Varianten siehe Abb. 3.15.

\subsubsection{Photosynthese 2000}

Bei $Q$. robur zeigen sich trotz sinkender $\Psi_{\text {pd }}$ keine Einschränkungen des NettoPhotosynthesevermögens ( $\mathrm{A}_{\max }$, gemessen bei Lichtsättigung) bei den trockengestressten Varianten (Abb. 3.29). Nur im Vergleich der De- mit den Dr-Bäumen liegt die Abnahme bei Dr knapp über der Signifikanzgrenze $(p=0,0532)$. Trockenstress führt aber bei der berechneten aktuellen Wassernutzungseffizienz (WUE ${ }_{a}$ ) sowohl bei Dr als auch bei DeDr zu einer Erhöhung der $\mathrm{WUE}_{\mathrm{a}}$, wenngleich es auch hier knapp oberhalb des Signifikanzniveaus liegt ( $\mathrm{p}=0,0539)$. Auch bei $Q$. petraea weisen die trockengestressten Varianten (Dr und DeDr) eine deutlich höhere $\mathrm{WUE}_{\mathrm{a}}$ bei niedrigen $\Psi_{\mathrm{pd}}$ auf. Eine Einschränkung der $\mathrm{A}_{\max }$ zeigt sich nur bei der trockengestressten Variante (Dr). Hier werden auch die am stärksten negativen $\Psi_{\text {pd }}$ gemessen. Entlaubung (d.h. Entlaubung im Vorjahr) hat keinen Effekt auf die $\mathrm{A}_{\max }$ und die Wassernutzungseffizienz. Eine weitere Aussage über die Wassernutzungseffizienz kann aus der Auftragung des NettoPhotosynthesevermögens bei Lichtsättigung $\left(A_{\max }\right)$ gegen die jeweilig gemessenen $g_{s}$ gewonnen werden. Entlaubungsbedingte Unterschiede in der $\mathrm{g}_{\mathrm{s}}$ traten 2001 nicht auf. Daher wurden die $\mathrm{g}_{\mathrm{s}}$ aller Varianten zusammengefasst, um die Änderung der $\mathrm{A}_{\max }$ in dem Bereich von limitierter bis ausreichender Wasserversorgung darzustellen. Dabei treten klare Artunterschiede auf. Während bei niedrigen (50 bzw. $100 \mathrm{mmol} \mathrm{m}^{-2} \mathrm{~s}^{-1}$ ) $\mathrm{g}_{\mathrm{s}}$ noch annähernd gleiche $\mathrm{A}_{\max }$-Werte $\left(4 \mathrm{bzw} .7 \mu \mathrm{mol} \mathrm{m} \mathrm{m}^{-2} \mathrm{~s}^{-1}\right.$ ) erreicht werden, so steigt mit zunehmender $\mathrm{g}_{\mathrm{s}}$ bei $Q$. robur die $\mathrm{A}_{\max }$ deutlich stärker an als bei $Q$. petraea 


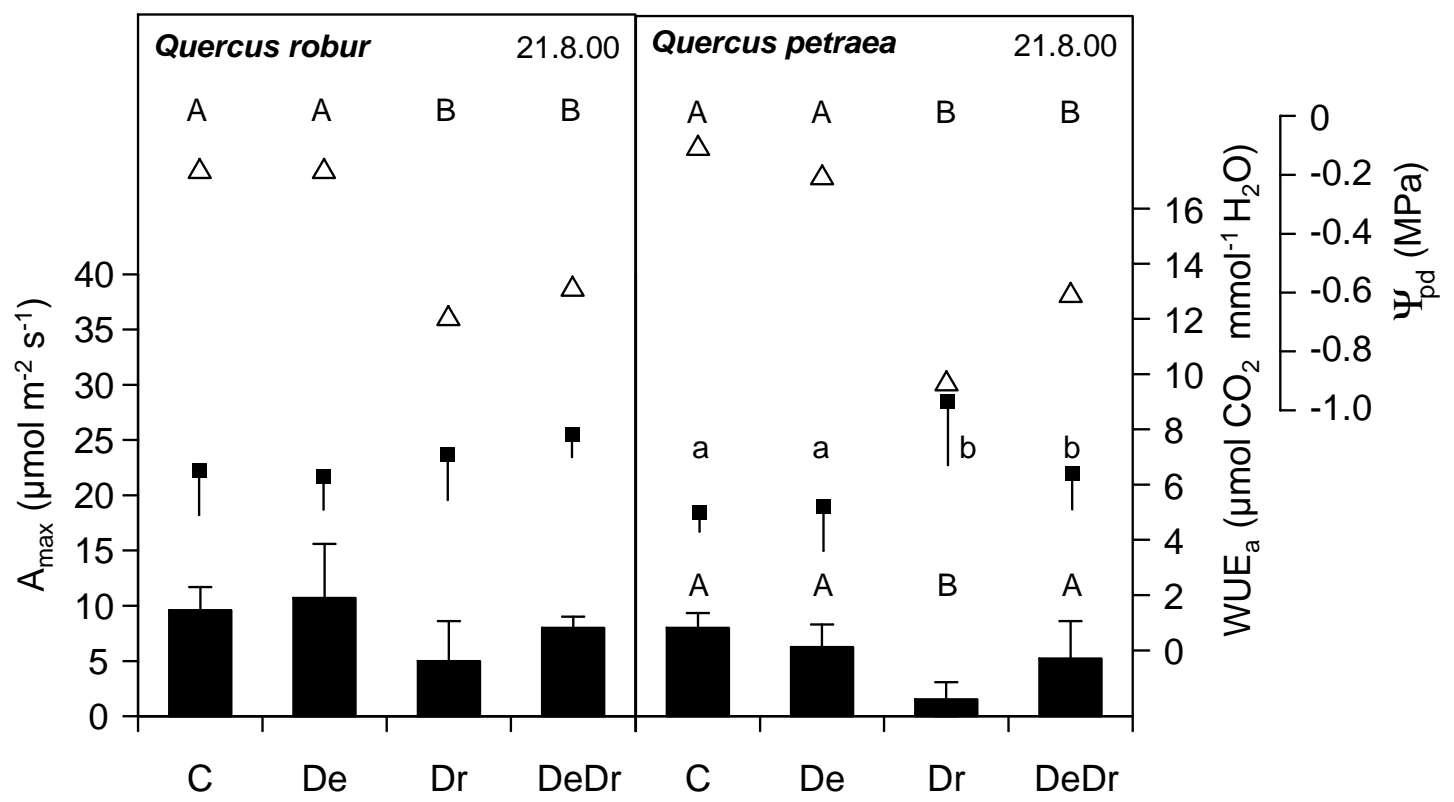

Abb. 3.29: Netto-Photosynthesevermögen ( $A_{\max }$, Balken), Wassernutzungseffizienz (WUE $\mathrm{a}_{\mathrm{a}}$, Quadrate) und Predawn-Wasserpotential ( $\Psi_{\text {pd }}$, Dreiecke) bei unterschiedlichen Behandlungsvarianten bei $Q$. robur und $Q$. petraea gegen Ende der Trockenperiode am 21.08.2000. Signifikante Unterschiede sind mit Klein- bzw. Großbuchstaben gekennzeichnet. Varianten siehe Abb. 3.15.

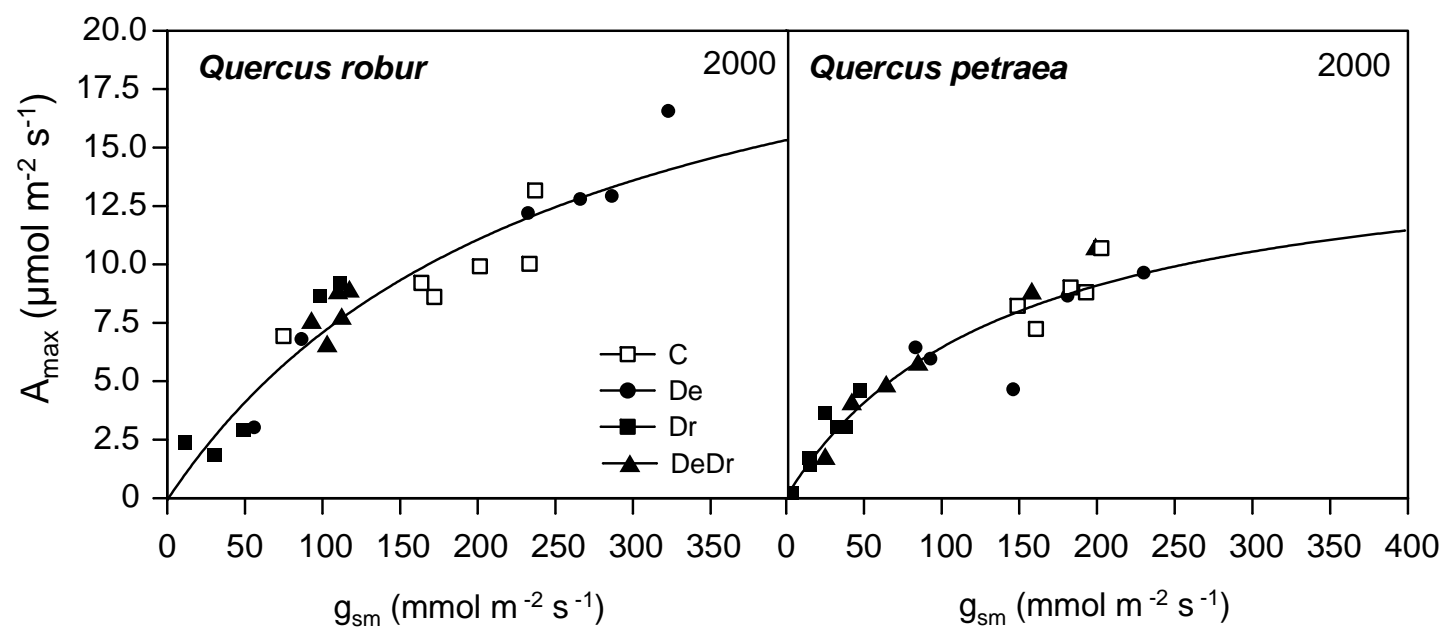

Abb. 3.30: Netto-Photosynthesevermögen $\left(A_{\max }\right)$ bei unterschiedlichen stomatären Leitfähigkeiten $\left(g_{s}\right)$ bei $Q$. robur und $Q$. petraea gegen Ende der Trockenperiode am 21.08.2000. Für die Ausgleichsfunktion wurden die Messwerte aller Varianten zusammengefasst. Varianten siehe Abb. 3.15. 


\subsection{Freilanduntersuchungen 2001}

\subsubsection{Wasserpotential und stomatäre Leitfähigkeit 2001}

Die Ergebnisse der Messungen der Wasserhaushaltsparameter 2001 zeigt Abb. 3.31. In diesem Jahr 2001 wurden Untersuchungen an 20-jährigen Freilandbäumen bei $Q$. robur durchgeführt. Die Behandlungsvarianten sind: Kontrolle (C), einmalige Entlaubung (De1, Entlaubung 2000) und zweimalige Entlaubung (De2, Entlaubung 1999 und 2000).

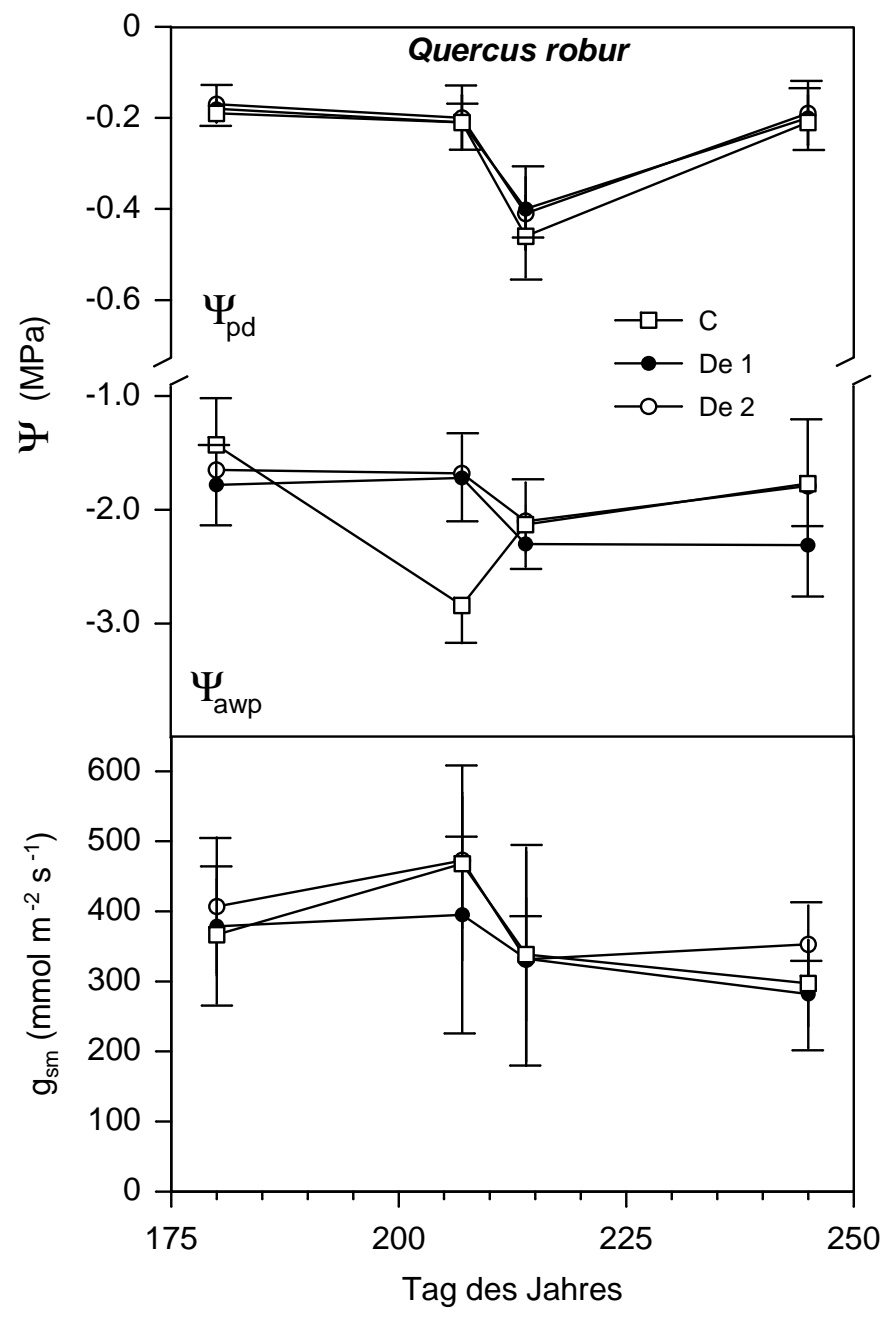

Abb. 3.31: Predawn- $\left(\Psi_{\mathrm{pd}}\right)$ und nachmittägliches $\left(\Psi_{\mathrm{awp}}\right)$ Wasserpotential sowie die maximale stomatäre Leitfähigkeit $\left(g_{\mathrm{sm}}\right)$ verschiedener Behandlungsvarianten bei $Q$. robur in der Untersuchungsperiode 2001. Signifikante Unterschiede zwischen den Varianten pro Messtermin sind mit Kleinbuchstaben gekennzeichnet. C, Kontrolle; De1, einmalige Entlaubung 2000; De2, zweimalige Entlaubung 1999 und 2000. 
Ein Jahr nach Ende der letzten Entlaubung unterscheiden sich weder die Predawn$\left(\Psi_{\mathrm{pd}}\right)$ noch die nachmittäglichen $\left(\Psi_{\text {awp }}\right)$ Wasserpotentiale sowie die maximale stomatäre Leitfähigkeit $\left(\mathrm{g}_{\mathrm{sm}}\right)$ der Kontrolle von den entlaubten Varianten De1 und De2. Aufgrund der wenig negativen $\Psi_{\mathrm{pd}}$ und der fehlenden Reduktion der $\mathrm{g}_{\mathrm{sm}}$ im Jahresverlauf ist von einer guten Wasserversorgung auch im Sommer auszugehen, daher fehlt Trockenstress in dieser Vegetationsperiode.

\subsubsection{Jahrringanalyse bei 20-jährigen Stieleichen 2001}

Die Ergebnisse der Jahrringanalyse 2001 sind in Tab. 3.6 dargestellt und umfassen den Zeitraum 1998 bis 2001. In den Frühholzbreiten unterscheiden sich die Varianten in den einzelnen Untersuchungsjahren nicht. Der Effekt der Entlaubung ist uneinheitlich. Bereits vor Entlaubung sind die Spätholzbreiten bei den späteren De1-Bäumen leicht (1998) bzw. stark (1999) reduziert, ohne dass Entlaubung als Faktor wirksam war. Jedoch führt Entlaubung im Jahr 2000 zu den geringsten Spätholzbreiten sowohl im Vergleich der Jahre als auch im Vergleich zwischen den Varianten. Bei den De2-Bäumen sind zumindest 1999 (erstmalige Entlaubung) sowie 2000 (zweimalige Entlaubung) im Trend verringerte Spätholzbreiten zu finden, während sich diese 1998 (keine Entlaubung) noch nicht von den Kontrollen unterscheiden. Im Jahr 2001, nach Ende der Entlaubung, sind die Spätholzbreiten bei beiden entlaubten Varianten (zumindest im Trend) immer noch gegenüber der Kontrolle verringert.

\subsubsection{Spezifische Blattfläche und Blattinhaltsstoffe 2001}

Die Ergebnisse der Analyse der Blattinhaltstoffe 2001 sowie die spezifische Blattfläche sind in Abbildung 3.32 dargestellt. Die Stickstoffkonzentration in den Blättern des zweiten Blattaustriebes ist bei beiden entlaubten Varianten (De1 und De2) am Ende der Vegetationsperiode 2001 gegenüber der Kontrolle verringert. Das C/N-Verhältnis in den Blättern unterscheidet sich zwar nicht signifikant zwischen den Varianten, bei De2 ist aber zumindest ein leichter Trend zu einem höheren $\mathrm{C} / \mathrm{N}$-Verhältnis im Vergleich mit der Kontrolle sichtbar. Die $\delta^{13} \mathrm{C}$-Werte nehmen mit zunehmener Entlaubungsintensität ab. Im Vergleich mit den jungen Eichen liegen die $\delta^{13} \mathrm{C}$-Werte 2001 auf dem gleichen Niveau wie in den Jahren 1999 und 2000. Auch die spezifische Blattfläche (SLA) ist bei der Kontrolle am geringsten und nimmt mit der Anzahl der vorherigen Entlaubungen (De1 bzw. De2) zu. Nach zweimaliger Entlaubung (De2) ist die SLA gegenüber der Kontrolle signifikant höher. Die SLA ist im Vergleich mit den jungen Eichen um fast die Hälfte reduziert. Gegensatz zu den jungen Bäumen 2000 resultiert jedoch Entlaubung hier in einer Zunahme der SLA. 
Tab. 3.6: Frühholz-, Spätholz- und Gesamt-Jahrringbreite $(\mu \mathrm{m})$ verschiedener Behandlungsvarianten bei $Q$. robur im Freilandversuch 2001. Angegeben sind die Mittelwerte und Standardabweichungen. Signifikante Unterschiede zwischen den Varianten innerhalb eines Jahrringes sind mit Kleinbuchstaben gekennzeichnet. FH, Frühholz; SH, Spätholz. Varianten: C, Kontrolle; De1, einmalige Entlaubung 2000; De2, zweimalige Entlaubung 1999 und 2000.

\begin{tabular}{|c|c|c|c|}
\hline Variante & FH & SH & Gesamtbreite \\
\hline \multicolumn{4}{|l|}{2001} \\
\hline $\mathrm{C}$ & $72,0 \pm 20,8$ & $368,3 \pm 74,3$ & $440,3 \pm 84,6$ \\
\hline De1 & $51,8 \pm 27,7$ & $259,2 \pm 96,7$ & $311,0 \pm 115,2$ \\
\hline De2 & $86,8 \pm 42,5$ & $241,8 \pm 142,4$ & $328,6 \pm 137,8$ \\
\hline \multicolumn{4}{|l|}{2000} \\
\hline $\mathrm{C}$ & $105,3 \pm 33,1$ & $293,5 \pm 144,2 \mathrm{a}$ & $398,8 \pm 172,0 \mathrm{a}$ \\
\hline De1 & $97,0 \pm 22,5$ & $71,0 \pm 35,1 \quad b$ & $168,0 \pm 38,3 \quad b$ \\
\hline De2 & $98,4 \pm 16,1$ & $172,6 \pm 90,8 \quad a$ & $271,0 \pm 104,4 a$ \\
\hline \multicolumn{4}{|l|}{1999} \\
\hline $\mathrm{C}$ & $105,5 \pm 31,9$ & $358,5 \pm 58,1 \quad$ a & $464,0 \pm 69,8 \quad a$ \\
\hline De1 & $90,2 \pm 6,9$ & $205,8 \pm 64,5 \quad b$ & $296,0 \pm 66,0 \quad b$ \\
\hline De2 & $86,6 \pm 32,5$ & $278,2 \pm 30,2 \quad \mathrm{a}$ & $364,8 \pm 58,4 \quad a$ \\
\hline \multicolumn{4}{|l|}{1998} \\
\hline $\mathrm{C}$ & $110,8 \pm 23,5$ & $339,8 \pm 141,8$ & $450,5 \pm 158,8$ \\
\hline De1 & $79,3 \pm 24,5$ & $267,8 \pm 148,4$ & $347,2 \pm 164,9$ \\
\hline De2 & $94,2 \pm 24,1$ & $302,4 \pm 65,4$ & $396,6 \pm 65,0$ \\
\hline
\end{tabular}




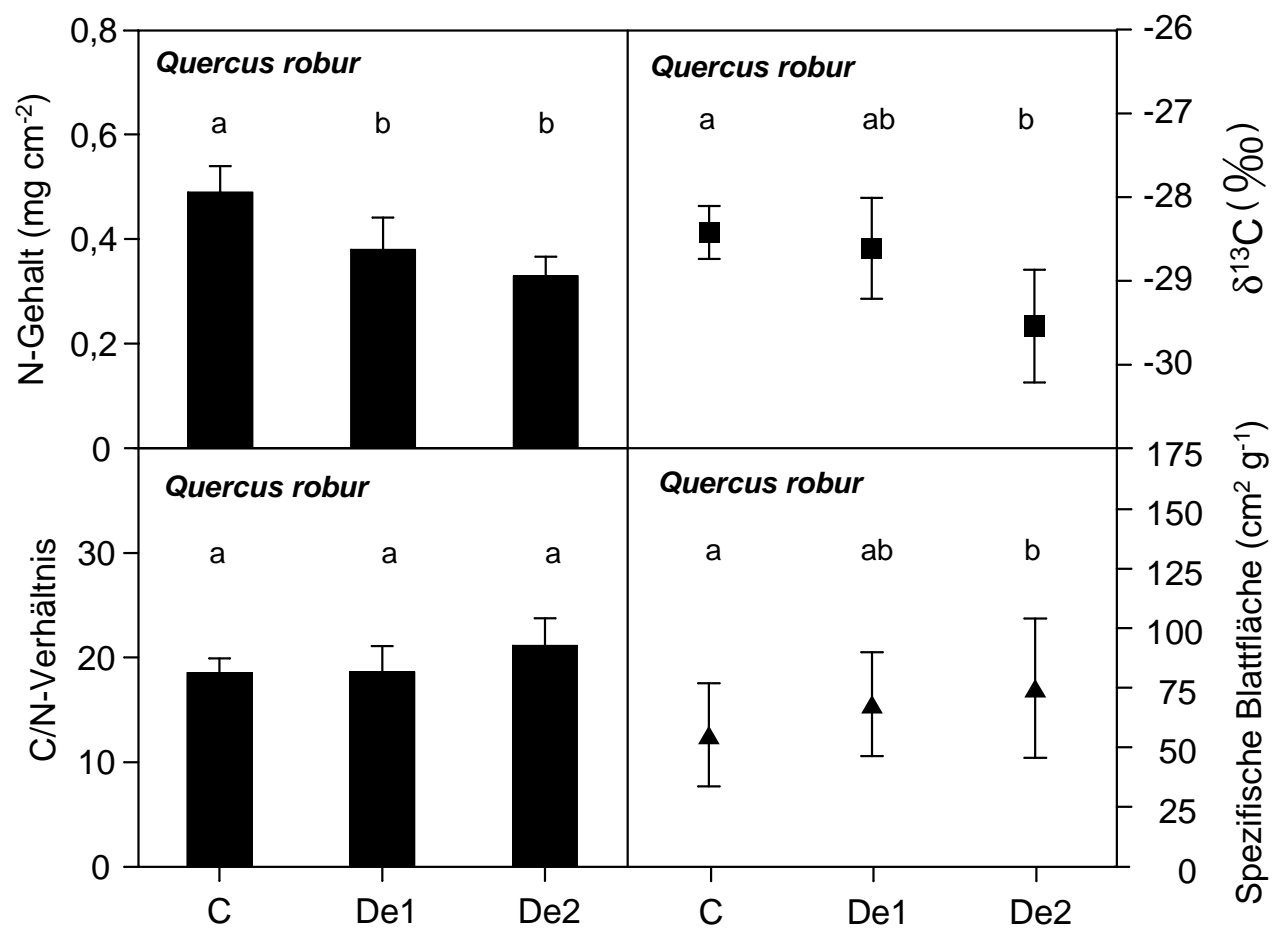

Abb. 3.32: Stickstoffgehalt, $\mathrm{C} / \mathrm{N}-$ Verhältnis und $\delta^{13} \mathrm{C}$-Verhältnis im Blatt sowie die spezifische Blattfläche bei verschiedenen Behandlungsvarianten bei $Q$. robur gegen Ende August 2001. Signifikante Unterschiede zwischen den Varianten sind mit Kleinbuchstaben gekennzeichnet. Varianten siehe Abb. 3.31.

\subsubsection{Feinwurzelbiomasse 2001}

Mit zunehmender Entfernung vom Stamm nimmt der Anteil der Feinwurzeln in den oberen $15 \mathrm{~cm}$ des Bodens bei allen Varianten am Ende der Vegetationsperiode 2001 leicht ab (Abb. 3.33). Eine Abnahme der Feinwurzelgehalte nach ein- oder zweimaliger vorhergehender Entlaubung wird nicht festgestellt. In $100 \mathrm{~cm}$ Entfernung vom Stamm sind nur die Feinwurzelgehalte bei den De1-Bäumen gegenüber der Kontrolle erhöht. Zweimalige Entlaubung führt in diesem Fall zu keinen Änderungen in den Feinwurzelgehalten im Vergleich mit der Kontrolle oder zu den De1-Bäumen. 


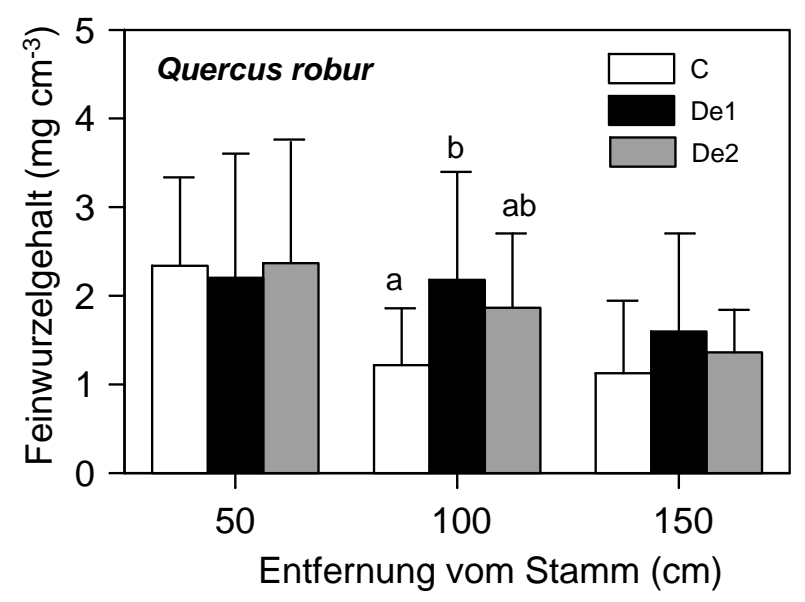

Abb. 3.33: Feinwurzelbiomasse bei verschiedenen Behandlungsvarianten bei Q. robur im Oktober 2001. Signifikante Unterschiede zwischen den Varianten sind mit Buchstaben gekennzeichnet. Varianten siehe Abb. 3.31.

\subsubsection{Stärkegehalt in Stammproben 2001}

Die Gesamt-Stärkegehalte im Stammholz der letzten drei Jahrringe (1999 bis 2001) weisen keine Unterschiede zwischen den Varianten auf. Die Anzahl der vorhergegangenen Entlaubungen hat somit keinen Einfluss auf den Stärkegehalt im Stamm. Auch im Vergleich mit den an jungen Eichen in den Jahren 1999 und 2000 gemessenen Stärkegehalten im Stammholz zeigen sich keine Unterschiede, die Stärkegehalte liegen in allen drei Untersuchungsperioden in einem ähnlichen Bereich.

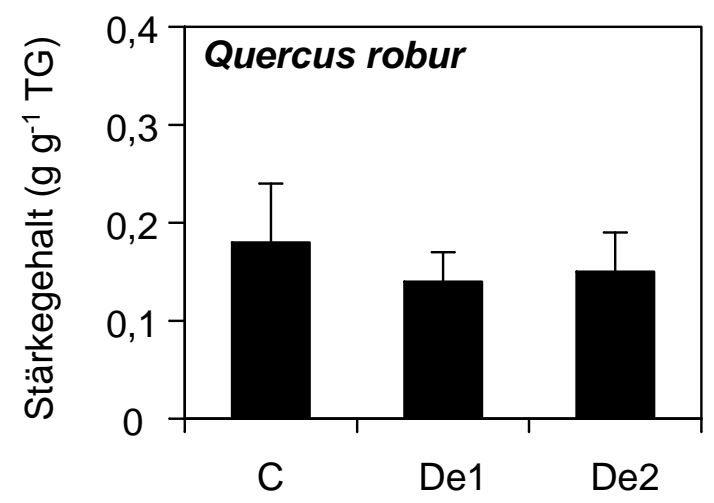

Abb. 3.34: Gesamt-Stärkegehalt der letzten drei Jahrringe am Ende der Vegetationsperiode 2001 bei verschiedenen Behandlungsvarianten bei $Q$. robur. Signifikante Unterschiede zwischen den Varianten sind mit Buchstaben gekennzeichnet. Varianten siehe Abb. 3.31. 


\section{Diskussion}

\subsection{Auswirkungen von Trockenheit und Entlaubung bei jungen Eichen in Abhängigkeit ihres zeitlichen Auftretens}

\subsubsection{Reaktion auf Trockenheit}

\section{Wasserpotentiale und hydraulische Leitfähigkeit bei Trockenstress}

Die bei den ausreichend wasserversorgten Varianten gemessenen minimalen PredawnWasserpotentiale $\Psi_{\mathrm{pd}}$ von im Mittel um -0,5 MPa (Abbildungen 3.1 und 3.15) stimmen mit den Ergebnissen bei ähnlichen Kultivierungsversuchen mit Sand als Substrat für beide Eichenarten überein (VIVIN et al. 1993; BRÉDA et al. 1995; VIVIN \& Guehl 1997; Thomas \& Gausling 2000). Das Blatt-Wasserpotential steht nach nächtlicher Wiederaufsättigung im Gleichgewicht mit dem Bodenwasserpotential. Unter Trockenstressbedingungen kommt es zu einer Absenkung des $\Psi_{\mathrm{pd}}$ (LÖSCH 2001). Unter mäßigem Trockenstress werden bei $Q$. robur und $Q$. petraea meist ein $\Psi_{\mathrm{pd}}$ von -0,8 MPa bis -1,1 MPa erreicht (BRÉDA et al. 1992; ARANDA et al. 2000; THOMAS \& GAusling 2000), während ein $\Psi_{\mathrm{pd}}$ um -2 MPa auf starken Trockenstress hindeutet (BRÉDA et al. 1992, 1995; FORT et al. 1997). Verglichen mit den genannten Werten kann für 1999 von einem moderaten Trockenstress (Q. robur: $-0,9 \mathrm{MPa}, Q$. petraea: -0,7 MPa), für 2000 (beide Arten bis -2,0 MPa) dagegen von einem starken Trockenstress ausgegangen werden (Abbildungen 3.1 und 3.15).

Während das Predawn-Potential den Zustand des Wasserhaushalts nach nächtlicher Wiederaufsättigung beschreibt (REICH \& HINCKLEY 1989), gibt das minimale Wasserpotential $\Psi_{\text {awp }}$ die aktuelle Belastung des Wasserhaushalts an. Um bei sinkender Bodenwasserverfügbarkeit einen ausreichenden Wasserpotentialgradienten vom Boden zum Blatt aufrechtzuerhalten, müssen die Wasserpotentiale in der Pflanze abgesenkt werden. Unter Trockenstressbedingungen erreichen spanische Altbäume der Traubeneiche minimal -2,6 MPa (ARANDA et al. 2000), bei THOMAs (2000) werden für junge Bäu- 
me der gleichen Art jedoch deutlich negativere Werte um -3,6 MPa angegeben. Dies entspricht den maximal gemessenen $\Psi_{\text {awp }}$ des Jahres 1999 (Abb. 3.1). Auch ein starker Trockenstress, wie er 2000 herrschte, führt zu keiner weiteren Absenkung der Wasserpotentiale unterhalb des Minimalwertes (Abb. 3.15). Die Eiche als Ringporer weist als spezifische Besonderheit eine Differenzierung des Holzes in weitlumige Frühholz- und englumige Spätholzgefäße auf. Damit ist die Eiche, vor allem aufgrund des größeren Gefäßdurchmessers des Frühholzes, deutlich empfindlicher gegenüber Cavitationen im Xylem (Vivin et al. 1993; Cochard et al. 1996). Da im Gegensatz zu Zerstreutporern Cavitation bei Eichen bereits bei vergleichsweise wenig negativen Wasserpotentialen auftritt, ist eine effektive stomatäre Regulation des Wasserverbrauchs nötig, um eine Embolisierung des Leitgewebes zu vermeiden (VIVIN et al. 1993; COCHARD et al. 1996).

Eine stomatäre Regulation kann über mehrere Pfade erfolgen (THOMAS et al. 1999a,b; LÖSCH 2001). Neben einer phytohormonalen Signalgebung von den Wurzeln aus oder einer Abhängigkeit vom VPD der Luft kann auch ein steigender Verlust an hydraulischer Leitfähigkeit das Schließen der Stomata induzieren (TYREE \& SPERRY 1989; Alder et al. 1996; NARDini \& SALLEO 2000). Die $\Psi_{\text {awp }}$ bleiben auch unter starken Trockenstressbedingungen im Jahr 2000 oberhalb des Schwellenwertes für Cavitation $\Psi_{\text {cav }}$, welcher für $Q$. robur mit -2,7 bis -3,0 MPa (TYREE \& COCHARD 1996; Higgs \& Wood 1995) und für $Q$. petraea mit -3,3 bis -3,6 MPa (COCHARd et al. 1992; TYREE \& COCHARD 1996) angegeben wird. Gleichzeitig werden auch verringerte $g_{s m}$-Werte (Abb. 3.3 und 3.17) gemessen, wie dies für Eichen unter Trockenstressbedingungen von BRÉDA et al. (1995) und THOMAS (2000) gezeigt wird. Ein Schließen der Stomata, d.h. eine Verringerung der $\mathrm{g}_{\mathrm{s}}$, schränkt die Wasserabgabe über die Blätter ein. Dies führt dazu, dass das Wasserpotential, welches zur Wasserversorgung des Blattes aufgewendet werden muß, weniger stark abgesenkt wird und $\Psi_{\text {cav }}$ nicht unterschritten wird. Dadurch kann eine starke bis vollständige Embolisierung des Xylems auch unter Trockenstress vermieden werden. Nach der Trockenperiode 1999 wird ein Verlust der hydraulischen Leitfähigkeit von $33 \%$ bei $Q$. robur und $46 \%$ bei $Q$. petraea gemessen (Tab. 3.2). Aber auch nach starkem Trockenstress 2000 kommt es zu höchstens 50\% Verlust an Leitfähigkeit in den Zweigen der trockengestressten Varianten Dr und DeDr (Tab. 4.1). Dies entspricht den von anderen Autoren gefundenen Ergebnissen bei Untersuchungen an $Q$. robur und $Q$. petraea. Bei vergleichbaren Wasserpotentialen wie in der vorliegenden Arbeit um -3,0 bis -3,5 MPa wird ein Verlust von 30 bis 50\% der hydraulischen Leitfähigkeit gemessen (COCHARD et al. 1992; HigGs \& WoOD 1995; TYREE \& COCHARD 1996). 
Tab. 4.1: Aktuelle und maximale hydraulische Leitfähigkeiten sowie der Verlust an Leitfähigkeit ( $\mathrm{LF}_{\mathrm{akt}}, \mathrm{LF}_{\max }$ und \% Verlust) diesjähriger Zweigabschnitte von $Q$. robur und Q. petraea, gemessen am Ende der Vegetationsperiode 2000. Mittelwerte und Standardfehler. Angabe der Leitfähigkeiten in $\mathrm{g} \mathrm{H}_{2} \mathrm{O} \mathrm{h}^{-1} \mathrm{kPa}^{-1}$. Signifikante Unterschiede zwischen den Varianten sind mit Kleinbuchstaben gekennzeichnet. C, Kontrolle; De, Entlaubung; Dr, Trockenstress; DeDr, Trockenstress und Entlaubung. aus: BARTELS (2001)

\begin{tabular}{|c|c|c|c|}
\hline Variante & $\mathbf{L F}_{\text {akt }}$ & $\mathbf{L F}_{\max }$ & $\%$ Verlust \\
\hline \multicolumn{4}{|l|}{ Q. robur } \\
\hline $\mathrm{C}$ & $0,07 \pm 0,02$ & $0,07 \pm 0,02$ & $15,6 \pm 3,7 \quad a$ \\
\hline De & $0,06 \pm 0,01$ & $0,07 \pm 0,01$ & $22,1 \pm 10,3 \mathrm{a}$ \\
\hline Dr & $0,03 \pm 0,01$ & $0,04 \pm 0,01$ & $34,6 \pm 6,5 b$ \\
\hline DeDr & $0,04 \pm 0,02$ & $0,06 \pm 0,01$ & $37,5 \pm 6,0 \quad b$ \\
\hline \multicolumn{4}{|c|}{ Q. petraea } \\
\hline $\mathrm{C}$ & $0,05 \pm 0,01 \mathrm{a}$ & $0,05 \pm 0,01 \mathrm{a}$ & $7,9 \pm 2,4 \quad a$ \\
\hline De & $0,05 \pm 0,01 \mathrm{a}$ & $0,05 \pm 0,01 \mathrm{a}$ & $10,8 \pm 2,3 \quad a$ \\
\hline Dr & $0,01 \pm 0,00 \mathrm{~b}$ & $0,02 \pm 0,00 \mathrm{~b}$ & $49,8 \pm 11,0 b$ \\
\hline DeDr & $0,02 \pm 0,01 \mathrm{~b}$ & $0,03 \pm 0,01 \mathrm{~b}$ & $41,2 \pm 10,2 b$ \\
\hline
\end{tabular}

\section{Stomatäre Leitfähigkeit und Transpiration bei Trockenstress}

Bei konstanter stomatärer Öffnungsweite steigt bei zunehmendem VPD die Wasserabgabe über die Transpiration aufgrund einer erhöhten Dampfdruckfdifferenz zwischen Blatt und Umgebungsluft (LÖSCH 2001). Diesem erhöhten Wasserbedarf kann einerseits durch ein Absenken des Wasserpotentials begegnet werden, wobei bei Eichen dies jedoch nur bis zur Cavitationsgrenze $\Psi_{\text {cav }}$ geschieht (TYREE \& COCHARD 1996). Alternativ kann eine Reduktion der Wasserabgabe über ein Schließen der Stomata erfolgen, wobei es zu Einschränkungen der Photosynthese kommt (LÖSCH 2001). Die stomatäre Öffnungsweite wird neben anderen Faktoren vor allem vom VPD der Umgebungsluft beeinflusst (MEINZER et al. 1997; THOMAS et al. 1999a,b; LÖSCH 2001). Allerdings weisen THOMAS \& EAMUS (1999) bei Eucalyptus tetrodonta darauf hin, dass eine erhöhte Sensitivität der $\mathrm{g}_{\mathrm{s}}$ gegenüber dem VPD erst bei $\Psi_{\mathrm{pd}}$ unterhalb -0,6 MPa ein- 
setzt. Als Reaktion auf Trockenstress wird von EPRON et al. (1992) und ARANDA et al. (2000) bei $Q$. petraea ein Schließen der Stomata bei steigendem VPD während des Tagesganges festgestellt. Bei EPRON et al. (1992) gehen zudem hohe $\mathrm{g}_{\mathrm{s}}$ einher mit hohen Photosyntheseraten in den Vormittagsstunden, während ab Mittag eine starke Abnahme der $\mathrm{g}_{\mathrm{s}}$ und der Photosyntheseraten stattfindet. TRiBoulot et al. (1996) finden bei Untersuchungen an 40-jährigen $Q$. robur und $Q$. petraea eine gute Korrelation zwischen der $\mathrm{g}_{\mathrm{sm}}$ und $\Psi_{\mathrm{pd}}$.

Diese Hinweise auf eine Vermeidung von Trockenstress finden sich auch in der vorliegenden Arbeit. Während der Trockenperioden 1999 und 2000 wird die maximale stomatäre Leitfähigkeit $\mathrm{g}_{\mathrm{sm}}$ bereits in den frühen Vormittagsstunden erreicht (Abb. 3.4 und 3.18). Ende August 1999, dem Zeitpunkt der minimalen $\Psi_{\mathrm{pd}}$, werden bei den trockengestressten Varianten (Dr und DeDr) von $Q$. robur und $Q$. petraea die maximale $\mathrm{g}_{\mathrm{s}}$ bereits am Vormittag gegen 9:00 Uhr bei niedrigen VPD-Werten gemessen. Bei steigendem VPD im Tagesverlauf sinkt die $\mathrm{g}_{\mathrm{s}}$, während die ausreichend wasserversorgten Bäume ( $\mathrm{C}$ und $\mathrm{De}$ ) erst mittags bei einem hohen VPD von 3,0 kPa eine Verringerung der stomatären Leitfähigkeit aufweisen. Auch unter starkem Trockenstress Anfang August 2000 werden die $\mathrm{g}_{\mathrm{sm}}$ der Dr- und DeDr-Varianten bereits am Vormittag gemessen, danach erfolgt mit zunehmendem VPD eine starke Reduktion der $\mathrm{g}_{\mathrm{s}}$ bis hin zu Stomataschluss. In beiden Jahren wird während der Trockenperiode bei beiden Arten eine Reduktion der Tagestranspirationssumme $\mathrm{E}_{\mathrm{d}}$ beobachtet (Abb. 3.5 und 3.19). In Trockenstressexperimenten mit einjährigen $Q$. robur (FORT et al. 1997) wird gezeigt, dass ein Absenken der $\Psi_{\mathrm{pd}}$ auf -1,9 MPa zu einer Reduktion der $\mathrm{g}_{\mathrm{sm}}$ von ca. $600 \mathrm{mmol} \mathrm{m}^{-2} \mathrm{~s}^{-1}$ auf unter $100 \mathrm{mmol} \mathrm{m}^{-2} \mathrm{~s}^{-1}$ führt, was in einer Reduktion der Transpirationssumme resultiert. Auch bei den hier untersuchten Eichen geht eine unter Trockenstressbedingungen beobachtete Abnahme der $\mathrm{E}_{\mathrm{d}}$ einher mit sinkenden $\mathrm{g}_{\mathrm{sm}}$ bei gleichzeitig absinkenden Wasserpotentialen.

Eine Öffnung der Stomata nur in den Vormittagsstunden bei niedrigen VPD dient der Vermeidung einer erhöhten Wasserabgabe, da die Transpiration aufgrund einer geringeren Dampfdruckdifferenz zwischen Blatt und Atmosphäre zu diesem Zeitpunkt geringer als in den heißen Mittagsstunden ist. Bereits am Vormittag werden an Strahlungstagen hohe Lichtintensitäten erreicht und ermöglichen eine hohe Photosyntheserate (vgl. EPRON et al. 1992). Da dieser Anpassungsmechanismus erst ab einem $\Psi_{\text {pd }}$ unterhalb -0,6 MPa, analog zu den Befunden von Thomas \& EAMus (1999), beobachtet wurde, kann von einer erhöhten Sensitivität der $g_{s}$ bei trockengestressten Eichen ausgegangen werden. Dieses Verhalten kann als trockenstressvermeidende Strategie (VIVIN et al. 1993) interpretiert werden. 


\section{Änderung der hydraulischen Leitfähigkeit auf der Fließstrecke Boden-Blatt bei Trockenstress}

Einschränkungen im Wasserhaushalt können neben der Messung der Transpirationssumme auch durch die berechnete Wasserleitungskapazität auf der Fließstrecke BodenBlatt $\left(\mathrm{g}_{\mathrm{sl}}\right)$ gezeigt werden, welche die Effizienz der Wasseraufnahme aus dem Boden und den Transport zu den Zweigen beschreibt (REICH \& HincKley 1989; BRÉDA et al. 1993). Die in der vorliegenden Untersuchung gefundenen $g_{s l} z w i s c h e n ~ 0,5$ und 2,0 mmol m $\mathrm{m}^{-2} \mathrm{~s}^{-1} \mathrm{MPa}^{-1}$ (Abb. 3.6 und 3.20) entsprechen den in der Literatur genannten Werten für junge Eichen (REICH \& Hinckley 1989; Simonin et al. 1994; ForT et al. 1997). COCHARD et al. 1996 weisen dagegen darauf hin, dass bei Q. petraea trotz sinkender $\mathrm{g}_{\mathrm{sl}}$ die $\Psi_{\text {awp }}$ konstant bleiben und der kritische Schwellenwert für Cavitation nicht unterschritten wird. SIMONIN et al. (1994) und FORT et al. (1997) stellen demgegenüber eine Abnahme der $\mathrm{g}_{\mathrm{sl}}$ aufgrund sinkender Wasserpotentiale fest. In der vorliegenden Arbeit sind die verringerten $\mathrm{g}_{\mathrm{sl}}$ bei beiden Arten 1999 neben einer verringerten Transpiration vor allem durch die gleichzeitig in stärkerem Maße abgesenkten

$\Psi_{\text {awp }}$ begründet. Bei starkem Trockenstress nimmt die $g_{\text {sl }}$ hauptsächlich aufgrund der stark verringerten Transpiration ab.

\section{Wassernutzungseffizienz und Photosynthese bei Trockenstress}

Unterschiede in der Zusammensetzung der ${ }^{12} \mathrm{C} /{ }^{13} \mathrm{C}$-Isotope $\left(\delta^{13} \mathrm{C}\right)$ in Blättern von $\mathrm{C}_{3^{-}}$ Pflanzen können als Maß für eine langfristige Wassernutzungseffizienz (WUE) angesehen werden (FARQUHAR et al. 1989; s.a. Kapitel 2.5.1). Als Reaktion auf Trockenheit kommt es zu einer Verringerung der $\mathrm{g}_{\mathrm{s}}$, welches in einem Sinken des $\mathrm{CO}_{2}$-Gehaltes im Blatt resultiert. Mit sinkendem $\mathrm{CO}_{2}$-Gehalt diskriminiert die RubisCo weniger stark gegenüber ${ }^{13} \mathrm{C}$. Dadurch wird dieses vermehrt im Gewebe eingebaut und die $\delta^{13} \mathrm{C}$-Werte werden positiver (cf. ZIEGLer 1995). Positivere $\delta^{13} \mathrm{C}$, d.h. eine Zunahme der WUE, gehen einher mit sinkenden $\mathrm{g}_{\mathrm{s}}$ (JONASSON et al. 1997), einer generell schlechteren Wasserversorgung (GARTEN \& TAYLOR JR. 1992) sowie sinkenden $\Psi_{\text {pd }}$ (PICON et al. 1997).

Im Gegensatz dazu unterscheiden sich die $\delta^{13} \mathrm{C}$-Werte der trockengestressten $Q$. robur und $Q$. petraea 1999 nicht von den ausreichend bewässerten Bäumen, obwohl ein Absinken der $\Psi_{\mathrm{pd}}$ und $\mathrm{g}_{\mathrm{s}}$ auf eine eingeschränkte Wasserversorgung hindeutet (Abb. 3.11). Erst nach starkem Trockenstress 2000 sind die $\delta^{13} \mathrm{C}$ bei den trockengestressten Bäumen von $Q$. petraea erhöht. Auch bei $Q$. robur ist zumindest ein gleichartiger 
Trend festzustellen (Abb. 3.25). Die Stärke des Trockenstresses kann entscheidend für eine Veränderung der $\delta^{13} \mathrm{C}$ sein. Thomas \& GAUSLing (2000) finden nach mäßigem Trockenstress bei $Q$. robur und $Q$. petraea ebenfalls keine Unterschiede im $\delta^{13} \mathrm{C}$, und auch bei Untersuchungen an nordamerikanischen Quercus-Arten (Q. rubra L. und $Q$. prinus L.) ändert sich das $\delta^{13} \mathrm{C}$ bei mäßigem Trockenstress nicht (TURnBUlL et al. 2001). CAVENDER-BARES \& BAZZAZ (2000) und DAMEsin et al. (1997) weisen darauf hin, das die $\delta^{13} \mathrm{C}$ die WUE hauptsächlich während der Zeit der Blattausbildung, d.h. einer Zeit ohne Trockenstress widerspiegeln. Somit kann ein erhöhter Anteil des unter nicht limitierten Bedingungen fixierten Kohlenstoffs im Gewebe das $\delta^{13} \mathrm{C}$-Verhältnis beeinflussen (PICON et al. 1996; XU et al. 2000).

Erst ein stärkerer Trockenstress im Jahr 2000 führt in der vorliegenden Untersuchung aufgrund der stärker negativen $\Psi_{\mathrm{pd}}$ und somit einer geringeren $\mathrm{g}_{\mathrm{s}} \mathrm{zu}$ einer prozentual stärkeren und länger dauernden Fixierung von ${ }^{13} \mathrm{C}$, so dass der Trockenheitseffekt trotz des Anteils des unter nicht limitierten Bedingungen eingebauten Kohlenstoffs sichtbar wird (vgl. Abb. 3.3, 3.17, 3.1 und 3.15).

In verschiedenen Arbeiten wird zudem auf die Abhängigkeit der $\delta^{13} \mathrm{C}$ mit der $\mathrm{g}_{\mathrm{s}}$ und der Photosynthese hingewiesen (ZHANG \& MARshal 1995; PiCON et al. 1996). Einschränkungen des Wasserhaushalts führen zu Reduktionen der Photosynthese aufgrund stomatärer Limitierung und zu einer erhöhten WUE (KUBISKE et al. 1996; PICON et al. 1997). Für das Jahr 2000 ist ein direkter Vergleich der langfristigen Wassernutzungseffizienz, d.h. $\delta^{13} \mathrm{C}$, und der aktuellen Wassernutzungseffizienz (WUE ${ }_{\mathrm{a}}$ ) möglich (Abb. 3.29). Diese berechnet sich aus dem Quotienten des Netto-Photosynthesevermögens und dem Wasserverbrauch durch die Transpiration und nimmt bei Trockenstress im Allgemeinen zu (FARQuHAR \& Richards 1984; PiCON et al. 1997). Trockenheit führt, wie zu erwarten war, zu einer Reduktion des Netto-Photosynthesevermögens $\left(\mathrm{A}_{\max }\right)$ aufgrund geringerer $\mathrm{g}_{\mathrm{s}}$ (vgl. Vivin et al. 1993; Dickson \& TOMLinson 1996; KUBiske et al. 1996; TURnBull et al. 2001), vor allem bei Q. petraea (Abb. 3.29). Aufgrund eingeschränkter stomatärer Öffnungsweiten kommt es zu einer vermehrten Fixierung von ${ }^{13} \mathrm{C}$ im Blattgewebe. Vergleichbar mit den Untersuchungen an jungen Q. robur (PICON et al. 1997) wird auch in der vorliegenden Untersuchung gleichzeitig mit den positiveren $\delta^{13} \mathrm{C}$-Werten eine Zunahme der $\mathrm{WUE}_{\mathrm{a}}$ bei den Dr-Varianten beider Arten beobachtet, d.h. pro fixiertem Kohlenstoff kommt es zu einem geringeren Wasserverbrauch. 


\section{Vergleich der Blattwassergehalte und Wasserpotentiale mit den Ergebnissen der P/V-Kurve}

Eine Abnahme der Wassergehalte im Blatt führt zu einer verringerten Photosynthesekapazität (KUBISKE et al. 1996), daher muss ein möglichst konstanter Wassergehalt über eine Regulation des Wasserpotentials aufrechterhalten werden. Unter Trockenstressbedingungen kann es jedoch zu einer Reduktion der relativen Blattwassergehalte $\left(\mathrm{RWC}_{\text {leaf }}\right)$ kommen. Untersuchungen an einjährigen $Q$. robur und $Q$. petraea (THOMAS \& GAUSLING 2000) zeigen, dass mit sinkendem $\Psi_{\mathrm{pd}}$, d.h. zunehmender Trockenheit, auch ein Absinken der $\mathrm{RWC}_{\text {leaf }}$ von ca. 90\% auf $86 \%$ einher geht, während die $\mathrm{g}_{\mathrm{sm}}$ im Vergleich mit den Kontrollen annähernd konstant bleiben. Für eine vergleichbare nordamerikanische Art (Q. rubra) werden 85,8\% bereits als letaler $\mathrm{RWC}_{\text {leaf }}$ bei Trockenheit angegeben (AUGÉ et al. 1998). Eine Reduktion der RWC leaf mit Absinken der $\Psi_{\text {awp }}$ zeigt sich 1999 vor allem bei den Dr- und DeDr-Varianten bei Q. petraea (Abb. 3.2). Gleichzeitig werden hier auch die geringsten $\mathrm{RWC}_{\text {leaf }} \mathrm{um} 80 \%$ gemessen. Verglichen mit den Angaben bei Thomas \& Gausling (2000) sind die $\mathrm{RWC}_{\text {leaf }}$ niedriger, allerdings werden dort auch nur $\Psi_{\text {awp }}$ bis -2,2 MPa gemessen. Bei Q. robur kann bei Trockenstress im Jahr 1999 ein Absinken des $\mathrm{RWC}_{\text {leaf }}$ durch Senken der $\Psi_{\text {awp }}$ größtenteils verhindert werden, nur bei der DeDr-Variante ist trotz sinkender $\Psi_{\text {awp }}$ eine Abnahme der RWC leaf, vergleichbar mit den Angaben bei THOMAS \& GAUSLING (2000), zu beobachten. Bei starkem Trockenstress 2000 ist weder ein Absenken

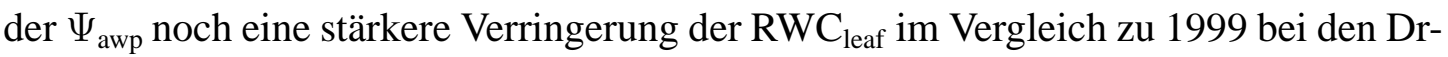
und DeDr-Bäumen zu beobachten (Abb. 3.16). Eine Erklärung hierfür findet sich in der stomatären Leitfähigkeit. Bereits in den frühen Vormittagsstunden kommt es zu einer Reduktion der $\mathrm{g}_{\mathrm{s}}$ bei den trockengestressten Bäumen. Zum Zeitpunkt der Messung der $\mathrm{RWC}_{\text {leaf }}$ und der $\Psi_{\text {awp }}$ sind die Stomata fast vollständig geschlossen. Aufgrund der zu diesem Zeitpunkt verringerten Transpiration werden relativ hohe $\mathrm{RWC}_{\text {leaf }}$ und dadurch nur eine geringe Absenkung der $\Psi_{\text {awp }}$ gemessen.

Bei einem Vergleich der aus der P/V-Kurve abgeleiteten $\mathrm{RWC}_{\mathrm{p}}$ und der gemessenen $\mathrm{RWC}_{\text {leaf }}$ in $\mathrm{Abb} .4 .1$ sinken die $\mathrm{RWC}_{\text {leaf }}$ nicht unter den Wert des Wassergehaltes am Turgornullpunkt. Auch ein Vergleich der gemessenen minimalen Wasserpotentiale $\left(\Psi_{\text {awp }}\right)$ mit $\Pi_{P}$, d.h. dem osmotischen Potential am Turgornullpunkt, lässt ein positiveres $\Psi_{\text {awp }}$ erkennen (Abb. 4.1). Auch unter starkem Trockenstress wird ein überhöhter Wasserverlust vermieden und kann als Hinweis auf eine Anpassung an Trockenstress interpretiert werden. 

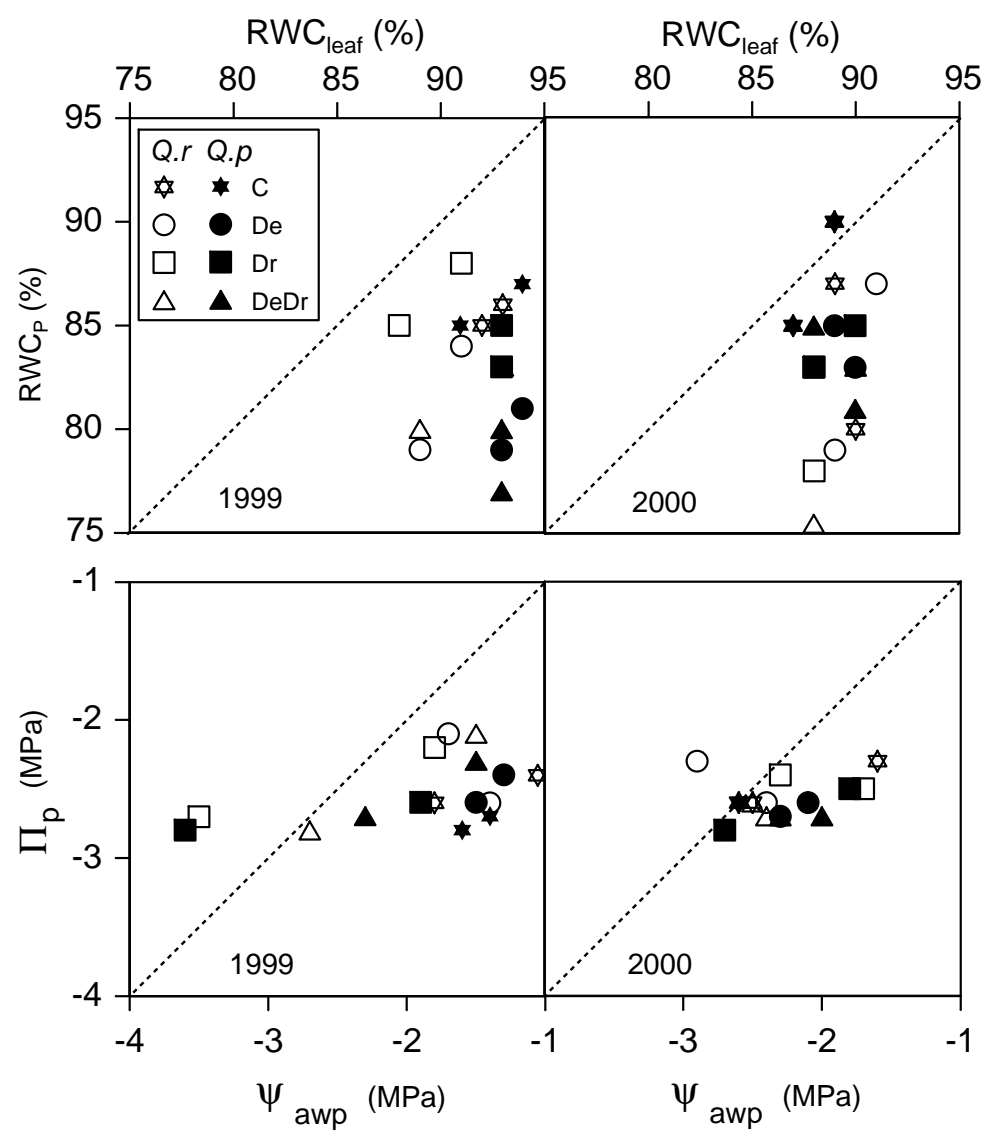

Abb. 4.1: Vergleich des aus der P/V-Kurve abgeleiteten Blattwassergehaltes am Turgornullpunkt $\left(R_{W} C_{p}\right)$ mit dem zeitnah gemessenen Blattwassergehalt $\left(R W_{C_{\text {leaf }}}\right)$ sowie des osmotischen Potentials am Turgornullpunkt $\left(\Pi_{\mathrm{P}}\right)$ mit dem zeitnah gemessenen nachmittäglichen Blattwasserpotential $\Psi_{\text {awp }}$ bei $Q$. robur und $Q$. petraea. Angegeben sind die Mittelwerte aus dem Zeitraum vor und nach der Trockenperiode der Jahre 1999 und 2000. Q. robur ist durch gefüllte Symbole, Q. petraea durch ungefüllte Symbole gekennzeichnet. C, Kontrolle; De, Entlaubung (1998 und 1999); Dr Trockenstress 1999 resp. 2000; DeDr, Kombination aus De und Dr.

\section{Hinweis auf ein osmotic adjustment als Anpassung an Trockenstress bei jungen Eichen?}

Eine weit verbreitete Anpassung an Trockenheit ist das Absenken der osmotischen Potentiale durch eine aktive Anreicherung von Osmotika (osmotic adjustment), um die Wasseraufnahme in die Zellen zu erleichtern (cf. LÖSCH 2001). Dies kann bei Eichen im Bereich um -0,5 MPa liegen (DREYER et al. 1990). Die Fähigkeit zu osmotic adjust- 
ment ist z.T. hochvariabel (LÖSCH 2001) und ist bei jungen Eichen abhängig von der Stärke des Trockenstresses sowie von der Schnelligkeit des Auftretens der Trockenheit. Junge $Q$. petraea zeigen nach starker Trockenheit kein osmotic adjustment (THOMAS 2000), bei mäßigem Trockenstress sind junge $Q$. robur und $Q$. petraea (THOMAS \& GAUSLING 2000) jedoch dazu in der Lage. Allerdings kann auch langsam einsetzende, starke Trockenheit bei jungen $Q$. petraea ein osmotic adjustment auslösen (COLLET \& GUEHL 1997). KLEINER et al. (1992) finden bei einer vergleichbaren nordamerikanischen Art (Quercus rubra) auch nach starkem Trockenstress mit einem $\Psi_{\mathrm{pd}}$ von -1,5 MPa keine Absenkung der osmotischen Potentiale.

Aufgrund des limitierten Pflanzenmaterials konnte kein Zeitverlauf der osmotischen Potentiale gemessen werden, wie dies für eine sichere Abschätzung des osmotic adjustments nötig wäre. Ein direkter Vergleich der osmotischen Potentiale zwischen den Varianten nach Trockenstress (Septemberwerte) zeigt 1999 keine Absenkung, wie dies bei einem osmotic adjustment zu erwarten gewesen wäre (Abb. 3.7). Die Berechung der Osmotikaveränderung nach NOITSAKIS \& TSIOUVARAS (1990) weist in beiden Jahren, mit Ausnahme der De-Bäume, zwar auf eine Zunahme der Osmotika hin, dies kann jedoch nicht als ein osmotic adjustment aufgrund von Trockenstress interpretiert werden, da sich die osmotischen Potentiale zwischen den Varianten nach Trockenstress nicht unterscheiden (Tab. 3.1). Im Jahresverlauf kann der Osmotikagehalt in der Zelle über Alterungserscheinungen zunehmen, ohne dass sich dies auf den Turgeszenzerhalt auswirkt (LÖSCH 2001).

Eine weitere Möglichkeit, die Wasseraufnahme zu erleichtern, kann über eine geänderte Gewebeelastizität $(\varepsilon)$ erfolgen. Unter Trockenstressbedingungen werden sowohl eine Zunahme wie auch eine Abnahme von $\varepsilon$ beobachtet (ABRAMS 1990; ELLSWORTH \& REICH 1992; ARANDA et al. 1996). Bei geringen $\varepsilon$ kann aufgrund der flexibleren Zellwände der Turgor bei Wasserverlust in den Blättern länger aufrechterhalten werden. Andererseits ermöglichen starre Zellwände einen höheren Wasserpotentialgradienten und damit eine erhöhte Wasserdurchleitung im Kontinuum Boden-Pflanze-Atmosphäre (cf. LÖSCH 2001). In der vorliegenden Untersuchung wird kein Unterschied bei $\varepsilon$ festgestellt. Dies kann in der geringen Stichprobenanzahl begründet sein, da dieser Parameter sehr variabel ist (Abb. 3.7 und 3.21). THOMAs (2000) weist zudem in diesem Zusammenhang darauf hin, dass das Elastizitätsmodul im Bereich der Wassersättigung gemessen wird und daher eine ökologische Interpretation bei Trockenheit eingeschränkt sein kann. 


\section{Änderung der Blattbiomasse und Blattfläche bei Trockenstress}

Neben physiologischen Anpassungen an Trockenheit kommt es auch zu einer Veränderung der Gesamtbiomasse und der Biomassenanteile zwischen den Kompartimenten Blatt, Spross und Wurzel (FORT et al. 1997). Eine trockenheitsbedingte verringerte Kohlenstoff-Fixierung kann zu einer Reduktion des Sprosszuwachses führen, wie dies vereinzelt für $Q$. robur und $Q$. petraea nachgewiesen wird (PICON et al. 1997; VIVIN \& GUEHL 1997). Im Gegensatz dazu ist in der vorliegenden Untersuchung weder bei dem Zuwachs an der Stammbasis noch in dem Höhenzuwachs eine Veränderung aufgrund von Trockenheit in beiden Jahren zu beobachten. Dies steht in Übereinstimmung mit den an den Zweigen gemessenen Früh- und Spätholzbreiten, welche ebenfalls keinen Einfluss von Trockenstress zeigen (vgl. Tab. 3.3 und BARTELS 2001).

In verschiedenen Untersuchungen zeigen junge $Q$. robur und $Q$. petraea nach Trockenheit eine Verringerung der Blattbiomasse (VIVIN \& GueHL 1997; ThOMAS 2000; Thomas \& GAUsLing 2000). Mögliche Erklärungen sind eine reduzierte Blattgröße (Thomas 2000) oder eine verringerte Blattanzahl (VIVIN \& GUEHL 1997). Eichen treiben nicht kontinuierlich über die Vegetationsperiode aus, sondern sind Arten mit distinkten Austriebs- und Ruhephasen (DICKSON \& TOMLINSON 1996). Ein kritischer Punkt ist der Zeitpunkt der Blattentwicklung, da die Gesamt-Blattfläche sich auf die kumulative Kohlenstoff-Fixierung auswirkt. Im Gegensatz zu Baumarten wie die Birke, die bei Trockenstress generell kleinere Blätter ausbildet (ASPELMEIER 2002), verzichten Eichen teilweise komplett auf einen Austrieb unter limitierenden Bedingungen (LAVARENNE-ALLARY 1965). Zusätzlich kann ein verringerter Turgor während der Blattausbildung zu einer verrringerten Blattgröße führen (DiCKSON \& TOMLINSON 1996; THOMAS 2000). Zweigabsprünge und eine daraus resultierende Reduktion der transpirierenden Oberfläche, wie sie bei Trockenheit bei ausgewachsenen Bäumen der Gattung Quercus bekannt sind, treten bei jungen Eichen nicht auf (HUBER 1955).

In der vorliegenden Untersuchungen ist bei $Q$. robur in beiden Jahren keine Reduktion der Gesamt-Blattfläche nach Trockenstress festzustellen (Abb. 3.8 und 3.22). VIVIN \& GUEHL (1997) und FORT et al. (1997) weisen zwar eine Reduktion der Blattfläche bei $Q$. robur nach Trockenheit nach, jedoch wird das durch die reduzierten Blattflächen des dritten bzw. vierten Blattaustriebes im Sommer erklärt. Im Gegensatz dazu wird in der vorliegenden Arbeit die Hauptmasse der Blattfläche durch den ersten und zweiten Blattaustrieb bedingt, so dass der Anteil des dritten Austriebes an der Gesamtfläche gering ist und ein vierter Austrieb fehlt. Bei $Q$. petraea ist die Blattfläche der 
trockengestressten Bäume (Dr) gegenüber der Kontrolle leicht, wenn auch nicht signifikant, verringert. PICON et al. (1997) finden analog eine starke Reduktion der Blattfläche nach Trockenheit bei dieser Art. Trockenheit führt bei $Q$. petraea 1999 - neben einer leichten Reduktion der Blattfläche - auch zu einer verminderten Blattbiomasse, während die spezifische Blattfläche konstant bleibt. Aufgrund des limitierten Blattmaterials erfolgte keine kontinuierliche Messung der Blattfläche und Blattbiomasse während des Sommers. Daher ist eine Interpretation schwierig, da dieser Effekt der reduzierten Blattfläche und -biomasse nur nach mäßigem Trockenstress 1999 auftritt, und nicht wie zu erwarten wäre, nach starker Trockenheit 2000. Eine mögliche Erklärung kann der unterschiedliche klimatische Verlauf des Frühsommers 1999 und 2000 geben. Die Monate Juni und Juli des Jahres 1999 sind durch heiße Sommertage gekennzeichnet, während im Jahr 2000 in dieser Zeit eine relativ kalte Witterung vorherrscht (vgl. Abb. 2.1). Dies legt die Möglichkeit nahe, dass der zweite Blattaustrieb von Q. petraea 1999 daher aufgrund der zu diesem Zeitpunkt herrschenden heißen Sommertage negativ beeinflusst wurde. Zudem trieb $Q$. robur in beiden Jahren bereits etwa zehn Tage früher aus als $Q$. petraea.

\section{Feinwurzelreaktion bei Trockenstress}

Eine Erhöhung der Feinwurzelbiomasse und damit bessere Ausnutzung des vorhandenen Bodenwassers stellt eine Anpassung an Trockenheit dar (vgl. auch KLEINER et al. 1992) und wird sowohl bei $Q$. robur (OsONUBI \& DAVIES 1981; VAN HEES 1997 ) als auch bei $Q$. petraea (THOMAs 2000) nachgewiesen. In beiden Jahren ist ein leichter Trend zu einer Erhöhung der Feinwurzelbiomassen bei den trockengestressten Bäumen zu beobachten, wie dies auch bei jungen Eichen in der Untersuchung von GAUsLing (1999) der Fall ist (Abb. 3.9 und 3.23). Neben einer direkten Zunahme der Feinwurzelbiomasse kann sich auch eine Reduktion der Blatt/Feinwurzelverhältnisse positiv auf die Wasserversorgung des Baumes unter Trockenstressbedingungen auswirken und in diesem Sinne als eine Anpassung an Trockenheit interpretiert werden. Bei den hier untersuchten Eichen tritt eine Verringerung des Blatt/Feinwurzelverhältnisses nur bei mäßigem Stress 1999 auf. Bei Q. robur geschieht dies durch eine Erhöhung der Feinwurzelbiomasse, vergleichbar mit den Ergebnissen von VAN HEES (1997). Bei Q . petraea resultiert eine reduzierte Blattbiomasse in einer Reduktion des Blatt/Feinwurzelverhältnisses, was mit den Befunden von FORT et al. (1997) und THOMAS \& GAUSLing (2000) übereinstimmt. Dementsprechend wird bei dieser Art 1999 
keine Zunahme der Feinwurzelbiomasse beobachtet. Eine bei den trockengestressten Bäumen verringerte Blattbiomasse bei gleichzeitig stärkerer Erhöhung der Feinwurzelmassen führt bei $Q$. petraea nach starkem Trockenstress zu einer Reduktion des Blatt/Feinwurzelverhältnisses (Thomas 2000). Im Gegensatz dazu findet bei den hier untersuchten Eichen nach starkem Trockenstress 2000 keine Änderung der Blatt/Feinwurzelverhältnisse im Vergleich mit den Kontrollen statt, obwohl ein Trend zu erhöhten Feinwurzelmassen sichtbar ist (Abb. 3.23). Eine Limitierung des Wurzelraumes durch die Pflanzgefäße kann nicht mit Sicherheit ausgeschlossen werden, da die Wurzeln aller Varianten auch die unteren Substratschichten ausfüllten. Eine vermehrte Bildung von Feinwurzeln zur Erschließung neuer Wasserressourcen kann daher für die trockengestressten Varianten keinen Vorteil mehr bringen.

\subsubsection{Reaktion auf Entlaubung}

\section{Kompensationsreaktion nach Entlaubung}

Pflanzen reagieren nach Entlaubung oft mit einer zumindest zeitweiligen Erhöhung der Photosyntheserate, um den Verlust an Biomasse (hier vor allem von Stickstoff und Kohlenhydraten) zu kompensieren. Dies wird sowohl bei den verbliebenen Blättern nach Entlaubung wie auch bei den Blättern nach Wiederaustrieb beobachtet (HEICHEL \& Turner 1983; LovetT \& Tobiessen 1993; Reich et al. 1993; Ellsworth et al. 1994; KolB et al. 1999). Dabei muss allerdings in Betracht gezogen werden, dass der Effekt der Entlaubung artspezifisch ist und von dem Zeitpunkt und der Intensität der Entlaubung, der Art der Entlaubung (Entfernen kompletter Blätter oder nur Blattverletzungen) sowie dem Pflanzenalter abhängt (vgl. z.B. REICH et al. 1993; ELLSWORTH et al. 1994; CoLlin et al. 2000). Im Gegensatz dazu ist bei Q. rubra (MCGRAW et al. 1990) keine erhöhte Photosyntheserate nach Entlaubung, sondern erst in Kombination mit Trockenheit festzustellen. HeICHEL \& TURNER (1983) weisen darauf hin, dass eine erhöhte $\mathrm{CO}_{2}$-Assimilation nur bei einer nicht vollständig wiederhergestellten Blattfläche nach Wiederbelaubung bei Acer rubrum L. gefunden wird, während bei Quercus rubra eine vollständig wiederhergestellte Blattfläche zu keiner erhöhten Assimilationsrate führt. Somit können zwei Reaktionsweisen nach Entlaubung unterschieden werden: Bei einer kompletten Wiederherstellung der ursprünglichen Gesamt-Blattfläche führt dies zu keinen Änderungen der Photosyntheserate bei den Blättern des zweiten Blattaustriebes. Bei einer nur unvollständig wiederhergestellten Gesamt-Blattfläche sind die nach Wiederbelaubung gebildeten Blätter photosynthetisch aktiver. 
Messungen des Photosynthesevermögens $A_{\max }$ konnten nur im Jahr 2000, d.h. ein Jahr nach Entlaubung, durchgeführt werden (Abb. 3.29). Allerdings korreliert die stomatäre Leitfähigkeit $g_{s}$ gut mit der Netto-Photosyntheserate (JARVIS \& DAVIES 1998) und der $\mathrm{CO}_{2}$-Assimilation (Heichel \& Turner 1983). Somit kann zumindest eine Abschätzung der $A_{\max }$ über die gemessene $g_{s}$ erfolgen. Eine Verdopplung der maximalen $\mathrm{g}_{\mathrm{s}}$ nach Entlaubung, wie sie 1999 beobachtet wird, kann als Hinweis auf eine verstärkte Photosyntheserate der Blätter des zweiten Blattaustriebes im Sinne der oben genannten Kompensationsreaktion interpretiert werden (Abb. 3.3). HEICHEL \& TURNER (1983) finden analog dazu, dass sowohl die $\mathrm{g}_{\mathrm{s}}$ als auch die $\mathrm{CO}_{2}$-Assimilationsrate bei Acer rubrum nach Entlaubung um 50\% erhöht ist.

Die nach Wiederbelaubung gebildeten Blätter weisen eine geringere SLA auf, d.h. es werden kleinere und dickere Blätter gebildet, während die Gesamt-Blattfläche reduziert ist (Abb. 3.12). Gleichzeitig sind (bezogen auf die Blattfläche) bei diesen Blättern die Chlorophyll- und Stickstoffgehalte (N-Gehalte) erhöht (Abb. 3.8). Dies lässt auf eine erhöhte Bildung assimilatorisch wirksamen Gewebes in den Blättern nach Wiederbelaubung schließen, da $\mathrm{N}$ unter anderem Hauptbestandteil des Chlorophylls ist. Eine Zunahme des Chlorophyllgehaltes im Blatt bedingt eine erhöhte Photosynthesekapazität (KuBis KE et al. 1996).

Eine Änderung der Blattmorphologie, d.h. eine Abnahme der spezifischen Blattfläche (SLA), wird oft als Anpassung an Trockenstress interpretiert (ABRAMS 1994; ABrams \& Mostoller 1995; Thomas 2000). Im Verhältnis zu transpirierender Oberfläche steigt hier die Wassernutzungseffizienz, es wird mehr Kohlenstoff pro Einheit $\mathrm{H}_{2} \mathrm{O}$ fixiert (KoZlowsKi et al. 1991). Nicht nur als Anpassung an Trockenstress, sondern auch als Reaktion nach Entlaubung kann sich dies positiv auf den Wasser- und Kohlenstoffhaushalt auswirken. Eine Erhöhung der Photosyntheserate der verbliebenen und der nach Entlaubung neugebildeten Blätter bedingt eine höhere $\mathrm{g}_{\mathrm{s}}$ und dadurch einen höheren Wasserverbrauch auf Basis der Blattfläche (vgl. auch BALDOCCHI et al. 1987; Weber \& GATes 1990; Ellsworth et al. 1994; HART et al. 2000). Nach Entlaubung kommt es in der vorliegenden Arbeit zu einer erhöhten $\mathrm{g}_{\mathrm{s}}$ bei den neugebildeten Blättern bei beiden Arten. Nicht nur als absolutes Maximum, sondern auch im Tagesgang sind die $\mathrm{g}_{\mathrm{s}}$ der entlaubten Bäume bis fast um das Zweifache gegenüber der Kontrolle erhöht (Abb. 3.4). Dies resultiert, vor allem bei $Q$. robur, in einer erhöhten Tagestranspirationssumme, d.h. einem erhöhten Wasserverbrauch pro $\mathrm{m}^{2}$ Blattfläche (Abb. 3.5). Gleichzeitig unterscheiden sich weder die $\Psi_{\text {pd }}$ noch die $\Psi_{\text {awp }}$ von denen der nicht entlaubten Bäume, im Gegensatz zu den Ergebnissen von KolB et al. (1999). 
Tab. 4.2: Vergleich der blattflächen- und pflanzenbezogenen Tagestranspirationssumme $E_{d}$ von $Q$. robur und $Q$. petraea gegen Ende der Vegetationsperiode 1999. Angegeben sind die Mittelwerte für $\mathrm{E}_{\mathrm{d}}$ blattflächenbezogen $\left(\mathrm{mmol} \mathrm{H}_{2} \mathrm{O} \mathrm{d}^{-1} \mathrm{~m}^{-2}\right)$ und $E_{d}$ pflanzenbezogen (mmol $\mathrm{H}_{2} \mathrm{O} \mathrm{d}^{-1}$ Pflanze $^{-1}$ ) und die Standardabweichungen. $\mathrm{C}$, Kontrolle; De, Entlaubung (1998 und 1999); Dr, Trockenstress 1999; DeDr, Kombination aus De und Dr.

\begin{tabular}{lrl}
\hline Variante & $\mathbf{E}_{\mathbf{d}}$ blattflächenbezogen & $\mathbf{E}_{\mathbf{d}}$ pflanzenbezogen \\
\hline & & \\
$Q$. robur & & \\
C & $28,8 \pm 12,0 \mathrm{a}$ & $7,0 \pm 1,9 \mathrm{a}$ \\
De & $41,3 \pm 3,7 \quad \mathrm{~b}$ & $4,9 \pm 1,8 \mathrm{ab}$ \\
Dr & $11,7 \pm 6,9 \quad \mathrm{c}$ & $2,5 \pm 0,8 \mathrm{~b}$ \\
DeDr & $24,5 \pm 8,8$ ad & $2,3 \pm 0,6 \mathrm{~b}$ \\
& & \\
$Q$. petraea & & \\
C & $18,6 \pm 3,8 \mathrm{a}$ & $5,8 \pm 0,4 \mathrm{a}$ \\
De & $23,3 \pm 2,3 \mathrm{a}$ & $2,3 \pm 0,7 \mathrm{~b}$ \\
Dr & $9,6 \pm 3,8 \mathrm{~b}$ & $2,0 \pm 0,8 \mathrm{bc}$ \\
DeDr & $20,3 \pm 7,1 \mathrm{a}$ & $1,1 \pm 0,2 \mathrm{c}$ \\
& & \\
\hline
\end{tabular}

In der vorliegenden Arbeit ist die fehlende Reaktion der Wasserpotentiale in erster Linie auf die stark reduzierte Gesamt-Blattfläche der De-Bäume zurückzuführen. Eine Berechnung der Tagestranspirationssumme auf Basis des Verbrauchs pro Pflanze führt aufgrund der stark reduzierten Blattfläche zu keinem höheren Gesamtverbrauch im Vergleich mit den nicht entlaubten Bäumen, sondern teilweise sogar zu geringeren Werten (Tab. 4.2). Dadurch kommt es bei den entlaubten Bäumen zu keiner stärkeren Absenkung der Wasserpotentiale. Die $\Psi_{\text {awp }}$ unterschreiten nicht den Schwellenwert für Cavitation $\Psi_{\text {cav }}$, so dass es bei beiden Arten auch nicht zu einem signifikant erhöhten Verlust an hydraulischer Leitfähigkeit kommt. Durch eine effektive stomatäre Regulation und eine ausreichende Nachlieferung über das Wasserleitungssystem können auch die $\mathrm{RWC}_{\text {leaf }}$ konstant gehalten werden, eine erhöhte Photosyntheserate wird daher nicht auf Kosten der Blattwassergehalte erreicht (Abb. 3.2). Auffällig bleibt in diesem Zusammenhang der Tagesgang der $\mathrm{g}_{s}$. Ähnlich wie bei den trockengestressten Bäumen 
werden auch bei den entlaubten Bäumen die $\mathrm{g}_{\mathrm{sm}}$ bereits in den frühen Vormittagsstunden gemessen. Dadurch wird ein überproportionaler Wasserverlust aufgrund steigendem VPD im Tagesverlauf vermieden.

\section{Effekt der Entlaubung auf die Biomassenpartitionierung und das Wachstum}

Der Effekt von Entlaubung auf das Wachstum und auf die Biomassenverteilung bezüglicher der Kompartimente Blatt, Stamm und Wurzel ist noch nicht abschließend geklärt. Entlaubung kann zu positiven oder negativen Reaktionen des Wachstums führen (KRAUSE \& RAFFA 1996; COLlin et al. 2000), und ist abhängig vom Zeitpunkt, der Entlaubungsintensität und dem Alter der Bäume (HEICHEL \& TURnER 1983; LOVETT \& Tobiessen 1993; Reich et al. 1993; KolB et al. 1999; Collin et al. 2000). Zusätzlich muss zwischen kurzzeitigen Änderungen des Stamm/Wurzelverhältnisses (MCGRAW et al. 1990) im Jahr der Entlaubung und langfristigen Änderungen bis zu einem Jahr nach Entlaubung (REICH et al. 1993; KolB et al. 1999) unterschieden werden, wobei die Rate des Wachstums nach Entlaubung artspezifisch ist (KRAUSE \& RAFFA 1996). LovetT \& ToBiessen (1993) und CANHAM et al. (1999) finden bei Untersuchungen an Quercus rubra keine Änderungen der Wurzel- oder Sprossbiomasse nach Entlaubung. Entlaubung führt zumindest bei jungen $Q$. petraea und $Q$. rubra jedoch oberirdisch zu einer Reduktion der Blattfläche (CHAAR et al. 1997) und der Blattmasse (ChAAR et al. 1997; LOVETT \& TOBIESsEN 1993), jeweils gemessen nach Wiederbelaubung. Bei $Q$. robur ist die Feinwurzelbiomasse nach Entlaubung reduziert (BLOCK et al. 1995), und bei Populus ist die Anzahl der Feinwurzeln nach Entlaubung geringer (Kosola et al. 2001). Krause \& RAFFA (1996) finden bei Larix nach Entlaubung eine Reduktion der Baumhöhe, wobei der Stammdurchmesser konstant bleibt, während bei Pinus Entlaubung zu einem geringeren Stammdurchmesser führt und sich nicht auf die Baumhöhe auswirkt. Entlaubung resultiert bei Eichen in einem reduzierten Zuwachs (GRADWELL 1974; RUBTSOV 1996), und zwar aufgrund einer verringerten Spätholzbildung (BLANK 1997; BLANK \& RIEMER 1999).

Die Blattfläche wie auch die Blattbiomasse der entlaubten dreijährigen Eichen ist am Ende der Vegetationsperiode 1999 bei beiden Arten reduziert (Abb. 3.9), analog zu den Befunden von CHAAR et al. (1997) bei Q. petraea. Auch unterirdisch werden weniger Feinwurzeln gebildet (BLOCK et al. 1995), aufgrund der oberirdisch in ähnlichem Ausmaß erfolgten Reduktion der Blattbiomasse blieb das Blatt/Feinwurzelverhältnis im 
Vergleich mit den nicht entlaubten Varianten jedoch konstant. Entlaubung führt nur bei Q. robur zu einer Reduktion der Baumhöhe. Bei beiden Arten ist jedoch der Zuwachs gemessen an der Stammbasis im Vergleich zum Versuchsanfang im Frühjahr 1998 reduziert (Abb. 3.10). Auch MEYER (2001) findet bei Untersuchungen an 20-jährigen $Q$. robur einen geringeren relativen Zuwachs des Stammdurchmessers nach ein- bzw. zweimaliger Entlaubung. Der in der vorliegenden Arbeit nach Entlaubung verringerte Zuwachs an der Stammbasis geht bei $Q$. robur einher mit einer an den Zweigen gemessenen Abnahme der Spätholzbreite 1999 bei beiden entlaubten Varianten (De und DeDr) im Vergleich mit der Kontrolle. Bei Q. petraea findet vor allem eine Abnahme der Spätholzbreite bei beiden entlaubten Varianten im Vergleich zwischen den Jahren 1998 (einmalige Entlaubung) und 1999 (zweimalige Entlaubung) statt (Tab. 3.3). Diese Abnahme des Spätholzes nach Entlaubung steht in Übereinstimmung mit den Ergebnissen von RuBtsov (1996), BLANK (1997) und BLANK \& RIEMER (1999). Entlaubung als einzelner Faktor führt zwar zu einer Reduktion des Spätholzes, hat aber keine verringerten stomatären Leitfähigkeiten und keinen erhöhten Verlust an hydraulischer Leitfähigkeit in den Zweigen zur Folge (Tab. 3.2). Verringerte Stärkegehalte in Feinwurzeln, im Stamm und in den Zweigen führen bei Populus im Jahr der Entlaubung zu einem verringerten Zuwachs aufgrund einer reduzierten Kohlenstoff-Allokation hin zur Stärke (Kosola et al. 2001). Eine entlaubungsbedingte Reduktion der gespeicherten Kohlenhydrate (z.B. Stärke) hat negative Auswirkungen auf das Wachstum und die Überlebensrate der betroffenen Bäume (WARGO et al. 1972; PARKER \& PATTON 1975; WeBB 1981; WARGo 1996; CANHAM et al. 1999). In der vorliegenden Arbeit kommt es zu einem reduzierten Zuwachs, einer verringerten Feinwurzelbildung und einer geänderten Blattmorphologie, vor allem im Jahr der Entlaubung. Dies kann durch einen Assimilatverlust erklärt werden. Andererseits lässt sich kein signifikanter Einfluß der Entlaubung auf die gemessenen Stärkegehalte im Stamm nachweisen (Abb. 3.14, 3.28). Die Stärkegehalte sind einem zyklischen Jahresverlauf unterworfen und erreichen im Oktober ihr Maximum (Ashworth et al. 1993; SAUter \& VAN Cleve 1994; GANSERT \& SPRICK 1998). Die Messung der Stärkegehalte erfolgte nur im Stamm am Ende der Vegetationsperiode, daher können entlaubungsbedingte Änderungen im Stärkespeicher während der Vegetationsperiode durch den nach Wiederbelaubung einsetzenden Kompensationseffekt maskiert werden. Ein weiterer Grund kann in den artspezifischen Allokationsunterschieden nach Entlaubung liegen. Bei Q. rubra geht eine entlaubungsbedingte Reduktion der Kohlenhydratreserven einher mit einer erhöhten Bildung von Wurzelbiomasse, auf Kosten des Stammzuwachses (CANHAM et al. 1999). In der vorliegenden Arbeit findet bei beiden Arten sowohl eine ober- wie unterirdische Reduktion 
der Zuwächse statt. Dies lässt eine entlaubungsbedingte Reduktion der Stärkegehalte in den Wurzeln (WARGo et al. 1972; PARKeR \& PATTON 1975) am Ende der Vegetationsperiode 1999 zumindest möglich erscheinen.

\subsubsection{Kombination von Entlaubung und Trockenheit}

\section{Antagonistische Effekte von Entlaubung und Trockenstress auf den Wasserhaushalt und die Biomassenpartitionierung}

Experimentelle Untersuchungen der Kombinationswirkung von Entlaubung und Trockenstress sind bei Bäumen bislang nur vereinzelt durchgeführt worden (vgl. z.B. PARKer \& PATton 1975; Wright et al. 1989; Kolb et al. 1999). Wright et al. (1989) führen eine erhöhte Überlebensrate von jungen Q. rubra nach mindestens $50 \%$ Verlust der Blattfläche nach Entlaubung auf einen verringerten Wasserverbrauch bei Trockenheit aufgrund der reduzierten transpirierenden Oberfläche zurück. Laut der Hypothese in der vorliegenden Arbeit kann Entlaubung in Kombination mit Trockenheit stressverschärfend wirken, da es über eine entlaubungsbedingte Reduktion des Spätholzes zu einer verringerten Wassernachleitungsreserve kommt, was zu Trocknisschäden bei Eichen führen kann. Alternativ kann eine entlaubungsbedingte Feinwurzelreduktion die Wasseraufnahme erschweren. Dies kann vor allem im Jahr nach Entlaubung zu Beeinträchtigungen im Wasserhaushalt führen. Eine Veränderung der Biomassenpartitionierung hin zu einer vollständig wiederhergestellten Gesamt-Blattfläche auf Kosten der Feinwurzelbildung erhöht den assimilatorischen Kohlenstoffgewinn und kompensiert den durch Entlaubung verursachten Assimilatverlust, gleichzeitig steigt die Anfälligkeit gegenüber Trockenstress aufgrund einer reduzierten Feinwurzelbildung.

Eine Interaktion der Effekte von Trockenheit und Entlaubung ist in der vorliegenden Arbeit vor allem bei den stomatären Leitfähigkeiten 1999 sichtbar (Abb. 3.3 und 3.4). Unter Trockenstressbedingungen ist die $g_{s}$ der DeDr-Bäume gegenüber den DeBäumen leicht reduziert, sie übersteigt aber immer noch die $\mathrm{g}_{\mathrm{s}}$ der Dr-Bäume und zum Teil sogar die der Kontrollbäume. Dies resultiert in einer gegenüber den Dr-Bäumen fast doppelt so hohen Tagestranspirationssumme $\mathrm{E}_{\mathrm{d}}$ pro $\mathrm{m}^{2}$ Blattfläche (Abb. 3.5). Dieses Verhalten kann als antagonistischer Effekt der Faktoren Entlaubung und Trockenheit interpretiert werden. Als Reaktion auf Trockenheit sinkt die $\mathrm{g}_{\mathrm{s}}$, um die Wasserabgabe durch Transpiration einzuschränken. Gleichzeitig steigt über die entlaubungsbedingte erhöhte Photosyntheserate der Bedarf an $\mathrm{CO}_{2}$, das Resultat ist ein erhöhter Wasserverbrauch, bezogen auf die Blattfläche. Ein ähnliches Verhalten der $g_{s}$ ist auch von 
diesjährigen Douglasien-Nadeln (KoLB et al. 1999) bekannt. Eine Kombination von Entlaubung und Trockenstress führt zu einer geringeren Reduktion der $\mathrm{g}_{\mathrm{s}}$ als Trockenheit allein. Dieses antagonistische Verhalten kann sich bei Eichen kritisch auswirken. Um eine Embolisierung des Leitgewebes zu vermeiden, haben Eichen eine sehr effektive stomatäre Regulation des Wasserverbrauches entwickelt und halten die Wasserpotentiale immer knapp über dem kritschen Cavitationsschwellenwert $\Psi_{\text {cav }}$ (TYREE \& COCHARD 1996). Das antagonistische Verhalten der $g_{s}$ nach Entlaubung läuft diesem zuwider und kann diesen Regulationsmechanismus zur Cavitationsvermeidung beeinträchtigen. Ein weiterer Hinweis auf eine stressverschärfende Interaktion von Entlaubung und Trockenheit findet sich bei den Blattwassergehalten $\left(\mathrm{RWC}_{\text {leaf }}\right) 1999$ in der vorliegenden Arbeit (Abb. 3.2). Bei beiden Arten verringern sich die $\mathrm{RWC}_{\text {leaf }}$ bei den DeDr- im Vergleich mit den Dr-Bäumen, trotz eines Absenkens der Wasserpotentiale. Dies kann als Einschränkung in der Wassernachleitung interpretiert werden. Hohe $\mathrm{g}_{\mathrm{s}}$ führen zu einem erhöhten Wasserbedarf. Bei einer nur ungenügenden Nachlieferung, trotz eines Absenkens des Wasserpotentials, läßt sich ein Absinken des Blattwassergehaltes nicht vermeiden. Das Xylem in den Zweigen kann aufgrund der Segmentationstheorie nach ZIMMERMANN (1983) als "Flaschenhals" im Wassertransport unter Trockenstressbedingungen angesehen werden. Rückschlüsse auf mögliche Einschränkungen im Wasserhaushalt können daher vor allem durch Messungen der hydraulischen Leitfähigkeit und der Jahrringbreiten (vor allem der Spätholzbreiten) von Zweigen gezogen werden, da hier nach NARDINI \& PITT (1999) als erstes Embolisierungen auftreten. Bei $Q$. petraea führt zweimalige Entlaubung im Jahr 1999 zu einer verringerten aktuellen hydraulischen Leitfähigkeit in den diesjährigen Zweigen sowie einer zumindest im Trend erhöhten Embolisierung des Leitgewebes bei den DeDr-Bäumen (Tab. 3.2). Entlaubung resultiert in einer verringerten Spätholzbreite 1999 im Vergleich zum Vorjahr, und auch die berechnete hydraulische Leitfähigkeit auf der Fließstrecke BodenBlatt $g_{s 1}$ ist 1999 bei den DeDr-Bäumen bei Q. petraea am geringsten (Abb. 3.6). Eine aufgrund einer verringerten Spätholzbildung reduzierte Wassernachleitungskapazität kann bei den gleichzeitig niedrigen Wasserpotentialen als Grund für die erhöhte Embolisierungsrate bei den DeDr-Bäumen von $Q$. petraea gelten. Zumindest bei dieser Art kann im Sinne der Hypothese von einer verstärkten Beeinträchtigung des Wasserhaushaltes bei der Kombination beider Faktoren ausgegangen werden. Bei $Q$. robur war zwar das Spätholz 1999 bei den DeDr-Bäumen im Vergleich mit der Kontrolle verringert, dies hatte jedoch keine höheren Verluste an hydraulischer Leitfähigkeit und keine verringerte $g_{\text {sl }}$ zur Folge (siehe Kapitel 4.2). Andererseits waren auch bei der Stieleiche 
die $\mathrm{RWC}_{\text {leaf }}$ bei den DeDr-Bäumen trotz eines Absenkens der Wasserpotentiale stärker verringert als bei den nur trockengestressten Bäumen (Dr). Daher kann auch für Q. robur die Hypothese nicht mit Sicherheit verworfen werden.

Nicht nur bei der Wassernachleitung im Stamm, sondern bereits bei der Wasseraufnahme durch die Feinwurzeln interagieren die Reaktionen bei Trockenheit und nach Entlaubung. Bei Trockenstress reagieren Eichen mit einer erhöhten Feinwurzelbildung, um die Wasserversorgung zu sichern (OsONUBI \& DAVIES 1981; VAN HEES 1997; Thomas 2000). Demgegenüber wird nach Entlaubung die Feinwurzelproduktion zugunsten der assimilierenden Blattfläche eingeschränkt (BLOCK et al. 1995). Dieses antagonistische Verhalten der Entlaubungs- und Trockenstressreaktion bezüglich der Feinwurzeln kann sich negativ auf den Wasserhaushalt auswirken.

Entlaubung führt in der vorliegenden Arbeit zu einer verringerten Feinwurzelbiomasse, in gleichem Maße ist jedoch auch die Gesamt-Blattfläche reduziert. Daher unterscheiden sich die De-Bäume in den Blatt/Feinwurzelverhältnissen nicht von den Kontrollen. Bei einem zusätzlichen Trockenstress verhindert ein Assimilatmangel die Trockenstressantwort, d.h. eine vermehrte Feinwurzelproduktion. Zwar unterscheiden sich die Blatt/Feinwurzelverhältnisse zwischen den Dr- und DeDr-Bäumen nicht voneinander, ein gegenüber den nicht trockengestressten Varianten verringertes Blatt/Feinwurzelverhältnis wird bei Dr jedoch durch eine erhöhte Feinwurzelproduktion erreicht, während bei DeDr dies vor allem aufgrund der verringerten Blattbiomasse geschieht. Eine flächenbezogene stark erhöhte Transpiration bei den DeDr-Bäumen kann dann aufgrund einer verringerten Wasseraufnahmekapazität trotz eines Absinkens des Wasserpotentials zu sinkenden Blattwassergehalten bei den DeDr-Bäumen führen. Dies unterstützt die Alternativhypothese mit einem Wirkungspfad über die Feinwurzeln bei beiden Arten.

\subsection{Artunterschiede in der Reaktion auf Trockenstress und Entlaubung}

$Q$. petraea unterscheidet sich von $Q$. robur durch einen geringeren Wasserbedarf und gilt als die besser an Trockenheit angepasste Art (COCHARD et al. 1992; LÉVY et al. 1992; Vivin et al. 1993; Dickson \& TOMLinson 1996). Der Schwellenwert für Cavitation liegt bei $Q$. petraea mit -3,3 bis -3,6 MPa (COCHARD et al. 1992, 1996) zudem deutlich unter dem von $Q$. robur mit -2,7 MPa (TYREE \& COCHARD 1996). Gleichzeitig gilt $Q$. petraea im Vergleich mit $Q$. robur als die Art mit der effektiveren stoma- 
tären Regulation zur Vermeidung von Embolien (COCHARD et al. 1992, 1996). Unter Trockenstressbedingungen unterscheiden sich beide Arten auch in ihrer Produktivität. Während bei $Q$. robur das Sprosswachstum bereits bei einem Wasserpotential unterhalb -2,0 MPa eingestellt wird, ist dies bei $Q$. petraea auch noch bei -2,5 MPa zu finden (VIVIN et al. 1993).

Eichen sind generell gut an den Verlust von Blättern durch Insektenbefall angepasst (GRADWELL 1974). Ähnlich wie bei der Reaktion auf Trockenstress finden sich allerdings auch hier artspezifische Unterschiede. Nach S volBA \& KLEIn SCHMit (2000) ist $Q$. robur stärker nach Entlaubung geschädigt als $Q$. petraea. Allerdings waren in dieser Untersuchung die intraspezifischen Unterschiede zwischen den einzelnen Herkunftsorten größer als die interspezifischen. $Q$. petraea reagiert auch in der vorliegenden Arbeit empfindlicher auf Entlaubung (allein und in Kombination mit Trockenstress) als $Q$. robur. Einerseits gilt $Q$. petraea generell als die an Trockenstress besser angepasste Art im Vergleich mit $Q$. robur. Andererseits führt eine Kombination aus Entlaubung und Trockenstress bei Q. petraea 1999 zu stärkeren Beeinträchtigungen im Wasserhaushalt als bei $Q$. robur, obwohl der Trockenstress aufgrund der weniger negativen $\Psi_{\mathrm{pd}}$ im Vergleich zu $Q$. robur schwächer ist.

$Q$. robur gilt als die evolutiv jüngere und produktivere Art im Vergleich beider Arten (LÉvy et al. 1992; Vivin et al. 1993). Darauf weist neben den erhöhten $A_{\max }{ }^{-}$ Werten auch der erhöhte Zuwachs im Stamm im Vergleich zu Q. petraea hin. Bereits ein Jahr nach Entlaubung ist kein Unterschied mehr zwischen den Stammdurchmessern der entlaubten und nicht entlaubten Bäume zu sehen, während bei $Q$. petraea diese bei den entlaubten Bäumen noch reduziert sind. Somit ist $Q$. robur in der Lage, den entlaubungsbedingten Assimilatverlust schneller als $Q$. petraea zu kompensieren. Eine höhere Produktivität wird hier auf Kosten eines erhöhten Wasserverbrauchs erreicht. Da die Gefäßflächen bei dieser Art grundsätzlich kleiner sind als bei $Q$. petraea (BARTELS 2001) und dies nach TYREE \& COCHARD (1996) eine verringerte Cavitationsgefahr bedingt, resultiert eine verringerte stomatäre Einschränkung des Wasserverbrauchs bei Trockenheit aufgrund der antagonistischen Reaktion der $\mathrm{g}_{\mathrm{s}}$ nicht in einer erhöhten Cavitation des Leitgewebes.

Da $Q$. petraea im Vergleich mit $Q$. robur eine geringere Produktivität aufweist, ist der Assimilatverlust durch Entlaubung bei dieser Art schwerwiegender, da eine geringere Kompensationsreaktion des Biomassenverlustes stattfindet. Bei einem generellen Assimilatmangel kann eine Trockenstressantwort der Feinwurzeln bei den DeDr-Bäumen nicht oder nur unvollständig erfolgen. Gleichzeitig kommt es nach zweimaliger Ent- 
laubung zu einer Abnahme der Spätholzbreite. Trotz eines erhöhten Wasserbedarfs ist sowohl die Wasseraufnahme über die Feinwurzeln als auch die Wasserleitungskapazität des Xylems, hier vor allem des Spätholzes, eingeschränkt. Stressverschärfend wirkt nun die antagonistische Reaktion der $\mathrm{g}_{\mathrm{s}}$ bei Trockenstress und Entlaubung, welche die notwendige effektive stomatäre Kontrolle des Wasserpotentials beeinträchtigt. Eine verringerte stomatäre Kontrolle kann zu einer stärkeren Absenkung der Wasserpotentiale führen. Da Eichen auch unter normalen Bedingungen nahe der Cavitationsgrenze operieren, steigt die Gefahr einer Embolisierung des Leitgewebes. Eine verstärkte Embolisierung führt dann zu einem erhöhten Verlust an hydraulischer Leitfähigkeit.

Ist $Q$. petraea an sich gut an das Auftreten eines Stressors angepasst, so wirkt sich ein gleichzeitiges Auftreten beider Stressoren negativ auf den Wasserhaushalt bei dieser Art aus. Obwohl $Q$. robur empfindlicher auf Trockenstress reagiert, ist die Kombination mit zweimaliger Entlaubung bei mäßigem Trockenstress kaum stressverschärfend. Ein möglicher Grund kann in der höheren Produktivität liegen. Die Reduktion der Feinwurzeln ist weniger stark ausgeprägt als bei $Q$. petraea, was sich wiederum positiv auf den Wasserhaushalt ausübt. Artspezifische Unterschiede in den Gefäßgrößen (BARTELS 2001) und in der physiologischen Reaktion auf Trockenstress und Entlaubung können demnach als Grund für die unterschiedliche Sensitivität des Wasserhaushalts bei beiden Arten gelten.

\subsection{Vergleich der Ergebnisse von jungen mit 20-jährigen Stieleichen}

\subsubsection{Unterschiede zwischen jungen und 20-jährigen Bäumen im Jahr nach letztmaliger Entlaubung}

Im Folgenden sollen kurz die Ergebnisse der Freilanduntersuchungen an den 20jährigen $Q$. robur im Sommer 2001 im Vergleich mit den jungen Eichen diskutiert werden. Die Variante De2 des Freilandversuches 2001 entspricht dabei der Variante De des Versuchs mit den jungen Bäumen im Untersuchungsjahr 2000. Aufgrund des Fehlens von Trockenstress im Freilandversuch 2001 kann nur die Reaktion im Jahr nach letztmaliger Entlaubung zwischen den 20-jährigen und den jungen Bäumen verglichen werden.

Auch bei den 20-jährigen Eichen sind ein Jahr nach Ende der letzten Entlaubung keine Unterschiede mehr in den maximalen stomatären Leitfähigkeiten $\left(\mathrm{g}_{\mathrm{sm}}\right)$ und den Wasserpotentialen zwischen den Varianten zu sehen (Abb. 3.31). Dies entspricht den 
Ergebnissen des Versuches mit den jungen Eichen 2000. Obwohl sich die $\mathrm{g}_{\mathrm{sm}}$ bei den im Freiland gemessenen Bäumen zwischen den beiden entlaubten Varianten und der Kontrolle nicht unterscheiden, sind die Kohlenstoff-Isotopenverhältnisse $\left(\delta^{13} \mathrm{C}\right)$ bei beiden entlaubten Varianten jedoch verringert (Abb. 3.32). Dies deutet auf eine verringerte Wassernutzungseffizienz hin. Da der $\delta^{13} \mathrm{C}$-Wert ein Maß für die langfristige Wassernutzungseffizienz (ZHANG \& MARSHAL 1995) ist und über das Jahr integriert, können schon kleine Unterschiede in der stomatären Öffnungsweite Änderungen von $\delta^{13} \mathrm{C}$ hervorrufen. Im Gegensatz zu den Versuchen mit jungen Eichen ist die spezifische Blattfläche (SLA) bei den Blättern der 20-jährigen Bäumen im Jahr nach letztmaliger Entlaubung erhöht. Bei gleicher Fläche sind die Blätter der De1- und De2-Bäume leichter. Dies kann durch einen verringerten N-Gehalt pro Fläche erklärt werden (Abb. 3.32).

Bei den jungen Eichen sind die Feinwurzelmassen auch ein Jahr nach letztmaliger Entlaubung zumindest im Trend reduziert. Im Gegensatz dazu werden bei den 20jährigen Bäumen keine Unterschiede in den Feinwurzelgehalten im Boden beobachtet (Abb. 3.33). Aus dem Jahr 2000 liegen für die Freilandbäume keine Ergebnisse für die Feinwurzelgehalte vor.

Entlaubung führt auch im Freilandversuch zu einer Reduktion der Spätholzbreiten (Tab. 3.6). Ein Jahr nach letztmaliger Entlaubung sind die Spätholzbreiten bei den De1- als auch bei den De2-Bäumen (zumindest im Trend) noch reduziert. Dies ist im Einklang mit den Untersuchungen bei den jungen Eichen (vgl. BARTELS 2001). Ein Problem sind die bereits vor Entlaubung bestehenden Unterschiede in den Spätholzbreiten (Jahre 1998 und 1999) bei den späteren De1-Bäumen. Eine bereits 1998 als Trend sichtbare und 1999 signifikante Reduktion der Spätholzbreite im Vergleich mit der Kontrolle erschwert die Interpretation des Effektes der Entlaubung auf das Spätholz. Vergleicht man die Spätholzbreiten der Jahre 1998 bis 2001, so werden zumindest im Jahr der Entlaubung (2000) die geringsten Spätholzbreiten gemessen. Auch bei der De2-Variante führt Entlaubung zu einer Reduktion des Spätholzes. Erst 1999, nach erstmaliger Entlaubung ist die Spätholzbreite zumindest im Trend verringert. Nach zweimaliger Entlaubung (2000) ist bereits eine (wenn auch nur als Tendenz) stärkere Reduktion zu sehen. Dies lässt sich als eine entlaubungsbedingte Spätholzreduktion interpretieren, da auch MEYER (2001) auf einen verringerten Stammzuwachs bei beiden entlaubten Varianten im Jahr 2000 hinweist. Eine mögliche Erklärung kann die Probenahme für die Jahrringanalyse sein. Während eine Messung der Umfänge den Zuwachs über die gesamte Stammbreite integriert, wird hier nur in einer Richtung beprobt. Dies kann zu unterschiedlichen Ergebnissen führen, wenn der Zuwachs stark einseitig erfolgt. 
Deutliche Unterschiede in der Reaktion auf Entlaubung treten zwischen den jungen und 20-jährigen Eichen nicht auf. Dies zeigt auch ein Vergleich der Stärkegehalte im Stamm (Abb. 3.34). Bei den jungen Eichen führte Trockenstress in zeitversetzter Kombination mit Entlaubung (Jahr 2000) trotz einer immer noch reduzierten Feinwurzelbiomasse zu keiner stärkeren Beeinträchtigung des Wasserhaushalts als Trockenstress allein. Bei den 20-jährigen Eichen unterscheiden sich die Feinwurzelgehalte 2001 nicht mehr zwischen den Varianten. Ein zusätzlicher Trockenstress sollte daher nicht zu einer stärkeren Beeinträchtigung des Wasserhaushalts führen. Eine zeitgleiche Wirkung beider Stressoren wurde bei den 20-jährigen Eichen nicht untersucht, allerdings können die reduzierten Spätholzbreiten auf eine Einschränkung der Wasserversorgung im Sinne der Hypothese interpretiert werden.

\subsubsection{Ursache-Wirkung-Schema bei jungen und älteren Eichen}

Nach Thomas et al. (2002) gilt die Faktorenkombination aus mindestens zweimaliger Entlaubung und Trockenstress als eine der möglichen Hauptursachen für das Eichensterben in Norddeutschland. Nach der Hypothese in der vorliegenden Arbeit führt eine nach Entlaubung aufgrund Assimilatmangels reduzierte Spätholzbreite bei Trockenheit zu einer eingeschränkten Wasserversorgung. Alternativ kann die Feinwurzelproduktion aufgrund eines nach Entlaubung verringerten Assimilatspeichers reduziert sein. Bei Trockenstress kann dies zu einer Einschränkung in der Wasserversorgung führen.

Die Ergebnisse der vorliegenden Arbeit unterstützen sowohl die Hypothese wie auch die Alternativhypothese. Dies gilt allerdings nur, wenn Trockenstress im zweiten Jahr der Entlaubung, d.h. zeitnah auftritt. Bei beiden Arten ist die Spätholzbreite nach Entlaubung verringert. Eine zeitnahe Kombination von Trockenstress und Entlaubung führt bei beiden Arten zu einer Verringerung der Blattwassergehalte trotz eines Absenkens der Wasserpotentiale bei den DeDr-Bäumen. Dies lässt auf eine eingeschränkte Wasserversorgung schließen. Da auch 20-jährige Stieleichen eine Reduktion des Spätholzes nach Entlaubung zeigen, steht zu vermuten, dass es auch hier über den Wirkungspfad einer verringerten Spätholzbreite bei Trockenheit zu Einschränkungen im Wasserhaushalt kommt.

Gleichzeitig wird sowohl bei $Q$. robur als auch bei $Q$. petraea eine Reduktion der Feinwurzeln festgestellt. Somit kann das Absinken der Blattwassergehalte entweder durch eine verringerte Wasseraufnahme (reduzierte Feinwurzeln) oder aufgrund einer verringerten Wassernachleitung (reduzierte Spätholzbreite) verursacht werden. Zudem ist ein sich gegenseitig verstärkender Effekt möglich. 
Allerdings wird nur bei $Q$. petraea ein im Trend erhöhter Verlust an hydraulischer Leitfähigkeit festgestellt, während dies bei jungen $Q$. robur nicht der Fall ist. Dies kann in den bei $Q$. robur weniger stark verringerten Feinwurzelbiomasse liegen. $Q$. robur weist die höheren stomatären Leitfähgkeiten sowie die höheren Zuwächse auf. Dadurch kann sie als die produktivere Art gelten. Der Effekt der Entlaubung wird hier schneller kompensiert als bei $Q$. petraea.

Im Gegensatz zu den Ergebnissen der vorliegenden Arbeit ist $Q$. robur in Norddeutschland in weitaus stärkerem Maße vom Eichensterben betroffen als $Q$. petraea (ACKERMANn \& HARTMANN 1992). Die stärksten Schäden werden dort auf hydromorphen Böden festgestellt, auf denen die Durchwurzelung der tieferen Bodenschichten (hier insbesondere Feinwurzeln) stark verringert ist (THOMAS \& HARTMANN 1996, 1998). Dadurch steigt die Gefahr von Trockenstress bei sommerlicher Trockenheit. Die durchwurzelten oberflächennahen Bodenschichten trocknen schnell aus, und eine verstärkte Wasserversorgung aus den tieferen Bodenschichten kann nicht oder nur ungenügend erfolgen. Tritt nun eine zusätzliche entlaubungsbedingte Reduktion der unter anderem für die Feinwurzelbildung benötigten Assimilatmenge auf, so kann in trockenen Sommern die Trockenstressantwort über eine vemehrte Feinwurzelbildung nicht oder nur ungenügend erfolgen, es kommt zu Trocknisschäden bei den Eichen. 


\section{Zusammenfassung}

Aufgrund von Jahrringanalysen und Klimaberichten kann Entlaubung in mindestens zwei aufeinander folgenden Jahren in Verbindung mit sommerlicher Trockenheit als Hauptursache für das Eichensterben in Norddeutschland gelten. Die UrsacheWirkungs-Beziehung der Faktoren "Entlaubung ein zwei aufeinander folgenden Jahren" und "Trockenstress" - allein und in Kombination miteinander - wurde unter kontrollierten Bedingungen an zu Versuchsbeginn dreijährigen Quercus robur und $Q$. petraea getestet. Zur Simulation von Insektenfraß wurden die Bäume in zwei aufeinander folgenden Jahren jeweils im Frühjahr manuell entlaubt. Im ersten Teilversuch wurde Trockenstress im Jahr der letztmaligen Entlaubung, im zweiten Teilversuch ein Jahr nach letztmaliger Entlaubung appliziert. In der vorliegenden Arbeit wurden Untersuchungen zum Wasserhaushalt, zum Gaswechsel, zur Biomassenpartitionierung, zur Holzanatomie sowie zu Stamm- und Blatt-Inhaltsstoffen (Stärke bzw. N, Chlorophyll und $\delta^{13} \mathrm{C}$ ) durchgeführt. Zusätzlich wurden die an den jungen Eichen gewonnenen Ergebnisse mit denen von 20-jährigen $Q$. robur in einer Baumschule verglichen (nur Entlaubung als Faktor).

1. Trockenstress führte zu einer Reduktion der stomatären Leitfähigkeit und der Transpiration sowie zu sinkenden Wasserpotentialen. Gleichzeitig war die Feinwurzelbiomasse nach Trockenstress erhöht.

2. Nach Entlaubung reagierten die Bäume mit einer erhöhten stomatären Leitfähigkeit und einer höheren Transpiration pro Einheit Blattfläche. Dies kann als Kompensationsreaktion auf den Assimilatverlust durch Entlaubung interpretiert werden. Nach Entlaubung fand eine Regeneration der Krone durch schlafende Knospen statt, jedoch war die Gesamtblattfläche pro Baum im Vergleich mit der Kontrolle deutlich verringert. Nach Entlaubung war die Feinwurzelbiomasse sowohl im Jahr der letztmaligen Entlaubung wie auch ein Jahr nach letztmaliger Entlaubung reduziert. Die Spätholzbreite war nach Entlaubung verringert, dies hatte jedoch keinen Einfluss auf die hydraulische Leitfähigkeit. 
3. Einschränkungen im Wasserhaushalt wurden erst bei einer kombinierten Wirkung der Stressoren beobachtet. Trockenstress im Jahr der letztmaligen Entlaubung führte bei $Q$. petraea zu einem erhöhten Verlust an hydraulischer Leitfähigkeit sowie zu einer stark reduzierten hydraulischen Leitfähigkeit auf der Fließstrecke Boden-Blatt. Im Jahr nach letztmaliger Entlaubung wurden Änderungen in der Biomassenpartitionierung festgestellt. Es fand zwar eine vollständige Wiederherstellung der Blattbiomasse statt, jedoch blieb die Feinwurzelbiomasse reduziert, vor allem bei $Q$. petraea. Allerdings resultierte eine Kombination beider Stressoren nicht in eine stärkere Beeinträchtigung des Wasserhaushalts als Trockenstress allein.

4. Q. petraea gilt zwar als die besser an Trockenstress angepasste Art, aufgrund einer verringerten Produktivität wirkt sich ein entlaubungsbedingter Assimilatverlust über eine verringerte Feinwurzelbildung bei Trockenstress jedoch negativer auf den Wasserhaushalt aus, als dies bei $Q$. robur der Fall war. $Q$. petraea reagierte insgesamt empfindlicher auf die Kombination der Stressoren als $Q$. robur. Unterschiede in der Reaktion auf Entlaubung bezüglich des Wasserhaushalts zwischen jungen und 20-jährigen Q. robur wurden nicht festgestellt.

5. Ein mechanistischer Zusammenhang zwischen einer entlaubungsbedingten Spätholzreduktion und einer Einschränkung der Wasserleitung im Stamm konnte weder verworfen noch mit Sicherheit belegt werden.

6. Jedoch wurden Hinweise auf den Wirkungspfad über eine reduzierte Feinwurzelproduktion und einer verringerten Wasseraufnahmekapazität gefunden. Dieser Faktorenkombination wird eine wichtige Bedeutung für das Eichensterben beigemessen. Dabei können andere biotische sowie abiotische Faktoren (z.B. hydromorphe Böden) stressverschärfend sein. 


\section{Literaturverzeichnis}

Abrams M.D. (1990): Adaptations and responses to drought in Quercus species of North America. Tree Physiology 7: 227-238.

ABRAMS M.D. (1994): Genotypic and phenotypic variation of stress adaptations in temperate tree species: a review of several case studies. Tree Physiology 14: 833842 .

Abrams M.D. \& Mostoller S.A. (1995): Gas exchange, leaf structure and nitrogen in contrasting successional tree species growing in open and understory sites during a drought. Tree Physiology 15: 631-370.

ACKermann J. \& Hartmann G. (1992): Kronenschäden in Eichenbeständen Niedersachsens nach Farbinfratrot-Luftbildern aus den Jahren 1988/89. Forst und Holz 47: 452-460.

Alder N.N., SPerry J.S. \& Pockman W.T. (1996): Root and stem xylem embolism, stomatal conductance, and leaf turgor in Acer grandidentatum populations along a soil moisture gradient. Oecologia 105: 293-301.

Aranda I., GiL L. \& PARdos J.A. (1996): Seasonal water relations of three broadleaved species (Fagus sylvtica L., Quercus petraea (Mattuschka) Liebl. and Quercus pyrenaica Willd. ) in a mixed stand in the centre of the Iberian Peninsula. Forest Ecology and Management 84: 219-229.

Aranda I., Gil L. \& PARdos J.A. (2000): Water relations and gas exchange in Fagus sylvatica L. and Quercus petraea (Mattuschka) Liebl. in a mixed stand at their southern limit of distribution in Europe. Trees 14: 344-352.

Ashworth E.N., StiRm V.E. \& VoleneC J.J. (1993): Seasonal variations in soluble sugars and starch within woody stems of Cornus sericea L. Tree Physiology 13: 379 388. 
ASPELMEIER S. (2002): Genotypic variation in drought response of silver birch (Betula pendula Roth.). Doktorarbeit, Georg-August-Universität, Göttingen.

Augé R.M., Duan X., Croker J.L., Witte W.T. \& Green C.D. (1998): Foliar dehydration tolerance of twelve deciduous tree species. Journal of Experimental Botany 49: 753-759.

BAldocchi D.D., Verma S.B. \& DE D.E.A. (1987): Canopy photosynthesis and water use efficiency in a deciduous forest. Journal of Applied Ecology 24: 251-260.

BARTEls C. (2001): Auswirkungen von Entlaubung und Trockenstress auf das wasserleitende System junger Eichen. Unveröffentlichte Diplomarbeit am A-v-HallerInstitut, Georg-August-Universität Göttingen.

BLANK R. (1997): Ringporigkeit des Holzes und häufige Entlaubung durch Insekten als spezifische Risikofaktoren der Eichen. Forst und Holz 52: 235-242.

BLANK R. \& RIEMER T. (1999): Quantifizierung des Einflusses blattfressender Insekten auf den Spätholzzuwachs der Eiche in Nordwestdeutschland. Forst und Holz 18: $569-576$.

Block J., Delb H., Hartmann G., Seemann D. \& Schröck H.W. (1995): Schwere Folgeschäden nach Kahlfraß durch Schwammspinner im Bienwald. AFZ/Der Wald 23: 1278-1281.

BMELF (1994): Nationaler Waldbericht.

Bréda N., Cochard H., Dreyer E. \& Granier A. (1992): Water transfer in a mature oak stand (Quercus petraea): seasonal evolution and effects of a severe drought. Canadian Journal of Forest Research 23: 1136-1143.

Bréda N., Granier A., Barataud F. \& Moyne C. (1995): Soil water dynamics in an oak stand. Plant and Soil 172: 17-27.

Bréda N., Granier A. \& Dreyer E. (1993): Effects of soil water depletion on water relation of Quercus petraea and Quercus robur under natural conditions at Champenoux forest (France). Annales des Sciences Forestières 50: 571-582. 
Canham C.D., Kobe R.K., LatTy E.F. \& Chazdon R.L. (1999): Interspecific and intraspecific variation in tree seedling survival: effcts of allocation to roots versus carbohydrate reserves. Oecologia 121: 1-11.

CAVENDER-BARES J. \& BAZZAZ F.A. (2000): Changes in drought response strategies with ontogenity in Quercus rubra : implications for scaling from seedlings to mature trees. Oecologia 124: 8-18.

ChaAr H., Colin F. \& Leborgne G. (1997): Artificial defoliation, decapitation of the terminal bud, and removal of the apical tip of the shoot in sessile oak seedlings and consequences on subsequent growth. Canadian Journal of Forest Research 27: $1614-1621$.

COCHARD H., BRÉDA N. \& GRANIER A. (1996): Whole tree hydraulic conductance and water loss regulation in Quercus during drought: evidence for stomatal control of embolism? Annales des Sciences Forestières 53: 197-206.

Cochard H., Bréda N., Granier A. \& Aussenac G. (1992): Vulnerability to air embolism of three Euopean oak species (Quercus petraea [Matt.] Liebl., Q. pubescens Willd., Q. robur L.). Annales des Sciences Forestières 49: 225-233.

Collet C. \& Guehl J.M. (1997): Osmotic adjustment in sessile oak seedlings in response to drought. Annales des Sciences Forestières 54: 389-394.

Collin P., Epron D., Alaoui-Sossé B. \& Badot P.M. (2000): Growth response of Common Ash seedlings (Fraxinus excelsior L.) to total and partial defoliation. Annals of Botany 85: 317-323.

DAmesin C., RAmbal S. \& Joffre R. (1997): Between-tree variation in leaf $\delta^{13} \mathrm{C}$ of Quercus pubescens and Quercus ilex among Mediterranean habitats with different water availability. Oecologia 111: 26-35.

Deutscher Wetterdienst (1998-2001): Monatlicher Witterungsreport der Jahre 1999-2001. Deuscher Wetterdienst, Offenbach .

Dickson R.E. \& TOMLINSON P.T. (1996): Oak growth, development and carbon metabolism in response to water stress. Annales des Sciences Forestières 53: 181196. 
DREYER E. (1994): Water stress, xylem dysfunctions and dieback mechanisms in European oak trees. In: Final Report STEP Research Programme CT90 0050 C. INRA, Nancy/Champenoux.

Dreyer E., Bousquet F. \& DUCREY M. (1990): Use of pressure volume curve in water relation analysis on woody shoots: influence of rehydration and comparison of four European oak species. Annales des Sciences Forestières 47: 285-297.

EllmoRE G.S. \& EWERS F.W. (1986): Fluid flow in the outmost xylem increment of a ring-porous tree, Ulmus americana. American Journal of Botany 73: 1771-1774.

EllsworTh D.S. \& REICH P.B. (1992): Water relations and gas exchange of Acer saccharum seedlings in contrasting natural light and water regimes. Tree Physiology 10: $1-20$.

Ellsworth D.S., Tyree M.T., PARKer B.L. \& S Kinner M. (1994): Photosynthesis and water-use efficiency of sugar maple Acer saccharum in relation to pear thrips defoliation. Tree Physiology 14: 619-632.

Epron D., Dreyer E. \& Bréda N. (1992): Photosynthesis of oak trees (Quercus petraea (Matt.) Liebl.) during drought under field conditions: diurnal evolution of net $\mathrm{CO}_{2}$ assimilation and photochemical efficiency of photosystem II. Plant, Cell and Environment 15: 809-820.

Farquhar G.D., Hubick K.T., Condon A.G. \& Richards R.A. (1989): Carbon isotope fractionation and plant water-use efficiency. In: RUNDEL P.W., EHLERINGER J.R. \& NAGY K.A. (Hg.) Stable Isotopes in ecological research, 21-40. Springer Verlag, New York, Berlin, Heidelberg.

FARQUHAR G.D. \& RICHARDS R.A. (1984): Isotopic composition of plant carbon correlates with water-use efficiency of wheat genotypes. Australian Journal of Plant Physiology 11: 539-552.

FLEISCHER M. (1989): Untersuchungen über zwei neue Eichenerkrankungen in Bayern. Doktorarbeit, Forstwissenschaftliche Fakultät der Universität München, München.

Fort C., Fauveau M.L., Muller F., Label P., Granier A. \& Dreyer E. (1997): Stomatal conductance, growth and root signalling in young oak seedlings subjected to partial soil drying. Tree Physiology 17: 281-289. 
GANSERT D. \& SPRICK W. (1998): Storage and mobilization of nonstructural carbohydrates and biomass development of beech seedlings (Fagus sylvatica L.) under different light regimes. Trees 12: 247-257.

GARTEN C.T. \& TAYLOR JR. G.E. (1992): Foliar $\delta^{13} \mathrm{C}$ within a temperate deciduous forest: spatial, temporal, and species sources of variation. Oecologia 90: 1-7.

GAUSLING T. (1999): Morphologische und physiologische Anpassungsreaktionen junger Stiel- und Traubeneichen (Quercus robur L. und Quercus petraea (Mattuschka) Liebl.) an leichten Trockenstress. Unveröffentlichte Diplomarbeit am A-v-HallerInstitut, Georg-August-Universität Göttingen.

GRADWELL G.R. (1974): The effects of defoliators on tree growth. In: MORRIS M.G. \& Perring F.H. (Hg.) The British Oak, 182-193.

Granier A., Anfodillo T., Sabatti M., Cochard H., Dreyer E., Tomasi M., VALENTINI M. \& BRÉDA N. (1994): Axial and radial water flow in the trunks of oak trees: a quantitative and qualitative analysis. Tree Physiology 14: 1383-1396.

HART M., HogG E. \& LiefFers V.J. (2000): Enhanced water relations of residual foliage following defoliation in Populus tremuloides. Canadian Journal of Botany 78: $583-590$.

HARTMAnN G. (1996): Ursachenanalyse des Eichensterbens in Deutschland - Versuch einer Synthese der bisherigen Befunde. Mitteilungen aus der Biologischen Bundesanstalt für Land- und Forstwirtschaft Berlin-Dahlem 318: 125-151.

Hartmann G. \& Blank R. (1992): Winterfrost, Kahlfraß und Prachtkäferbefall als Faktoren im Ursachenkomplex des Eichensterbens in Norddeutschland. Forst und Holz 47: 443-452.

HARTMANN G. \& BLANK R. (1998): Aktuelles Eichensterben in Niedersachsen - Ursachen und Gegenmaßnahmen. Forst und Holz 53: 733-735.

HARTMANN G., BLANK R. \& LEWARK S. (1989): Eichensterben in Norddeutschland - Verbreitung, Schadbilder, mögliche Ursachen. Forst und Holz 44: 475-487.

Heichel G.H. \& TURNER N.C. (1983): $\mathrm{CO}_{2}$ assimilation of primary and regrowth foliage of red maple (Acer rubrum L.) and red oak (Quercus rubra L.): response to defoliation. Oecologia 57: 14-19. 
HigGs K.H. \& Wood V. (1995): Drought susceptibility and xylem dysfunction in seedlings of 4 European oak species. Annales des Sciences Forestières 52: 507-513.

HuBER B. (1955): Zweigabsprünge. Allgemeine Forst Zeitschrift 10: 620-621.

HUBER F. (1993): Déterminisme de la suface de vaisseaux du bois des chênes indigènes (Quercus robur L, Quercus petraea Liebl). Effet individuel, effet de l'appareil foliaire, des conditions climatiques et de l'âge de l'arbre. Annales des Sciences Forestières 50: 509-524.

JARVIS A.J. \& DAVIES W.J. (1998): The coupled response of stomatal conductance to photosynthesis and transpiration. Journal of Experimental Botany 49: 399-406.

Jonasson S., Medrano H. \& Hanson P.J. (1997): Variation in leaf longevity of Pistacia lentiscus and its relationship to sex and drought stress inferred from leaf $\delta^{13}$ C. Functional Ecology 11: 282-289.

Kleiner K.W., Abrams M.D. \& Schultz J.C. (1992): The impact of water and nutrient deficiencies on the growth, gas exchange and water relations of red oak and chestnut oak. Tree Physiology 11: 271-287.

Koide R.T., Robichaux R.H., Morse S.R. \& Smith C.M. (1989): Plant water status, hydraulic resistance and capacitance. In: PEARCY R.W. (Hg.) Plant Physiological Ecology, 160-179. Chapman and Hall, New York.

Kolb T.E., Dodds K.A. \& Clancy K.M. (1999): Effect of western spruce budworm defoliation on the physiology and growth of potted Douglas-Fir seedlings. Forest Science 45: 280-291.

Kosola K.R., Dickman D.I., Paul E.A. \& Parry D. (2001): Repeated insect defoliation effects on growth, nitrogen acquisition , carbohydrates, and root demography of poplars. Oecologia 129: 65-74.

Kozlowski T.T., Kramer P.J. \& Pallardy S.G. (1991): The physiological ecology of woody plants. Academic Press, San Diego, New York, Boston.

KRAUSE S.C. \& RAFFA K.F. (1996): Differential growth and recovery rates following defoliation in related deciduous and evergreen trees. Trees 10: 308-316. 
Kubiske M.E., Abrams M.D. \& Mostoller S.A. (1996): Stomatal and nonstomatal limitations of photosynthesis in relation to the drought and shade tolerance of tree species in open and understory environments. Trees 11: 76-82.

LANGel R., Schikowski J. \& REINEKING A. (1996): Variation der $\delta^{15} \mathrm{~N} /{ }^{14} \mathrm{~N}$ - und $\delta^{13} \mathrm{C} /{ }^{12} \mathrm{C}$-Werte von Acetanilid und deren Einsatz als Sekundärstandard für ONLINE IRMS Messungen. Posterbeitrag zur Jahrestagung der Arbeitsgemeinschaft "Stabile Isotope", 30.9. - 2. 10. 1996.

LAVARENNE-ALlARY S. (1965): Recherches sur la croissance des bourgeons de chêne et de quelques espèces ligneuses. Annales des Sciences Forestières 22: 1-203.

Leuschner C., Hertel D., Coners H. \& Büttner V. (2001): Root competition between beech and oak: a hypothesis. Oecologia 126: 276-284.

LÉvy G., Becker M. \& Duhamel D. (1992): A comparison of pedunculate and sessile oaks: radial growth in the center and northwest of France. Forest Ecology and Management 55: 51-63.

LinNENBRINK M., LÖSCH R. \& KAPPEN L. (1992): Water relations of hedgerow shrubs in Northern Central Europe. I. Bulk water relations. Flora 187: 121-133.

Longman K.A. \& Coutts M.P. (1974): Physiology of the oak tree. In: MoRRIS M.G. \& PERring F.H. (Hg.) The British Oak, 194-221. Classey, Faringdon/England.

LÖsch R. (2001): Wasserhaushalt der Pflanzen. UTB für Wissenschaft. Quelle \& Meyer, Wiebelsheim.

Lovett G.M. \& Tobiessen P. (1993): Carbon and nitrogen assimilation in red oaks (Quercus rubra L.) subject to defoliation and nitrogen stress. Tree Physiology 12 : 259-270.

McGraw J.B., Gottschalk K.W., Vavrek M.C. \& Chester A.L. (1990): Interactive effects of resource availabilities and defoliation on photosynthesis, growth, and mortality of red oak seedlings. Tree Physiology 7: 247-254.

Meinzer F.C., Andrade J.L., Goldstein G., Holbrook N.M., Cavelair J. \& JACKSON P. (1997): Control of transpiration from the upper canopy of a tropical 
forest: the role of stomatal boundary layer and hydraulic architecture components. Plant, Cell and Environment 18: 1242-1252.

Meyer G. (2001): Auswirkung künstlicher Entlaubung auf die Frosthärte des Bastgewebes junger Stieleichen (Quercus robur L.). Unveröffentlichte Diplomarbeit am A-v-Haller-Institut, Georg-August-Universität Göttingen.

MORAN R. (1982): Formulae for Determination of Chlorophyllous pigments extracted with N,N-Dimethylformamide. Plant Physiology 69: 1376-1381.

NARDini A. \& PITT F. (1999): Drought resistance of Quercus pubescens as a function to root hydraulic conductance, xylem embolism and hydraulic architecture. New Phytologist 143: 485-494.

NARDini A. \& SALLEO S. (2000): Limitation of stomatal conductance by hydraulic traits: sensing or preventing xylem cavitation? Trees DOI 10.1007/s004680000071.

Nobel P.S. (1999): Physicochemical \& environmental Plant Physiology. Academic Press, San Diego, London, Boston, New York, Sydney, Tokyo, Toronto, 2. Auflage.

Noitsakis B. \& Tsiouvaras C. (1990): Seasonal changes in components of leaf water potential and leaf area growth rate in kermes oak. Acta Oecologica 11: 419427.

OSONUBI O. \& DAVIES W.J. (1981): Root growth and water relations of oak and birch seedlings. Oecologia 51: 343-350.

PARKER J. \& PATTON R.L. (1975): Effects of drought and defoliation on some metabolites in roots of Black Oak seedlings. Canadian Journal of Forest Research 5: 457-463.

Picon C., Ferhi A. \& Guehl J.M. (1997): Concentrations and $\delta^{13}$ C of leaf carbohydrates in relation to gas exchange in Quercus robur under elevated $\mathrm{CO}_{2}$ and drought. Journal of Experimental Botany 48: 1547-1556.

Picon C., Guehl J.M. \& Ferhi A. (1996): Leaf gas exchange and carbon isotope composition responses to drought in a drought-avoiding (Pinus pinaster) and a drought-tolerant (Quercus petraea) species under present and elevated atmospheric $\mathrm{CO}_{2}$ concentrations. Plant, Cell and Environment 19: 182-190. 
REICH P.B. \& HincKley T.M. (1989): Influence of pre-dawn water potential and soil-to-leaf hydraulic conductance on maximum daily diffusive conductance in two oak species. Functional Ecology 3: 719-726.

Reich P.B., Walters M.B., Krause S.C., Vanderklein D.W., Raffa K.F. \& TABOnE T. (1993): Growth, nutrition and gas exchange of Pinus resinosa following artificial defoliation. Trees 7: 67-77.

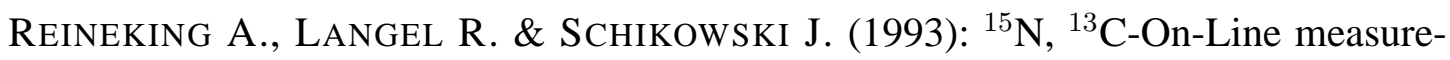
ments with an Elemental Analyzer (Carlo Erba, NA 1500), a modified trapping box and a Gas Isotope Mass Spectrometer (Finnigan, MAT 251). Environmental Health Studies 29: 169-174.

RUBTSOV V.V. (1996): Influence of repeated defoliations by insects on wood increment in common oak. Annales des Sciences Forestières 53: 407-412.

SACHS L. (1984): Applied statistics - a handbook of techniques. Springer, New York.

SAliendra N.Z., Sperry J.S. \& COMStock J.P. (1995): Influence in leaf water status on stomatal response to humidity, hydraulic conductance, and soil drought in Betula occidentalis. Planta 196: 357-366.

SAUter J.J. \& VAN Cleve B. (1994): Storage, mobilization and interrelations of starch, sugars, protein and fat in the ray storage tissue of poplar trees. Trees 8: 297304.

Scholander P.F., Hammel H.T., Bradstreet E.D. \& Hemmingsen E.A. (1965): Sap pressure in vascular plants. Science 148: 339-346.

SHAPIRO S.S. \& WILK M.B. (1965): An analysis of variance test for normality (complete samples). Biometrika 52: 591-611.

Simonin G.H., Cochard H., Delatour C., Granier A. \& Dreyer E. (1994): Vulnerability of young oaks (Quercus robur) to embolism during water stress and after inoculation with Ophiostoma querci. Annales des Sciences Forestières 51: 493504.

SLAVIK B. (1974): Methods of studying plant water relations, Band 9 von Ecological Studies. Springer, Berlin. 
SPERry J.S., Donnelly J.R. \& Tyree M.T. (1988): A method for measuring hydraulic conductivity and embolism in xylem. Plant, Cell and Environment 11: 35-40.

SPERRY J.S. \& SALIENDRA N.Z. (1994): Intra- and inter-plant variation in xylem cavitation in Betula occidentalis. Plant, Cell and Environment 17: 1233-1241.

Svolba J. \& Kleinschmit J. (2000): Herkunftsuterschiede beim Eichensterben. Forst und Holz 55: 15-17.

Thomas D.S. \& EAmus D. (1999): The influence of predawn leaf water potential on stomatal responses to atmospheric water content at constant $\mathrm{C}_{i}$ and on stem hydraulic conductance and foliar ABA concentrations. Journal of Experimental Botany 50: 243-251.

Thomas D.S., EAmUS D. \& Bell D. (1999a): Optimization theory of stomatal behaviour I. A critical evaluation of five methods of calculation. Journal of Experimental Botany 50: 385-392.

Thomas D.S., Eamus D. \& Bell D. (1999b): Optimization theory of stomatal behaviour II. Stomatal responses of several tree species of north Australia to changes in light, soil and atmospheric water content and temperature. Journal of Experimental Botany 50: 393-400.

ThOMAS F.M. (2000): Growth and water relations of four deciduous tree species ( $\mathrm{Fa}$ gus sylvatica L., Quercus petraea [Matt.] Liebl., Q. pubescens Willd. Sorbus aria [L.] Cr.) occuring at Central-European tree-line sites on shallow calcareous soils: physiological reactions of seedlings to severe drought. Flora 195: 104-105.

ThOMAS F.M. \& BlAnK R. (1996): The effect of excess nitrogen and of insect defoliation on the frost hardiness of bark tissue of adult oaks. Annales des Sciences Forestières 53: 395-406.

Thomas F.M., Blank R. \& Hartmann G. (2002): Abiotic and biotic factors and their interactions as causes of oak decline in Central Europe. Forest Pathology, in press .

Thomas F.M. \& GAUsling T. (2000): Morphological and physiological responses of oak seedlings (Quercus petraea and Q. robur) to moderate drought. Annales des Sciences Forestières 57: 325-333. 
Thomas F.M. \& HARTMAnN G. (1996): Soil and tree water relations in mature oak stands in northern Germany differng in the degree of decline. Annales des Sciences Forestières 53: 697-720.

Thomas F.M. \& HARTMAnN G. (1998): Tree rooting patterns and soil water relations of healthy and damaged stands of mature oak (Quercus robur L, and Quercus petraea[Matt.] Liebl.). Plant and Soil 203: 145-158.

Triboulot M.B., Fauveau M.L., Bréda N., Label P. \& Dreyer E. (1996): Stomatal conductance and xylem-sap abscisic acid (ABA) in adult oak trees during a gradually imposed drought. Annales des Sciences Forestières 53: 207-220.

Turnbull M.H., Whitehead D., Tissue D.T., Schuster W.S.F., Brown K.J., ENGEL V.C. \& GRIFFIN K.L. (2001): Photosynthetic characteristics in canopies of Quercus rubra, Quercus prinus and Acer rubrum differ in response to soil water availability. Oecologia DOI 10.1007/s00442-001-0842-z.

Tyree M.T. \& Cochard H. (1996): Summer and winter embolism in oak: impact on water relations. Annales des Sciences Forestières 53: 173-180.

Tyree M.T. \& JARVis P.G. (1982): Water in tissue and cells. In: LANGE O.L., NoBel P.S., Osmond C.B. \& Ziegler H. (Hg.) Encyclopedia of Plant Physiology, Band 2 von Physiological Plant Ecology II New Ser. 12 B, 36-77. Springer, Berlin, Heidelberg, New York.

TYREE M.T. \& SPERRY J.S. (1989): Vulnerability of xylem to cavitation and embolism. Annual Review of Plant Physiology and Molecular Biology 40: 19-38.

VAN HEES A.F.M. (1997): Growth and morphology of pedunculate oak (Quercus robur L.) and beech (Fagus sylvatica L.) seedlings in relation to shading and drought. Annales des Sciences Forestières 54: 9-18.

Vivin P., Aussenac G. \& LÉvy G. (1993): Difference in drought resistance among three deciduous oak species grown in large boxes. Annales des Sciences Forestières 50: 221-233.

VIVIN P. \& GUEHL J.M. (1997): Changes in carbon uptake and allocation patterns in Quercus robur seedlings in response to elevated $\mathrm{CO}_{2}$ and water stress: an evaluation with ${ }^{13} \mathrm{C}$ labelling. Annales des Sciences Forestières 54: 597-610. 
Von Willert D., Matyssek R. \& Herppich W. (1995): Experimentelle Pflanzenökologie. Georg Thieme Verlag, Stuttgart, New York.

WACHTER H. (1999): Untersuchungen zum Eichensterben in Nordrhein-Westfalen, Teil 1 (1900-1950). Schriftenreihe der Landesforstverwaltung Nordrhein-Westfalen 9: $61 \mathrm{pp}$.

WACHTER H. (2001): Untersuchungen zum Eichensterben in Nordrhein-Westfalen, Teil 2 (1950-2000). Schriftenreihe der Landesforstverwaltung Nordrhein-Westfalen 13: $112 \mathrm{pp}$.

WARGO P.M. (1996): Consequences of environmental stress on oak: predisposition to pathogens. Annales des Sciences Forestières 53: 359-368.

WARgo P.M., PARKer J. \& Houston D.R. (1972): Starch content in roots of defoliated sugar maple. Forest Science 18: 203-204.

WeBB W.L. (1981): Relation of Starch content to conifer mortality and growth loss after defoliation by the douglas-fir tussock moth. Forest Science 27: 224-232.

Weber J.A. \& GATES D.M. (1990): Gas exchange in Quercus rubra (northern red oak) during drought: analysis of relations among photosynthesis, transpiration, and leaf conductance. Tree Physiology 7: 215-225.

Wright S., Hall R.W. \& PEACOCK J.W. (1989): Effect of simulated insect damage on growth and survival of northern red oak (Quercus rubra L.) seedlings. Environmental Entomology 18: 235-239.

Xu Z.H., S Affigna P.G., FArquhar G.D., Simpson J.A., Haines R.J., Walker S., Osborne D.O. \& Guinto D. (2000): Carbon isotope discrimination and oxygen isotope composition in clones of the $F_{1}$ hybrid between slash pine and Caribbean pine in relation to tree growth, water-use-efficiency and foliar nutrient concentration. Tree Physiology 20: 1209-1217.

ZHANG J.W. \& MARSHAL J.D. (1995): Variation in carbon isotope discrimination and photosynthetic gas exchange among populations of Pseudotsuga menziesii and Pinus ponderosa in different environments. Functional Ecology 9: 402-412.

ZIEGLER H. (1995): Stable isotopes in plant physiology and ecology, Band 56 von Progress in Botany. Springer, Berlin, Heidelberg. 
Zimmermann M.H. (1983): Xylem structure and the ascent of sap. Springer, Berlin.

ZimmermanN M.H. \& BROWN C.L. (1971): Trees - structure and function. Springer, Berlin. 


\section{Anhangtabellen}

Tab. A1: Predawn- und nachmittägliche (Afternoon)- Wasserpotentiale (MPa) bei Quercus robur und Q. petraea im Untersuchungsjahr 1999. Angegeben sind die Mittelwerte und Standardabweichungen von je fünf Bäumen pro Variante. C Kontrolle, De Entlaubung 1998 und 1999, Dr Trockenheit 1999, DeDr Kombination aus De und Dr. Signifkante Unterschiede aller trockengestressten gegenüber allen ausreichend bewässerten Varianten sind mit * gekennzeichnet.

\section{Predawn}

$\begin{array}{cccccccccc}\text { Q. robur } & \mathbf{C} & \text { std } & \text { De } & \text { std } & \text { Dr } & \text { std } & \text { DeDr } & \text { std } & \\ 18.06 .99 & \mathbf{- 0 , 1} & 0,04 & \mathbf{- 0 , 1} & 0,04 & \mathbf{- 0 , 1} & 0,04 & \mathbf{- 0 , 1} & 0,01 & \\ 23.07 .99 & \mathbf{- 0 , 2} & 0,08 & \mathbf{- 0 , 2} & 0,04 & \mathbf{- 0 , 2} & 0,03 & \mathbf{- 0 , 2} & 0,07 & \\ 13.08 .99 & \mathbf{- 0 , 2} & 0,03 & \mathbf{- 0 , 3} & 0,08 & \mathbf{- 0 , 9} & 0,36 & \mathbf{- 0 , 9} & 0,22 & * \\ 10.09 .99 & \mathbf{- 0 , 1 8} & 0,04 & \mathbf{- 0 , 2 1} & 0,07 & \mathbf{- 0 , 4 5} & 0,20 & \mathbf{- 0 , 4 6} & 0,11 & \\ 29.09 .99 & \mathbf{- 0 , 3} & 0,12 & \mathbf{- 0 , 3 6} & \mathbf{0 , 0 7} & \mathbf{- 0 , 3 1} & \mathbf{0 , 0 9} & \mathbf{- 0 , 3 4} & 0,13 & \\ & & & & & & & & & \\ \text { Q. petraea } & & & & & & & & & \\ 18.06 .99 & \mathbf{- 0 , 1} & 0,04 & \mathbf{- 0 , 1} & 0,03 & \mathbf{- 0 , 1} & 0,03 & \mathbf{- 0 , 1} & 0,03 & \\ 23.07 .99 & \mathbf{- 0 , 1} & 0,05 & \mathbf{- 0 , 3} & 0,10 & \mathbf{- 0 , 2} & 0,07 & \mathbf{- 0 , 3} & 0,11 & \\ 13.08 .99 & \mathbf{- 0 , 2} & 0,03 & \mathbf{- 0 , 2} & 0,06 & \mathbf{- 0 , 6} & 0,14 & \mathbf{- 0 , 7} & 0,20 & * \\ 10.09 .99 & \mathbf{- 0 , 1 7} & 0,03 & \mathbf{- 0 , 1 6} & \mathbf{0 , 1 1} & \mathbf{- 0 , 6 7} & 0,19 & \mathbf{- 0 , 4 7} & 0,15 & * \\ 29.09 .99 & \mathbf{- 0 , 2 9} & 0,04 & \mathbf{- 0 , 3 2} & \mathbf{0 , 1 2} & \mathbf{- 0 , 3 3} & 0,10 & \mathbf{- 0 , 4 9} & 0,19 & *\end{array}$

\section{Afternoon}

\begin{tabular}{|c|c|c|c|c|c|c|c|c|}
\hline Q. robur & C & std & De & std & $\mathrm{Dr}$ & std & DeDr & std \\
\hline 30.06 .99 & $-1,0$ & 0,25 & $-1,7$ & 0,15 & $-1,8$ & 0,33 & $-1,5$ & 0,49 \\
\hline 18.07.99 & $-1,7$ & 0,44 & $-1,6$ & 0,37 & $-1,6$ & 0,44 & $-1,2$ & 0,15 \\
\hline 09.08 .99 & $-1,8$ & 0,34 & $-1,4$ & 0,22 & $-3,5$ & 0,28 & $-2,7$ & 0,84 \\
\hline 27.08 .99 & $-0,9$ & 0,17 & $-1,0$ & 0,23 & $-2,0$ & 0,29 & $-2,0$ & 0,69 \\
\hline 28.09.99 & $-0,87$ & 0,14 & $-0,58$ & 0,08 & $-0,88$ & 0,18 & $-0,8$ & 0,12 \\
\hline \multicolumn{9}{|l|}{ Q. petraea } \\
\hline 30.06 .99 & $-1,6$ & 0,18 & $-1,3$ & 0,44 & $-1,9$ & 0,50 & $-1,5$ & 0,64 \\
\hline 18.07 .99 & $-2,0$ & 0,33 & $-2,0$ & 0,47 & $-2,2$ & 0,46 & $-2,2$ & 0,15 \\
\hline 09.08 .99 & $-1,4$ & 0,38 & $-1,5$ & 0,33 & $-3,6$ & 0,54 & $-2,3$ & 0,38 \\
\hline 27.08 .99 & $-1,6$ & 0,22 & $-1,0$ & 0,09 & $-2,2$ & 0,35 & $-1,8$ & 0,26 \\
\hline 28.09 .99 & $-1,2$ & 0,13 & $-1,05$ & 0,09 & $-1,25$ & 0,23 & $-1,02$ & 0,21 \\
\hline
\end{tabular}

Tab. A2: Blattwassergehalt ( $\mathrm{RWC}_{\text {leaf, }}$ in \%) bei Quercus robur und Q. petraea im Untersuchungsjahr 1999. Angegeben sind die Mittelwerte und Standardabweichungen von je fünf Bäumen pro Variante. C Kontrolle, De Entlaubung 1998 und 1999, Dr Trockenheit 1999, DeDr Kombination aus De und Dr.

\begin{tabular}{ccccccccc} 
Q. robur & C & \multicolumn{3}{c}{ De } & \multicolumn{3}{c}{ Dr } & \multicolumn{3}{c}{ DeDr } \\
27.06 .99 & $\mathbf{9 3 , 2}$ & 1,3 & $\mathbf{9 1 , 5}$ & 2,4 & $\mathbf{9 1 , 5}$ & 1,8 & $\mathbf{9 2 , 7}$ & 2,9 \\
02.08 .99 & $\mathbf{9 2 , 8}$ & 0,9 & $\mathbf{8 5 , 3}$ & 0,6 & $\mathbf{9 2 , 8}$ & 2,2 & $\mathbf{8 6 , 8}$ & 1,2 \\
29.08 .99 & $\mathbf{9 2 , 2}$ & 2,0 & $\mathbf{8 8 , 5}$ & 2,4 & $\mathbf{8 7 , 9}$ & 2,8 & $\mathbf{8 8 , 8}$ & 3,6 \\
29.09 .99 & $\mathbf{8 0 , 6}$ & 9,2 & $\mathbf{9 5 , 6}$ & 3,0 & $\mathbf{8 1 , 2}$ & 4,2 & $\mathbf{9 0 , 4}$ & 7,5
\end{tabular}


Tab. A2 (Forts.): Blattwassergehalt ( $\mathrm{RWC}_{\text {leaf }}$, in \%) bei Quercus robur und Q. petraea im Untersuchungsjahr 1999. Angegeben sind die Mittelwerte und Standardabweichungen von je fünf Bäumen pro Variante. C Kontrolle, De Entlaubung 1998 und 1999, Dr Trockenheit 1999, DeDr Kombination aus De und Dr.

\begin{tabular}{lcccccccc} 
Q. petraea & C & \multicolumn{3}{c}{ De } & \multicolumn{1}{c}{ Dr } & DeDr \\
28.06 .99 & $\mathbf{9 1 , 3}$ & 1,7 & $\mathbf{9 3 , 3}$ & 2,1 & $\mathbf{9 3 , 1}$ & 1,4 & $\mathbf{9 2 , 8}$ & 1,0 \\
02.08 .99 & $\mathbf{8 8 , 0}$ & 2,0 & $\mathbf{8 7 , 3}$ & 1,3 & $\mathbf{8 6 , 8}$ & 2,6 & $\mathbf{8 2 , 3}$ & 4,0 \\
29.08 .99 & $\mathbf{9 4 , 0}$ & 0,8 & $\mathbf{9 4 , 2}$ & 0,4 & $\mathbf{9 2 , 7}$ & 1,6 & $\mathbf{9 3 , 2}$ & 2,8 \\
29.09 .99 & $\mathbf{9 3 , 1}$ & 0,6 & $\mathbf{9 0 , 2}$ & 1,8 & $\mathbf{9 4 , 7}$ & 2,1 & $\mathbf{9 2 , 4}$ & 1,6
\end{tabular}

Tab. A3: Maximale stomatäre Leitfähigkeit $\left(\mathrm{mmol} \mathrm{m}^{-2} \mathrm{~s}^{-1}\right)$ bei Quercus robur und Q. petraea im Jahr 1999. Angegeben sind die Mittelwerte und Standardabweichungen von je fünf Bäumen pro Variante. C Kontrolle, De Entlaubung 1998 und 1999, Dr Trockenheit 1999, DeDr Kombination aus De und Dr. Signifikante Unterschiede zwischen den Varianten sind mit Buchstaben gekennzeichnet.

\begin{tabular}{|c|c|c|c|c|c|c|c|c|}
\hline Q. robur & C & std & De & std & $\mathrm{Dr}$ & std & DeDr & std \\
\hline 25.06 .99 & 223,0 & $69,4 a$ & 394,4 & $74,8 \mathrm{~b}$ & 236,5 & $114,0 a b$ & 366,4 & $121,7 a b$ \\
\hline 02.07 .99 & 121,0 & $80,9 a$ & 292,1 & $75,4 b$ & 21,9 & $11,6 d$ & 263,4 & $28,1 \mathrm{c}$ \\
\hline 12.07 .99 & 184,1 & $115,5 a$ & 289,1 & $87,5 b$ & 190,4 & $185,1 \mathrm{ab}$ & 332,5 & $132,1 \mathrm{ab}$ \\
\hline 17.07 .99 & 195,2 & $80,8 a$ & 338,7 & $42,9 b$ & 243,5 & $106,9 a b$ & 293,4 & $114,2 a b$ \\
\hline 16.08 .99 & 271,1 & $114,3 a$ & 504,2 & $74,1 b$ & 113,8 & $66,1 \mathrm{~d}$ & 276,8 & $122,3 c$ \\
\hline 24.08 .99 & 217,1 & $90,1 a$ & 452,7 & $84,1 \mathrm{~b}$ & 259,8 & $273,1 a b$ & 224,6 & $127,9 a b$ \\
\hline Q. petraea & C & std & De & std & Dr & std & DeDr & std \\
\hline 30.06 .99 & 138,7 & $10,7 a$ & 220,6 & $13,7 b$ & 165,5 & 73,8ab & 204,1 & $38,6 a b$ \\
\hline 02.07 .99 & 206,2 & $37,0 a$ & 282,0 & $27,8 b$ & 119,2 & $35,9 d$ & 203,9 & $23,9 c$ \\
\hline 25.07 .99 & 222,0 & $58,5 a$ & 316,2 & $48,0 \mathrm{~b}$ & 232,3 & $85,3 a b$ & 302,9 & $34,9 a b$ \\
\hline 23.08 .99 & 207,4 & $55,2 a$ & 329,6 & $112,6 b$ & 121,3 & $27,9 \mathrm{c}$ & 349,8 & $229,0 a b$ \\
\hline 28.08 .99 & 206,0 & $76,5 a$ & 284,8 & $56,2 b$ & 192,8 & $105,9 a b$ & 280,9 & $45,2 a b$ \\
\hline
\end{tabular}

Tab. A4: Tagesgang der stomatären Leitfähigkeit $\left(\mathrm{mmol} \mathrm{m}^{-2} \mathrm{~s}^{-1}\right)$, VPD $(\mathrm{kPa})$ und $\Delta \mathrm{w}\left(\mathrm{Pa} \mathrm{kPa}^{-1}\right)$ bei Quercus robur und Q. petraea am 16.08.1999 (Q. robur) und 23.08.1999 (Q. petraea). Angegeben sind die Mittelwerte und Standardabweichungen von je fünf Bäumen pro Variante. C Kontrolle, De Entlaubung 1998 und 1999, Dr Trockenheit 1999, DeDr Kombination aus De und Dr.

\begin{tabular}{|c|c|c|c|c|c|c|c|c|c|c|c|c|}
\hline $\begin{array}{l}\text { Q. robur } \\
\text { Tages- } \\
\text { zeit (h) }\end{array}$ & $\begin{array}{c}\text { C } \\
\text { gs }\end{array}$ & std & $\begin{array}{l}\text { De } \\
\text { gs }\end{array}$ & std & $\begin{array}{l}\mathrm{Dr} \\
\text { gs }\end{array}$ & std & $\begin{array}{c}\text { DeDr } \\
\text { gs }\end{array}$ & std & VPD & std & $\Delta \mathbf{w}$ & std \\
\hline 07:00 & 182,4 & 84,6 & 280,4 & 156,8 & 112 & 68,9 & 241,6 & 113,2 & 0,6 & 0,1 & 3,2 & 3 \\
\hline 09:00 & 261,2 & 85,5 & 504,2 & 74,1 & 113,8 & 66,1 & 276,8 & 122,3 & 2,2 & 0,1 & 7,9 & \\
\hline $10: 30$ & 271,1 & 114,3 & 406,0 & 90,0 & 57,7 & 37,5 & 258,1 & 162,2 & 2,5 & 0,6 & 15,0 & \\
\hline $12: 30$ & 209,4 & 115,8 & 390,3 & 73,1 & 61,6 & 45,3 & 120,6 & 40,0 & 2,8 & 0,3 & 17,3 & \\
\hline $14: 00$ & 209,9 & 116,9 & 360,6 & 99,7 & 70,1 & 37,2 & 135,1 & 62,4 & 2,8 & 0,3 & 12,6 & \\
\hline $15: 30$ & 165,4 & 110,4 & 340,6 & 100,5 & 65,8 & 23,8 & 120,4 & 65,8 & 2,7 & 0,3 & 11,8 & \\
\hline $17: 00$ & 144,8 & 89,7 & 300,2 & 89,5 & 70,12 & 41,8 & 110,5 & 42,1 & 2,6 & 0,2 & 10,5 & \\
\hline
\end{tabular}


Tab. A4 (Forts.): Tagesgang der stomatären Leitfähigkeit $\left(\mathrm{mmol} \mathrm{m} \mathrm{m}^{-2} \mathrm{~s}^{-1}\right)$, VPD $(\mathrm{kPa})$ und $\Delta \mathrm{w}$ $\left(P a \mathrm{kPa}^{-1}\right.$ ) bei Quercus robur und Q. petraea am 16.08.1999 (Q. robur) und 23.08.1999 (Q. petraea). Angegeben sind die Mittelwerte und Standardabweichungen von je fünf Bäumen pro Variante. $C$ Kontrolle, De Entlaubung 1998 und 1999, Dr Trockenheit 1999, DeDr Kombination aus De und Dr.

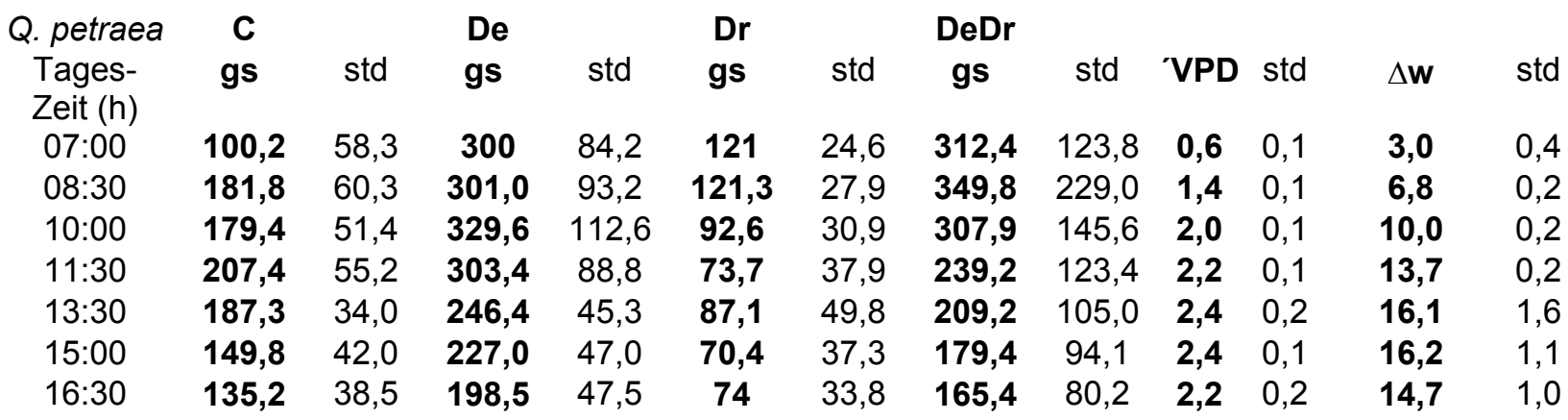

Tab. A5: $\Delta \mathrm{w}(\mathrm{MPa})$ zum Zeitpunkt der maximalen stomatären Leitfähigkeit bei Quercus robur und Q. petraea im Jahr 1999. Angegeben sind die Mittelwerte und Standardabweichungen von je fünf Bäumen pro Variante. C Kontrolle, De Entlaubung 1998 und 1999, Dr Trockenheit 1999, DeDr Kombination aus De und Dr.

$\begin{array}{cccccccccc}\begin{array}{c}\text { Tag des Jahres } \\ \text { Q. robur }\end{array} & \text { Datum } & \mathbf{C} & \text { std } & \text { De } & \text { std } & \text { Dr } & \text { std } & \text { DeDr } & \text { std } \\ 176 & 25.06 .99 & \mathbf{1 7 , 2} & 0,6 & \mathbf{1 2 , 0} & 0,4 & \mathbf{1 6 , 4} & 0,7 & \mathbf{1 4 , 0} & 0,2 \\ 183 & 02.07 .99 & \mathbf{2 8 , 2} & 0,6 & \mathbf{2 6 , 4} & 1,6 & \mathbf{2 9 , 8} & 0,4 & \mathbf{2 4 , 7} & 3,0 \\ 193 & 12.07 .99 & \mathbf{1 6 , 6} & 1,2 & \mathbf{1 7 , 1} & 1,4 & \mathbf{1 7 , 9} & 1,7 & \mathbf{2 6 , 0} & 1,7 \\ 198 & 17.07 .99 & \mathbf{1 1 , 6} & 0,6 & \mathbf{1 7 , 9} & 0,6 & \mathbf{1 8 , 7} & 1,3 & \mathbf{2 2 , 9} & 0,7 \\ 228 & 16.08 .99 & \mathbf{1 5 , 0} & 1,1 & \mathbf{7 , 9} & 0,2 & \mathbf{7 , 9} & 0,2 & \mathbf{7 , 9} & 0,2 \\ 236 & 24.08 .99 & \mathbf{1 4 , 2} & 0,5 & \mathbf{1 4 , 3} & 0,5 & \mathbf{1 3 , 7} & 0,9 & \mathbf{1 3 , 3} & 3,6 \\ & & & & & & & & & \\ \text { Tag des Jahres } & \text { Datum } & \mathbf{C} & \text { std } & \text { De } & \text { std } & \text { Dr } & \text { std } & \text { DeDr } & \text { Std } \\ \text { Q. petraea } & & & & & & & & & \\ 181 & 30.06 .99 & \mathbf{1 4 , 4} & 0,2 & \mathbf{1 9 , 8} & 0,7 & \mathbf{1 6 , 2} & 0,3 & \mathbf{2 1 , 4} & 0,4 \\ 183 & 02.07 .99 & \mathbf{2 0 , 6} & 0,1 & \mathbf{2 0 , 1} & 1,5 & \mathbf{2 0 , 1} & 0,3 & \mathbf{1 8 , 6} & 0,4 \\ 206 & 25.07 .99 & \mathbf{2 3 , 0} & 0,4 & \mathbf{1 1 , 6} & 0,7 & \mathbf{2 3 , 3} & 0,9 & \mathbf{2 7 , 7} & 2,6 \\ 235 & 23.08 .99 & \mathbf{1 3 , 7} & 0,2 & \mathbf{1 0 , 0} & 0,2 & \mathbf{6 , 8} & 0,2 & \mathbf{6 , 8} & 0,2 \\ 240 & 28.08 .99 & \mathbf{2 0 , 7} & 0,8 & \mathbf{1 8 , 6} & 1,3 & \mathbf{2 1 , 4} & 0,9 & \mathbf{1 4 , 3} & 0,8\end{array}$

Tab. A6: Tagestranspirationssumme $E_{d}\left(\mathrm{~mol} \mathrm{~d}^{-1} \mathrm{~m}^{-2}\right)$ bei Quercus robur und Q. petraea an drei Teminen im Jahr 1999. Angegeben sind die Mittelwerte und Standardabweichungen von je fünf Bäumen pro Variante. C Kontrolle, De Entlaubung 1998 und 1999, Dr Trockenheit 1999, DeDr Kombination aus De und Dr. Signifikante Unterschiede zwischen den Varianten sind mit Buchstaben gekennzeichnet.

\begin{tabular}{cclclcr} 
Q. robur & $\mathbf{1 7 . 0 7 . 9 9}$ & \multicolumn{1}{c}{ std } & $\mathbf{1 6 . 0 8 . 9 9}$ & std & $\mathbf{2 4 . 0 8 . 9 9}$ & std \\
C & $\mathbf{2 5 , 0}$ & 7,6 & $\mathbf{2 8 , 8}$ & $12,0 \mathrm{a}$ & $\mathbf{1 9 , 8}$ & $9,8 \mathrm{a}$ \\
De & $\mathbf{3 5 , 3}$ & 5,2 & $\mathbf{4 1 , 3}$ & $3,7 \mathrm{~b}$ & $\mathbf{3 8 , 6}$ & $3,8 \mathrm{~b}$ \\
Dr & $\mathbf{3 2 , 6}$ & 13,4 & $\mathbf{1 1 , 7}$ & $6,9 \mathrm{c}$ & $\mathbf{1 4 , 1}$ & $7,8 \mathrm{c}$ \\
DeDr & $\mathbf{3 9 , 2}$ & 9,9 & $\mathbf{2 4 , 5}$ & $8,8 \mathrm{ad}$ & $\mathbf{1 7 , 1}$ & $6,3 \mathrm{~d}$
\end{tabular}


Tab. A6 (Forts.): Tagestranspirationssumme $\mathrm{E}_{\mathrm{d}}\left(\mathrm{mol} \mathrm{d}^{-1} \mathrm{~m}^{-2}\right)$ bei Quercus robur und Q. petraea an drei Teminen im Jahr 1999. Angegeben sind die Mittelwerte und Standardabweichungen von je fünf Bäumen pro Variante. C Kontrolle, De Entlaubung 1998 und 1999, Dr Trockenheit 1999, DeDr Kombination aus De und Dr. Signifikante Unterschiede zwischen den Varianten sind mit Buchstaben gekennzeichnet.

$\begin{array}{ccccccc}\text { Q. petraea } & \mathbf{2 5 . 0 7 . 9 9} & \text { std } & \mathbf{2 3 . 0 8 . 9 9} & \text { std } & \mathbf{2 8 . 0 8 . 9 9} & \text { std } \\ \text { C } & \mathbf{2 9 , 1} & 9,1 & \mathbf{1 8 , 6} & 3,8 \mathrm{a} & \mathbf{2 7 , 1} & 6,8 \\ \text { De } & \mathbf{3 9 , 8} & 3,6 & \mathbf{2 3 , 3} & 2,3 \mathrm{a} & \mathbf{3 4 , 1} & 5,8 \\ \text { Dr } & \mathbf{3 4 , 1} & 6,4 & \mathbf{9 , 6} & 3,8 \mathrm{~b} & \mathbf{2 7 , 4} & 8,8 \\ \text { DeDr } & \mathbf{4 1 , 4} & 3,6 & \mathbf{2 0 , 3} & 7,1 \mathrm{a} & \mathbf{3 6 , 0} & 6,1\end{array}$

Tab. A7: Berechnete hydraulische Leitfähigkeit auf der Fließstrecke Boden-Blatt $\left(\mathrm{g}_{\mathrm{sl}}\right)$ an zwei Terminen vor und während der Trockenperiode 1999 (Werte in mmol m $\mathrm{m}^{-2} \mathrm{~s}^{-1} \mathrm{MPa}^{-1}$ ) bei Q. robur und Q. petraea. Die Berechnungen der Mittelwerte und Standardabweichungen erfolgten auf Grundlage von fünf Bäumen pro Variante. C Kontrolle, De Entlaubung 1998 und 1999, Dr Trockenheit 1999, DeDr Kombination aus De und Dr. Signifikante Unterschiede zwischen den Varianten sind mit Buchstaben gekennzeichnet.

$\begin{array}{ccccr}\text { Q. robur } & \mathbf{1 7 . 0 7 . 9 9} & \text { std } & \mathbf{1 6 . 0 8 . 9 9} & \text { std } \\ \text { C } & \mathbf{0 , 5 5} & 0,16 & \mathbf{0 , 4 5} & 0,24 \mathrm{a} \\ \text { De } & \mathbf{0 , 4 2} & 0,27 & \mathbf{0 , 4 4} & 0,19 \mathrm{a} \\ \text { Dr } & \mathbf{0 , 7 3} & 0,29 & \mathbf{0 , 0 7} & 0,02 \mathrm{~b} \\ \text { DeDr } & \mathbf{0 , 5 2} & 0,19 & \mathbf{0 , 1 0} & 0,03 \mathrm{~b} \\ & & & & \\ & & & & \\ \text { Q. petraea } & \mathbf{2 5 . 0 7 . 9 9} & \text { std } & \mathbf{2 3 . 0 8 . 9 9} & \text { std } \\ \text { C } & \mathbf{1 , 0 8} & 0,25 \mathrm{a} & \mathbf{0 , 6 8} & 0,17 \mathrm{a} \\ \text { De } & \mathbf{0 , 4 1} & 0,17 \mathrm{~b} & \mathbf{0 , 3 3} & 0,11 \mathrm{~b} \\ \text { Dr } & \mathbf{0 , 3 3} & 0,10 \mathrm{a} & \mathbf{0 , 1 4} & 0,06 \mathrm{c} \\ \text { DeDr } & \mathbf{0 , 1 7} & 0,05 \mathrm{~b} & \mathbf{0 , 0 9} & 0,04 \mathrm{~d}\end{array}$

Tab. A8: Ergebnisse der Druck/Volumen-Kurve bei Quercus robur und Q. petraea im Jahr 1999. Osmotisches Potential bei Sättigung $\left(\Pi_{0}\right.$, in $\left.\mathrm{MPa}\right)$ und am Turgornullpunkt $\left(\Pi_{\mathrm{P}}\right.$, in $\left.\mathrm{MPa}\right)$, der relative symplastische Wassergehalt am Turgornullpunkt (RWCsp, in \%), der relative Wassergehalt am Turgornullpunkt (RWCp, in \%) sowie der maximale Elastizitätsmodul ( $\varepsilon$, in MPa) gewonnen aus drei Parallen pro Variante. Die Messungen erfolgten an zwei Terminen: vor (Juni) und am Ende der Trockenperiode (September). Angegeben sind die Mittelwerte und Standardabweichungen pro Variante. C Kontrolle, De Entlaubung 1998 und 1999, Dr Trockenheit 1999, DeDr Kombination aus De und Dr. Signifikante Unterschiede zwischen den Terminen sind mit Buchstaben gekennzeichnet. ANOVA s. Tab. B3.

\begin{tabular}{|c|c|c|c|c|c|c|c|c|c|c|c|}
\hline Q. robur & & $\Pi_{0}$ & std & $\Pi_{\mathbf{P}}$ & std & $R_{W} C_{s p}$ & std & $R_{W} C_{p}$ & std & $\varepsilon$ & std \\
\hline C & Juni & $-1,9$ & 0,2 & $-2,4$ & 0,2 & 49,2 & $3,1 \mathrm{a}$ & 85,8 & 1,3 & 12,0 & 3,0 \\
\hline $\mathrm{De}$ & & $-1,6$ & 0,0 & $-2,1$ & $0,0 a$ & 55,5 & 7,4 & 83,8 & 3,5 & 11,0 & 1,1 \\
\hline $\mathrm{Dr}$ & & $-1,8$ & 0,1 & $-2,2$ & $0,1 a$ & 46,3 & 9,7 & 87,9 & 2,2 & 11,9 & $3,4 a$ \\
\hline DeDr & & $-1,5$ & $0,2 a$ & $-2,1$ & $0,2 a$ & 50,0 & 3,3 & 83,1 & 4,0 & 7,3 & 1,5 \\
\hline C & Sept. & $-1,8$ & 0,4 & $-2,6$ & 0,1 & 40,5 & $3,9 b$ & 85,2 & 2,3 & 8,1 & 2,4 \\
\hline $\mathrm{De}$ & & $-1,8$ & 0,2 & $-2,6$ & $0,3 b$ & 46,2 & 0,9 & 78,6 & 6,8 & 5,8 & 5,1 \\
\hline $\mathrm{Dr}$ & & $-1,9$ & 0,0 & $-2,6$ & $0,1 b$ & 37,0 & 3,5 & 84,7 & 0,7 & 5,5 & $0,0 \mathrm{~b}$ \\
\hline DeDr & & $-1,9$ & $0,2 b$ & $-2,8$ & $0,1 b$ & 45,7 & 10,3 & 79,8 & 5,4 & 6,3 & 3,7 \\
\hline
\end{tabular}


Tab. A8 (Forts.): Ergebnisse der Druck/Volumen-Kurve bei Quercus robur und Q. petraea im Jahr 1999. Osmotisches Potential bei Sättigung $\left(\Pi_{0}\right)$ und am Turgornullpunkt (ПР), der relative symplastische Wassergehalt am Turgornullpunkt (RWCsp), der relative Wassergehalt am Turgornullpunkt (RWCp) sowie der maximale Elastizitätsmodul $(\varepsilon)$ gewonnen aus drei Parallen pro Variante. Die Messungen erfolgten an zwei Terminen: vor (Juni) und am Ende der Trockenperiode (September). Angegeben sind die Mittelwerte und Standardabweichungen pro Variante. C Kontrolle, De Entlaubung 1998 und 1999, Dr Trockenheit 1999, DeDr Kombination aus De und Dr. Signifikante Unterschiede zwischen den Terminen sind mit Buchstaben gekennzeichnet. ANOVA s. Tab. B3.

\begin{tabular}{|c|c|c|c|c|c|c|c|c|c|c|}
\hline Q. & & $\Pi_{0}$ & std & $\Pi_{\mathbf{P}}$ & std & $R_{W} C_{s p}$ & std & RWCp & std & $\varepsilon$ \\
\hline C & Juni & $-2,1$ & 0,2 & $-2,8$ & 0,1 & 49,7 & 7,4 & 85,2 & 7,1 & 12,4 \\
\hline $\mathrm{De}$ & & $-1,7$ & 0,3 & $-2,4$ & $0,1 a$ & 58,2 & $2,5 a$ & 78,6 & 11,8 & 10,8 \\
\hline $\mathrm{Dr}$ & & $-1,9$ & 0,1 & $-2,6$ & 0,2 & 49,5 & $1,6 a$ & 83,0 & 5,5 & 8,9 \\
\hline DeDr & & $-1,6$ & 0,2 & $-2,3$ & 0,1 & 48,1 & 1,4 & 77,3 & 8,4 & 6,7 \\
\hline C & Sept. & $-2,1$ & 0,2 & $-2,7$ & 0,1 & 45,8 & 5,8 & 86,5 & 3,2 & 11,8 \\
\hline $\mathrm{De}$ & & $-1,7$ & 0,2 & $-2,6$ & $0,1 b$ & 37,7 & $7,6 b$ & 80,7 & 4,8 & 5,4 \\
\hline $\mathrm{Dr}$ & & $-2,0$ & 0,3 & $-2,8$ & 0,0 & 32,1 & $1,7 b$ & 85,4 & 3,1 & 9,7 \\
\hline DeDr & & $-1,8$ & 0,3 & $-2,7$ & 0,2 & 43,4 & 6,2 & 80,3 & 4,3 & 7,8 \\
\hline
\end{tabular}

Tab. A9: Berechnete Änderung der Osmotikagehalte bei Quercus robur und Q. petraea zwischen Juni (vor Trockenstress) und September (nach Trockenstress) im Jahr 1999. Die Werte sind für den Bereich bei Sättigung, (Quotient der $\Pi_{P}{ }^{*} R W C_{s}$-Werte von Juni und September) und am Turgornullpunkt (Quotient der $\Pi_{0}{ }^{*} \mathrm{RWC}_{\mathrm{s}}$ von Juni und September) ermittelt worden. Angegeben sind die Mittelwerte und Standardabweichungen von je vier Bäumen pro Variante. C Kontrolle, De Entlaubung 1998 und 1999, Dr Trockenheit 1999, DeDr Kombination aus De und Dr.

$\begin{array}{ccccc}\text { Q. robur } & \Pi_{\mathrm{P}}{ }^{*} \mathrm{RWC} \mathrm{C}_{\mathrm{s}} & \text { std } & \Pi_{0}{ }^{*} \mathrm{RWC} \mathrm{C}_{\mathrm{s}} & \text { std } \\ \text { C } & \mathbf{0 , 5} & 0,5 & \mathbf{0 , 8} & 0,1 \\ \mathrm{De} & \mathbf{0 , 7} & 0,1 & \mathbf{0 , 9} & 0,3 \\ \mathrm{Dr} & \mathbf{0 , 6} & 0,1 & \mathbf{0 , 8} & 0,1 \\ \text { DeDr } & \mathbf{0 , 5} & 0,4 & \mathbf{0 , 7} & 0,1 \\ & & & & \\ \text { Q. petraea } & \Pi_{\mathrm{P}}{ }^{*} \mathrm{RWC} \mathrm{C}_{\mathrm{s}} & \text { std } & \Pi_{0^{*}} \mathrm{RWC}_{\mathrm{s}} & \text { std } \\ \text { C } & \mathbf{0 , 9} & 0,1 & \mathbf{0 , 8} & 0,1 \\ \text { De } & \mathbf{0 , 6} & 0,1 & \mathbf{0 , 8} & 0,3 \\ \mathrm{Dr} & \mathbf{0 , 4} & 0,4 & \mathbf{0 , 4} & 0,4 \\ \text { DeDr } & \mathbf{0 , 8} & 0,2 & \mathbf{0 , 8} & 0,1\end{array}$

Tab. A10: Blattfläche $\left(\mathrm{m}^{2}\right)$, Blattbiomasse ( $\mathrm{g} \mathrm{TG}$ ) und spezifische Blattfläche (SLA, in $\mathrm{cm}^{2} \mathrm{~g}^{-1} \mathrm{TG}$ ) bei Quercus robur und Q. petraea am Ende der Vegetationsperiode 1999. Angegeben sind die Mittelwerte und Standardabweichungen von je fünf Bäumen pro Variante. C Kontrolle, De Entlaubung 1998 und 1999, Dr Trockenheit 1999, DeDr Kombination aus De und Dr. Signifikante Unterschiede zwischen den Varianten sind mit Buchstaben gekennzeichnet.

$\begin{array}{lccccccr}\text { Art } & \text { Variante } & \text { Blattfläche } & \text { std } & \text { Blattmasse } & \text { std } & \text { SLA } & \text { std } \\ \text { Q. robur } & \mathrm{C} & \mathbf{0 , 3} & 0,1 \mathrm{a} & \mathbf{2 0 , 3} & 6,3 \mathrm{a} & \mathbf{1 3 0 , 1} & 12,4 \mathrm{a} \\ & \mathrm{De} & \mathbf{0 , 1} & 0,0 \mathrm{~b} & \mathbf{1 1 , 8} & 2,3 \mathrm{~b} & \mathbf{9 8 , 5} & 16,7 \mathrm{~b} \\ & \mathrm{Dr} & \mathbf{0 , 2} & 0,1 \mathrm{a} & \mathbf{1 9 , 3} & 5,6 \mathrm{a} & \mathbf{1 2 4 , 4} & 15,4 \mathrm{a} \\ & \mathrm{DeDr} & \mathbf{0 , 1} & 0,0 \mathrm{~b} & \mathbf{9 , 8} & 1,4 \mathrm{~b} & \mathbf{1 0 2 , 6} & 15,5 \mathrm{~b}\end{array}$


Tab. A10 (Forts.): Blattfläche $\left(\mathrm{m}^{2}\right)$, Blattbiomasse ( $\mathrm{g}$ TG) und spezifische Blattfläche (SLA, in $\mathrm{cm}^{2}$ $\mathrm{g}^{-1}$ TG) bei Quercus robur und Q. petraea am Ende der Vegetationsperiode 1999. Angegeben sind die Mittelwerte und Standardabweichungen von je fünf Bäumen pro Variante. C Kontrolle, De Entlaubung 1998 und 1999, Dr Trockenheit 1999, DeDr Kombination aus De und Dr. Signifikante Unterschiede zwischen den Varianten sind mit Buchstaben gekennzeichnet.

$\begin{array}{cccccccc}\text { Art } & \text { Variante } & \text { Blattfläche } & \text { std } & \text { Blattmasse } & \text { std } & \text { SLA } & \text { std } \\ \text { Q. petraea } & \mathrm{C} & \mathbf{0 , 3} & 0,1 \mathrm{a} & \mathbf{2 4 , 7} & 7,2 \mathrm{a} & \mathbf{1 3 3 , 4} & 6,6 \mathrm{a} \\ & \mathrm{De} & \mathbf{0 , 1} & 0,0 \mathrm{~b} & \mathbf{1 0 , 3} & 3,5 \mathrm{~b} & \mathbf{9 6 , 2} & 7,1 \mathrm{~b} \\ & \mathrm{Dr} & \mathbf{0 , 1} & 0,0 \mathrm{a} & \mathbf{5 , 5} & 1,6 \mathrm{c} & \mathbf{1 1 1 , 2} & 22,3 \mathrm{a} \\ & \mathrm{DeDr} & \mathbf{0 , 2} & 0,1 \mathrm{~b} & \mathbf{1 5 , 1} & \mathbf{2 , 9 d} & \mathbf{1 3 7 , 7} & 8,5 \mathrm{~b}\end{array}$

Tab. A11: Wurzelbiomasse ( $\mathrm{g}$ TG) und Blatt/Feinwurzel-Verhältnis (B/FW, in $\mathrm{g} \mathrm{g}^{-1}$ ) bei Quercus robur und Q. petraea am Ende der Vegetationsperiode 1999. Angegeben sind die Mittelwerte und Standardabweichungen von je fünf (Dr und DeDr) bzw. drei (C und De) Bäumen pro Variante, getrennt nach einzelnen Grössenklassen sowie die Gesamtwurzelbiomasse.C Kontrolle, De Entlaubung 1998 und 1999, Dr Trockenheit 1999, DeDr Kombination aus De und Dr. Signifikante Unterschiede zwischen den Varianten $(<2 \mathrm{~mm}$ und B/FW) sind mit Buchstaben gekennzeichnet.

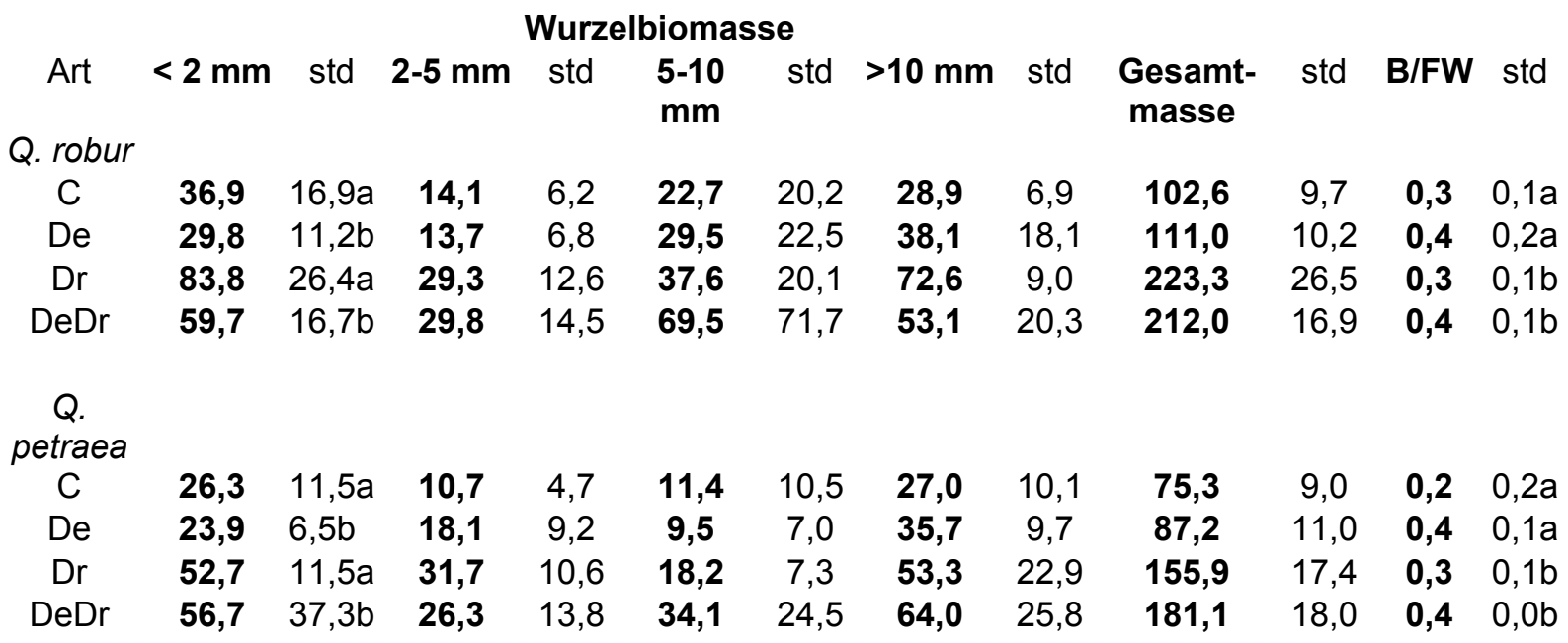

Tab. A12: Höhen- und Durchmesserzuwachs (in \% zum Startwert 1998) bei Quercus robur und Q. petraea am Ende der Vegetationsperiode 1999. Angegeben sind die Mittelwerte und Standardabweichungen von je fünf Bäumen pro Variante. C Kontrolle, De Entlaubung 1998 und 1999, Dr Trockenheit 1999, DeDr Kombination aus De und Dr. Signifikante Unterschiede zwischen den Varianten sind mit Buchstaben gekennzeichnet.

$\begin{array}{cclcc}\text { Q. robur } & \text { Höhe } & \text { std } & \text { Durchmesser } & \text { std } \\ \text { C } & \mathbf{1 4 , 5} & 10,1 \mathrm{a} & \mathbf{3 1 , 8} & 5,9 \mathrm{a} \\ \text { De } & \mathbf{7 , 0} & 9,5 \mathrm{~b} & \mathbf{1 6 , 6} & 6,3 \mathrm{~b} \\ \text { Dr } & \mathbf{1 6 , 1} & 10,3 \mathrm{a} & \mathbf{2 4 , 5} & 6,0 \mathrm{a} \\ \text { DeDr } & \mathbf{2 , 9} & 6,8 \mathrm{~b} & \mathbf{1 9 , 7} & 16,2 \mathrm{~b} \\ & & & & \\ \text { Q. petraea } & & & & \\ \text { C } & \mathbf{7 , 9} & 5,5 & \mathbf{3 4 , 3} & 7,1 \mathrm{a} \\ \text { De } & \mathbf{4 , 9} & 9,7 & \mathbf{1 7 , 3} & 5,9 \mathrm{~b} \\ \text { Dr } & \mathbf{7 , 6} & 4,4 & \mathbf{2 7 , 7} & 12,4 \mathrm{a} \\ \text { DeDr } & \mathbf{2 , 0} & 8,2 & \mathbf{2 2 , 6} & 18,3 \mathrm{~b}\end{array}$


Tab. A13: Ergebnisse der Blattanalyse bei Quercus robur und Q. petraea im Jahr 1999. Dargestellt sind die $\mathrm{N}$-Gehalte $\left(\mathrm{mg} \mathrm{cm}^{-2}\right)$, das $\mathrm{C} / \mathrm{N}-$ Verhältnis im Blatt sowie das $\delta^{13} \mathrm{C}$-Isotopenverhältnis $(\%)$. Angegeben sind die Mittelwerte und Standardabweichungen von je fünf Bäumen pro Variante. $C$ Kontrolle, De Entlaubung 1998 und 1999, Dr Trockenheit 1999, DeDr Kombination aus De und Dr. Signifikante Unterschiede zwischen den Varianten sind mit Buchstaben gekennzeichnet.

$\begin{array}{ccccccc}\text { Q. robur } & \mathbf{N} & \text { std } & \mathbf{C / N} & \text { std } & \delta^{\mathbf{1 3}} \mathbf{C} & \text { std } \\ \text { C } & \mathbf{0 , 1 3} & 0,02 a & \mathbf{2 7 , 7} & 3,6 \mathrm{a} & \mathbf{- 2 8 , 8} & 1,0 \\ \text { De } & \mathbf{0 , 2 4} & 0,05 b & \mathbf{1 9 , 0} & 4,3 b & \mathbf{- 2 8 , 5} & 0,2 \\ \text { Dr } & \mathbf{0 , 1 5} & 0,04 \mathrm{a} & \mathbf{2 7 , 2} & 3,9 \mathrm{a} & \mathbf{- 2 8 , 4} & 0,5 \\ \text { DeDr } & \mathbf{0 , 2 1} & 0,04 \mathrm{~b} & \mathbf{2 0 , 8} & 9,5 \mathrm{~b} & \mathbf{- 2 8 , 1} & 0,5 \\ & & & & & & \\ \text { Q. petraea } & & & & & & \\ \text { C } & \mathbf{0 , 1 2} & 0,01 \mathrm{a} & \mathbf{2 6 , 3} & 7,8 \mathrm{a} & \mathbf{- 2 9 , 0} & 0,7 \\ \text { De } & \mathbf{0 , 2 1} & 0,02 \mathrm{~b} & \mathbf{2 1 , 6} & 2,3 \mathrm{~b} & \mathbf{- 2 8 , 8} & 0,3 \\ \text { Dr } & \mathbf{0 , 1 2} & 0,01 \mathrm{a} & \mathbf{2 4 , 3} & 9,7 \mathrm{a} & \mathbf{- 2 8 , 7} & 0,1 \\ \text { DeDr } & \mathbf{0 , 2 1} & 0,06 \mathrm{~b} & \mathbf{1 9 , 5} & 6,0 \mathrm{~b} & \mathbf{- 2 8 , 9} & 0,6\end{array}$

Tab. A14: Chlorophyllgehalte $\left(\mu \mathrm{g} / \mathrm{cm}^{2}\right)$ in Blättern von Quercus robur und Q. petraea während der Vegetationsperiode 1999 und 2000 an fünf (1999) resp. vier (2000) Untersuchungsterminen.

Angegeben sind die Mittelwerte und Standardabweichungen von je fünf (1999) bzw. sechs (2000) Bäumen pro Variante. Varianten 1999: C Kontrolle, De Entlaubung 1998 und 1999, Dr Trockenheit 1999, DeDr Kombination aus De und Dr. Varianten 2000: C Kontrolle, De Entlaubung 1998 und 1999, Dr Trockenheit 2000, DeDr Kombination aus De und Dr.

$\begin{array}{ccccccccccc}1999 & & & & & & & & & & \\ \text { Q. robur } & \mathbf{0 2 . 0 7 . 9 9} & \text { std } & \mathbf{2 0 . 0 7 . 9 9} & \text { std } & \mathbf{3 0 . 0 7 . 9 9} & \text { std } & \mathbf{1 2 . 0 8 . 9 9} & \text { std } & \mathbf{2 4 . 0 8 . 9 9} & \text { std } \\ \text { C } & \mathbf{2 3 , 4} & 1,9 \mathrm{a} & \mathbf{2 4 , 7} & 1,5 \mathrm{a} & \mathbf{2 4 , 6} & 1,2 \mathrm{a} & \mathbf{2 5 , 4} & 1,1 \mathrm{a} & \mathbf{2 6 , 0} & 1,2 \mathrm{a} \\ \text { De } & \mathbf{2 9 , 1} & 4,5 \mathrm{~b} & \mathbf{3 3 , 0} & 2,8 \mathrm{~b} & \mathbf{3 2 , 2} & 3,1 \mathrm{~b} & \mathbf{3 4 , 2} & 3,0 \mathrm{~b} & \mathbf{3 5 , 3} & 2,5 \mathrm{~b} \\ \text { Dr } & \mathbf{2 3 , 2} & 2,7 \mathrm{a} & \mathbf{2 5 , 2} & 2,6 \mathrm{a} & \mathbf{2 6 , 2} & 2,8 \mathrm{a} & \mathbf{2 5 , 1} & 4,5 \mathrm{a} & \mathbf{2 6 , 1} & 3,7 \mathrm{a} \\ \text { DeDr } & \mathbf{3 0 , 4} & 3,6 \mathrm{~b} & \mathbf{3 1 , 8} & 3,9 \mathrm{~b} & \mathbf{3 1 , 4} & 2,3 \mathrm{~b} & \mathbf{3 2 , 8} & 3,9 \mathrm{~b} & \mathbf{3 2 , 8} & 5,0 \mathrm{~b} \\ & & & & & & & & & & \\ \text { Q- petraea } & & & & & & & & & & \\ \text { C } & \mathbf{2 2 , 9} & 2,0 & \mathbf{2 4 , 4} & 0,8 \mathrm{a} & \mathbf{2 4 , 7} & 2,1 \mathrm{a} & \mathbf{2 5 , 6} & 1,9 \mathrm{a} & \mathbf{2 5 , 6} & 2,0 \mathrm{a} \\ \text { De } & \mathbf{2 3 , 8} & 2,1 & \mathbf{2 7 , 3} & 1,6 \mathrm{~b} & \mathbf{2 8 , 5} & 2,7 \mathrm{~b} & \mathbf{3 0 , 7} & 1,8 \mathrm{~b} & \mathbf{2 9 , 8} & 2,0 \mathrm{~b} \\ \text { Dr } & \mathbf{2 4 , 7} & 2,8 & \mathbf{2 7 , 1} & 2,6 \mathrm{c} & \mathbf{2 6 , 9} & 2,6 \mathrm{a} & \mathbf{2 6 , 1} & 3,3 \mathrm{a} & \mathbf{2 6 , 9} & 3,7 \mathrm{a} \\ \text { DeDr } & \mathbf{2 2 , 7} & 1,2 & \mathbf{3 0 , 0} & 1,7 \mathrm{~d} & \mathbf{2 8 , 4} & 1,1 \mathrm{~b} & \mathbf{2 9 , 0} & 2,6 \mathrm{~b} & \mathbf{3 0 , 9} & 4,4 \mathrm{~b} \\ & & & & & & & & & & \\ \mathbf{2 0 0 0} & & & & & & & & & & \\ \text { Q. robur } & \mathbf{2 2 . 0 6 . 0 0} & \text { std } & \mathbf{2 0 . 0 7 . 0 0} & \text { std } & \mathbf{2 2 . 0 8 . 0 0} & \text { std } & \mathbf{2 2 . 0 9 . 0 0} & \text { std } & & \\ \text { C } & \mathbf{3 1 , 9} & 3,9 & \mathbf{3 1 , 4} & 3,9 & \mathbf{3 0 , 9} & 2,6 & \mathbf{2 9 , 8} & 2,5 & & \\ \text { De } & \mathbf{3 3 , 3} & 3,6 & \mathbf{3 1 , 1} & 2,5 & \mathbf{3 0 , 3} & 2,9 & \mathbf{3 1 , 2} & 4,3 & & \\ \text { Dr } & \mathbf{3 0 , 4} & 1,9 & \mathbf{3 0 , 3} & 1,9 & \mathbf{2 8 , 1} & 1,6 & \mathbf{2 6 , 5} & 3,6 & & \\ \text { DeDr } & \mathbf{3 2 , 8} & 3,1 & \mathbf{3 1 , 7} & 3,3 & \mathbf{2 9 , 6} & 2,8 & \mathbf{2 8 , 7} & 1,0 & & \\ & & & & & & & & & & \\ \text { Q- petraea } & & & & & & & & & & \\ \text { C } & \mathbf{2 7 , 7} & 1,1 & \mathbf{2 9 , 4} & 3,1 \mathrm{a} & \mathbf{2 8 , 0} & 2,0 & \mathbf{2 6 , 8} & 2,6 & & \\ \text { De } & \mathbf{2 6 , 2} & 1,6 & \mathbf{2 4 , 9} & 1,2 \mathrm{~b} & \mathbf{2 4 , 0} & 1,9 & \mathbf{2 5 , 3} & 1,5 & & \\ \text { Dr } & \mathbf{2 9 , 9} & 4,0 & \mathbf{2 7 , 5} & 1,6 \mathrm{a} & \mathbf{2 7 , 3} & 3,3 & \mathbf{2 7 , 6} & 2,6 & & \\ \text { DeDr } & \mathbf{2 7 , 1} & 3,0 & \mathbf{2 5 , 7} & 2,5 \mathrm{~b} & \mathbf{2 7 , 4} & 2,9 & \mathbf{2 7 , 7} & 2,1 & & \\ & & & & & & & & & & \end{array}$


Tab. A15: Predawn- und nachmittägliche (Afternoon)- Wasserpotentiale (MPa) bei Quercus robur und Q. petraea im Untersuchungsjahr 2000. Angegeben sind die Mittelwerte und Standardabweichungen von je sechs Bäumen pro Variante. C Kontrolle, De Entlaubung 1998 und 1999, Dr Trockenheit 2000, DeDr Kombination aus De und Dr. Signifikante Unterschiede zwischen allen trockengestressten und allen ausreichend bewässerten Varianten sind mit * gekennzeichnet.

\begin{tabular}{|c|c|c|c|c|c|c|c|c|c|}
\hline Predawn & & & & & & & & & \\
\hline Q. robur & C & std & De & std & $\mathrm{Dr}$ & std & DeDr & std & \\
\hline 21.06 .00 & $-0,8$ & 0,4 & $-0,7$ & 0,5 & $-0,6$ & 0,5 & $-0,5$ & 0,1 & \\
\hline 29.06 .00 & $-0,4$ & 0,4 & $-0,3$ & 0,5 & $-0,4$ & 0,5 & $-0,5$ & 0,1 & \\
\hline 29.07 .00 & $-0,4$ & 0,2 & $-0,2$ & 0,1 & $-1,9$ & 0,3 & $-1,6$ & 0,4 & \\
\hline 15.08 .00 & $-0,7$ & 0,3 & $-0,8$ & 0,3 & $-0,9$ & 0,2 & $-0,7$ & 0,3 & \\
\hline 22.08 .00 & $-0,2$ & 0,0 & $-0,2$ & 0,0 & $-0,7$ & 0,1 & $-0,6$ & 0,2 & \\
\hline 12.09 .00 & $-0,2$ & 0,1 & $-0,3$ & 0,2 & $-0,7$ & 0,2 & $-0,6$ & 0,1 & \\
\hline Q. petraea & C & std & De & std & $\mathrm{Dr}$ & std & DeDr & std & \\
\hline 21.06 .00 & $-0,5$ & 0,4 & $-0,4$ & 0,5 & $-0,4$ & 0,5 & $-0,6$ & 0,2 & \\
\hline 29.06 .00 & $-0,4$ & 0,4 & $-0,3$ & 0,5 & $-0,3$ & 0,5 & $-0,5$ & 0,1 & \\
\hline 29.07 .00 & $-0,2$ & 0,1 & $-0,3$ & 0,1 & $-1,8$ & 0,3 & $-1,7$ & 0,5 & \\
\hline 15.08 .00 & $-0,8$ & 0,2 & $-0,7$ & 0,2 & $-0,9$ & 0,2 & $-0,8$ & 0,1 & \\
\hline 22.08 .00 & $-0,1$ & 0,0 & $-0,2$ & 0,0 & $-0,9$ & 0,2 & $-0,6$ & 0,1 & \\
\hline 12.09 & $-0,1$ & 0,1 & $-0,2$ & 0,0 & $-0,6$ & 0,3 & $-0,6$ & 0,2 & \\
\hline
\end{tabular}

$\begin{array}{cccccccccc}\begin{array}{c}\text { Afternoon } \\ \text { Q. robur }\end{array} & \text { C } & \text { std } & \text { De } & \text { std } & \text { Dr } & \text { std } & \text { DeDr } & \text { std } & \\ 20.06 .00 & \mathbf{- 1 , 6} & 0,6 & \mathbf{- 2 , 9} & 0,5 & \mathbf{- 2 , 3} & 0,5 & \mathbf{- 2 , 5} & 0,7 & \\ 29.07 .00 & \mathbf{- 2 , 7} & 0,6 & \mathbf{- 2 , 6} & 0,5 & \mathbf{- 2 , 6} & 0,4 & \mathbf{- 3 , 0} & 0,5 & \\ 14.08 .00 & \mathbf{- 2 , 3} & 0,3 & \mathbf{- 2 , 7} & 0,5 & \mathbf{- 2 , 3} & 0,3 & \mathbf{- 2 , 7} & 0,4 & \text { * } \\ 22.08 .00 & \mathbf{- 2 , 5} & 0,3 & \mathbf{- 2 , 4} & 0,7 & \mathbf{- 1 , 7} & 0,3 & \mathbf{- 2 , 4} & 0,4 & \\ 11.09 .00 & \mathbf{- 2 , 9} & 0,2 & \mathbf{- 3 , 0} & 0,2 & \mathbf{- 2 , 8} & 0,4 & \mathbf{- 2 , 7} & 0,3 & \\ & & & & & & & & & \\ \text { Q. petraea } & \text { C } & \text { std } & \text { De } & \text { std } & \text { Dr } & \text { std } & \text { DeDr } & \text { std } & \\ 20.06 .00 & \mathbf{- 2 , 1} & 0,6 & \mathbf{- 2 , 1} & 0,6 & \mathbf{- 1 , 8} & 0,8 & \mathbf{- 2 , 0} & 0,6 & \\ 29.07 .00 & \mathbf{- 2 , 4} & 0,3 & \mathbf{- 2 , 0} & 0,2 & \mathbf{- 2 , 9} & 0,4 & \mathbf{- 2 , 9} & 0,2 & \text { * } \\ 14.08 .00 & \mathbf{- 2 , 6} & 0,5 & \mathbf{- 2 , 8} & 0,2 & \mathbf{- 2 , 7} & 0,6 & \mathbf{- 3 , 1} & 0,3 & \\ 22.08 .00 & \mathbf{- 2 , 6} & 0,4 & \mathbf{- 2 , 3} & 0,4 & \mathbf{- 2 , 7} & 1,2 & \mathbf{- 2 , 3} & 0,2 & \\ 11.09 .00 & \mathbf{- 2 , 9} & 0,2 & \mathbf{- 2 , 8} & 0,1 & \mathbf{- 3 , 1} & 0,3 & \mathbf{- 2 , 9} & 0,3 & \end{array}$

Tab. A16: Blattwassergehalt ( $R W C_{\text {leaf }}$ in \%) bei Quercus robur und Q. petraea im Untersuchungsjahr 2000. Angegeben sind die Mittelwerte und Standardabweichungen von je sechs Bäumen pro Variante. C Kontrolle, De Entlaubung 1998 und 1999, Dr Trockenheit 2000, DeDr Kombination aus De und Dr.

\begin{tabular}{lcccccccc} 
Q. robur & $\mathbf{C}$ & \multicolumn{3}{c}{$\mathrm{De}$} & \multicolumn{3}{c}{$\mathrm{Dr}$} & \multicolumn{3}{c}{$\mathrm{DeDr}$} \\
28.06 .00 & $\mathbf{9 0 , 0}$ & 2,0 & $\mathbf{8 9 , 5}$ & 2,9 & $\mathbf{8 8 , 2}$ & 3,3 & $\mathbf{8 8 , 4}$ & 1,7 \\
02.08 .00 & $\mathbf{8 9 , 4}$ & 1,4 & $\mathbf{8 9 , 9}$ & 1,5 & $\mathbf{9 2 , 3}$ & 0,6 & $\mathbf{9 2 , 5}$ & 3,4 \\
17.08 .00 & $\mathbf{9 0 , 7}$ & 1,3 & $\mathbf{9 0 , 7}$ & 2,2 & $\mathbf{8 9 , 2}$ & 1,1 & $\mathbf{9 0 , 3}$ & 1,3 \\
30.08 .00 & $\mathbf{8 9 , 5}$ & 1,8 & $\mathbf{9 1 , 1}$ & 3,6 & $\mathbf{8 8 , 4}$ & 2,0 & $\mathbf{8 9 , 9}$ & 0,6 \\
& & & & & & & & \\
Q. petraea & $\mathbf{C}$ & & $\mathbf{D e}$ & & $\mathbf{D r}$ & & $\mathbf{D e D r}$ & \\
28.06 .00 & $\mathbf{8 7 , 4}$ & 3,8 & $\mathbf{8 9 , 4}$ & 3,0 & $\mathbf{8 8 , 2}$ & 3,8 & $\mathbf{8 9 , 6}$ & 1,1 \\
02.08 .00 & $\mathbf{9 0 , 1}$ & 1,3 & $\mathbf{8 6 , 8}$ & 1,7 & $\mathbf{9 0 , 1}$ & 2,7 & $\mathbf{8 7 , 8}$ & 2,0 \\
17.08 .00 & $\mathbf{9 0 , 6}$ & 1,3 & $\mathbf{9 0 , 6}$ & 1,1 & $\mathbf{8 4 , 1}$ & 4,9 & $\mathbf{8 7 , 7}$ & 1,8 \\
30.08 .00 & $\mathbf{8 9 , 1}$ & 1,2 & $\mathbf{9 0 , 3}$ & 0,8 & $\mathbf{9 0 , 3}$ & 2,1 & $\mathbf{8 8 , 1}$ & 1,9
\end{tabular}


Tab. A17: Maximale stomatäre Leitfähigkeit $\left(\mathrm{mmol} \mathrm{m}^{-2} \mathrm{~s}^{-1}\right)$ bei Quercus robur und Q. petraea im Jahr 2000. Angegeben sind die Mittelwerte und Standardabweichungen von je sechs Bäumen pro Variante. C Kontrolle, De Entlaubung 1998 und 1999, Dr Trockenheit 2000, DeDr Kombination aus De und Dr. Signifikante Unterschiede zwischen den Varianten sind mit Buchstaben gekennzeichnet.

\begin{tabular}{|c|c|c|c|c|c|c|c|c|}
\hline Q. robur & C & std & $\mathrm{De}$ & std & $\mathrm{Dr}$ & std & DeDr & std \\
\hline 20.06 .00 & 278,8 & 67,2 & 282,3 & 73,3 & 229,2 & 89,2 & 209,9 & 124,7 \\
\hline 01.08 .00 & 306,1 & $67,2 \mathrm{a}$ & 257,7 & $89,1 a$ & 12,5 & $7,1 \mathrm{~b}$ & 14,6 & $5,7 \mathrm{c}$ \\
\hline 14.0 & 304,5 & 85,2 & 252,7 & 109,8 & 167,0 & 120,2 & 175,5 & 111,6 \\
\hline 24.08 .00 & 303,4 & $83,5 a$ & 304,0 & $106,6 a$ & 155,6 & $54,4 b$ & 157,1 & $44,9 b$ \\
\hline ea & C & std & $\mathrm{De}$ & std & Dr & std & DeDr & std \\
\hline 20.0 & 241,8 & $48,5 a$ & 196,8 & $62,3 b$ & 157,9 & $61,0 c$ & & $48,2 d$ \\
\hline 01. & 225,0 & $83,1 a$ & 169,4 & $83,5 a$ & 34,2 & $27,5 b$ & 86,6 & $52,6 \mathrm{~b}$ \\
\hline & 220,4 & $74,5 a$ & 190,6 & $83,5 a$ & 145,8 & $41,1 \mathrm{~b}$ & 129,6 & $40,8 b$ \\
\hline 24.08 . & 207,6 & $50,9 a$ & 193,0 & $43,0 a$ & 81,1 & $44,2 \mathrm{~b}$ & 118,6 & $47,7 \mathrm{~b}$ \\
\hline
\end{tabular}

Tab. A18: Tagesgang der stomatären Leitfähigkeit $\left(\mathrm{mmol} \mathrm{m}^{-2} \mathrm{~s}^{-1}\right)$, VPD $(\mathrm{kPa})$ und $\Delta \mathrm{w}\left(\mathrm{Pa} \mathrm{kPa}^{-1}\right)$ bei Quercus robur und Q. petraea am 01.08.2000. Angegeben sind die Mittelwerte und

Standardabweichungen von je sechs Bäumen pro Variante. C Kontrolle, De Entlaubung 1998 und 1999, Dr Trockenheit 2000, DeDr Kombination aus De und Dr.

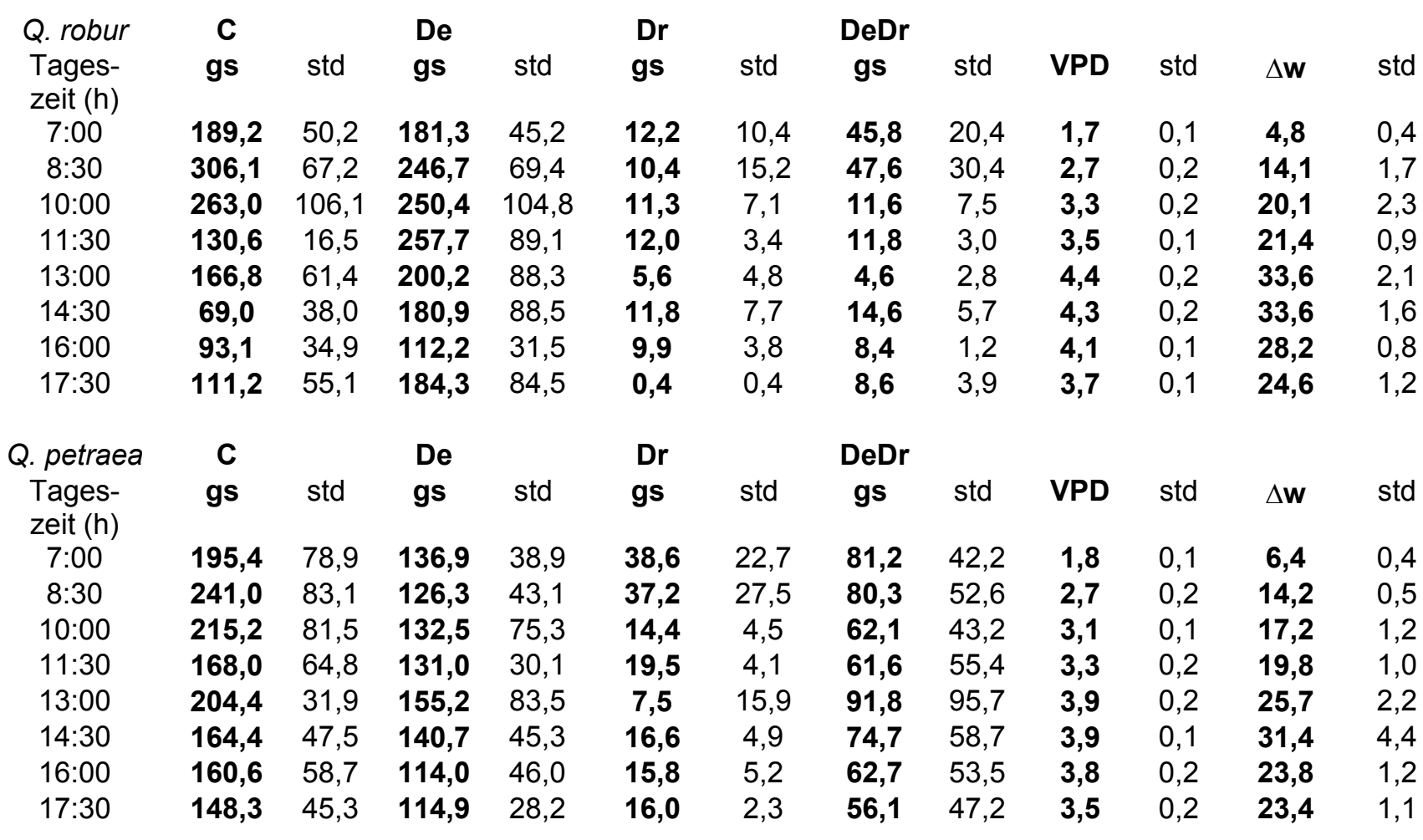


Tab. A19: $\Delta \mathrm{w}$ (MPa) zum Zeitpunkt der maximalen stomatären Leitfähigkeit bei Quercus robur und Q. petraea im Jahr 2000. Angegeben sind die Mittelwerte und Standardabweichungen von je sechs Bäumen pro Variante. C Kontrolle, De Entlaubung 1998 und 1999, Dr Trockenheit 2000, DeDr Kombination aus De und Dr.

$\begin{array}{cccccccccc} & \text { Datum } & \mathbf{C} & \text { std } & \text { De } & \text { std } & \text { Dr } & \text { std } & \text { DeDr } & \text { std } \\ \text { Q. robur } & 20.06 .00 & \mathbf{4 4 , 9} & 1,0 & \mathbf{4 4 , 9} & 1,08 & \mathbf{1 5 , 8} & 0,54 & \mathbf{2 5 , 9} & 0,7 \\ & 01.08 .00 & \mathbf{1 4 , 1} & 1,7 & \mathbf{2 1 , 4} & 0,9 & \mathbf{4 , 8} & 0,4 & \mathbf{1 4 , 1} & 1,7 \\ & 14.08 .00 & \mathbf{4 , 6} & 0,2 & \mathbf{1 3 , 8} & 0,9 & \mathbf{4 , 6} & 0,2 & \mathbf{1 3 , 8} & 0,9 \\ & 24.08 .00 & \mathbf{6 , 9} & 0,4 & \mathbf{1 0 , 0} & 0,9 & \mathbf{6 , 9} & 0,32 & \mathbf{1 0 , 0} & 0,9 \\ & & & & & & & & & \\ \text { Q. petraea } & 20.06 .00 & \mathbf{1 5 , 6} & 0,7 & \mathbf{1 5 , 6} & 0,7 & \mathbf{1 5 , 6} & 0,70 & \mathbf{1 5 , 6} & 0,7 \\ & 01.08 .00 & \mathbf{1 4 , 2} & 0,5 & \mathbf{2 5 , 7} & 2,2 & \mathbf{6 , 4} & 0,4 & \mathbf{2 5 , 7} & 2,2 \\ & 14.08 .00 & \mathbf{7 , 0} & 0,8 & \mathbf{1 3 , 7} & 0,6 & \mathbf{7 , 0} & 0,8 & \mathbf{7 , 0} & 0,8 \\ & 24.08 .00 & \mathbf{1 0 , 6} & 0,6 & \mathbf{1 0 , 6} & 0,6 & \mathbf{5 , 5} & 0,3 & \mathbf{1 0 , 6} & 0,6\end{array}$

Tab. A20: Tagestranspirationssumme $\mathrm{E}_{\mathrm{d}}\left(\mathrm{mol} \mathrm{d}^{-1} \mathrm{~m}^{-2}\right)$ bei Quercus robur und Q. petraea an drei Teminen im Jahr 2000. Angegeben sind die Mittelwerte und Standardabweichungen von je sechs Bäumen pro Variante. C Kontrolle, De Entlaubung 1998 und 1999, Dr Trockenheit 2000, DeDr Kombination aus De und Dr. Signifikante Unterschiede zwischen den Varianten sind mit Buchstaben gekennzeichnet.

$\begin{array}{ccccccc}\text { Q. robur } & \mathbf{0 1 . 0 8 . 2 0 0 0} & \text { std } & \mathbf{1 4 . 0 8 . 2 0 0 0} & \text { std } & \mathbf{2 4 . 0 8 . 2 0 0 0} & \text { std } \\ \text { C } & \mathbf{2 1 , 6} & 8,6 \mathrm{a} & \mathbf{2 4 , 6} & 8,3 \mathrm{a} & \mathbf{2 6 , 3} & 5,8 \mathrm{a} \\ \text { De } & \mathbf{2 6 , 9} & 5,4 \mathrm{a} & \mathbf{2 8 , 9} & 11,1 \mathrm{a} & \mathbf{2 8 , 5} & 8,0 \mathrm{a} \\ \text { Dr } & \mathbf{1 , 6} & 0,5 \mathrm{~b} & \mathbf{1 3 , 9} & 9,1 \mathrm{~b} & \mathbf{1 1 , 8} & 3,0 \mathrm{~b} \\ \text { DeDr } & \mathbf{2 , 9} & 0,8 \mathrm{~b} & \mathbf{1 7 , 1} & 7,1 \mathrm{~b} & \mathbf{1 5 , 4} & 2,7 \mathrm{~b} \\ \text { Q. petraea } & & & & & & \\ \text { C } & \mathbf{2 2 , 8} & 6,6 \mathrm{a} & \mathbf{2 9 , 1} & 5,9 \mathrm{a} & \mathbf{2 2 , 7} & 3,0 \mathrm{a} \\ \text { De } & \mathbf{1 8 , 5} & 3,1 \mathrm{a} & \mathbf{2 5 , 4} & 7,1 \mathrm{a} & \mathbf{1 8 , 3} & 2,1 \mathrm{a} \\ \text { Dr } & \mathbf{3 , 3} & 0,8 \mathrm{~b} & \mathbf{1 4 , 9} & 4,3 \mathrm{~b} & \mathbf{3 , 9} & 2,6 \mathrm{~b} \\ \text { DeDr } & \mathbf{9 , 1} & 6,3 \mathrm{~b} & \mathbf{1 4 , 6} & 5,6 \mathrm{~b} & \mathbf{1 1 , 7} & 4,3 \mathrm{~b}\end{array}$

Tab. A21: Berechnete hydraulische Leitfähigkeit auf der Fließstrecke Boden-Blatt $\left(\mathrm{g}_{\mathrm{si}}\right)$ an vier Terminen vor und während der Trockenperiode 2000 (Werte in $\mathrm{mmol} \mathrm{m}^{-2} \mathrm{~s}^{-1} \mathrm{MPa}^{-1}$ ) bei $Q$. robur und Q. petraea. Die Berechnungen der Mittelwerteund Standardabweichungen erfolgten auf Grundlage von sechs Bäumen pro Variante. C Kontrolle, De Entlaubung 1998 und 1999, Dr Trockenheit 2000, DeDr Kombination aus De und Dr. Signifikante Unterschiede zwischen den Varianten sind mit Buchstaben gekennzeichnet.

$\begin{array}{ccccccccc}\text { Q. robur } & \mathbf{2 0 . 0 6 . 0 0} & \text { std } & \mathbf{0 1 . 0 8 . 0 0} & \text { std } & \mathbf{1 4 . 0 8 . 0 0} & \text { std } & \mathbf{2 4 . 0 8 . 0 0} & \text { std } \\ \text { C } & \mathbf{2 , 1 4} & 0,84 & \mathbf{0 , 3 8} & 0,18 \mathrm{a} & \mathbf{0 , 7 4} & 0,36 \mathrm{a} & \mathbf{0 , 5 6} & 0,08 \mathrm{a} \\ \text { De } & \mathbf{1 , 3 9} & 0,15 & \mathbf{0 , 7 3} & 0,42 \mathrm{~b} & \mathbf{0 , 7 9} & 0,24 \mathrm{a} & \mathbf{1 , 0 0} & 0,23 \mathrm{~b} \\ \text { Dr } & \mathbf{1 , 2 8} & 0,87 & \mathbf{0 , 0 7} & 0,05 \mathrm{c} & \mathbf{0 , 7 0} & 0,24 \mathrm{~b} & \mathbf{0 , 4 7} & 0,26 \mathrm{c} \\ \text { DeDr } & \mathbf{1 , 4 0} & 0,60 & \mathbf{0 , 1 0} & 0,02 \mathrm{~d} & \mathbf{0 , 5 3} & 0,19 \mathrm{~b} & \mathbf{0 , 5 9} & 0,15 \mathrm{~d} \\ & & & & & & & & \\ \text { Q. petraea } & \mathbf{2 0 . 0 6 . 0 0} & \text { std } & \mathbf{0 1 . 0 8 . 0 0} & \text { std } & \mathbf{1 4 . 0 8 . 0 0} & \text { std } & \mathbf{2 4 . 0 8 . 0 0} & \text { std } \\ \text { C } & \mathbf{1 , 5 6} & 0,54 \mathrm{a} & \mathbf{0 , 6 5} & 0,33 \mathrm{a} & \mathbf{0 , 8 5} & 0,43 \mathrm{a} & \mathbf{0 , 4 4} & 0,35 \mathrm{a} \\ \text { De } & \mathbf{1 , 1 0} & 0,33 \mathrm{~b} & \mathbf{0 , 8 3} & 0,27 \mathrm{a} & \mathbf{0 , 5 4} & 0,20 \mathrm{~b} & \mathbf{0 , 5 1} & 0,11 \mathrm{a} \\ \text { Dr } & \mathbf{1 , 7 4} & 0,61 \mathrm{a} & \mathbf{0 , 0 8} & 0,05 \mathrm{~b} & \mathbf{0 , 4 3} & 0,22 \mathrm{c} & \mathbf{0 , 1 6} & 0,16 \mathrm{~b} \\ \text { DeDr } & \mathbf{0 , 5 5} & 0,28 \mathrm{c} & \mathbf{0 , 1 8} & 0,14 \mathrm{~b} & \mathbf{0 , 2 7} & 0,06 \mathrm{~d} & \mathbf{0 , 3 4} & 0,12 \mathrm{~b}\end{array}$


Tab. A22: Ergebnisse der Druck/Volumen-Kurve bei Quercus robur und Q. petraea im Jahr 2000. Osmotisches Potential bei Sättigung ( $\Pi_{0}$, in MPa) und am Turgornullpunkt ( $\Pi_{\mathrm{P}}$, in MPa), der relative symplastische Wassergehalt am Turgornullpunkt (RWCsp, in \%), der relative Wassergehalt am Turgornullpunkt (RWCp, in \%) sowie der maximale Elastizitätsmodul ( $\varepsilon$, in MPa) gewonnen aus vier Parallen pro Variante. Die Messungen erfolgten an zwei Terminen: vor (Juni) und am Ende der Trockenperiode (September). Angegeben sind die Mittelwerte und Standardabweichungen pro Variante. C Kontrolle, De Entlaubung 1998 und 1999, Dr Trockenheit 2000, DeDr Kombination aus De und Dr. Signifikante Unterschiede zwischen den Terminen sind mit Buchstaben gekennzeichnet. ANOVA s. Tab. B4.

\begin{tabular}{|c|c|c|c|c|c|c|c|c|c|c|}
\hline Q. robur & & $\Pi_{0}$ & std & Пр & std & $\mathrm{RWC}_{\mathrm{sp}}$ & std & RWC $_{p}$ & std & $\varepsilon$ \\
\hline C & Juni & $-1,7$ & $0,2 a$ & $-2,4$ & $0,1 \mathrm{a}$ & 46,7 & 2,4 & 77,6 & 6,0 & 3,6 \\
\hline $\mathrm{De}$ & & $-1,5$ & $0,0 a$ & $-2,3$ & 0,2 & 42,4 & 5,2 & 78,7 & 8,1 & 4,1 \\
\hline $\mathrm{Dr}$ & & $-1,6$ & 0,1 & $-2,3$ & 0,1 & 50,9 & $1,3 a$ & 80,0 & 4,0 & 3,9 \\
\hline DeDr & & $-1,7$ & 0,1 & $-2,6$ & 0,2 & 49,8 & 6,1 & 75,0 & 8,5 & 3,4 \\
\hline C & Sept. & $-1,8$ & $0,1 b$ & $-2,5$ & $0,1 b$ & 42,2 & 7,7 & 83,5 & 6,7 & 3,9 \\
\hline $\mathrm{De}$ & & $-2,0$ & $0,0 \mathrm{~b}$ & $-2,6$ & 0,2 & 42,0 & 10,7 & 87,1 & 7,7 & 9,0 \\
\hline $\mathrm{Dr}$ & & $-2,0$ & 0,1 & $-2,6$ & 0,2 & 38,0 & $8,1 b$ & 86,9 & 3,9 & 7,1 \\
\hline DeDr & & $-1,9$ & 0,2 & $-2,7$ & 0,0 & 43,8 & 9,8 & 82,8 & 2,1 & 6,4 \\
\hline $\begin{array}{c}\text { Q. } \\
\text { petraea }\end{array}$ & & $\Pi_{0}$ & std & $\Pi_{P}$ & std & $\mathrm{RWC}_{\mathrm{sp}}$ & std & RWC $_{p}$ & std & $\varepsilon$ \\
\hline C & Juni & $-1,8$ & 0,0 & $-2,4$ & 0,2 & 47,5 & 6,1 & 82,0 & 3,3 & 5,1 \\
\hline $\mathrm{De}$ & & $-1,9$ & 0,1 & $-2,4$ & 0,0 & 48,4 & 2,2 & 84,8 & 0,8 & 8,7 \\
\hline $\mathrm{Dr}$ & & $-1,9$ & $0,0 a$ & $-2,5$ & $0,0 a$ & 46,8 & 3,2 & 85,4 & 2,6 & 7,9 \\
\hline DeDr & & $-2,0$ & 0,1 & $-2,8$ & 0,1 & 52,7 & 7,2 & 80,8 & 2,0 & 9,7 \\
\hline C & Sept. & $-2,1$ & 0,0 & $-2,8$ & 0,1 & 42,0 & 10,2 & 85,2 & 0,4 & 8,2 \\
\hline $\mathrm{De}$ & & $-2,0$ & 0,1 & $-2,7$ & 0,1 & 50,8 & 6,0 & 83,0 & 5,9 & 7,8 \\
\hline $\mathrm{Dr}$ & & $-2,0$ & $0,0 \mathrm{~b}$ & $-2,6$ & $0,3 b$ & 48,8 & 5,1 & 89,5 & 2,8 & 13,2 \\
\hline DeDr & & $-2,1$ & 0,1 & $-2,7$ & 0,1 & 46,0 & 5,9 & 85,1 & 4,9 & 9,5 \\
\hline
\end{tabular}

Tab. A23: Berechnete Änderung der Osmotikagehalte bei Quercus robur und Q. petraea zwischen Juni (vor Trockenstress) und September (nach Trockenstress) im Jahr 1999. Die Werte sind für den Bereich bei Sättigung, (Quotient der $\Pi_{P}{ }^{*}{ } W C_{s}$-Werte von Juni und September) und am Turgornullpunkt (Quotient der $\Pi_{0}{ }^{*} \mathrm{RWC}_{\mathrm{s}}$ von Juni und September) ermittelt worden. Angegeben sind die Mittelwerte und Standardabweichungen von je drei Bäumen pro Variante. C Kontrolle, De Entlaubung 1998 und 1999, Dr Trockenheit 2000, DeDr Kombination aus De und Dr.

$\begin{array}{ccccc}\text { Q. robur } & \Pi_{\mathrm{P}}{ }^{*} \mathrm{RWC} \mathrm{C}_{\mathrm{s}} & \text { std } & \Pi_{0}{ }^{*} \mathrm{RWC} & \text { std } \\ \text { C } & \mathbf{0 , 8} & 0,2 & \mathbf{0 , 7} & 0,1 \\ \mathrm{De} & \mathbf{0 , 9} & 0,2 & \mathbf{0 , 7} & 0,3 \\ \mathrm{Dr} & \mathbf{0 , 7} & 0,1 & \mathbf{0 , 7} & 0,1 \\ \text { DeDr } & \mathbf{0 , 8} & 0,2 & \mathbf{0 , 7} & 0,1 \\ & & & & \\ \text { Q. petraea } & \Pi_{\mathrm{P}}{ }^{*} \mathrm{RWC} \text { s } & \text { std } & \Pi_{0^{*}} \mathrm{RWC}_{\mathrm{s}} & \text { std } \\ \text { C } & \mathbf{0 , 9} & 0,2 & \mathbf{0 , 8} & 0,2 \\ \mathrm{De} & \mathbf{1 , 0} & 0,1 & \mathbf{1 , 1} & 0,1 \\ \mathrm{Dr} & \mathbf{1 , 0} & 0,2 & \mathbf{0 , 8} & 0,1 \\ \mathrm{DeDr} & \mathbf{0 , 9} & 0,2 & \mathbf{0 , 8} & 0,2\end{array}$


Tab. A24: Blattfläche $\left(\mathrm{m}^{-2}\right)$, Blattbiomasse ( $\mathrm{g} \mathrm{TG}$ ) und spezifische Blattffläche (SLA, in $\left.\mathrm{cm}^{-2} \mathrm{~g}^{-1} \mathrm{TG}\right)$ bei Quercus robur und Q. petraea am Ende der Vegetationsperiode 2000. Angegeben sind die Mittelwerte und Standardabweichungen von je sechs Bäumen pro Variante. C Kontrolle, De Entlaubung 1998 und 1999, Dr Trockenheit 2000, DeDr Kombination aus De und Dr. Signifikante Unterschiede zwischen den Varianten sind mit Buchstaben gekennzeichnet.

$\begin{array}{cccccccc}\text { Art } & \text { Variante } & \text { Blattfläche } & \text { std } & \text { Blattmasse } & \text { std } & \text { SLA } & \text { std } \\ \text { Q. robur } & \text { C } & \mathbf{0 , 5} & 0,1 & \mathbf{4 2 , 8} & 5,3 & \mathbf{1 2 7 , 2} & 17,1 \\ & \mathrm{De} & \mathbf{0 , 6} & 0,1 & \mathbf{4 8 , 7} & 8,4 & \mathbf{1 2 9 , 7} & 10,4 \\ & \mathrm{Dr} & \mathbf{0 , 6} & 0,2 & \mathbf{4 3 , 5} & 10,8 & \mathbf{1 3 6 , 0} & 14,0 \\ & \mathrm{DeDr} & \mathbf{0 , 5} & 0,1 & \mathbf{4 2 , 4} & 6,3 & \mathbf{1 2 1 , 9} & 19,7 \\ \text { Q. petraea } & \mathrm{C} & \mathbf{0 , 5} & 0,1 & \mathbf{3 9 , 5} & 6,9 & \mathbf{1 2 5 , 5} & 14,0 \\ & \mathrm{De} & \mathbf{0 , 5} & 0,1 & \mathbf{3 5 , 2} & \mathbf{7 , 0} & \mathbf{1 3 3 , 9} & 13,3 \\ & \mathrm{Dr} & \mathbf{0 , 5} & 0,2 & \mathbf{3 5 , 8} & 8,4 & \mathbf{1 3 8 , 0} & 13,5 \\ & \mathrm{DeDr} & \mathbf{0 , 4} & \mathbf{0 , 1} & \mathbf{3 1 , 7} & 6,6 & \mathbf{1 3 6 , 0} & 6,0\end{array}$

Tab. A25: Wurzelbiomasse ( $\mathrm{g} \mathrm{TG}$ ) und Blatt/Feinwurzel-Verhältnis (B/FW, in $\left.\mathrm{g} \mathrm{g}^{-1}\right)$ ) bei Quercus robur und Q. petraea am Ende der Vegetationsperiode 2000. Angegeben sind die Mittelwerte und Standardabweichungen von je sechs Bäumen pro Variante, getrennt nach einzelnen Grössenklassen sowie die Gesamtwurzelbiomasse.C Kontrolle, De Entlaubung 1998 und 1999, Dr Trockenheit 2000, DeDr Kombination aus De und Dr. Signifikante Unterschiede zwischen den Varianten (> $2 \mathrm{~mm}$ und $\mathrm{B} / \mathrm{FW}$ ) sind mit Buchstaben gekennzeichnet.

\begin{tabular}{|c|c|c|c|c|c|c|c|c|c|c|c|c|}
\hline & & & & urzelb & mass & & & & & & & \\
\hline Art & $<2 \mathrm{~mm}$ & std & $\begin{array}{l}2-5 \\
\mathrm{~mm}\end{array}$ & std & $\begin{array}{l}5-10 \\
\mathrm{~mm}\end{array}$ & std & $>10 \mathrm{~mm}$ & std & $\begin{array}{l}\text { Gesamt } \\
\text {-masse }\end{array}$ & std & B/FW & std \\
\hline Q. robur & & & & & & & & & & & & \\
\hline C & 68,7 & 18,1 & 30,5 & 4,8 & 51,0 & 18,7 & 112,1 & 46,0 & 262,3 & 34,7 & 0,6 & 0,2 \\
\hline $\mathrm{De}$ & 59,2 & 32,2 & 26,3 & 8,5 & 44,0 & 15,6 & 107,1 & 36,7 & 236,7 & 34,7 & 1,0 & 0,4 \\
\hline $\mathrm{Dr}$ & 77,4 & 23,8 & 28,9 & 6,6 & 45,1 & 26,8 & 83,6 & 21,6 & 235,0 & 26,1 & 0,6 & 0,2 \\
\hline DeDr & 53,2 & 13,0 & 25,2 & 1,8 & 43,3 & 16,2 & 80,0 & 36,3 & 201,7 & 22,9 & 0,8 & 0,2 \\
\hline Q. petrae & & & & & & & & & & & & \\
\hline C & 80,3 & $7,7 a$ & 40,2 & 17,8 & 60,1 & 8,0 & 147,9 & 44,8 & 328,4 & 46,8 & 0,5 & 0,1 \\
\hline $\mathrm{De}$ & 54,7 & $18,7 a b$ & 28,8 & 6,8 & 49,1 & 12,9 & 88,9 & 24,7 & 221,5 & 25,0 & 0,7 & 0,1 \\
\hline $\mathrm{Dr}$ & 91,4 & $27,7 \mathrm{ac}$ & 26,5 & 5,9 & 40,2 & 16,9 & 83,6 & 24,1 & 241,7 & 31,9 & 0,5 & 0,3 \\
\hline DeDr & 49,3 & $16,5 b$ & 25,4 & 8,3 & 38,2 & 20,5 & 65,3 & 18,5 & 178,2 & 17,0 & 0,7 & 0,1 \\
\hline
\end{tabular}

Tab. A26: Höhen- und Durchmesserzuwachs (in \% zu Startwert 1998) bei Quercus robur und Q. petraea am Ende der Vegetationsperiode 2000. Angegeben sind die Mittelwerte und Standardabweichungen von je fünf Bäumen pro Variante. C Kontrolle, De Entlaubung 1998 und 1999, Dr Trockenheit 2000, DeDr Kombination aus De und Dr. Signifikante Unterschiede zwischen den Varianten sind mit Buchstaben gekennzeichnet.

$\begin{array}{ccccc}\text { Q. robur } & \text { Höhe } & \text { std } & \text { Durchmesser } & \text { std } \\ \text { C } & \mathbf{6 , 5} & 3,2 & \mathbf{3 9 , 7} & 17,3 \\ \text { De } & \mathbf{1 1 , 4} & 4,5 & \mathbf{4 1 , 0} & 15,9 \\ \text { Dr } & \mathbf{1 3 , 2} & 7,8 & \mathbf{4 6 , 6} & 10,2 \\ \text { DeDr } & \mathbf{1 0 , 2} & 7,3 & \mathbf{3 6 , 1} & 11,0\end{array}$


Tab. A26 (Forts.): Höhen- und Durchmesserzuwachs (in \% zu Startwert 1998) bei Quercus robur und Q. petraea am Ende der Vegetationsperiode 2000. Angegeben sind die Mittelwerte und

Standardabweichungen von je fünf Bäumen pro Variante. C Kontrolle, De Entlaubung 1998 und 1999, Dr Trockenheit 2000, DeDr Kombination aus De und Dr. Signifikante Unterschiede zwischen den Varianten sind mit Buchstaben gekennzeichnet.

$\begin{array}{ccccc}\text { Q. petraea } & \text { Höhe } & \text { std } & \text { Durchmesser } & \text { std } \\ \text { C } & \mathbf{6 , 5} & 6,0 & \mathbf{3 8 , 0} & 7,5 \mathrm{a} \\ \text { De } & \mathbf{1 0 , 1} & 8,4 & \mathbf{1 7 , 0} & 8,1 \mathrm{~b} \\ \text { Dr } & \mathbf{9 , 2} & 7,0 & \mathbf{4 4 , 6} & 11,2 \mathrm{a} \\ \text { DeDr } & \mathbf{6 , 0} & 9,8 & \mathbf{2 5 , 0} & 9,5 \mathrm{~b}\end{array}$

Tab. A27: Ergebnisse der Blattanalyse bei Quercus robur und Q. petraea im Jahr 2000. Dargestellt sind die $\mathrm{N}$-Gehalte $\left(\mathrm{mg} \mathrm{cm}^{-2}\right)$, das $\mathrm{C} / \mathrm{N}$-Verhältnis im Blatt sowie das $\delta^{13} \mathrm{C}$-Isotopenverhältnis (\%o). Angegeben sind die Mittelwerte und Standardabweichungen von je fünf Bäumen pro Variante. $C$ Kontrolle, De Entlaubung 1998 und 1999, Dr Trockenheit 2000, DeDr Kombination aus De und Dr. Signifikante Unterschiede zwischen den Varianten sind mit Buchstaben gekennzeichnet.

\begin{tabular}{lclllll} 
Q. robur & $\mathbf{N}$ & std & $\mathbf{C} / \mathbf{N}$ & std & \multicolumn{1}{c}{$\delta^{\mathbf{1 3}} \mathbf{C}$} & std \\
C & $\mathbf{0 , 1 5}$ & 0,03 & $\mathbf{2 5 , 6 3}$ & 1,73 & $\mathbf{- 2 8 , 1 7}$ & 0,44 \\
De & $\mathbf{0 , 1 6}$ & 0,01 & $\mathbf{2 3 , 9 4}$ & 2,78 & $\mathbf{- 2 8 , 0 9}$ & 0,70 \\
Dr & $\mathbf{0 , 1 4}$ & 0,02 & $\mathbf{2 6 , 3 2}$ & 2,81 & $\mathbf{- 2 7 , 8 4}$ & 0,79 \\
DeDr & $\mathbf{0 , 1 5}$ & 0,03 & $\mathbf{2 6 , 5 3}$ & 1,37 & $\mathbf{- 2 7 , 8 2}$ & 0,50 \\
& & & & & & \\
Q. petraea & $\mathbf{N}$ & std & $\mathbf{C} / \mathbf{N}$ & std & $\delta^{\mathbf{1 3} \mathbf{C}}$ & std \\
C & $\mathbf{0 , 1 3}$ & 0,02 & $\mathbf{3 0 , 6 5}$ & $3,36 \mathrm{a}$ & $\mathbf{- 2 8 , 9 1}$ & $0,38 \mathrm{a}$ \\
De & $\mathbf{0 , 1 3}$ & 0,02 & $\mathbf{2 8 , 4 3}$ & $1,86 \mathrm{~b}$ & $\mathbf{- 2 8 , 6 7}$ & $0,55 \mathrm{a}$ \\
Dr & $\mathbf{0 , 1 2}$ & 0,01 & $\mathbf{2 9 , 4 8}$ & $2,69 \mathrm{a}$ & $\mathbf{- 2 7 , 4 9}$ & $0,52 \mathrm{~b}$ \\
DeDr & $\mathbf{0 , 1 3}$ & 0,02 & $\mathbf{2 6 , 6 5}$ & $2,24 \mathrm{~b}$ & $\mathbf{- 2 8 , 1 4}$ & $0,66 \mathrm{~b}$
\end{tabular}

Tab. A28: Stärkegehalte ( $\mathrm{g} \mathrm{g}^{-1} \mathrm{TG}$, gemessen an Stammquerschnitten) bei jungen $Q$. robur und Q. petraea 1999 und 2000 sowie bei 20-jährigen Q. robur 2001. Angeben sind die Mittelwerte und Standardabweichungen aus je fünf (1999) und sechs (übrige Jahre) Bäumen pro Varianten. Varianten 1999: C Kontrolle, De Entlaubung 1998 und 1999, Dr Trockenheit 1999, DeDr Kombination aus De und Dr. Varianten 2000: C Kontrolle, De Entlaubung 1998 und 1999, Dr Trockenheit 2000, DeDr Kombination aus De und Dr. Varianten 2001: C Kontrolle, De1 Entlaubung 2000, De2 Entlaubung 1999 und 2000. Signifikante Unterschiede zwischen den Varianten sind mit Buchstaben gekennzeichnet.

\begin{tabular}{lcccc} 
Art & Variante & Jahr & Stärke & std \\
Q. robur & $\mathrm{C}$ & 1999 & $\mathbf{0 , 0 9}$ & $0,02 \mathrm{a}$ \\
& $\mathrm{De}$ & 1999 & $\mathbf{0 , 2 0}$ & $0,03 \mathrm{~b}$ \\
& $\mathrm{Dr}$ & 1999 & $\mathbf{0 , 1 0}$ & $0,02 \mathrm{a}$ \\
& $\mathrm{DeDr}$ & 1999 & $\mathbf{0 , 1 5}$ & $0,05 \mathrm{ab}$ \\
\cline { 2 - 5 } & $\mathrm{C}$ & 2000 & $\mathbf{0 , 1 5}$ & $0,04 \mathrm{ab}$ \\
& $\mathrm{De}$ & 2000 & $\mathbf{0 , 1 2}$ & $0,06 \mathrm{~b}$ \\
& $\mathrm{Dr}$ & 2000 & $\mathbf{0 , 0 9}$ & $0,03 \mathrm{~b}$ \\
& $\mathrm{DeDr}$ & 2000 & $\mathbf{0 , 2 1}$ & $0,01 \mathrm{a}$ \\
\hline
\end{tabular}


Tab. A28 (Forts.): Stärkegehalte ( $\mathrm{g} \mathrm{g}^{-1} \mathrm{TG}$, gemessen an Stammquerschnitten) bei jungen Q. robur und Q. petraea 1999 und 2000 sowie bei 20-jährigen Q. robur 2001. Angeben sind die Mittelwerte und Standardabweichungen aus je fünf (1999) und sechs (übrige Jahre) Bäumen pro Varianten. Varianten 1999: C Kontrolle, De Entlaubung 1998 und 1999, Dr Trockenheit 1999, DeDr Kombination aus De und Dr. Varianten 2000: C Kontrolle, De Entlaubung 1998 und 1999, Dr Trockenheit 2000, DeDr Kombination aus De und Dr. Varianten 2001: C Kontrolle, De1 Entlaubung 2000, De2 Entlaubung 1999 und 2000. Signifikante Unterschiede zwischen den Varianten sind mit Buchstaben gekennzeichnet.

\begin{tabular}{ccccc} 
Art & Variante & Jahr & Stärke & std \\
Q. petraea & $\mathrm{C}$ & 1999 & $\mathbf{0 , 0 9}$ & $0,02 \mathrm{a}$ \\
& $\mathrm{De}$ & 1999 & $\mathbf{0 , 0 9}$ & $0,02 \mathrm{a}$ \\
& $\mathrm{Dr}$ & 1999 & $\mathbf{0 , 1 1}$ & $0,03 \mathrm{ab}$ \\
& $\mathrm{DeDr}$ & 1999 & $\mathbf{0 , 1 4}$ & $0,02 \mathrm{~b}$ \\
\cline { 2 - 5 } & $\mathrm{C}$ & 2000 & $\mathbf{0 , 1 2}$ & 0,01 \\
& $\mathrm{De}$ & 2000 & $\mathbf{0 , 0 9}$ & 0,02 \\
& $\mathrm{Dr}$ & 2000 & $\mathbf{0 , 0 9}$ & 0,04 \\
& $\mathrm{DeDr}$ & 2000 & $\mathbf{0 , 0 9}$ & 0,02 \\
\cline { 2 - 5 } Q. robur & $\mathrm{C}$ & 2001 & $\mathbf{0 , 1 8}$ & \\
& $\mathrm{De} 1$ & 2001 & $\mathbf{0 , 1 4}$ & 0,06 \\
& $\mathrm{De} 2$ & 2001 & $\mathbf{0 , 1 5}$ & 0,03
\end{tabular}

Tab. A29: Netto-Photosynthesevermögen $A_{\max }\left(\mu m o l m^{-2} \mathrm{~s}^{-1}\right)$ und berechnete Wassernutzungseffizienz WUE $\mathrm{W}_{\mathrm{a}}\left(\mu \mathrm{mol} \mathrm{CO}_{2} \mathrm{mmol}^{-1} \mathrm{H}_{2} \mathrm{O}\right.$ ) bei Quercus robur und Q. petraea am 21.08.2000. Angegeben sind die Mittelwerte und Standardabweichungen von je fünf Bäumen pro Variante. C Kontrolle, De Entlaubung 1998 und 1999, Dr Trockenheit 2000, DeDr Kombination aus De und Dr. Signifikante Unterschiede zwischen den Varianten sind mit Buchstaben gekennzeichnet.

$\begin{array}{cccccc}\text { Art } & \text { Variante } & \mathbf{A}_{\max } & \text { std } & \mathbf{W U E}_{\mathbf{a}} & \text { std } \\ \text { Q. robur } & \mathrm{C} & \mathbf{9 , 6} & 2,1 & \mathbf{6 , 0} & 1,6 \\ & \mathrm{De} & \mathbf{1 0 , 7} & 4,9 & \mathbf{5 , 8} & 1,2 \\ & \mathrm{Dr} & \mathbf{5 , 0} & 3,6 & \mathbf{6 , 9} & 1,7 \\ & \mathrm{DeDr} & \mathbf{8 , 0} & 1,0 & \mathbf{7 , 3} & 0,8 \\ \text { Q. petraea } & \mathrm{C} & \mathbf{8 , 8} & 1,3 \mathrm{a} & \mathbf{5 , 0} & 0,7 \mathrm{a} \\ & \mathrm{De} & \mathbf{7 , 1} & 2,0 \mathrm{a} & \mathbf{5 , 2} & 1,6 \mathrm{a} \\ & \mathrm{Dr} & \mathbf{2 , 5} & 1,5 \mathrm{~b} & \mathbf{9 , 0} & 2,3 \mathrm{~b} \\ & \mathrm{DeDr} & \mathbf{2 , 0} & 3,3 \mathrm{a} & \mathbf{6 , 4} & 1,3 \mathrm{~b}\end{array}$


Tab. A30: Predawn- und nachmittägliche (Afternoon)- Wasserpotentiale (MPa) bei 20-jährigen Quercus robur im Untersuchungsjahr 2001. Angegeben sind die Mittelwerte und

Standardabweichungen von je sechs Bäumen pro Variante. C Kontrolle, De1 Entlaubung 2000, De2 Entlaubung 1999 und 2000. Signifikante Unterschiede zwischen den Varianten sind mit Buchstaben gekennzeichnet.

$\begin{array}{ccccccccc}\text { Predawn } & \mathbf{2 9 . 0 6 . 0 1} & \text { std } & \mathbf{2 6 . 0 7 . 0 1} & \text { std } & \mathbf{0 2 . 0 8 . 0 0} & \text { std } & \mathbf{3 1 . 0 8 . 0 1} & \text { std } \\ \text { C } & \mathbf{- 0 , 2} & 0,0 & \mathbf{- 0 , 2} & 0,1 & \mathbf{- 0 , 5} & 0,1 & \mathbf{- 0 , 2} & 0,1 \\ \text { De1 } & \mathbf{- 0 , 2} & 0,0 & \mathbf{- 0 , 2} & 0,1 & \mathbf{- 0 , 4} & 0,1 & \mathbf{- 0 , 2} & 0,1 \\ \text { De2 } & \mathbf{- 0 , 2} & 0,0 & \mathbf{- 0 , 2} & 0,1 & \mathbf{- 0 , 4} & 0,1 & \mathbf{- 0 , 2} & 0,1\end{array}$

$\begin{array}{ccccccccc}\text { Afternoon } & 29.06 .01 & \text { std } & \mathbf{2 6 . 0 7 . 0 1} & \text { std } & \mathbf{0 2 . 0 8 . 0 1} & \text { std } & \mathbf{3 1 . 0 8 . 0 1} & \text { std } \\ \text { C } & -1,4 & 0,4 & -\mathbf{2 , 8} & 3,2 & -\mathbf{- 2 , 1} & 0,4 & -\mathbf{1 , 8} & 0,6 \\ \text { De1 } & -1,8 & 0,3 & -1,7 & 0,4 & \mathbf{- 2 , 3} & 0,1 & \mathbf{- 2 , 3} & 0,4 \\ \text { De2 } & -1,7 & 0,3 & -1,7 & 0,3 & -2,1 & 0,1 & -1,8 & 0,5\end{array}$

Tab. A 31: Maximale stomatäre Leitfähigkeit $\left(\mathrm{mmol} \mathrm{m}^{-2} \mathrm{~s}^{-1}\right)$ bei Quercus robur im Jahr 2001. Angegeben sind die Mittelwerte und Standardabweichungen von je sechs Bäumen pro Variante. C Kontrolle, De1 Entlaubung 2000, De2 Entlaubung 1999 und 2000. Signifikante Unterschiede zwischen den Varianten sind mit Buchstaben gekennzeichnet.

$\begin{array}{ccccccc}\text { Termin } & \mathbf{C} & \text { std } & \text { De1 } & \text { std } & \text { De2 } & \text { std } \\ 29.06 .01 & \mathbf{3 6 6 , 7} & 98,6 & \mathbf{3 7 8 , 7} & 67,1 & \mathbf{4 0 6 , 9} & 98,7 \\ 26.07 .01 & \mathbf{4 6 8 , 0} & 138,1 & \mathbf{3 9 5 , 2} & 168,1 & \mathbf{4 7 2 , 8} & 96,9 \\ 02.08 .01 & \mathbf{3 3 8 , 3} & 152,6 & \mathbf{3 3 2 , 3} & 152,9 & \mathbf{3 3 1 , 6} & 87,2 \\ 02.09 .01 & \mathbf{2 9 7 , 1} & 61,3 & \mathbf{2 8 2 , 1} & 77,4 & \mathbf{3 5 2 , 9} & 55,7\end{array}$

Tab A32: Feinwurzelgehalte $\left(\mathrm{mg} \mathrm{cm}^{-3}\right)$ in drei unterschiedlichen Entfernungen vom Stamm bei 20jährigen $Q$ robur am Ende der Vegetationsperiode 2001. Angegeben sind die Mittelwerte und Standardabweichungen von je sechs Bäumen pro Variante. C Kontrolle, De1 Entlaubung 2000, De2 Entlaubung 1999 und 2000. Signifikante Unterschiede zwischen den Varianten sind mit Buchstaben gekennzeichnet.

$\begin{array}{ccccccl}\begin{array}{c}\text { Entfernung } \\ \text { vom Stamm }(\mathrm{cm})\end{array} & \mathbf{C} & \text { std } & \text { De1 } & \text { std } & \text { De2 } & \text { std } \\ 50 & \mathbf{2 , 3} & 1,0 & \mathbf{2 , 2} & 1,4 & \mathbf{2 , 4} & 1,4 \\ 100 & \mathbf{1 , 2} & 0,6 \mathrm{a} & \mathbf{2 , 2} & 1,2 \mathrm{~b} & \mathbf{1 , 9} & 0,8 \mathrm{ab} \\ 150 & \mathbf{1 , 1} & 0,8 & \mathbf{1 , 6} & \mathbf{1 , 1} & \mathbf{1 , 4} & 0,5\end{array}$

Tab. A33: Stickstoffgehalt ( $\mathrm{N}$, in $\left.\mathrm{mg} \mathrm{cm}^{-2}\right), \mathrm{C} / \mathrm{N}-$ Verhältnis, spezifische Blattfläche (SLA, in $\left.\mathrm{cm}^{2} \mathrm{~g}^{-1} \mathrm{TG}\right)$ und das $\delta^{13} \mathrm{C}$-Verhältnis (\%o) in Blättern bei 20-jährigen Q. robur Ende August 2001. Angegeben sind die Mittelwerte und Standardabweichungen von je sechs Blättern (SLA: 20 Blätter) pro Variante. C Kontrolle, De1 Entlaubung 2000, De2 Entlaubung 1999 und 2000. Signifikante Unterschiede zwischen den Varianten sind mit Buchstaben gekennzeichnet.

$\begin{array}{ccccccccc}\text { Variante } & \mathbf{N} & \text { std } & \mathbf{C} / \mathbf{N} & \text { std } & \text { SLA } & \text { std } & \delta^{13} \mathbf{C} & \text { std } \\ \text { C } & \mathbf{0 , 5} & 0,1 \mathrm{a} & \mathbf{1 8 , 6} & 1,4 \mathrm{a} & \mathbf{5 5 , 2} & 21,6 \mathrm{a} & \mathbf{- 2 8 , 4} & 0,3 \mathrm{a} \\ \text { De1 } & \mathbf{0 , 4} & 0,1 \mathrm{~b} & \mathbf{1 8 , 6} & 2,5 \mathrm{a} & \mathbf{6 8 , 1} & 21,8 \mathrm{ab} & \mathbf{- 2 8 , 6} & 0,6 \mathrm{ab} \\ \text { De2 } & \mathbf{0 , 3} & 0,0 \mathrm{~b} & \mathbf{2 1 , 2} & 2,6 \mathrm{a} & \mathbf{7 4 , 8} & \mathbf{2 9 , 2 b} & \mathbf{- 2 9 , 5} & 0,7 \mathrm{~b}\end{array}$


Ergebnisse der Zweifachen Varianzanalyse

Faktoren: E Entlaubung, W Trockenheitt, E x W Kombination beider Faktoren, ns nicht signifikant

Tab. B1: Maximale stomatäre Leitfähigkeit in der Vegetationsperiode 1999 und 2000. Signifikante Unterschiede zwischen den Varianten sind mit Großbuchstaben gekennzeichnet.

\begin{tabular}{c|ccccccc} 
& \multicolumn{3}{|c}{$\mathbf{1 9 9 9}$} & & $\mathbf{2 0 0 0}$ \\
& $\mathbf{E}$ & $\mathbf{W}$ & $\mathbf{E} \mathbf{x} \mathbf{W}$ & $\mathbf{W}$ & $\mathbf{E} \mathbf{x}$ \\
\hline Q. robur & & & & & & \\
C & B & A & ns & ns & A & ns \\
De & A & A & ns & ns & A & ns \\
Dr & B & B & ns & ns & B & ns \\
DeDr & A & B & ns & ns & B & ns \\
& & & & & & \\
Q. petraea & & & & & & \\
C & B & A & ns & ns & A & ns \\
De & A & A & ns & ns & A & ns \\
Dr & B & B & ns & ns & B & ns \\
DeDr & A & B & ns & ns & B & ns
\end{tabular}

Tab. B2:Tagesgang der stomatäre Leitfähigkeit 19991999 und 2000. Signifikante Unterschiede zwischen den Varianten sind mit Großbuchstaben gekennzeichnet.

\begin{tabular}{c|ccccccc} 
& \multicolumn{3}{|c}{$\mathbf{1 9 9 9}$} & \multicolumn{3}{c}{$\mathbf{2 0 0 0}$} \\
& $\mathbf{E}$ & $\mathbf{W}$ & $\mathbf{E} \mathbf{x} \mathbf{W}$ & $\mathbf{E}$ & $\mathbf{W}$ & $\mathbf{E} \mathbf{x} \mathbf{~}$ \\
\hline Q. robur & & & & & & \\
C & A & A & ns & ns & A & ns \\
De & B & A & ns & ns & A & ns \\
Dr & A & B & ns & ns & B & ns \\
DeDr & B & B & ns & ns & B & ns \\
& & & & & & \\
Q. petraea & & & & & & \\
C & A & A & ns & ns & A & ns \\
De & B & A & ns & ns & A & ns \\
Dr & A & B & ns & ns & B & ns \\
DeDr & B & B & ns & ns & B & ns
\end{tabular}


Tab. B3: Druck/Volumenkurve 1999. Signifikante Einflüsse sind mit *** gekennzeichnet. Juni: vor Trockenperiode, September: nach Trockenperiode

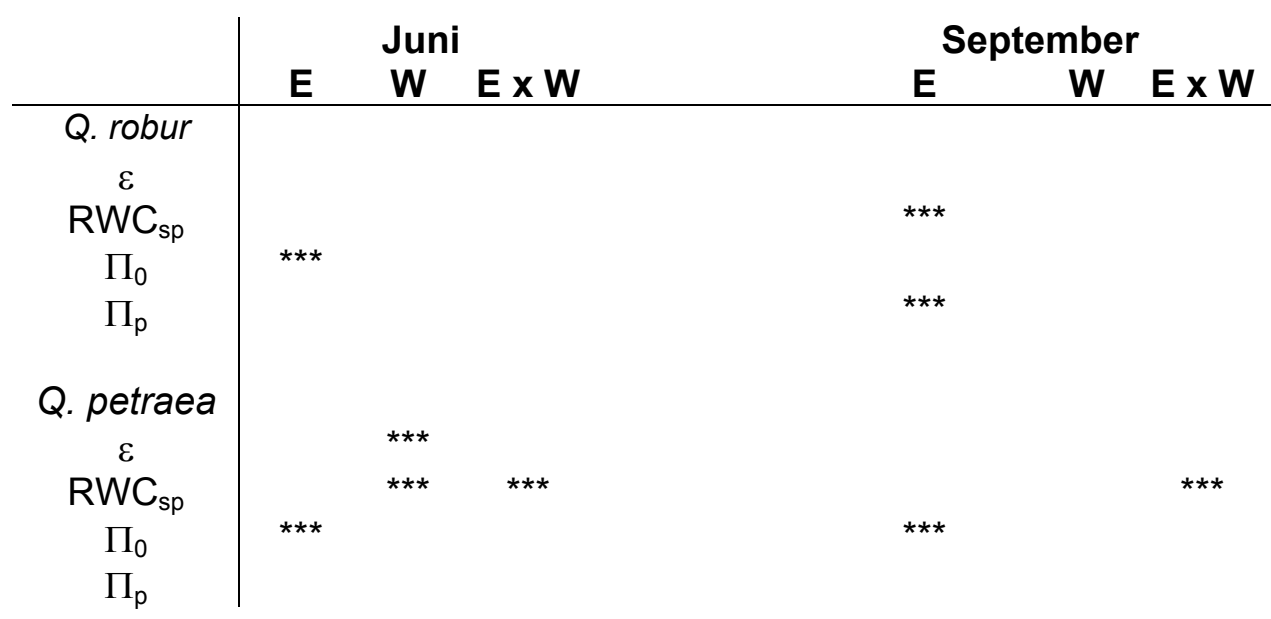

Tab. B4: Druck/Volumenkurve 2000

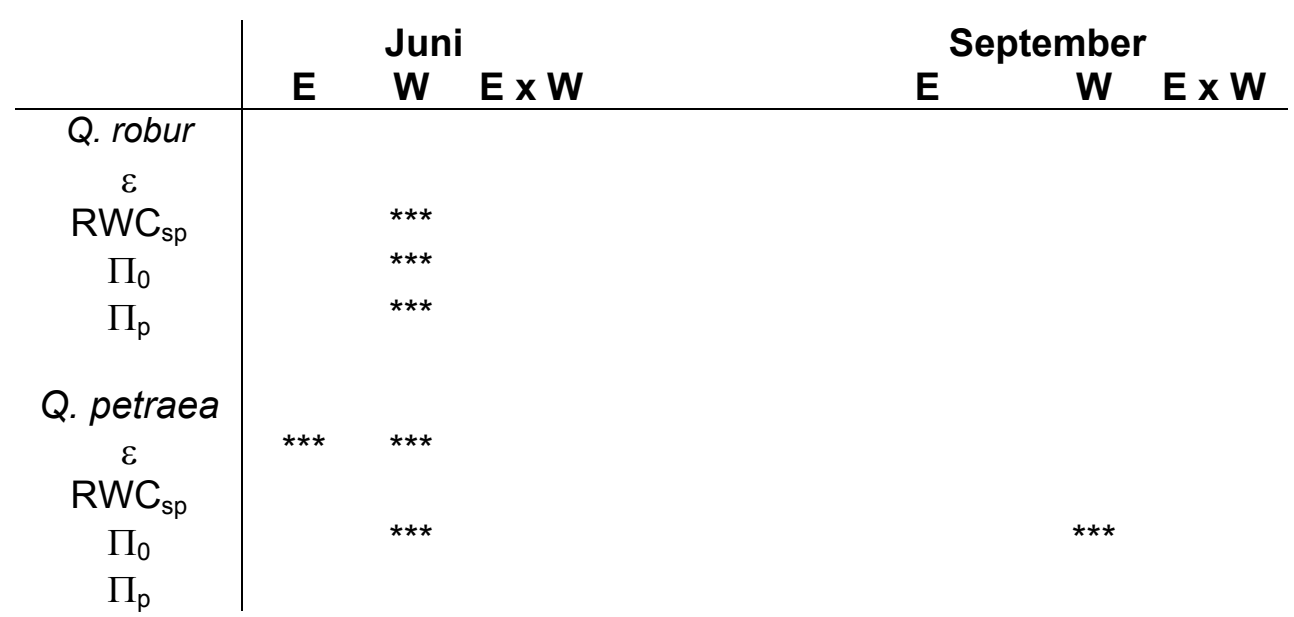




\section{Danksagung}

Für unermüdliche Diskussionsbereitschaft und das Thema bedanke ich mich bei Herrn Dr. Frank M. Thomas. Für die Durchführung der Arbeit am Albrecht-von-HallerInstitut gilt mein Dank Herrn Prof. Dr. Christoph Leuschner und Herrn Prof. Dr. Michael Runge. Danke auch an Herrn Günter Hartmann und Frau Ratburg Blank von der Forstlichen Versuchsanstalt in Göttingen für die Diskussionsbereitschaft und die Hilfe bei den Jahrringanalysen. Für die Unterstützung von Seiten der Umweltstiftung geht mein Dank an Frau Dr. Hedda Schlegel-Starmann. Für die gute Zusammenarbeit und die nette Zeit (nicht nur in Weende) geht mein persönlicher Dank vor allem an Lars, Stella, Ralf und Heinz sowie allen übrigen Mitarbeitern hier am Institut, sowie an meine Mutter für die finanzielle Unterstützung in der Anfangsphase der Arbeit.

Mein ganz spezieller Dank für „Alles“ geht an Jasmin. Danke!

Diese Arbeit wurde gefördert durch ein dreijähriges Promotionsstipendium von der Bundesstiftung Umwelt (AZ 6000/630) in den Jahren 1999-2002. 